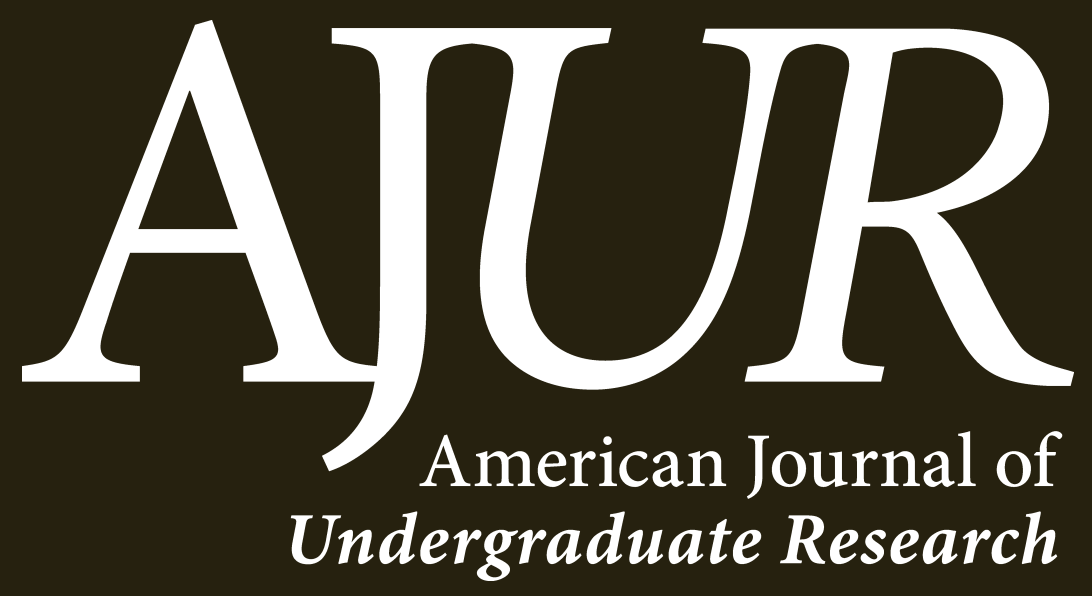

Volume 13 | Issue 2 | June 2016 $w w w . a j u r o n l i n e . o r g$ 


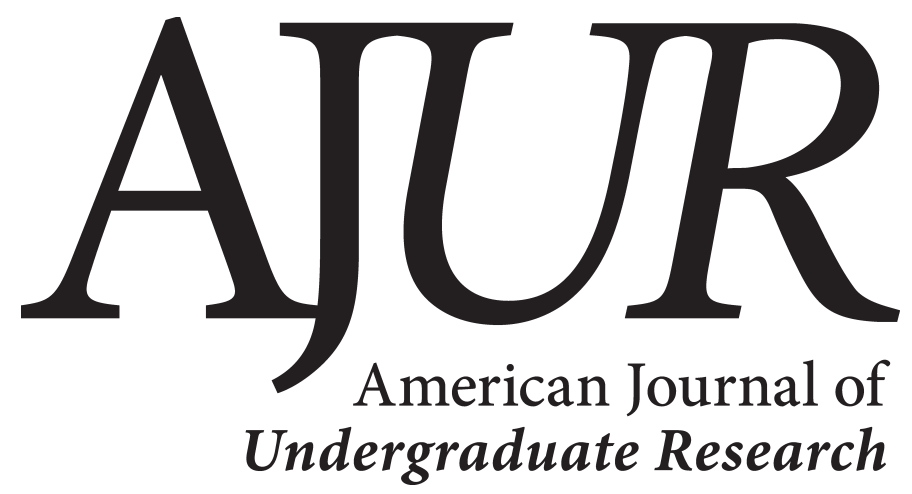

Volume 13 | Issue 2 | June 2016

www.ajuronline.org

2

3

5

15

AJUR History and Editorial Board Special Thanks to AJUR's Sponsors

Robust Nonlinear Control of BLDC Motor in Quadcopter Applications Steven T. Elliott \& Thomas W. Carr

Development of Four-Square Fiducial Markers for Analysis of Paper Analytical Devices Jenna Wilson, Tabitha Ricketts, Ian Bentley \& Ewa Misiolek

Sensitivity Analysis of Common Input Parameters in Tools for Modeling Energy in Homes

Sheikh Tijan Tabban \& Nelson Fumo

Feeding Anti-Semitism: Representations of Jewish Food

Practices in Der ewige Jude

Forrest Picher

hTERT Suppression via Small Interference RNA in Cervical Cancer Cells Shawn Gray \& Douglas Christensen

Malate: Quinone Oxidoreductase and Malic Enzyme are required for the Plant Pathogen Pseudomonas syringae pv. tomato DC3000 to Utilize Malate Zabrina Ebert, Preston Jacob, Katrina Jose, Lina Fouad, Katherine Vercellino, Steven Van Dorn, Mahaa Sidiqqi \& Eve M. Mellgren

Engaging Students in Science through a Nature Hike: A Case of Two Students with ADHD

Ashleigh Moore, Kristy Lynn Daniel \& Aimée K. Thomas

Evaluation of Antiulcer Activity of Laghusoothshekhar (an Ayurvedic Formula) in Pyloric Ligature Induced Gastric Ulcers in Albino Rats Nilofer Sayed \& Vandana Barve

Using Statistical Approaches to Model Natural Disasters Audrene S. Edwards \& Kumer Pial Das

Explicit Solution for Cylindrical Heat Conduction

Kaitlyn Parsons, Tyler Reichanadter, Andi Vicksman \& Harvey Segur 
American Journal of Undergraduate Research (AJUR) is a national, peer-reviewed, open-source, quarterly, multidisciplinary student research journal. It is indexed internationally by EBSCO, and is listed via the Library of Congress under ISSNs of 1536-4585 (for print) and 2375-8732 (for web). The journal was established in 2002.

EDITORIAL TEAM Volume 13 | Issue 2 | June 2016

Dr. Kestutis G. Bendinskas, Editor, editor@ajuronline.org

Dr. Anthony Contento, Assistant Technical Editor, technicaleditor@ajuronline.org

Rose Throop, Art and Copy Editor, copyeditor@ajuronline.org

Daniel Laird, Web Master,webmaster@ajuronline.org

Bonita Graham, LaTex Editor

EDITORIAL BOARD by subject area

ACCOUNTING

Dr. Dean Crawford, dean.crawford@oswego.edu

ART HISTORY

Dr. Lisa Seppi, lisa.seppi@oswego.edu

ASTROPHYSICS

Dr. Shashi Kanbur, shashi.kanbur@oswego.edu

BEHAVIORAL NEUROSCIENCE

Dr. Aileen M. Bailey, ambailey@smcm.edu

\section{BIOCHEMISTRY}

Dr. Pamela K. Kerrigan, pamela.kerrigan@mountsaintvincent.edu

\section{BIOENGINEERING}

Dr. Jorge I. Rodriguez, jorger@clemson.edu

BIOINFORMATICS

Dr. Kevin Daimi, daimikj@udmercy.edu

Dr. John R. Jungck, jungck@udel.edu

Dr. Isabelle Bichindaritz, ibichind@oswego.edu

BIOLOGY, PHYSIOLOGY

Dr. David Dunn,

david.dunn@oswego.edu

BIOLOGY, DEVELOPMENTAL

Dr. Poongodi Geetha-Loganathan, p.geethaloganathan@oswego.edu

BIOLOGY, MICROBIOLOGY

Dr. Peter Newell, peter.newell@oswego.edu

\section{BOTANY} wbromer@stfrancis.edu

Dr. Julien Bachelier, julien.bachelier@oswego.edu

\section{CHEMISTRY}

Dr. Alfredo Castro, castroa@felician.edu

Dr. Charles Kriley,

cekriley@gcc.edu

Dr. Douglas Mulford, douglas.mulford@emory.edu

Dr. Mark A. Benvenuto

benvenma@udmercy.edu

COMMUNICATION STUDIES

Dr. Jennifer Gerometta, jgerometta@iona.edu

COMPUTER SCIENCES

Dr. Dele Oluwade,

deleoluwade@yahoo.com

Dr. Kevin Daimi,

daimikj@udmercy.edu

\section{ECOLOGY}

Dr. William R. Bromer, wbromer@stfrancis.edu

\section{ECONOMICS}

Dr. Elizabeth Schmitt, elizabeth.schmitt@oswego.edu

EDUCATION, PHYSICS

Dr. Andrew D. Gavrin,

agavrin@iupui.edu

ENGINEERING, ELECTRICAL

Dr. Michael Omidiora,

michael.omidiora@nyu.edu

ENGINEERING, ENVIRONMENTAL

Dr. Eileen M. Cashman, eileen.cashman@humboldt.edu

ENGINEERING, MANUFACTURING AND CONSTRUCTION, ROBOTICS

Dr. Haoyu Wang,

wanghao@mail.ccsu.edu
Dr. William R. Bromer

\section{ENGINEERING, SOFTWARE \\ Dr. Kevin Daimi, \\ daimikj@udmercy.edu \\ ENVIRONMENTAL SCIENCE \\ Dr. Eileen M. Cashman, eileen.cashman@humboldt.edu \\ GEOLOGY \\ Dr. Larry Davis, \\ ldavis@csbsju.edu \\ HISTORY \\ Dr. Richard Weyhing, richard.weyhing@oswego.edu \\ Dr. Murat Yasar, \\ murat.yasar@oswego.edu \\ HONORARY EDITORIAL BOARD MEMBER \\ Dr. Lorrie Clemo, \\ lorrie.clemo@oswego.edu}

KINESIOLOGY / EXERCISE SCIENCE

Dr. David Senchina,

david.senchina@drake.edu

LITERARY STUDIES

Dr. Douglas Guerra, douglas.guerra@oswego.edu

\section{MATHEMATICS}

Dr. John Emert,

emert@bsu.edu

Dr. Jeffrey J. Boats,

boatsjj@udmercy.edu

Dr. J.D. Phillips,

jophilli@nmu.edu

Dr. Dele Oluwade,

deleoluwade@yahoo.com

Dr. Christopher Baltus,

christopher.baltus@oswego.edu

Dr. Mark Baker,

mark.baker@oswego.edu
METEOROLOGY

Dr. Steven Skubis, steven.skubis@oswego.edu

\section{NANOSCIENCE}

Dr. Gary Baker, bakergar@missouri.edu

NEUROSCIENCE

Dr. Pamela E. Scott-Johnson, pamela.scottjohnson@morgan.edu

Dr. Amy Overman, aoverman@elon.edu

PHYSICS

Dr. Carolina Ilie, carolina.ilie@oswego.edu

\section{POLITICAL AND SOCIAL SCIENCES}

Dr. Dean Dohrman, dean.dohrman@csuglobal.edu

\section{PSYCHOLOGY}

Dr. Amy Overman, aoverman@elon.edu

Dr. Pamela E. Scott-Johnson, pamela.scottjohnson@morgan.edu

STATISTICS

Dr. Mark Ecker, markecker@uni.edu

TECHNOLOGY, ENGINEERING

Dr. Recayi Pecen, regpecen@na.edu 


\section{SPECIAL THANKS}

AJUR is made possible through the assistance of our sponsors.

Support for this issue has been provided by Wiley as well as the Office of the Provost at the State University of New York at Oswego. Thank you!
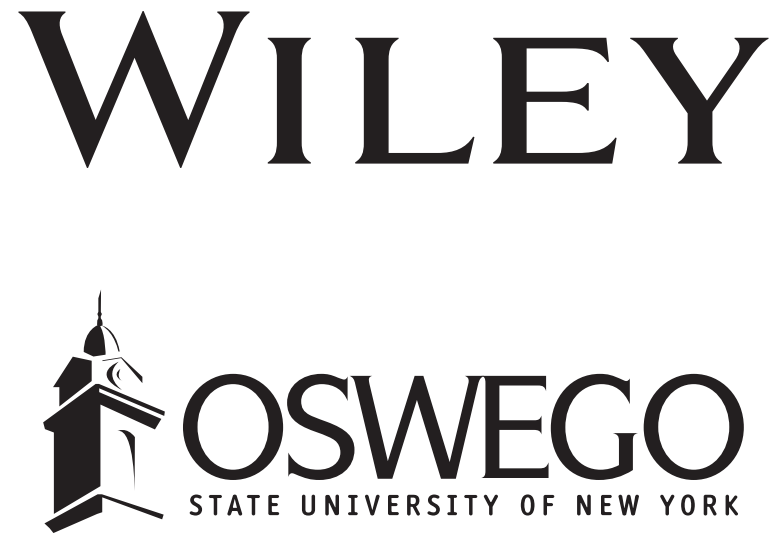

Interested in supporting quality undergraduate research?

Request sponsorship information at editor@ajuronline.org 


\title{
Robust Nonlinear Control of BLDC Motor in Quadcopter Applications
}

\author{
Steven T. Elliott and Thomas W. Carr \\ Department of Mathematics, Southern Methodist University, Dallas, TX \\ Student: stelliott@smu.edu \\ Mentor:tcar@smu.edu
}

\begin{abstract}
This paper describes the development of a nonlinear closed loop motor control system for a quadcopter micro-unmanned aerial vehicle (micro-UAV) platform. Research groups have analyzed the performance of brushless direct current (BLDC) motors with nonlinear effects in various applications, focusing on areas such as friction's effect on position. This paper analyzes the nonlinear effects of BLDC motors on speed when these motors are used in quadcopter flying robots. Notably, to account for nonlinear torque from the aerodynamic forces on a quadcopter rotor, a Control Lyapunov Function (CLF) approach is used in designing a stable feedback control system. The paper also explains the custom model and simulation of the system built in MATLAB/Simulink used to demonstrate and quantify the successful performance of the design.
\end{abstract}

\section{KEYWORDS}

Control Lyapunov Function; Micro-Unmanned Aerial Vehicle; Aerial Robotics; Quadcopters; Nonlinear Motor Control

\section{INTRODUCTION}

One area of research and development that has enormous potential is the multicopter micro-UAV. This flying robot typically uses four propellers, one mounted on each of the four ends of a cross-shaped frame as shown in Figure 1. Two propellers lying opposite to each other both rotate clockwise, and the other pair rotates counterclockwise, canceling the torques. Pitch, roll, and yaw movements are achieved by varying the speed of the motors; the robot carries an onboard controller and battery as well. ${ }^{1}$ Quadcopters range in size as small as 6 centimeters from tip to tip and 3 grams in weight. ${ }^{2}$

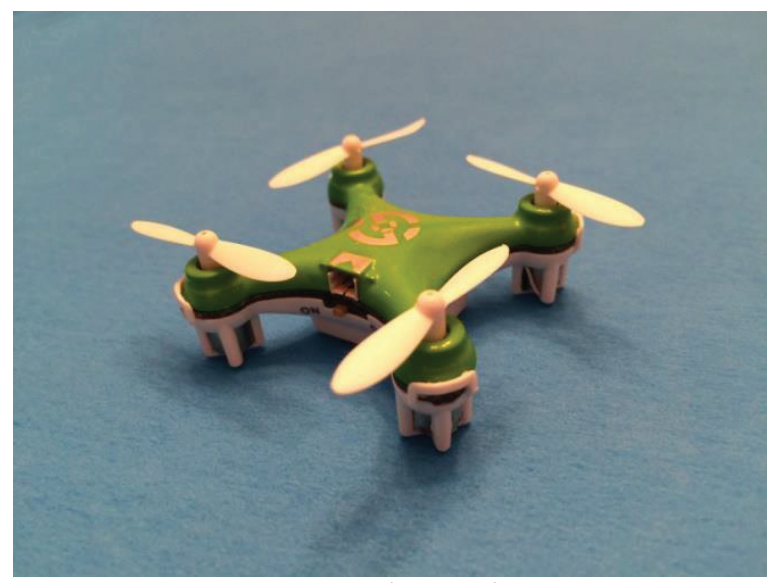

Figure 1. A quadcopter micro-UAV.

With their vertical flight and hover abilities, durability, and ease of use both indoors and outdoors, quadcopters are growing in popularity and have many promising applications, either as individual vehicles or in cooperation with others. ${ }^{2-5}$ Some of the uses include search and rescue, surveillance, exploration, photography, transport, and construction; quadcopters can be particularly helpful in environments that are inaccessible, contaminated, or otherwise dangerous. ${ }^{6,7}$

The performance of the quadcopter depends on the speed of response of the motors in achieving controlled, stable flight. Research groups studying quadcopters often assume unchanging aerodynamics, but quadcopters experience significant aerodynamic disturbance effects due to their surroundings, complex interactions with multiple UAVs or, at small scales, even to mild wind gusts. ${ }^{7,8}$ Researchers often deal with these by reducing the speed, keeping greater distance between the quadcopter and its surroundings, using simpler trajectories, attempting to limit the roll and pitch angles, and controlling the environment. ${ }^{2}$ 
Quadcopters are poised to become a widely used technology, and improvements in quadcopter controls could have a significant impact on their efficacy. Researchers have taken many different approaches to this control system design, summarized well in References 6, 7, 9. A few of the techniques include vehicle control loops that use feedback linearization for velocity and attitude control, ${ }^{1,4}$ proportional-integral-derivative (PID) control for attitude and position, 2,5 a predictor-corrector algorithm for angular velocity control, ${ }^{4}$ sequences of controllable trajectories accomplishing more complex maneuvers, ${ }^{5}$ iterative learning, ${ }^{5}$ and a decentralized adaptive controller for attitude and altitude. ${ }^{9}$ Instead, this work focuses on a fundamental control problem for quadcopter systems: the stable and precise response of the onboard low-level motor controllers.

Quadcopters use Brushless DC (BLDC) motors, each with an electronic controller that determines the rotor's phase over time (and therefore speed) via a sensor or with so-called sensorless methods, and uses the information to drive the rotor's rotation. BLDCs offer advantages over the older, electromechanically commutated, brushed DC motors: greater power efficiency, finelyadjustable speed, precise motion control, ease of programmability, and low maintenance. ${ }^{10}$

Other research groups have analyzed the performance with nonlinear effects of BLDCs in various applications, focusing on areas such as the effect of friction on position. ${ }^{11,12}$ In particular, this paper differs from the work done by Sabra et al. ${ }^{11}$ since this paper analyzes the nonlinear effects of BLDC motors on speed for quadcopter applications, and this paper utilizes a set point tracking analysis to ensure that the system is stable around a constant equilibrium point. Specifically, the goal of this work is to derive a nonlinear closed loop feedback control equation and prove the stability of the system using Lyapunov stability analysis with a Control Lyapunov Function (CLF). This work includes a simulation in MATLAB/Simulink of a propeller/BLDC motor system with friction, propeller torque and damping control. The simulation implements the model system and is used to demonstrate and measure the performance of the system.

This paper is organized as follows. The Methods and Procedures section contains subdivisions explaining CLF theory, the quadcopter motor model, Lyapunov analysis, and the custom Simulink simulation. The Results and Discussion section is next, followed by the final section which offers conclusions and areas for further research.

\section{METHODS AND PROCEDURES}

\section{Theory of CLF}

This project builds on prior research using CLF as a method of controlling nonlinear systems. ${ }^{1,11,13}$ Lyapunov stability, developed by mathematician Aleksandr Mikhailovich Lyapunov, guarantees the stability of a closed nonlinear system when certain scalar functions, the Lyapunov functions, meet a set of criteria summarized below.

Consider a nonlinear system represented by the following state space equation:

$$
\dot{x}=F(x, u) ; x \in \mathbb{R}^{n} ; u \in \mathbb{R}^{m} \text {. }
$$

Equation 1.

$F$ is a vector field in $\mathbb{R}^{n}, x$ represents the state variables, and $u$ represents the control function.

A Lyapunov function, denoted $V(x)$, must fulfill certain requirements to prove system stability. $V(x)$ is positive definite if $V(0)=0$ and $V(x)>0$ for $x \neq 0$, while the time derivative $\dot{V}(x)$ is negative definite if $\dot{V}(0)=0$ and $\dot{V}(x)<0$ for $x \neq 0$. If $V(x)$ is a continuously differentiable positive definite function such that $\dot{V}(x)$ is negative definite, then the system is asymptotically stable; if no suitable Lyapunov equations can be found such that $V(x)$ and $\dot{V}(x)$ are not positive definite and negative definite, respectively, then the system cannot be proven to be asymptotically stable. ${ }^{14,15}$

While the Lyapunov functions for some nonlinear systems are physical energy functions, in many cases there is no specific method for crafting Lyapunov functions, which then must be found through trial and error.

A nonlinear system is considered affine (or linear-in-control, since a linear proportional controller is used to control the nonlinear system) with respect to the input when the system has the form

$$
\dot{x}=F(x, u)=f_{0}(x)+\sum_{i=1}^{m} u_{i} f_{i}(x) .
$$

Equation 2. 
Since $x \in \mathbb{R}^{n}$, the $f_{i}, i=0,1, \ldots, m$, are vector fields in $\mathbb{R}^{n}$. Specifically, they are $j=1,2, \ldots, n$ equations of the form

$$
\dot{x}_{j}=f_{0 j}(x)+\sum_{i=1}^{m} u_{i} f_{i j}(x) .
$$

The system is assumed to have an initial condition $x=0$ such that $F(0, u)=0$. Assume a positive definite Control Lyapunov Function, $V(x)$, exists where $x$ represents all variables implemented in the Lyapunov function. Therefore,

$$
\dot{V}(x)=\nabla V \cdot \frac{d x}{d t}=\sum_{j=1}^{n} \frac{\partial V}{\partial x_{j}} \frac{d x}{d t}
$$

Substituting for $\dot{x}$ gives

$$
\begin{aligned}
\dot{V} & =\nabla V \cdot\left(f_{0}+\sum_{i=1}^{m} u_{i} f_{i}\right) \\
& =\nabla V \cdot f_{0}+\sum_{i=1}^{m} u_{i}\left(\nabla V \cdot f_{i}\right)
\end{aligned}
$$

Equation 5.

If $u_{i}=-\nabla V \cdot f_{i}$, then

$$
\dot{V}=\nabla V \cdot f_{0}-\sum_{i=1}^{m}\left(\nabla V \cdot f_{i}\right)^{2}
$$

Equation 6.

This feedback law, $u_{i}=-\nabla V \cdot f_{i}$, is called damping control.14

The Quadcopter Motor Model

The damping control method explained above will now be applied to the system depicted in Figure 2 . The system is an equivalent circuit model containing a control voltage, a characteristic resistance and inductance, and a DC motor driving a propeller.

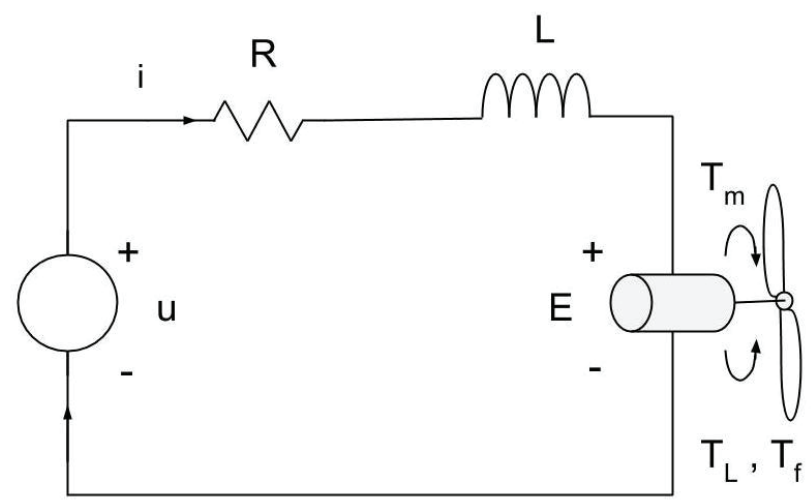

Figure 2. An equivalent circuit model of a series DC motor. 
Table 1 shows the motor parameters used in the model. In addition to the common features of a typical motor such as resistance, inductance, current, angular velocity, and moment of inertia, several other parameters are included in order to model nonlinearities effectively. For example, the model includes back EMF, which is induced when the permanent magnets in the motor rotate. Also included is the torque constant, which represents the torque generated by the current flowing through the motor. The viscous friction coefficient represents the friction generated by the rotating motor shaft, and the propeller aerodynamic constant is a measure of how the form of the propeller generates torque on the motor shaft as it rotates and creates thrust in air of a given density.

\begin{tabular}{|c|c|c|}
\hline Parameter & Description & Units \\
\hline$u_{1}$ & Control voltage & Volts, $\mathrm{V}$ \\
\hline$L$ & Inductance & Henrys, $\mathrm{H}$ \\
\hline$I$ & Motor current & Amperes, $\mathrm{A}$ \\
\hline$R$ & Resistance & Ohms, $\Omega$ \\
\hline$K_{e}$ & Back EMF constant & $\mathrm{V} \mathrm{s} / \mathrm{rad}$ \\
\hline$v_{0}$ & Input voltage & Volts, $\mathrm{V}$ \\
\hline$\omega$ & Rotor angular velocity & $\mathrm{rad} / \mathrm{s}$ \\
\hline$J$ & Moment of inertia & $\mathrm{kg} \mathrm{m}{ }^{2}$ \\
\hline$K_{t}$ & Torque constant & $\mathrm{N} \mathrm{m} / \mathrm{A}$ \\
\hline$b$ & Viscous friction coefficient & $\mathrm{N} \mathrm{m} \mathrm{s} / \mathrm{rad}$ \\
\hline$K_{A}$ & Propeller aerodynamic constant & $\mathrm{kg} \mathrm{m}^{2} \mathrm{~N}^{2} / \mathrm{s}^{2}$ \\
\hline
\end{tabular}

The model of the dynamic BLDC motor driving a propeller is represented by a set of nonlinear state equations. The equation for $\omega$ includes the nonlinear term $K_{A}|\omega| \omega$, which represents the magnitude and direction of the propeller torque:

$$
\begin{aligned}
\dot{I} & =\frac{1}{L}\left(-R I-K_{e} \omega+v_{0}\right), \text { and } \\
\dot{\omega} & =\frac{1}{J}\left(-b \omega+K_{t} I-K_{A} \omega|\omega|\right) .
\end{aligned}
$$

Equation 7.

Alternatively:

$$
\begin{aligned}
& \dot{\omega}=\frac{1}{J}\left(-b \omega+K_{t} I-K_{A} \omega^{2}\right) \text { for } \omega>0 . \\
& \dot{\omega}=\frac{1}{J}\left(-b \omega+K_{t} I+K_{A} \omega^{2}\right) \text { for } \omega<0 .
\end{aligned}
$$

Equation 8.

First, an analysis of the motor model with a fixed set point — or target state that the control system seeks to maintain — is developed. The equations relating change in current and change in angular velocity around the set point are given by

$$
\Delta I+I_{0}=I \text { and } \Delta \omega+\omega_{0}=\omega \text {, }
$$

Equation 9.

where $I_{0}$ and $\omega_{0}$ represent a non-zero equilibrium point resulting from a constant input voltage, $v_{0}$. Specifically, they satisfy

$$
0=\frac{1}{L}\left(-R I_{0}-K_{e} \omega_{0}+v_{0}\right) \text { and } 0=\frac{1}{J}\left(-b \omega_{0}+K_{t} I_{0}-K_{A} \omega_{0}^{2}\right) \text {. }
$$

To ensure that the system can track a constant set point, the expressions for $I$ and $\omega$ are substituted into the state equations for change in current and change in angular velocity as follows, starting with the equation for current:

$$
\dot{I}=\frac{1}{L}\left(-R \Delta I-R I_{0}-K_{e} \Delta \omega-K_{e} \omega_{0}+v_{0}\right) .
$$

Equation 10. 
Substituting for $I_{0}$ and $\omega_{0}$, another expression is obtained,

$$
\dot{I}=\frac{1}{L}\left(-R \Delta I-K_{e} \Delta \omega\right)
$$

Equation 11.

which is similar in form to the original state equation. Next, the set point analysis for the change in angular speed is developed. For the case $\omega>0$ and after substituting for $I_{0}$ and $\omega_{0}$,

$$
\dot{\omega}=\frac{1}{J}\left(-\left(b+2 K_{A} \omega_{0}\right) \Delta \omega+K_{t} \Delta I-K_{A} \Delta \omega^{2}\right)
$$

Equation 12.

The above analysis transforms the state equations to be dependent on variables $\Delta I$ and $\Delta \omega$, or the distance moved in current and angular velocity from the equilibrium point $I_{0}$ and $\omega_{0}$. Next, a Lyapunov analysis will be conducted on the new state equations to demonstrate that the system is globally asymptotically stable around that equilibrium point.

Lyapunov Analysis

Let the chosen Control Lyapunov Function $V$ be a function of two variables $\Delta I$ and $\Delta \omega$ with $c_{1}$ and $c_{2}$ being control parameters:

$$
V=\frac{1}{2} c_{1} \Delta I^{2}+\frac{1}{2} c_{2} \Delta \omega^{2} .
$$

Equation 13.

Since $V>0$ for all values of $\Delta I \neq 0$ and $\Delta \omega \neq 0$, and $V=0$ when $\Delta I=\Delta \omega=0, V$ is a positive definite function, which meets the first Lyapunov requirement. $\dot{V}$ is given by the equation (for $\Delta \omega>0$ ):

$$
\begin{aligned}
\dot{V} & =c_{1} \Delta I \Delta \dot{I}+c_{2} \Delta \omega \Delta \dot{\omega} \\
& =-\frac{c_{1} R \Delta I^{2}}{L}-\frac{c_{1} K_{e} \Delta I \Delta \omega}{L}-\frac{c_{2}\left(b+2 K_{A} \omega_{0}\right) \Delta \omega^{2}}{J}+\frac{c_{2} K_{t} \Delta I \Delta \omega}{J}-\frac{c_{2} K_{A} \Delta \omega^{3}}{J} .
\end{aligned}
$$

Equation 14.

For $\omega<0$, the above equation is replaced with the following:

$$
\dot{V}=-\frac{c_{1} R \Delta I^{2}}{L}-\frac{c_{1} K_{e} \Delta I \Delta \omega}{L}-\frac{c_{2}\left(b+2 K_{A} \omega_{0}\right) \Delta \omega^{2}}{J}+\frac{c_{2} K_{t} \Delta I \Delta \omega}{J}+\frac{c_{2} K_{A} \Delta \omega^{3}}{J} .
$$

Equation 15.

In both cases, $\dot{V}=0$ when $\Delta I=\Delta \omega=0$. To ensure that $\dot{V}$ is negative definite and $\dot{V}<0$ for all values of $\Delta I \neq 0$ and $\Delta \omega \neq 0$, $-\frac{c_{1} K_{e} \Delta I \Delta \omega}{L}$ and $\frac{c_{2} K_{t} \Delta I \Delta \omega}{J}$ must cancel to zero. For this to occur, $\frac{c_{1} K_{e} \Delta I \Delta \omega}{L}=\frac{c_{2} K_{t} \Delta I \Delta \omega}{J}$ and $\frac{c_{1}}{c_{2}}=\frac{K_{t} L}{K_{e} J}$. Therefore, as long as $\frac{c_{1}}{c_{2}}=\frac{K_{t} L}{K_{e} J}, \dot{V}$ is negative definite, which meets the second Lyapunov requirement, and thus the system is asymptotically stable.

Next, the damping control analysis is carried out by casting the equations back into the form of Equation 3, with $n=2$ and $m=1$, mapping $\left[\begin{array}{ll}x_{1} & x_{2}\end{array}\right]=\left[\begin{array}{ll}\Delta I & \Delta \omega\end{array}\right]$.

$$
\begin{gathered}
{\left[\begin{array}{c}
\dot{x}_{1} \\
\dot{x}_{2}
\end{array}\right]=\left[\begin{array}{c}
-\frac{R}{L} x_{1}-\frac{K_{e}}{L} x_{2} \\
\frac{K_{t}}{J} x_{1}-\frac{b+2 K_{A} \omega_{0}}{J} x_{2}-\frac{K_{A}}{J} x_{2}^{2}
\end{array}\right]+u_{1}\left[\begin{array}{c}
\frac{1}{L} \\
0
\end{array}\right]} \\
\nabla V(x)=\left[\begin{array}{ll}
c_{1} \Delta I & c_{2} \Delta \omega
\end{array}\right]
\end{gathered}
$$

Equation 16.

Equation 17.

Substituting Equations 6 and 9 results in a new damping control function.

$$
u_{1}=\frac{-c_{1} \Delta I}{L}
$$

Equation 18. 


\section{Simulation}

The simulation of the electrical current control of the DC motor was created in MATLAB/Simulink, and the block diagram is shown below. The block diagram implements the two state equations and damping control function that were explained previously. The design uses standard components like the integrator, gain, adder, and multiplier blocks, as well as the user-selected parameters that define system dynamics. Simulink calculates the system response to the user's inputs and initial conditions, and displays are the user-selected data signals, while dynamically showing rise time, settling time, and more.

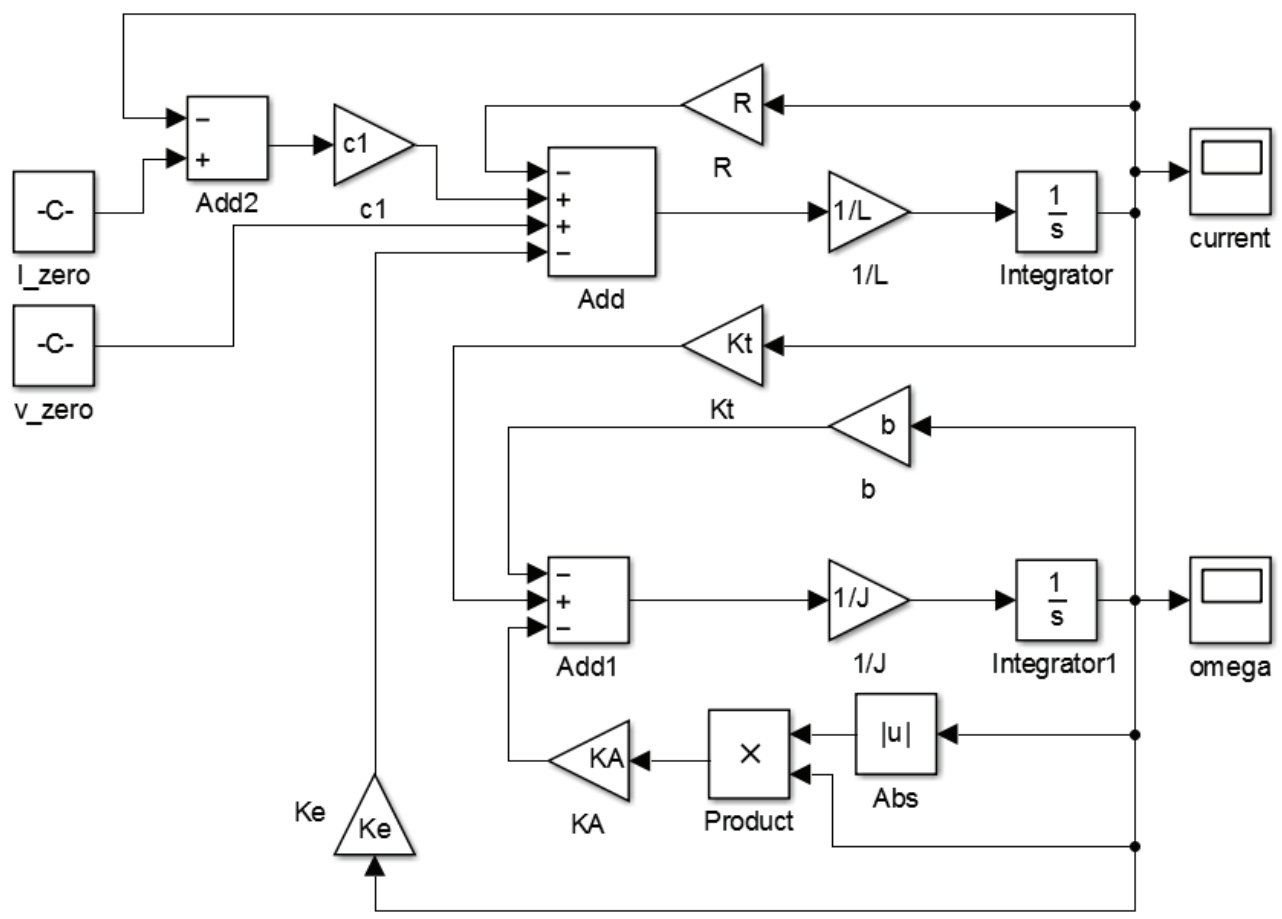

Figure 3. Simulink model of the electric current control for the DC motor.

The constant $I_{0}$ input, similar to a current setpoint in a control system, complements the effects of the setpoint voltage, $v_{0}$, and speeds up the response of the system. The net constant input to the system is $v_{0}+c_{1} I_{0}$.

The baseline motor parameter values in Table 2 below, except for $K_{A}$, were taken from the datasheet of a well characterized, commercially available, BLDC motor that possesses a power specification typical of quadcopter motors. ${ }^{16}$ The value of $K_{A}$ was calculated from a static coefficient taken from publicly available quadcopter research data. ${ }^{17}$ Specifically, the propeller coefficient for a $10 \times 5$ inch propeller, $C_{P}=0.04$, was substituted into the equation:

$$
K_{A}=\frac{C_{P} \rho_{\text {air }} D}{2 \pi}
$$

Equation 19.

where $\rho_{\text {air }}=1.225 \mathrm{~kg} / \mathrm{m}^{3}$ and $D$, which equals $0.254 \mathrm{~m}$ (10 inches), is the diameter of a typical quadcopter rotor, resulting in a $K_{A}$ of $8.24 \times 10^{-6} \mathrm{~kg} \mathrm{~m} \mathrm{~N}^{2} / \mathrm{s}^{2}$.

\begin{tabular}{|c|c|}
\hline Parameter & Baseline value \\
\hline$L$ & $0.48 \mathrm{mH}$ \\
\hline$I$ & Motor current, A \\
\hline$R$ & $0.70 \Omega$ \\
\hline$K_{e}$ & $1.10 \cdot 10^{-2} \mathrm{~V} \mathrm{~s} / \mathrm{rad}$ \\
\hline$\omega$ & Rotor angular velocity, rad $/ \mathrm{s}$ \\
\hline$J$ & $3.60 \cdot 10^{-6} \mathrm{~kg} \mathrm{~m}{ }^{2}$ \\
\hline$K_{t}$ & $0.0109 \mathrm{~N} \mathrm{~m} / \mathrm{A}$ \\
\hline$b$ & $3.30 \cdot 10^{-4} \mathrm{~N} \mathrm{~m} \mathrm{~s} / \mathrm{rad}$ \\
\hline$K_{A}$ & $8.24 \cdot 10^{-6} \mathrm{~kg} \mathrm{~m}^{2} \mathrm{~N}^{2} / \mathrm{s}^{2}$ \\
\hline
\end{tabular}

Table 2. Baseline motor parameter values. 


\section{RESULTS AND DISCUSSION}

According to the Lyapunov stability analysis demonstrated earlier, the motor control system simulated in Simulink should be able to track a constant set point while remaining asymptotically stable. As a demonstration, the simulation was run with various values for control parameter $c_{1}$ and using the baseline parameters in Table 2 . A graph of current versus time for various values of $c_{1}$ is shown in Figure 4 below, and a graph of angular velocity versus time for various values of $c_{1}$ is shown in Figure $\mathbf{5}$ below. The system showed stable behavior since it could track rise times smoothly for all values of $c_{1}$ tested, with rise time being the time elapsed during the transition from $10 \%$ to $90 \%$ of its steady state current or angular velocity, starting from zero. Note that the system tracked rise times smoothly and quickly, with no overshoot, oscillation, or other signs of instability.

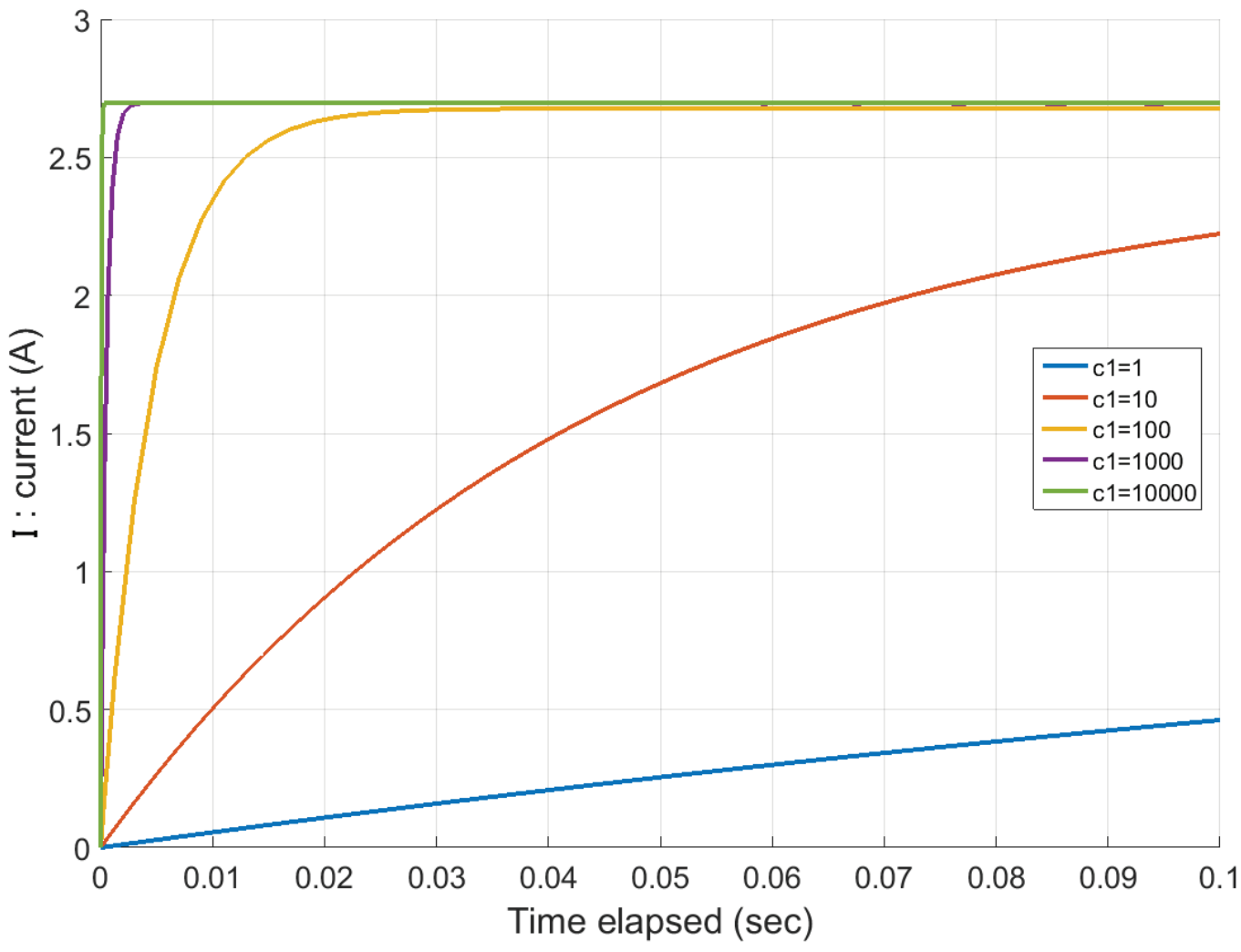

Figure 4. Simulation current response for a range of control parameter $c_{1}$, but motor parameters held constant. 


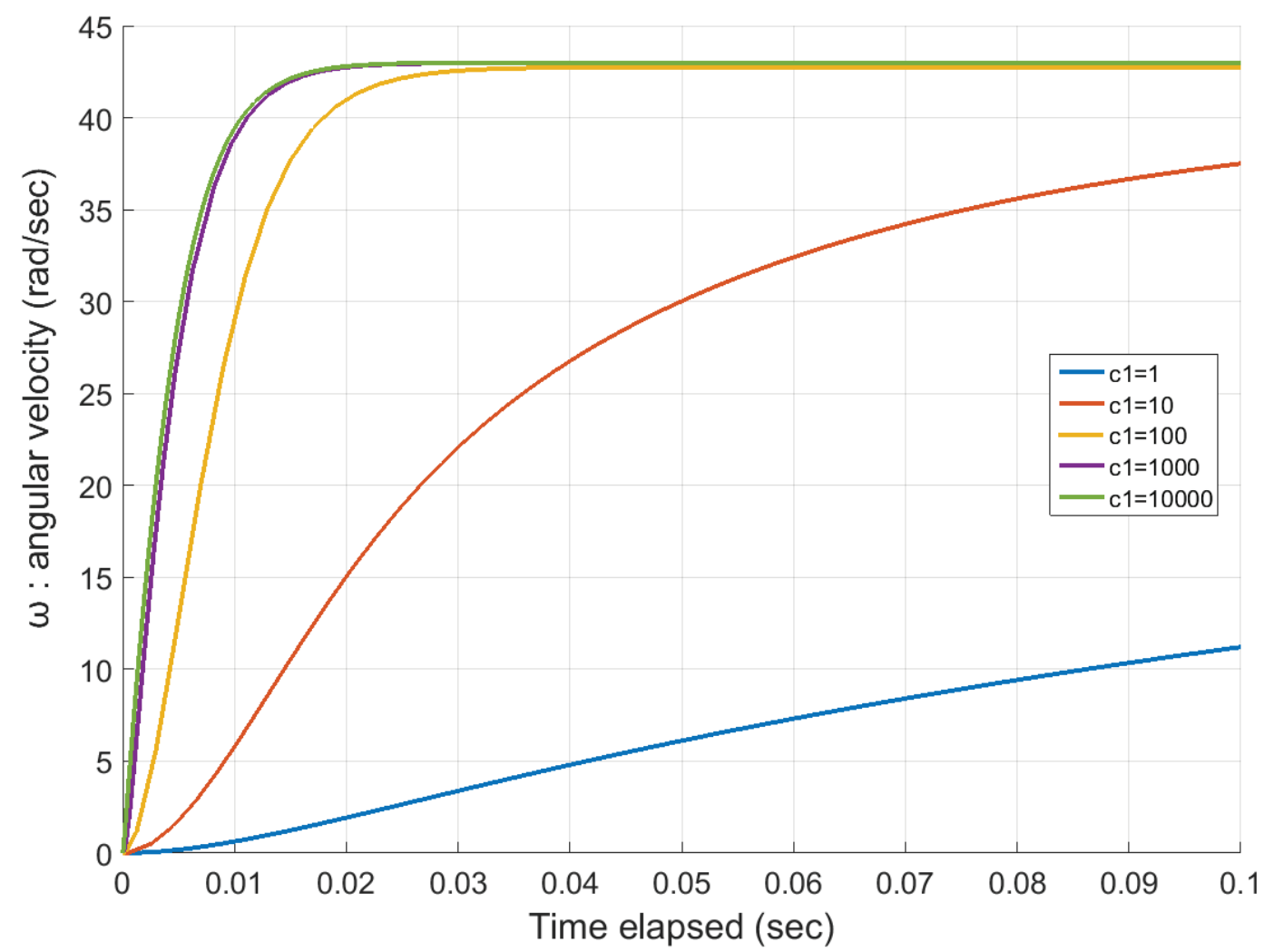

Figure 5. Simulation angular velocity response for a range of control parameter $\mathrm{c}_{1}$, but motor parameters held constant.

As these results demonstrate, the larger $c_{1}$ values result in faster response times, while the system remains stable even for very high values of $c_{1}$, consistent with theory. However, to further demonstrate the robustness of the system, another test must be completed. In the next test, the values of physical parameters are decreased or increased to examine the effect on system performance.

The parameters that vary during this test are $R, L, K_{e}, b, J, K_{t}$, and $K_{A}$. In the real world, the physical parameters that determine the performance of the quadcopter BLDC may vary from nominal values due to measurement errors, manufacturing variance, and environment changes such as temperature and air density. Figure $\mathbf{6}$ below shows the simulated steady state current as $c_{1}$ increases with varying motor parameter values. To illustrate a wide variation from nominal, all the parameters are inputted as either $50 \%$ or $200 \%$ of the baseline values. Simulations test all parameters set at both percentages and for all possible combinations. The graph in Figure $\mathbf{6}$ below shows that the steady-state current value is robust to variations in all motor parameters tested. Steady-state current variation in the presence of motor parameter variation improves a great deal as the control parameter $c_{1}$ increases. These results demonstrate that the system is robust to variations in motor parameter values, since the system remains stable for the wide variation of parameter values tested and the response varies in a narrow range. 


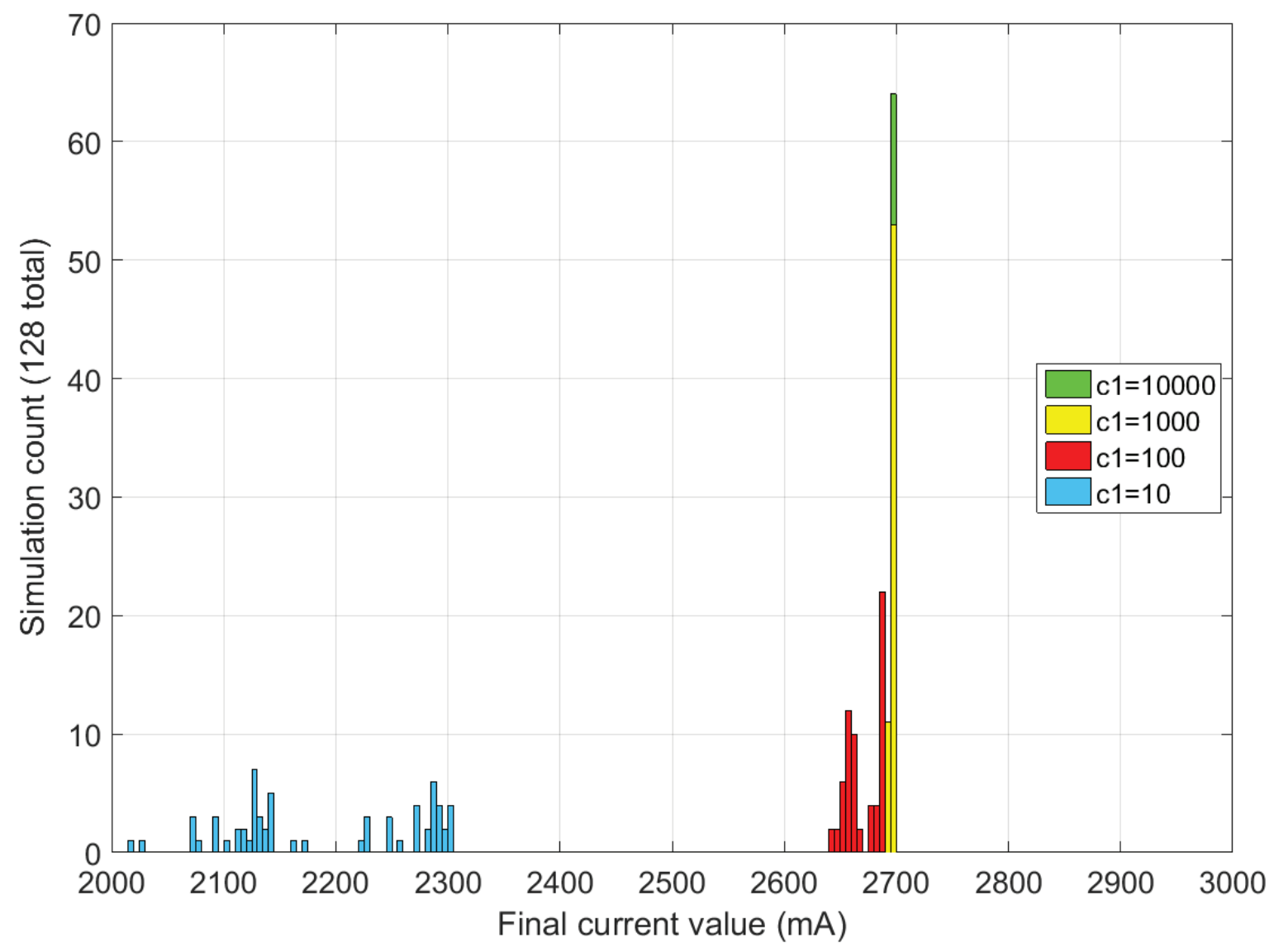

Figure 6. Histograms showing steady-state current variation across all motor parameter combinations. As $c_{1}$ increases, the variation improves to near zero at $c_{1}=10000$.

\section{CONCLUSIONS}

As shown, Lyapunov stability theory was applied to closed loop current control of a BLDC motor. A Lyapunov function was designed with associated feedback control that was proven to make the system stable. A model and simulation of the nonlinear BLDC motor showed the accuracy and robustness of the mathematical derivation.

There are several potential paths for future research on this motor control system. One topic for future research could be to include a full PID controller to minimize steady state error and possibly improve response time, and analyze the PID controller for stability. In addition, considering that the damping control method resulted in feedback only for the electric current variable, another area of study could be to use a different analysis technique that allows feedback control using the speed variable, including possibly a PID controller for speed. A third area for future research could be to build a physical model of the system and compare this model to the theory behind it. 


\section{REFERENCES}

1. Voos, H. (2009) Nonlinear control of a quadrotor micro-UAV using feedback-linearization, in Proceedings 2009 IEEE International Conference on Mechatronics, Malaga, Spain.

2. Michael, N., Mellinger, D., Lindsey, Q., and Kumar, V. (2010) The GRASP multiple micro-UAV testbed, in IEEE Robotics and Automation Magazine 17(3), 56-65.

3. Gurdan, D., Stumpf, J., Achtelik, M., Doth, K., Hirzinger, G., and Rus, D. (2007) Energy-efficient autonomous four-rotor flying robot controlled at $1 \mathrm{kHz}$, in Proceedings 2007 IEEE International Conference on Robotics and Automation, Roma, Italy.

4. Lupashin, S., Hehn, M., Mueller, M. W., Schoellig, A. P., Sherback, M., and D’Andrea, R. (2014) A platform for aerial robotics research and demonstration: the Flying Machine Arena, Mechatronics 24(1), 41-54.

5. Mellinger, D., Michael, N., and Kumar, V. (2012) Trajectory generation and control for precise aggressive maneuvers with quadrotors, International Journal of Robotics Research 31(5), 664-674.

6. Dong, W., Gu, G., Zhu, X., and Ding, H. (2015) Development of a quadrotor test bed — modeling, parameter identification, controller design and trajectory generation, International Journal of Advanced Robotic Systems, 1-14.

7. Hoffmann, G., Huang, H., Waslander, S., and Tomlin, C. (2007) Quadrotor helicopter flight dynamics and control: Theory and experiment, in ALAA Guidance, Navigation and Control Conference and Exhibit, Hilton Head, South Carolina.

8. Belatti, T., Kumar, V., Powers, C. University of Pennsylvania School of Engineering and Applied Science SUNFEST Program, Quadrotor flight in constrained environments,_http://www.seas.upenn.edu/sunfest/docs/papers/12-belatti.pdf (accessed June 2015)

9. Mohammadi, M., and Shahri, A. (2013) Adaptive nonlinear stabilization control for a quadrotor UAV: Theory, simulation, and experimentation, Journal of Intelligent and Robotic Systems, 105-122.

10. Hughes, A., and Drury, D. (2013) Electric Motors and Drives: Fundamentals, Types and Applications 3rd ed., 357-358, Newnes, Oxford, UK.

11. Sabra, M., Khasawneh, B., and Zohdy, M. (2014) Robust nonlinear position control of BLDC motor with friction, in 2014 IEEE Transportation Electrification Conference and Expo (ITEC), Dearborn, Michigan.

12. Lin, H., Yan, W., Wang, J., Yao, Y., and Gao, B. (2009) Robust nonlinear speed control for a brushless DC motor using model reference adaptive backstepping approach, in 2009 International Conference on Mechatronics and Automation, Changchun, China.

13. Ghandhari, M., Andersson, G., and Hiskens, I. A. (2001) Control Lyapunov Functions for controllable series devices, IEEE Power Engineering Review, 21(10), 60-61.

14. Bacciotti, A., and Rosier, L. (2006) Liapunov Functions and Stability in Control Theory 2nd ed., 70-77, Springer Science \& Business Media, Berlin, Germany.

15. Khalil, H. K. (2001) Nonlinear Systems 3rd ed., 116-133, Prentice Hall, Upper Saddle River, New Jersey.

16. MOOG Incorporated, Silencer Series Brushless DC Motors datasheet, http:// www.moog.com/products/motors-servomotors/brushlessmotors/inside-rotor-brushless-dc-motors/bn-series/ (accessed July 2015)

17. Brandt, J., Deters, R., Ananda, G., and Selig, M. University of Illinois at Urbana-Champaign, UIUC Propeller Database, http:/ / m-selig.ae.illinois.edu/props/propDB.html (accessed July 2015)

\section{ABOUT THE STUDENT AUTHOR}

Steven Elliott is currently a student at Southern Methodist University in Dallas, Texas. He plans to earn a Bachelor of Science degree in engineering, followed by graduate school.

\section{PRESS SUMMARY}

One area of research and development that has enormous potential for many promising applications is the quadcopter microunmanned aerial vehicle (micro-UAV) platform. Quadcopters are poised to become a widely used technology, and improvements in quadcopter controls could have a significant impact on their efficacy. This paper analyzes nonlinear effects on brushless direct current (BLDC) motors when used in quadcopter flying robot applications. Specifically, the goal of this work is to use advanced mathematics to derive a nonlinear closed loop motor control equation and prove the stability of the system using Lyapunov stability analysis. This work includes a custom simulation of the system in MATLAB/Simulink that successfully demonstrates and quantifies the performance of the design. 


\title{
Development of Four-Square Fiducial Markers for Analysis of Paper Analytical Devices
}

\author{
Jenna Wilson ${ }^{* a}$, Tabitha Ricketts ${ }^{b}$, Ian Bentley $^{c}$, Ewa Misiolek $^{a}$ \\ ${ }^{a}$ Department of Mathematics and Computer Science, Saint Mary's College, Notre Dame, IN \\ ${ }^{b}$ Department of English, Saint Mary's College, Notre Dame, IN \\ ${ }^{c}$ Department of Chemistry and Physics, Saint Mary's College, Notre Dame, IN
}

Students: *jwilso01@saintmarys.edu,tricke01@saintmarys.edu

Mentor: ibentley@saintmarys.edu,misiolek@saintmarys.edu

\begin{abstract}
Fiducial markers are used in image processing to determine locations of interest based on fixed points of reference. There are a number of applications for these markers across various fields ranging from advertising to radiation therapy. The four-square fiducial markers discussed in this manuscript allow for the determination of locations of interest on digital images. These new markers are easily detected, provide information about image orientation, and allow for local color sampling. The markers are intended for use in a pharmaceutical assessment process in which images of colorimetric chemical tests are taken by a smart-phone in the field, uploaded to a database, and analyzed to collect quantitative information about the colors resulting from the tests.
\end{abstract}

\section{KEYWORDS}

Image Processing; Digital Imaging; Fiducial Markers; Image Thresholding; Color Calibration; MATLAB; Paper Analytical Devices

\section{INTRODUCTION}

In 2003, the World Health Organization (WHO) estimated that up to 25\% of all medications consumed in developing countries were either counterfeit or substandard. ${ }^{1}$ While the quality of pharmaceuticals is typically validated in quality control laboratories run by manufacturers and government agencies including the $\mathrm{WHO},{ }^{2}$ the validation process is often expensive, time-consuming, and generally inaccessible to the everyday consumer, especially in developing countries. To combat this issue, Paper Analytical Devices (PADs) provide an efficient, low-cost test to identify active ingredients in such medications, see e.g. Weaver $e$ t al. ${ }^{3,4}$ The PADs Project is an interdisciplinary research effort between Saint Mary's College and the University of Notre Dame that focuses on developing PADs to test for specific ingredients indicative of substandard pharmaceuticals. ${ }^{5}$ Each PAD is approximately the size of a business card and contains a series of cellulose paper strips, called lanes. The lanes are pretreated with chemical reagents that, upon combination with certain ingredients common to a given pharmaceutical, yield colorimetric products as shown in Figure $\mathbf{1}$.

To test a suspect medication with a PAD, a user first applies the medication, typically as a powder or crushed pill, along a specified track that runs through the middle of the lanes, ensuring that a sufficient amount of medication is applied to each lane. Next, the user dips the PAD into water such that the blue area at the bottom of the PAD is submerged and holds it there until a blue product forms at the top of the rightmost lane, which indicates that water has travelled to the top of the lanes. When the bottoms of the lanes are immersed, the water travels up the cellulose lanes via capillary action and combines the reagents and medication, resulting in a measurable colorimetric reaction.

Each lane tests for a specific ingredient. The resulting color in each lane indicates whether the corresponding ingredient is present in the test medication. At present, there are multiple variations of the PAD, including versions that test for common ingredients in specific medications, including antibiotics and antimalarials, as well as a "general" PAD that tests for generic ingredients, such as inappropriate fillers known to be common in counterfeit and substandard medications. Depending on the version of PAD, each lane might test for a different ingredient or multiple lanes might test for the same ingredient. Repeated tests on separate lanes is often used to verify results in the case that medication is not applied evenly across each lane; for example, if more medication is applied to the first few lanes than the last few. 


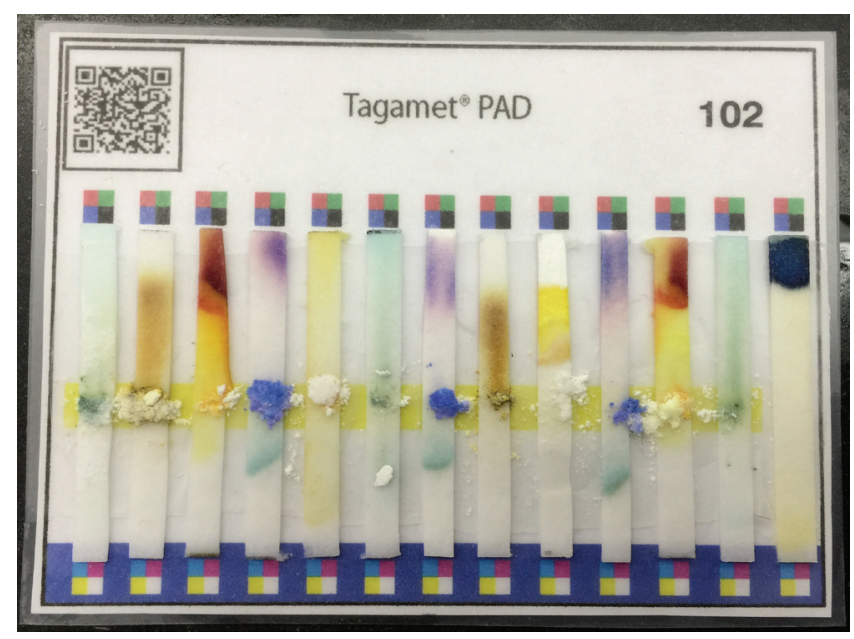

Figure 1. Smart-phone generated image of a completed PAD with 13 lanes, produced by E. Barstis. The colorimetric products resulting from chemical reactions between the pretreated reagents and pharmaceutical ingredients occur at various positions along the lane.

Each test might also produce a different type of colorimetric result. Some tests might turn one color when a certain ingredient is present and turn a different color when the ingredient is not detected. Others might turn a single color that varies in intensity in response to different concentrations of a target ingredient. For example, one test might turn the lane black in the presence of an ingredient and turn green when the ingredient is not detected while another might transition from yellow to dark orange when high concentrations of the ingredient are present. This can make it difficult for an untrained user to interpret the results of the PAD, especially for tests where the difference in color is very slight.

Image analysis software has the potential to introduce major improvements over the current use of manual PAD analysis, as it fully circumvents the optical subjectivity of a user. We are developing computational image analysis programs in MATLAB ${ }^{6}$ to objectively attain quantitative colorimetric data and allow for rapid analysis of a large number of images in order to more quickly and more accurately assess the results of reactions on a PAD. Ultimately, the goal is to allow an untrained user to conduct a determinative analysis of the colorimetric results of a PAD using a common smart phone.

In the planned system, the user will simply take a photograph of the PAD that has been used to test a medication and has produced colorimetric results, referred to as a "completed" PAD and shown in Figure 1, and upload it to our database via text message. Once the image is received, the software will first identify the location of the lanes, and then analyze the results of the PAD by comparing regions of interest with cataloged color data for known reactions. Most tests are set up such that the colorimetric reaction occurs in the area of the lane above the applied medication, but because some tests result in a reaction immediately where the medication is applied, examined regions of interest include the areas above and including the applied medication, separately. Finally, the program will determine what ingredients have been detected and notify the user of the results in less than one minute.

The primary difficulty in developing such software lies in the initial step of identifying the location of the lanes on the PAD, especially when standard image and lighting quality cannot be assumed. We have solved this problem and successfully automated lane identification by developing specialized fiducial markers that each contain four colors and placing them at the top and bottom of each lane, as shown in Figure 1. This manuscript addresses the development of these fiducial markers and their application to not only lane identification, but also image orientation and lighting-specific color calibration.

The following sections of this paper discuss the fundamentals of digital imaging relevant to our application, the use of fiducial markers in image processing, and the development of the new fiducial markers used on the PAD. The merits of the four-square markers will also be discussed, along with the results from a recent field-test. Appendix A contains an algorithm for finding four-square fiducial markers. Appendix B contains another algorithm for an interpolation routine used to both identify missing markers and also exclude extraneous pixels falsely identified as belonging to markers. 


\section{Digital imaging}

A digital image is a discrete, finite representation of a continuous scene that contains both spatial and color data stored within a 2-D matrix. ${ }^{7}$ Each element of the matrix is referred to as a picture element, more commonly abbreviated to pixel. The value stored in each pixel corresponds to the intensity of monochromatic light at that location in the image, given by the row and column of the pixel in the matrix. ${ }^{8}$ Thus, monochromatic images such as grayscale images, in which color is represented as shades of gray, can be stored as a single 2-D matrix because one value is sufficient to represent the intensity at each pixel.

Color images, on the other hand, require more information. Digital color is produced visually through the superimposition of three monochromatic images and numerically through a linear combination of values from three 2-D matrices, ${ }^{7}$ or "channels," corresponding to each of the three additive primary colors: red, green, and blue (RGB). These colors are referred to as additive because they create color by adding specified amounts of these primary colors to an absence of color, represented by the color black (K). In contrast, cyan, magenta, and yellow (CMY) are referred to as subtractive because they are created by completely subtracting RGB, respectively, from a complete presence of color, represented by the color white (W). The CMYK color space is most commonly used in printing by adding specified amounts of the subtractive color to produce color on a white medium, rather than trying to subtract amounts of the additive primaries. Likewise, the RGB color space is used primarily for digital displays by adding RGB light at varied intensities to an otherwise black screen, as is represented when no display is turned on. While other color spaces exist for digital images, the work discussed in this manuscript uses RGB images with channels containing values spanning from 0 to 255 and focuses on the eight "pure" colors, namely RGBKCMYW, created by the combinations of RGB values provided in Table 1 and illustrated in Figure 2. The use of these eight colors will be discussed in a later section.

\begin{tabular}{|c||c|c|c|}
\hline & Red Value & Green Value & Blue Value \\
\hline \hline Black & 0 & 0 & 0 \\
\hline Red & 255 & 0 & 0 \\
\hline Green & 0 & 255 & 0 \\
\hline Blue & 0 & 0 & 255 \\
\hline Cyan & 0 & 255 & 255 \\
\hline Magenta & 255 & 0 & 255 \\
\hline Yellow & 255 & 255 & 0 \\
\hline White & 255 & 255 & 255 \\
\hline
\end{tabular}

Table 1. RGB values corresponding to each of the eight "pure" colors in the RGB color space.

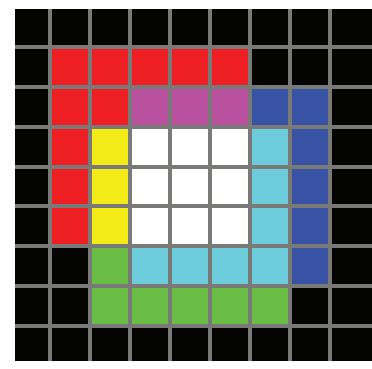

(a) RGB color image

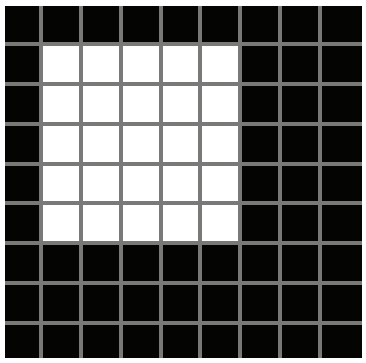

(b) Red pixels of image

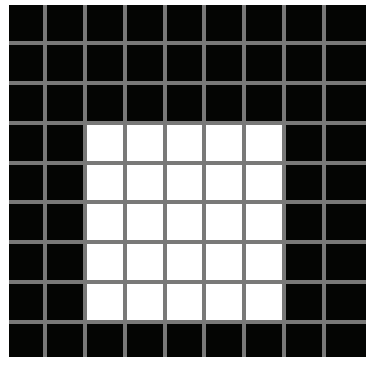

(c) Green pixels of image

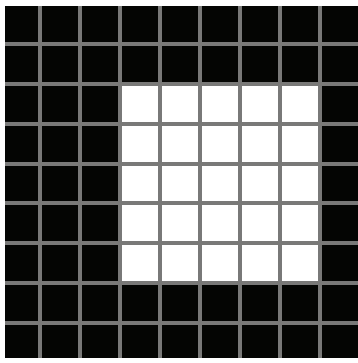

(d) Blue pixels of image

Figure 2. Demonstration of a 9-pixel-by-9-pixel composite image and the corresponding RGB channels.

As the range of data able to be stored, and thus the range of potential colors displayed in a digital image, depends on the file format, it was necessary to consider image file formats that would best preserve image color and clarity. For various reasons, our programs have been calibrated to and tested with Joint Photographic Experts Group (JPEG) images. The compression algorithm used to store JPEG images was originally created to generate photo-realistic images, ${ }^{9}$ and thus minimizes data loss when storing an image. 
Moreover, JPEG images generally use 24-bit color, meaning that they have the capacity to store values for and generate $2^{24}=256^{3}=16,777,216$ colors. Thus, JPEG images can store and display all combinations of values, from 0 to 255 , in the RGB color space without incurring losses due to color correction. Although alternate formats can be used to store 24-bit data and higher, the mainstream use of JPEG images by smart phones and other digital photography devices, in addition to the qualities previously mentioned, were preferable for the development and implementation of our fiducial markers.

\section{Object identification and fiducial markers}

As previously discussed, the primary problem in developing software to analyze images of PADs was automating lane identification. There are two approaches for identifying objects or locating regions of interest in an image that were considered. One makes use of pre-installed fiducial markers (see e.g. Kato ${ }^{10}$ and Naimark ${ }^{11}$ ) while the other, called point or feature matching, involves the analysis of various object components and compares those to components found on a reference image (see e.g. Davison ${ }^{12}$ and Stricker ${ }^{13}$ ). This section discusses both approaches, including the factors that led to the use of fiducial markers on the PADs, and demonstrates some current, more common uses of fiducial markers in object identification.

Feature matching is a fast technique for identifying object components in an image given a reference image despite clutter, scale change, or plane rotation. MATLAB's Computer Vision ToolBox provides functions, such as detectSURFFeatures and matchFeatures, to implement this technique with efficient feature detection and comparison algorithms. ${ }^{6}$

Feature matching was deemed ill-suited for this project for two main reasons. The most obvious problem with this technique is that the MATLAB implementation requires that both the sample image and reference image are grayscale images. As the overall goal of this project is to quantify color produced by chemical reactions, it did not seem logical or beneficial to use grayscale images.

Possible workarounds were considered but not implemented as they all posed more problems than solutions. Additionally, a reference image would likely have to come from the user in order to accurately detect and compare the features of the PAD, due to differences in image quality that occur simply from environmental differences in the camera and lighting. Not only would this provide additional work for the user, but it would also make for a less reliable program, as it is impossible to assure that every user will send a sufficient reference image. On account of these difficulties, an approach utilizing fiducial markers is preferable for identifying lanes on images of PADs.

The fiducial markers indicate a fixed point of reference or measure in image processing. Fiducial markers can be implanted to add precision for localized radiation therapy, ${ }^{14}$ included in printed circuit board design to provide precision when mounting boards with automated equipment, ${ }^{15}$ or used in computer-based object recognition and tracking. Bar-codes and QR codes are commonly used fiducial markers.

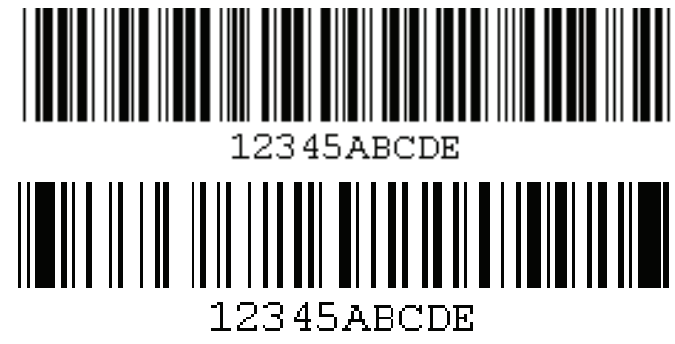

(a) Examples of bar-codes. ${ }^{16}$
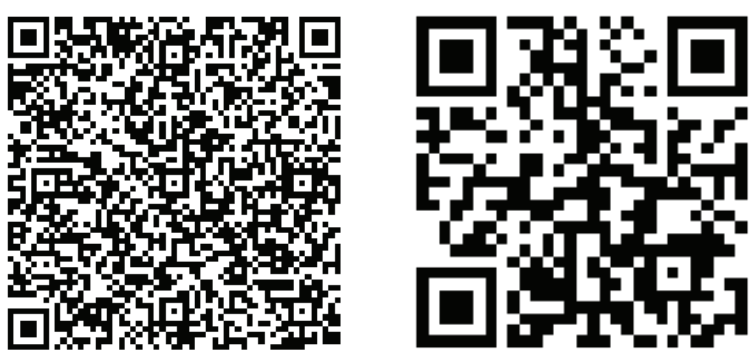

(b) Examples of QR Codes. ${ }^{17,18}$

Figure 3. Commonly seen fiducial markers used for object identification and data representation in business and advertising.

The term bar-code typically refers to a series of vertical lines of varying thickness and spacing, as seen in Figure 3a. These are used primarily for product identification and data representation. This type of bar-code provides a one-dimensional representation of data, while QR codes, as seen in Figure 3b, provide a two-dimensional representation of data. A standard QR code contains three large corner markers that are used to indicate position and orientation. These markers are composed of three concentric squares in 
black, white, and black. A smaller marker of the same type is often included near the bottom-right of a QR code and sometimes additional concentric square markers are included to allow for alignment. These fiducial markers and similar variations were considered for use on the PAD, but proved difficult to identify in our application. The shortcomings of these markers will be discussed in detail in the next section.

\section{METHODS AND PROCEDURES}

The principle motivation for using fiducial markers is to identify lane locations, but it proved nearly impossible to identify any lanes or markers consistently in images with poor orientation, such as skew, rotation, or excess background, or those taken in extremely dim or varied lighting. As such, the desired applications and functionality of the markers grew to encompass solutions to these problems. Moreover, since determining a lane's location requires identifying the markers both above and below it, lanes will go unidentified unless the markers are consistently identified. This section includes a discussion of these problems, the process of developing a fiducial marker to solve them, and the ways in which they are solved in the implementation of our final fiducial marker design.

Before attempting to identify lanes, an image must be oriented correctly in order to pair the markers appropriately according to lane, but this is impossible to do without some additional information or reference point to orient the image. We first considered adding a unique marker to indicate the top-left of the image, but instead decided to use two sets of markers to designate the top and bottom of the PAD.

There are three steps used to prepare an image for lane identification: major rotations of $90^{\circ}, 180^{\circ}$, or $270^{\circ}$ are used to account for images taken or read sideways or upside down; cropping is used to eliminate excess background; and minor rotations by less than $90^{\circ}$ are used to adjust for skew. The image of a PAD is cropped based on the locations of the outermost top and bottom markers. Similarly, the degree of the minor rotations can be calculated and accounted for based on the slope between the outermost top or bottom markers. However, since this technique requires the position of the outermost markers to be known, the program must first search for and find the markers before orienting the image and identifying the lanes themselves.

Although this is a simple workaround to implement, markers are rarely found in images with poor color quality. Color calibration can be used to correct for imperfect color due to the quality of printing, image capturing, and other environmental variables, as well as more drastic color imperfections, such as in images that lack sufficient brightness, contrast, or both. While global color adjustment can be used to modify the color of the entire image in order to aid marker identification, it does not sufficiently adjust the color in images containing vast light gradation. The effects of lighting variability is likely to be the most severe when a picture is taken with the flash on, resulting in bright central lanes and dark outer lanes. Additionally, if a portion of a light source is obstructed, then shadow can be cast on the image. By sampling colors on the fiducial markers, the colors of each lane can be calibrated individually, increasing contrast and allowing for more accurate data.

The initial fiducial markers designs developed and tested to address these concerns were composed of three concentric squares, similar to those seen in the corners of QR codes. These squares were edited to incorporate various patterns of RGB and CMY colors, such as those seen it Figure 4, to designate the top and bottom markers, respectively, and to allow for local color sampling.

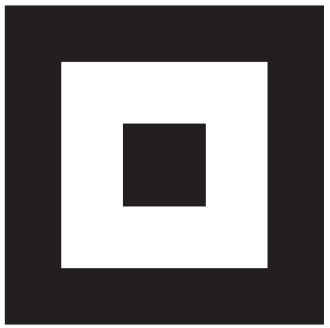

(a) Fiducial marker used in QR codes

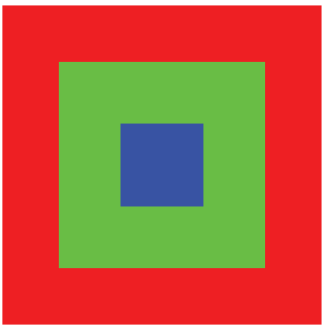

(b) RGB fiducial marker

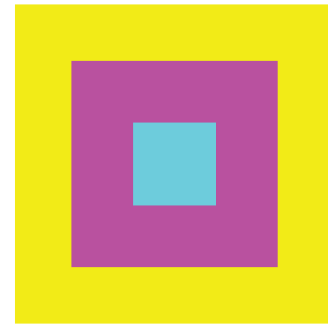

(c) YMC fiducial marker

Figure 4. Fiducial marker design composed of concentric squares, including that used in QR codes and variations tested on the PADs. 
Concentric square markers of this type are identified by a specific sequence of color transitions among adjacent pixels. That is, the algorithm used to identify these markers would first identify continuous regions of the colors used in the markers and then group these regions and label them as markers if they were bordering each other in the appropriate sequence. Unfortunately, the adjacent colors on the concentric square markers had substantially blurred edges caused by both printing and photographing. This resulted in muddled colors, making it difficult for the program to consistently find the markers since the change in color affected the program's ability to identify continuous regions of any color or bordering sequences of colored regions.

Eventually, two new fiducial markers were developed consisting of four adjacent colored squares, rather than concentric squares. The four-square marker composed of adjacent RGBK squares, shown in Figure 5a, is used to identify the top of each lane while that composed of CMYW squares, shown in Figure 5b, corresponds to the bottom of each lane. These colors have been chosen in order to contrast the background on the PAD. These four-square markers are easily, efficiently, and accurately identified through regional comparisons of four corners about a central pixel, especially when compared to the previous method used for the concentric markers.

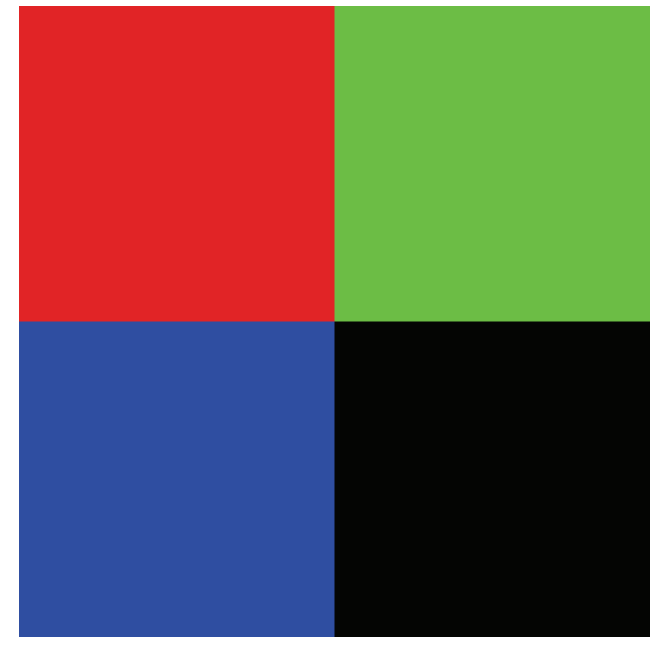

(a) RGBK fiducial marker

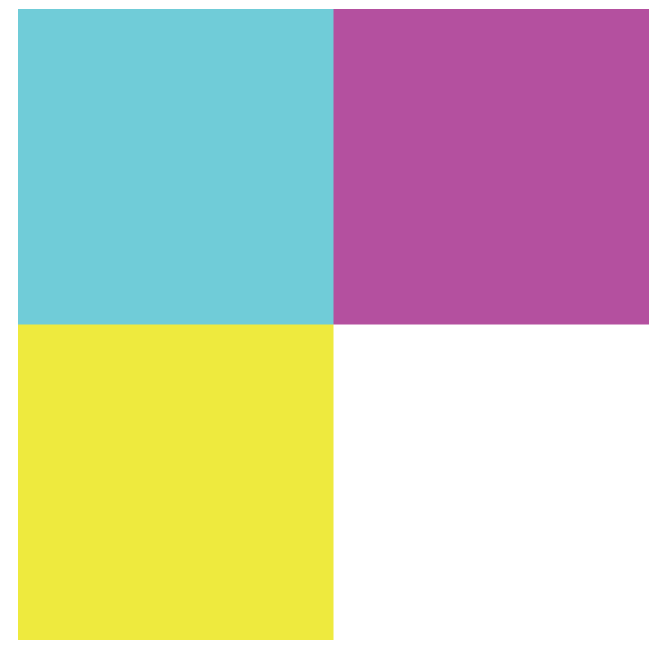

(b) CMYW fiducial marker

Figure 5. Four-square fiducial marker design composed of adjacent colored squares.

The identification of regional comparisons can be demonstrated through a binary representation of each RGB channel of the markers. The binary representation is attained by assigning logical values of 1 (true) to pixels with the maximum value of 255 in that channel's color and 0 (false) to all others. This representation generates a 3-bit binary image, comprised of the superposition of binary (1-bit) matrices in each of the RGB channels, resulting in the $2^{3}=8$ pure colors. Both the binary (1-bit) and RGB (24-bit) values are provided in Table 2 and each channel of the binary representation of the four-square marker is illustrated in Figure 6.

\begin{tabular}{|c|c|c|c|c|}
\hline Color & \multicolumn{3}{|c|}{ RGB values } & Binary values \\
\hline Black & 0 & 0 & 0 & {$\left[\begin{array}{lll}0 & 0 & 0\end{array}\right]$} \\
\hline Red & 255 & 0 & 0 & $\left.\begin{array}{lll}1 & 0 & 0\end{array}\right]$ \\
\hline Green & 0 & 255 & 0 & {$\left[\begin{array}{lll}0 & 1 & 0\end{array}\right]$} \\
\hline Blue & 0 & 0 & 255 & $\begin{array}{lll}{\left[\begin{array}{lll}0 & 0 & 1\end{array}\right]}\end{array}$ \\
\hline Cyan & 0 & 255 & 255 & $\left.\begin{array}{llll}0 & 1 & 1\end{array}\right]$ \\
\hline Magenta & 255 & 0 & 255 & {$\left[\begin{array}{lll}1 & 0 & 1\end{array}\right]$} \\
\hline Yellow & 255 & 255 & 0 & {$\left[\begin{array}{lll}1 & 1 & 0\end{array}\right]$} \\
\hline White & 255 & 255 & 255 & [ $\left.\begin{array}{llll}1 & 1 & 1\end{array}\right]$ \\
\hline
\end{tabular}

Table 2. RGB and binary values corresponding to each of the eight "pure" colors in the RGB color space. 

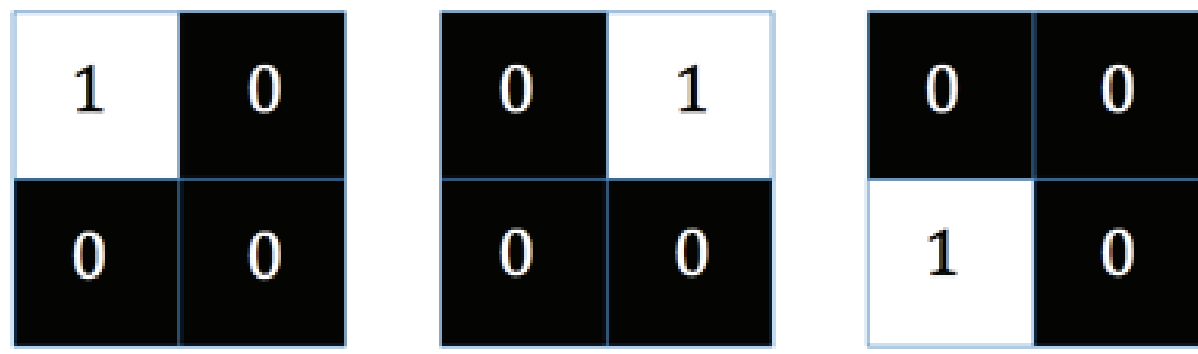

(a) Binary matrices of each RGB channel for RGBK fiducial marker.
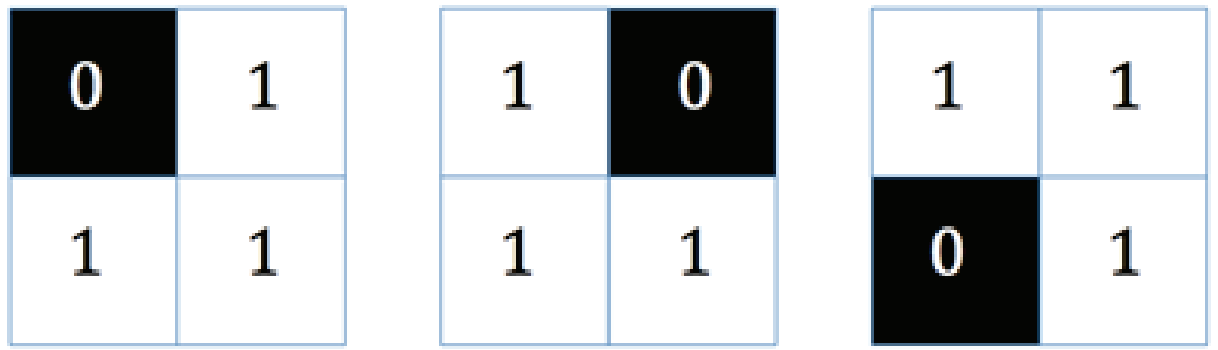

(b) Logical matrices of each RGB channel for CMYW fiducial marker.

Figure 6. Binary matrix corresponding to the red (left), green (middle), and blue (right) channels of the four-square fiducial markers.

The left-most combination of squares in Figure 6a shows the 2-D binary matrix of the red pixels of the RGBK marker. Note that the only matrix element containing a value of 1 corresponds to the red quadrant of the RGBK marker while all other quadrants return 0s. Similarly, the left-most square in Figure $\mathbf{6 b}$ shows the binary matrix of the red pixels of the CMYW marker. As discussed in the introduction, cyan is created in the absence of red, hence, the quadrant corresponding to the cyan quadrant of the CMYW marker returns a 0 in the red channel while all other quadrants contain values of 1 .

In order to generate the binary matrices of a captured colored image, we utilize image thresholding to convert each of the RGB values in the pixel to a binary value by assigning 1 to color values of a pixel exceeding the threshold and 0 otherwise. That is:

$$
L(x, y, c)= \begin{cases}1 & \text { if } I(x, y, c)>T \\ 0 & \text { otherwise }\end{cases}
$$

Equation 1.

where the color image, $I(x, y, c)$, contains RGB values at each pixel and the corresponding binary image, $L(x, y, c)$, is determined using a threshold value, $T .{ }^{19}$ Here, $x$ denotes the horizontal position and $y$ the vertical positions measured from the top left, while $c$ designates the channel, either red, green or blue. For example, a pure red pixel located in the top-left corner of an image would correspond to $I(1,1,[255,0,0])$. Furthermore, the red value of this pixel would correspond to $I(1,1,1)=255$. In this manner, each of the three color matrices are converted into binary matrices using one threshold value.

Thresholding allows a program to recognize "impure" colors that occur whenever a fiducial marker does not contain the expected RGB values. Note that if each pixel's RGB values are at either of the appropriate extremes, that is, the value of each channel is either 0 or 255, then any threshold values ranging from 1 to 254 will result in the same 2-D binary matrices shown in Figure $\mathbf{6}$. Further, the odds of incorrectly identifying random noise as a specific orientation of one of the two four-square color markers is low, specifically 1 in $8^{4}=4096$, since each of the four quadrants must be one of eight colors, and the colors of each quadrant are determined independently. When considering both colored four-square markers, these odds remain low, but change to 2 in $8^{4}=4096$, or 1 in 2048. As mentioned earlier, the program searches for markers before adjusting orientation, raising the odds of identifying random noise as markers to 8 in $8^{4}=4096$, or 1 in $8^{3}=512$, to account for both markers in any of the four rotations; however, it will be discussed later how the program accounts for noise identified as incorrectly oriented markers and thus eliminates 
the need to consider all four rotations in these chances. This is important because the photographic images taken in the field will vary as a result of the quality of printing on the PAD and the digital image taken, so a low chance of identifying stray pixels as markers allows images to be analyzed accurately with less dependence on the quality of the image.

Our program searches for markers using a range of threshold values to accommodate for environmental variations. These values are not predetermined, but are set according to the variations of color within each specific image. At each threshold, the program iterates through the pixels of the image, at each comparing the RGB values of the pixels a specified distance to the upper-left, upper-right, lower-left, and lower-right. If the corresponding binary image indicates a sequence of RGBK or CMYW markers, then the position of the central pixel is saved as a potential marker and records RGBK and CMYW sequences that correspond to major rotations. All saved pixels are later grouped and labeled. The complete algorithm used to identify the fiducial markers on an image is included in Appendix A.

Once a sufficient number of markers are found to proceed with the image analysis, the image is rotated according to the color sequence that the majority of possible markers indicates. For example, if an image is rotated by $180^{\circ}$, the bottom-right quadrant of each RGBK marker and CMYW marker will be red and cyan rather than black and white, respectively. Thus, if the majority of possible markers were found with this color sequence, the image will be rotated accordingly. Except in extremely poor quality images, the majority of possible markers found will be pixels from the markers themselves because the probability of incorrectly identifying random noise as one of these markers is low, as previously discussed, and thus signal the necessary degree of rotation and eliminate any pixels identified with a different color sequence from the pool of possible markers. In this way, the development of these fiducial markers has resolved the problem of motivating the proper rotation without requiring an additional marker to indicate the orientation.

Figure 7 demonstrates an example the visual output of the marker identification programs run on the image in Figure 1. Notice that the image in Figure 7 has been slightly rotated, cropped, and color adjusted, and indicates expected marker position and color. The expected center of each marker has been determined using the algorithm discussed in Appendix B. Once these adjustments have been made, the borders of the lanes can be calculated based on the marker positions and the color analysis can proceed.

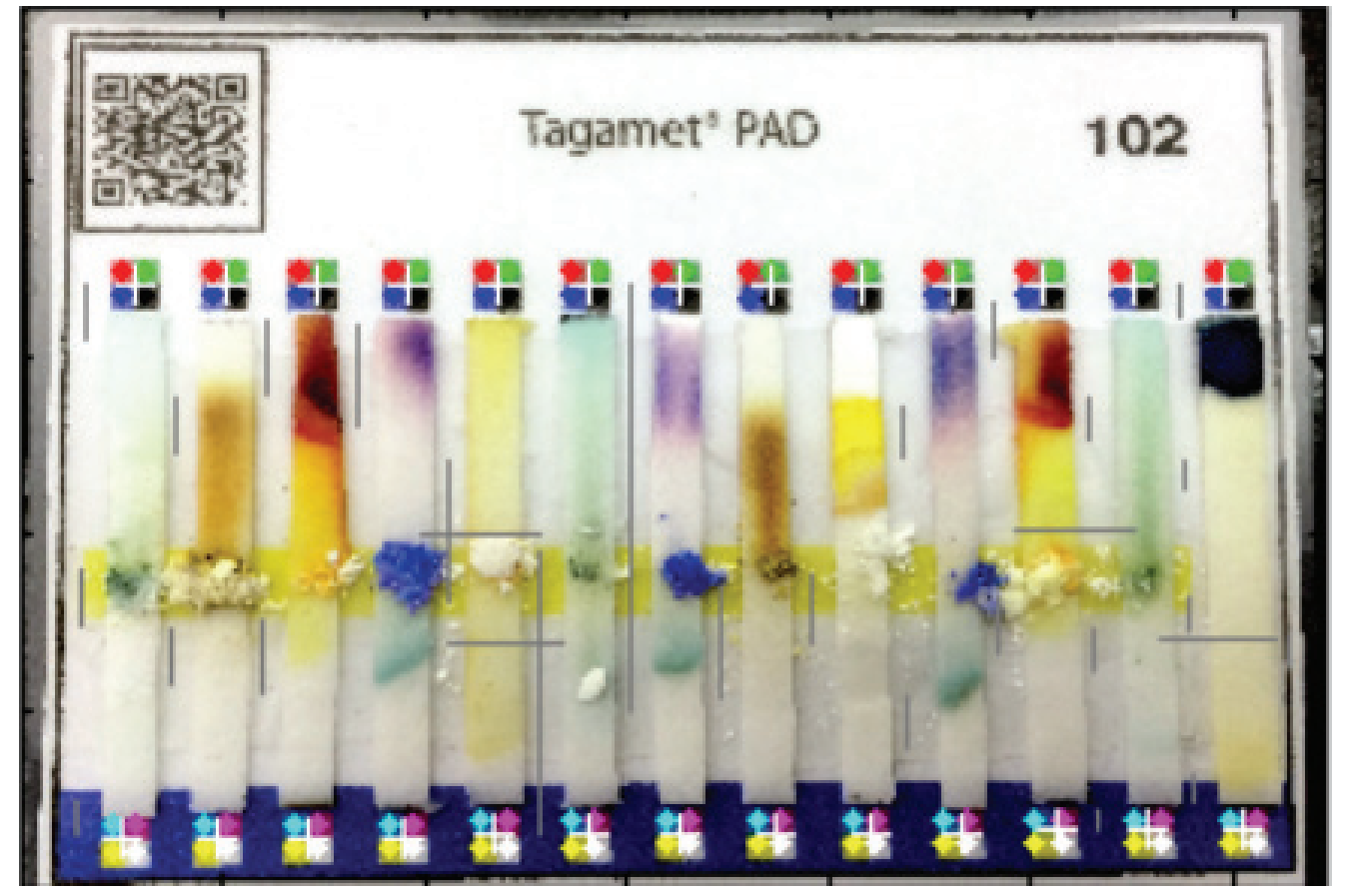

Figure 7. Analyzed version of Figure 1. Small colored circles have been overlaid on top of the image to indicate locations of color sampling on markers and small white cross-hairs indicate the expected center of each marker based on a linear fit. 
Beyond lane identification, which was the main goal intended to be accomplished with these markers, these markers can be used to aid the color analysis through local color sampling. Under the assumption that the RGB values of the colors in the fiducial markers will provide the most extreme of values, the colors in a lane can be calibrated based on the RGB values of its markers by "stretching" the range of RGB values to contain a maximum value of 255 and a minimum of 0 . For example, if the pixels in the center of the red quadrant of a lane's RGBK marker has RGB values of $[220,30,10]$ and those in the cyan quadrant of the corresponding CMYW marker has RGB values of $[20,230,225]$, then the red values in that lane can be adjusted so that they span from 0 to 255 rather than from 20 to 220. This can be applied to each RGB range and to each lane individually. Since color analysis of the PADs relies on a comparison of RGB values to those of catalogued data, this step standardizes the range of colors between samples and catalogued data.

\section{RESULTS}

A field-test of both the usability and computational analysis of PADs was conducted at Saint Mary's College on the 4th and 5th of March, 2015. As part of these tests, 172 iPhone images of PAD samples were taken by untrained users and sent to a database. These images were then used to test the reliability of our program. For these images, the program iterated through successive threshold values. Specifically, values of $T=32,64,96,128,160,192$ were used to determine the binary images and subsequently the fiducial markers. All markers were identified that contained the appropriate four-square color sequence in the quadrants at a distance of seven pixels vertically and horizontally from the center.

Of the 172 images, $80 \%$ had all 26 markers correctly identified. For an additional $6 \%$ of the iPhone images, the program was able to identify the outermost corner markers, allowing all remaining markers to be estimated using the interpolation routine described in Appendix B. The remaining 14\% of the iPhone images had incorrectly identified lanes or no identified lanes. For $12 \%$ of the images, the corner markers were not correctly identified because all four corner markers were not present in the photograph. For the other $2 \%$, the program did not identify any markers at all because the images were too distorted or blurry for the color sequences in the markers to be consistently detected.

\section{DISCUSSION}

Fiducial markers are needed to aid in the rapid and accurate analysis of PADs to test the validity of pharmaceuticals. Fiala ${ }^{\mathbf{2 0}}$ discusses basic criteria for measuring fiducial marker performance. For our intended use on PADs, the most critical criteria are false positive and false negative rates, vulnerability to lighting conditions, and speed performance. The markers introduced here consist of four differently colored squares placed into adjacent quadrants. The signature color combinations of markers are scanned for and if the outermost corner markers are all found, then regions of interest can be identified.

The newly developed four-square markers and the identification routine included in Appendix A are robust even in variable lighting situations when multiple thresholds are used, though this use comes at the cost of performance speed. Additionally, the use of a solid color background further reduces the number of false positive marker identifications. The exclusion routine included in Appendix B can determine rows of adjacent markers and eliminate outliers, thus diminishing the sensitivity on false positive and false negative counts. These techniques, however, are vulnerable to occlusion of a corner marker and do not provide perspective support.

The lane identification procedure makes use of many optimized MATLAB functions resulting in a program that takes about 20 seconds to identify lanes. In the future, clearly stated user instructions will be created to improve the success rate, as inexpert photography was the greatest source of incorrect lane identification in initial field-tests by untrained users. Additionally, the calibration parameters can be optimized to improve the success rate with images from a wider variety of devices as well as those from the smart phones and digital devices already tested, and speed the process further. Future development toward the ultimate goal of analyzing images of PADs will require the cataloging of colors corresponding to known chemical reactions and the creation of a color comparison program to identify reactions and notify users of the outcome. 


\section{CONCLUSION}

Overall, the four-square fiducial markers developed for analyzing images of the PADs serve as simple yet effective indicators of the orientation of a PAD in an image, the location of lanes, and the colors near each lane. Based on the success of these markers, we are one step closer to providing a means for the public to test the quality of their medications.

\section{ACKNOWLEDGMENTS}

This research was sponsored by the Marjorie Neuhoff Summer Science Research Communities Grant at Saint Mary's College. We thank E. P. Aldrich, E. Barstis, and D. Marquez for many helpful discussions, and T. L. O. Barstis and K. Haas for supervising the field-tests.

\section{REFERENCES}

1. Bagozzi, D. (2003) Substandard and counterfeit medicines, World Health Organization http://www.who.int/mediacentrelfactsheets/2003/fs275/en/.

2. World Health Organization (2007) Quality assurance of pharmaceuticals: a compendium of guidelines and related materials. Vol. 2, Good manufacturing practices and inspection. 2nd ed.

3. Weaver, A., Reiser, H., Barstis, T., Benvenuti, M., Ghosh, D., Hunckler, M., Joy, B., Koenig, L., Raddell, K. and Lieberman, M. (2013) Paper Analytical Devices for Fast Field Screening of Beta Lactam Antibiotics and Antituberculosis Pharmaceuticals, Anal Chem 85(13), 6453-6460.

4. Weaver, A. and Lieberman, M. (2015) Paper Test Cards for Presumptive Testing of Very Low Quality Antimalarial Medications, Am J Trop Med Hyg 92, 2-7.

5. Paper Analytical Device Project. (C2015, University of Notre Dame. http://padproject.nd.edu/.

6. MATLAB and Simulink are registered trademarks of The MathWorks, Inc. (01994-2015. http://www.mathworks.com/.

7. Solomon, C. and Breckon, T. (2011) Fundamentals of Digital Image Processing: A Practical Approach with Examples in Matlab, 1-12, 49-80, Wiley-Blackwell, John Wiley and Sons, Ltd. Publication.

8. Gonzalez, R. C. and Woods, R. E. (2008) Digital Image Processing, Third Edition, Pearson Education Inc.

9. Qidwai, U. and Chen, C.H. (2010) Digital Image Processing: An Algotithmic Approach with MATLAB, 1-28, CRC Press, Chapman and Hall.

10. Kato, H. and Billinghurst, M. (1999) Marker tracking and HMD calibration for a video-based augmented reality conferencing system, in 2nd IEEE and ACM International Workshop on Augmented Reality, 85-94.

11. Naimark, L. and Foxlin, E. (2002) Circular data matrix fiducial system and robust image processing for a wearable vision-inertial self-tracker, IEEE and ACM International Symposium on Mixed and Augmented Reality, 27-36.

12. Davison, A. J. (2003) Real-time simultaneous localisation and mapping with a single camera, Ninth IEEE International Conference on Computer Vision, 1403-1410, IEEE Computer Society.

13. Stricker, D. and Kettenbach, T. (2001) Real-time and markerless vision-based tracking for outdoor augmented reality applications, IEEE and ACM International Symposium on Augmented Reality, 189-190.

14. Erickson, B. J. and Jack, C. R. Jr. (1993) Correlation of single photon emission CT with MR image data using fiduciary markers, $\operatorname{AJNR} 14(3), 713$.

15. Carlton Industries Corporation (2004) Fiducial Mark Design Guidelines, 2-3.

16. Code 39 and Code 93 barcodes. (C) Copyright Measurement Equipment Corporation. http://www.makebarcode.com/.

17. QR Code, (C2015 About.com. http://desktoppub.about.com/od/glossary/g/QR-Code.htm.

18. QR Code Linking to www.linkedin.com/in/jwilson23, (C2015 QRStuff. http://www.qrstuff.com/

19. Marques, O. (2011) Practical Image and Video Processing Using MATLAB, 61-100, 125-199, 365-405, IEEE Press, John Wiley and Sons, Ltd. Publication.

20. Fiala, M. (2010) Designing Highly Reliable Fiducial Markers, IEEE Transactions on Pattern Analysis and Machine Intelligence 32(7), 1317-1324. 


\section{STUDENT AUTHORS}

Jenna Wilson is currently an undergraduate student enrolled in a five-year dual-degree engineering program at Saint Mary's College and the University of Notre Dame in Notre Dame, IN. She will graduate with a Bachelor of Science in Mathematics and a Bachelor of Arts in Philosophy from Saint Mary's College in May 2016, as well as a Bachelor of Science in Computer Science with a concentration in media computing from the University of Notre Dame the following year in May 2017. Jenna is particularly interested in computer graphics and plans to pursue a career in 3D computer animation.

Tabitha Ricketts is currently in her fifth year of a five-year dual-degree engineering program at Saint Mary's College and the University of Notre Dame in Notre Dame, IN. She graduated with a Bachelor of Arts in English Writing from Saint Mary's College in May 2015 and will graduate with a Bachelor of Science in Computer Science with a concentration in cyber security from the University of Notre Dame in May 2016. Tabitha plans to pursue a career in digital forensic analytics.

\section{PRESS SUMMARY}

Bar-code scanners, like those seen in grocery stores, are able to distinguish between products by analyzing a sequence of vertical bars. We have developed a comparable set of markers which allow us to determine the locations of interest on digital photographs The determination of these regions was a critical first step toward our ultimate goal of providing a means of verifying the quality of pharmaceuticals by sampling for active ingredients. 


\section{APPENDIX A: ALGORITHM FOR LOCATING THE FOUR-SQUARE FIDUCIAL MARKERS}

This algorithm takes in an original image, detects each four-square fiducial marker and labels them using routines in MATLAB. ${ }^{6}$ The MATLAB functions used require the MATLAB's Image Processing Toolbox and are included in the comments on the right side of the corresponding pseudocode. In-line comments are highlighted in green.

Input: digital image $I$ of a completed PAD

$\triangleright$ see Figure 1

\section{Initialization}

1: read digital image $I$

$\triangleright$ using imread

2: set threshold values

3: set distance $d$ to the number of pixels from a central pixel to its possible marker color quadrants

\section{Global Lighting Adjustment}

4: set scale to a small number of pixels proportional to the image size to be disregarded as noise or background

5: initialize color value iterator $i$ and pixel counter sum

6: initialize $\min$

$\triangleright$ records minimum color value for each channel

7: initialize $\max$

$\triangleright$ records maximum color value for each channel

8: for each RGB color channel $C$ do 9: $\quad$ generate histogram $H(c)$ representing the number of pixels with color value $0 \leq c \leq 255 \quad$ using imhist
$\quad \triangleright$ find minimum value

$i \leftarrow 0$

$\triangleright$ set $i$ to 0

sum $\leftarrow H(i)$

$\triangleright$ set $\operatorname{sum}=H(i)$

while sum $<$ scale do

$$
\text { sum } \leftarrow \text { sum }+H(i)
$$

$i \leftarrow i+1$

$\triangleright$ add $H(i)$ to sum

end while

$\min (C) \leftarrow i$

$\triangleright$ record $i$ as minimum color value of $C$

$\triangleright$ find maximum value

$i \leftarrow 255$

$\triangleright$ set $i$ to 255

sum $\leftarrow H(i)$

$\triangleright$ set sum to $H(i)$

while sum $<$ scale do

$\triangleright$ add $H(i)$ to sum

sum $\leftarrow$ sum $+H(i)$

$\triangleright$ decrement $i$ by 1

end while

$\max (C) \leftarrow i$

adjust the range of color values from $\min (C)$ to $\max (C)$ to 0 to 255

$\triangleright$ record $i$ as maximum color value of $C$

end for

\section{Major Rotation}

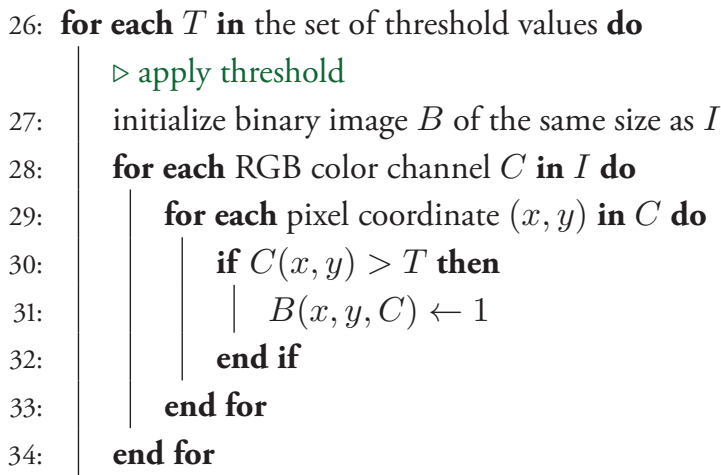

$\triangleright$ if the color value is greater than the threshold $\triangleright$ see Equation 1. 
$\triangleright$ determine the necessary degree of rotation

\section{Locate Markers}

48: for each $T$ in the set of threshold values do

$\triangleright$ apply threshold

49:

50:

65: label each neighborhood of true pixels in $M$ as a marker

initialize binary image $B$ of the same size as $R$

for each RGB color channel $C$ in $R$ do

for each pixel coordinate $(x, y)$ in $C$ do $B(x, y, C) \leftarrow 1$

end if

end for

end for

$\triangleright$ identify oriented markers

for each pixel coordinate $(x, y)$ in $R$ do

if quadrants $(x, y)=\mathrm{RGBK} \vee \mathrm{CMYW}$ then

$M(x \pm d, y \pm d) \leftarrow 1$

end if

end for $\triangleright$ for $0^{\circ}, 90^{\circ}, 180^{\circ}, 270^{\circ}$ rotation, respectively

$\triangleright$ see lines 26-34

if $C(x, y)>T$ then $\quad \triangleright$ if the color value is greater than the threshold

initialize binary image $M$ of the same size as $R \quad \triangleright$ to store pixels identified as possibly belonging to a marker

$\triangleright$ find the sequence of colors $d$ pixels from $(x, y)$ given by $B$ according to Table 2 and store to quadrants quadrants $(x, y) \leftarrow[B(x-d, y-d) B(x+d, y-d) B(x-d, y+d) B(x+d, y+d)]$

$\triangleright$ see Figure 6

$\triangleright$ set the neighborhood of pixels in $M$ to true

$\triangleright$ see Equation 1.

$\triangleright$ sequence indicates no rotation

$\triangleright$ sequence indicates $90^{\circ}$ rotation

$\checkmark$ sequence indicates $180^{\circ}$ rotation

$\triangleright$ sequence indicates $270^{\circ}$ rotation

$\triangleright$ using imrotate 


\section{APPENDIX B: ALGORITHM FOR EXTRACTING FALSELY IDENTIFIED FIDUCIAL MARKERS}

This algorithm is used to identify groups of fiducial markers placed in a row from any extra markers (false positives), and is used to extrapolate any internally-missed markers (false negatives) using routines in $\mathrm{MATLAB}^{6}$ and are included in the comments on the right side of the corresponding pseudocode. In-line comments are highlighted in green.

Require: locations of the centers of identified markers

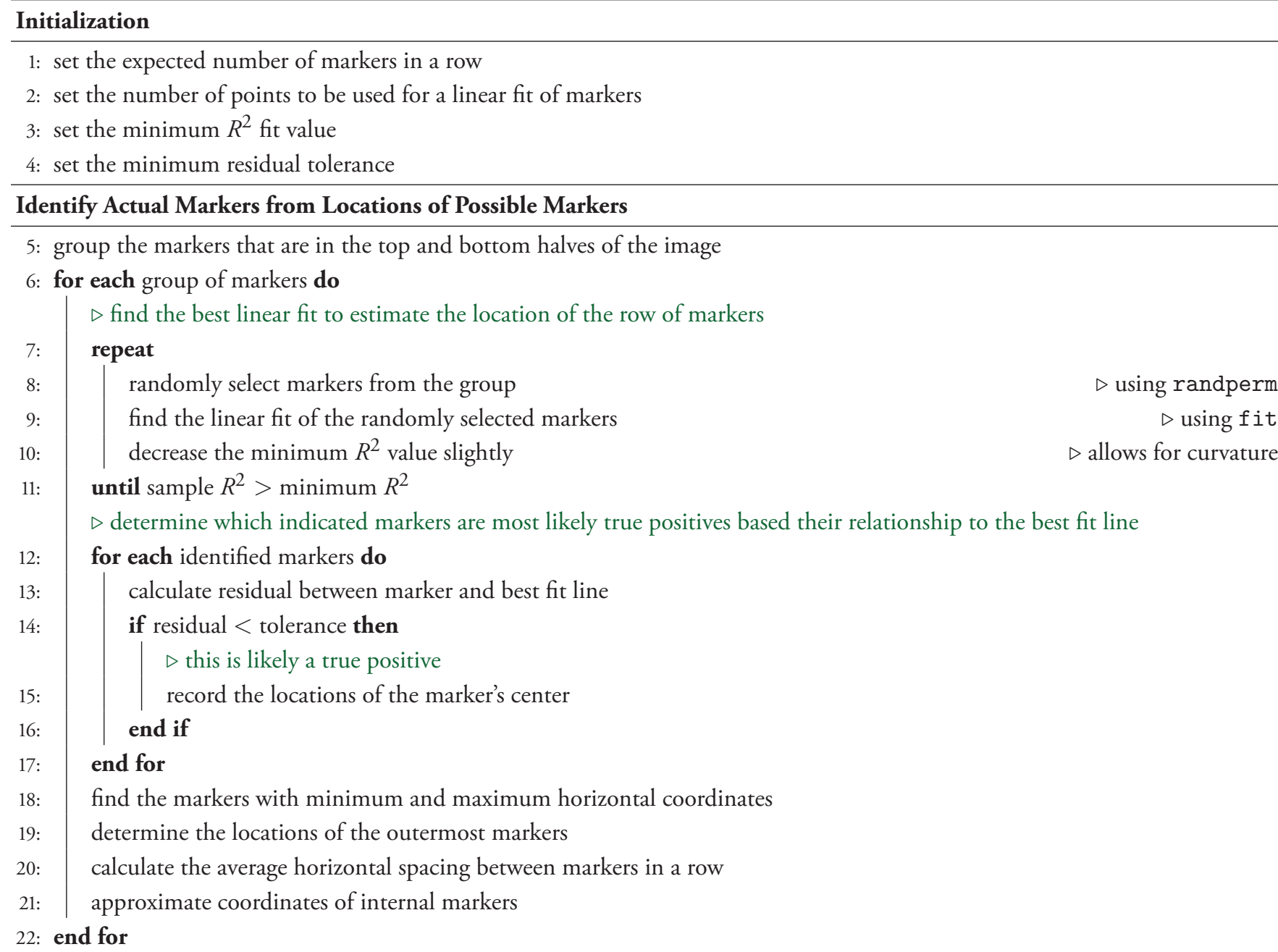




\title{
Sensitivity Analysis of Common Input Parameters in Tools for Modeling Energy in Homes
}

\author{
Sheikh Tijan Tabban, Nelson Fumo* \\ Department of Mechanical Engineering, The University of Texas at Tyler, Tyler, TX \\ Student:stabban@patriots.uttyler.edu \\ Mentor:*nfumo@uttyler.edu
}

\begin{abstract}
Energy models of buildings can be developed and used for analysis of energy consumption. A model offers the opportunity to simulate a building under specific conditions for analysis of energy efficiency measures or optimum design. Due to the great amount of information needed to develop an energy model of a building, the number of inputs can be reduced by making variable the most relevant input parameters and making the others to take common or standard values. In this study, an analysis of input parameters required by computational tools to estimate energy consumption in homes was done in two stages. In the first stage, common input parameters were identified for three software and three webtools based on the criteria that the input parameter should be common for at least two software and at least one webtool. In the second stage, a sensitivity analysis was performed on the inputs identified in the first stage. The software BEopt, developed by the National Renewable Energy Laboratory, was used as the source of typical input parameters to be compared, and to perform the simulations for the sensitivity analysis. The base or reference model to perform simulations for the sensitivity analysis corresponds to a model developed with information from a research house located on the campus of the University of Texas at Tyler and default inputs for the BEopt B-10 reference benchmark. Results show that besides the location, and consequently the weather, common parameters are building orientation, air leakage, space conditioning settings, space conditioning schedule, water heating equipment, and terrain. Among these parameters, the sensitivity analysis identified the largest variations in energy consumption for variations on space conditioning schedule (heating and cooling setpoints), followed by the type of water heating equipment.
\end{abstract}

\section{KEYWORDS}

Residential Buildings; Energy Consumption; Energy Analysis; Input Parameters; Building Simulation; Source Energy

\section{INTRODUCTION}

Energy efficiency in the residential sector has collected a strong interest in developed countries like United States and Canada because of the amount of energy consumed by this sector. In the United States the residential sector accounts for about $22.2 \%$ of the total energy consumption ${ }^{1}$, while in Canada it is about $17 \%{ }^{2}$. The United States National Renewable Energy Laboratory $\left(\mathrm{NREL}^{3}\right.$ and Canada's agency CanmetENERGY 4 investigate and promote ways to reduce the energy intensity of residential and commercial buildings. One way to do this is by creating computational tools capable of modeling building energy performances accurately. All tools need inputs that allow a description of the building in the model development. However, based on the approach used to develop the model, that is engineering, statistical, or hybrid ${ }^{1}$, more or less inputs are needed.

Energy models can help to identify building characteristics that can reduce energy consumption while maintaining economic feasibility. As an example, in an attempt to better understand the balance between investment costs, energy consumption, and indoor environment quality in high rise residential buildings in China, Zhao et. al. ${ }^{5}$ used dynamic simulations to investigate the influence of envelope design parameters on energy demands for heating and cooling reduction. Their results allowed them to conclude that the most sensitive design parameters where air tightness and insulation thickness of external walls. They also stated that window to wall ratio on the south façade, and building orientation can help to reduce energy demand.

To estimate energy consumption in buildings two approaches can be utilized: bottom-top or top-down. This work is related to energy models of individual buildings that can be used later for a bottom-top approach. In this sense, as mentioned by Arababadi et al. ${ }^{6}$, engineering models can be used to calculate the energy demand of individual buildings with input parameters associated to physical characteristics and energy end uses (e.g., lighting, appliances, and water heating). Then, those results can be used to scale up the results to represent the building stock of the region studied. Based on this approach, they investigated the use of a stepwise regression approach as a means to substitute the time consuming sensitive analysis used to identify relevant parameters. They mention that the literature suggests that the level of complexity of energy models needs to be limited and the accuracy of models 
can be increased by reducing the number of input parameters by avoiding the assumptions made for factors such as building construction and occupancy, among others. As a conclusion, they stated that the stepwise regression approach can help to identify the most relevant inputs, making possible to reduce the number of inputs which facilitates the use of the model and simulations.

From another point of view, codes and standards can be used as a reference on what is needed to satisfy residential prescriptive requirements. For example, the International Energy Conservation Code ${ }^{7}$ for residential energy efficiency defines requirements based on three categories: building thermal envelope, systems, and electrical power and lighting systems. While ASHRAE standards $^{8}$ defines recommended parameters based on four categories: envelope, lighting, HVAC, and service water heating (SWH). In general, for envelope, the R-value and U-value are the parameters considered, for lighting, the power density, and for HVAC and SWH, the efficiency is the parameter prescribed.

There is a great amount of input parameters that are needed to create the energy model of a building. However, simplifications could be made based on the objective of the model. As discussed by Urban and Glicksman', for an early design stage simplification of the modeling process using a user-interface makes a simulation tool accessible to a wider audience. Based on this justification, they developed the tool MIT Design Advisor to assist the users, such as architects, to investigate which design factors can save the most energy without affecting thermal comfort. The MIT Design Advisor tool uses zone configuration, building location and orientation, room dimensions and orientation, windows characteristics, wall insulation, thermal mass, occupancy (occupancy density and schedule, equipment load, and lighting), and ventilation (natural or mechanical) as the basic input options. Their preliminary trials have shown encouraging results.

In a model, the impact of an input parameter on the total energy consumption is different from one parameter to another. So, a sensitive analysis can be used to identify the parameters with the greatest impact. For example, Ioannou and L. Itard ${ }^{10}$ performed a Monte Carlo sensitivity analysis on building and occupant behavior factors affecting annual heating energy consumption in Northern Europe. They found that when the behavioral parameters were not taken into account, the most critical parameters were the window $\mathrm{U}$-value, window transmittance, and wall conductivity. With the impact of the wall conductivity being the most significant parameter when the uncertainty of the building-related parameters increases. When behavioral parameters like thermostat setpoints and ventilation flow rate are considered in the analysis, they diminish the importance of the building parameters.

Reports as those mentioned previously, motivated this study with the idea of identifying the minimum number of relevant input parameters to support the development of hybrid models with the intention of developing a simple tool for estimating residential energy consumption. Therefore, input parameters used in energy analysis of residential buildings are compared by several tools. The main source of these tools was the Building Energy Software Tools Directory ${ }^{11}$, which provides a large list of software tools for evaluating building energy efficiency, renewable energy, and sustainability in buildings. The main criterion for the selection among the available software tools was to select only those free of charge. Among the software tools identified, the Building Energy Optimization (BEopt) software ${ }^{12}$ was chosen to be the base template for comparing the input parameters. BEopt was chosen because of its relevance and continuous development by NREL with the support of the U.S. Department of Energy through the Building America Program ${ }^{13}$, and because of its simplicity to develop the building geometry and selection of input parameters from common options. The impact of common input parameters on energy consumption was assessed through a sensitivity analysis using the input parameters of the B-10 benchmark as the reference. The B-10 benchmark is a model in BEopt based on the 2009 International Energy Conservation Code and the Building America protocol.

The geometry and weather considerations for this study are based on the TxAIRE House \#1 located on the campus of the University of Texas at Tyler. The Texas Allergy, Indoor Environment, and Energy Institute (TxAIRE) has two houses designed to serve as realistic test facilities for developing and demonstrating new technologies related to energy efficiency, indoor air quality, and the sustainable construction material methods. ${ }^{14}$

\section{MATERIALS AND METHODS}

Software and Webtools

Based on inputs accessibility from software and webtools consulted, the list below is the software and webtools used for the comparison of the input parameters in residential buildings.

Software:

- $\quad$ BEopt (Building Energy Optimization)

- EnergyGauge

- Home Energy Saver 
Webtools:

- Home Energy Yard Stick

- Home Energy Scoring Tool

- Hot2 XP

The following is a description of each one of them:

\section{BEopt}

BEopt (Building Energy Optimization) ${ }^{12}$ is a free software developed by the National Renewable Energy Laboratory under the support of the U.S. Department of Energy through the Building America Program. The software provides the capability to analyze residential building designs and the entire cost of the efficiency platform of an entire building calculating the energy savings along with the path to zero net energy. It can also be used to analyze both old and new buildings using the evaluation of single building designs, parametric sweeps, and cost based optimization according to the BEopt website. BEopt also provides detailed simulation based on the house characteristics. BEopt uses EnergyPlus ${ }^{15}$ as simulation engine to run simulations with an hour by hour time-step.

\section{EnergyGauge}

EnergyGauge ${ }^{16}$ was developed by the Florida Solar Energy Center of the University of Central Florida, partnering with the U.S. Environmental Protection Agency and the U.S. Department of Energy (EPA). EnergyGauge can be used for both residential and commercial buildings, and currently EnergyGauge software uses version 4 for residential buildings and version 5 for commercial buildings. The EnergyGauge software is not free, but since it is recognized and used for energy audits and design of low energy homes, it was added to this study. This software can be used for residential buildings energy analysis and can also be used for improvement and economic analysis of existing buildings. The developers state that EnergyGauge can provide accurate computation of heating and cooling system part load performance, accurate prediction of indoor air relative humidity, and hourly prediction of end-use electrical and gas energy consumption for evaluation of peak impacts. The developers also state that the software has the ability to compute whole house mechanical ventilation system including run time ventilation, dehumidifiers, solar thermal system, and photovoltaic system. ${ }^{16}$ Energy Gauge offers a free trial period; it was sufficient time to record the input parameters that was needed for the comparison.

\section{Home Energy Saver}

Home Energy Saver (HES) ${ }^{17}$ computes a home's energy use on-line in a matter of seconds based on models and data developed at the U.S. Department of Energy's Lawrence Berkeley National Laboratory. According to the developers HES empowers homeowners and renters to save money, live better, and help the earth by reducing energy use in their homes. HES recommends energy saving upgrades that are appropriate to the home and make sense for the home's climate and local energy prices. The money invested in these upgrades commonly earns "interest" in the form of energy bill savings, at an annual rate of $20 \%$ or more. HES also estimates the home's carbon footprint and shows how much it can be reduced. As well, HES generates a list of energysaving upgrade recommendations for the user's consideration. The upgrades recommended by HES offer other benefits as well. Depending on the type of improvement made, the homeowner can achieve better comfort (warmer in winter, cooler in summer), fewer drafts, lower maintenance costs, and improved security and fire safety that improve life and increase the home's value.

\section{Home Energy Yardstick}

ENERGY STAR is a voluntary program from EPA that helps businesses and individuals save money and protects the climate through superior energy efficiency. Home Energy Yardstick was developed by Energy Star in collaboration with EPA. Home Energy Yardstick ${ }^{18}$ provides a simple assessment of a building's annual energy use in comparison to similar buildings. By answering a few basic questions about the home, the home's Home Energy Yardstick score can be obtained. Insights include how much of the home's energy usage is related to heating and cooling versus other everyday uses like appliances, lighting, and hot water. Links to guidance from ENERGY STAR provide data on how to increase home's score, improve comfort, lower utility bills, and an estimate of your home's annual carbon emissions. ${ }^{12}$

\section{Home Energy Scoring Tool}

The Home Energy Score ${ }^{19}$ is a national rating system developed by the U.S. Department of Energy; it allows Qualified Assessors to generate clear, credible home energy assessments at a reasonable cost. The Score reflects the energy efficiency of a home based on the home's structure, heating and cooling, and hot water systems. The Home Facts provide details about the current structure and systems. Recommended customized upgrades and saving tips help consumers compare the energy use of different homes to their own. The home energy scoring tool is not free and requires a qualified assessor to access the home energy scoring tool 
website. Qualified assessors can gather the information needed to assess a home in one short online visit. This low-cost, high value assessment can be provided as a stand-alone service or as an add-on to a home inspection or comprehensive energy assessment. A free pdf of the input parameters was provided by the Home Energy Scoring Tool website to allow future users to see the sample of the input parameters. ${ }^{13}$

\section{HOT2®XP}

HOT2 ${ } X^{20}$ is developed by professionals by CanmetENERGY for North America home design. HOT2®XP is the new software created to replace Hot2000, however the underlying engine is that of HOT2000 and thus provides a state-of-the-art analysis. Its graphical user interface and simplified input make it a quick and easy tool for analyzing energy use in houses. HOT2®XP is also used as the compliance software for the Canadian Energy Guide for House Programs.

HOT2 ${ }^{\circ} \mathrm{XP}$ forecasts energy consumption for residential construction projects accurately; it predicts energy cost and performance of natural gas, electric, propane, oil and wood heating equipment; and calculates thermal resistance of envelope components, including thermal bridging of construction materials. The data for the HOT2®XP is entered through a menu-driven interface and internal structural libraries provide many defaults inputs. According to the developers, the user can override these defaults and add additional details, which will increase the accuracy of the analysis. The software tools enable users to assess various types of renewable energy and energy efficient technologies to meet Canada's clean air and greenhouse gas emissions objectives. They increase the industry's ability to optimize integrated energy efficient design in domestic and international markets, reduce operating costs, comply with code requirements, and qualify for funding and incentive programs. ${ }^{21}$

\section{Input Variable Matrix}

For the comparison of the input parameters for the different software and webtools selected for this study, a matrix was created to ease the comparison. Three software and three webtools were selected based on the free access to the inputs information.

The matrix developed is presented in the Appendix. The matrix is divided into nine columns, the first column is the category column where input options from the geometry screen, options screen, and site screen of the BEopt are indicated. The second column is a subcategory section, and the third column is the option column. The software and webtools are identified in the columns from the fourth to the ninth columns where the comparison takes place. The common input parameters, based on the stated criteria, are summarized as building orientation, air leakage, space conditioning settings, space conditioning schedule, water heating settings, and type of terrain.

\section{RESULTS}

\section{Sensitivity Analysis}

Sensitivity analysis was performed for the inputs identified and is listed in the previous section. The sensitivity analysis was done by running simulations with defined variations in each input parameter and comparing the source energy use with respect to the B-10 benchmark reference. The weather file used in all simulations corresponds to the Tyler Pounds Field (regional airport). For each input parameter considered, simulation results are presented in a table. For all tables, source energy use in millions of Btu per year (MMBtu/yr) and percentage variation are shown. The variation corresponds to the reduction (positive percentage) or increase (negative percentage) of the energy use when compared to the B-10 benchmark model. The energy systems are as given by the results from BEopt simulations, with (E) indicating electricity and $(\mathrm{G})$ natural gas. From all tables, it can be seen that the results show that energy use from some of the energy systems are not affected by the changes on the input parameters investigated. These energy systems are miscellaneous equipment (electricity or natural gas), ventilation fans, and large appliances. Lights do not show variations for any of the investigated inputs, and possible variations due to building orientation are not captured by the simulations because of the fixed lighting schedule.

\section{Variations in orientation settings}

In the B-10 benchmark settings, the orientation is North $(\mathrm{N})$, which is the same of the TxAIRE House \#1. Simulations were performed for the following sequence of house orientation variations: South (S), East (E), West (W), South-East (SE), SouthWest (SW), North-West (NW), and North East (NE). Results for this input are shown in Table 1. The results illustrate that the energy use from energy systems associated to the HVAC system are affected by building orientation mainly because of the variation of load due to exposure of walls and windows to solar radiation. The impact of the orientation will depend on the windows' area in each façade facing a cardinal direction. Since it is generally accepted that the long axis of a house should run east-west to reduce energy use, it can be noted that the larger energy reductions of $0.7 \%$ is achieved for the western orientation. On the other hand, the north-east orientation illustrates the typical inverse variation in heating and cooling loads found from changes in orientation. For the simulated house, the cooling load decreased by $1.2 \%$, but the heating load increased by $1.2 \%$. 


\section{Variations in air leakage settings}

Variations in air leakage are defined as air changes at a pressure of $50 \mathrm{kPa}$ (ACH 50). In the B-10 benchmark settings, the air leakage default option is the $7 \mathrm{ACH}-50$. Simulations correspond to the following sequence of options change on air leakage: 6 ACH-50, 5 ACH-50, 4 ACH-50, 3 ACH-50, 2 ACH-50, and, 1 ACH-50. Results for this input are shown in Table 2. The results illustrate that the energy use from energy systems associated to the HVAC system are affected by the air leakage due to the additional load that air leakage implies. As the air leakages are reduced, the energy usage is reduced. It can be noted that an energy reduction of about $0.3 \%$ can be achieved by reducing the leakages by one category; for example, from $\mathrm{ACH}-4$ to $\mathrm{ACH}-3$ there is a reduction from $0.5 \%$ to $0.8 \%$ when compared to the benchmark (B-10_ACH-7). For this study, the maximum reduction of $1.7 \%$ was achieved for the air leakage setting of ACH-1.

\section{Variations in space conditioning settings}

In the B-10 benchmark settings, the default option corresponds to Central Air Conditioner (A/C) with efficiency of SEER 13 and gas Furnace with efficiency of 78\%. Table 3a shows results for variations in the A/C efficiency as SEER 14 (A/C-14) and SEER 15 (A/C-15), without changes in the furnace. Table $3 \mathbf{b}$ shows results for changing the A/C and furnace by an Air Source Heat Pump (HP) with different efficiencies: SEER 13 (HP-13), SEER 14 (HP-14), and SEER 15 (HP-15). Results from Table 3a show the energy usage associated with the HVAC system, which is affected mainly by the variation of the load due to the seasonal energy efficiency factor (SEER). As the efficiency of the air conditioning unit increases, the energy used will decrease. A maximum energy reduction of $1.9 \%$ was achieved by using an air conditioning unit with a rating of SEER-15. Similarly, results from Table 3b show the energy usage associated with the HVAC system but with variations due to Heating Seasonal Performance Factor (HSPF) and the SEER of the heat pump. As the efficiency of the air source heat pump increases, the energy used decreases. For this study, the maximum reduction of 5.6 \% was achieved for the air source heat pump setting of SEER-15. It can be noted that for the same SEER, a heat pump gave a greater energy reduction than the A/C-furnace $(5.6 \%$ compared to $1.9 \%)$.

\section{Variations in space conditioning schedule}

This sensitivity analysis was done by changing the cooling setpoint and heating setpoint for the space conditioning schedule. In the B-10 benchmark settings, the default option corresponds to $76^{\circ} \mathrm{F}$ and $71^{\circ} \mathrm{F}$ for the cooling and heating setpoints, respectively. Table 4a shows results where the cooling setpoint was decreased and the heating setpoint was increased as follows: $75^{\circ} \mathrm{F} / 72^{\circ} \mathrm{F}$, $74^{\circ} \mathrm{F} / 73^{\circ} \mathrm{F}, 73^{\circ} \mathrm{F} / 74^{\circ} \mathrm{F}$, and $72^{\circ} \mathrm{F} / 75^{\circ} \mathrm{F}$. While Table $4 \mathrm{~b}$ shows results where the cooling setpoint was increased and the heating setpoint was decreased as follows: $77^{\circ} \mathrm{F} / 70^{\circ} \mathrm{F}, 78^{\circ} \mathrm{F} / 69^{\circ} \mathrm{F}$, and $79^{\circ} \mathrm{F} / 68^{\circ} \mathrm{F}$. As expected, the energy use increased when the set point for cooling is lowered and the set point for heating is raised. This is due to the fact that the difference between the indoor and outdoor temperatures increase, which is the driving force for heat transfer. Table 4a illustrates that the energy used by the systems associated to the HVAC systems are affected by the variation of the load due to the decrease in cooling and increase in heating setpoints settings. It can be noted that there was an increase in the energy used when compared to the B-10 benchmark, with a maximum increment of $17.5 \%$ for the cooling/heating setting of $72^{\circ} \mathrm{F} / 75^{\circ} \mathrm{F}$. Similarly, Table $4 \mathrm{~b}$ illustrates that the energy used from the system associated to the HVAC systems are affected by the increase in cooling and decrease in heating setpoints settings. A decrease in the energy use was noted when compared to the B-10 benchmark, with a maximum reduction of $10.2 \%$ for the cooling/heating setting of $79^{\circ} \mathrm{F} / 68^{\circ} \mathrm{F}$.

\section{$V$ ariations in water heating settings}

In the B-10 benchmark settings, the default option correspond to a gas water heater. Variations were set by changing the options. Table 5 shows results for the following water heater options: gas tankless water heater (GTWH), electric standard water heater (ESWH), electric tankless water heater (ETWH), and heat pump water heater (HPWH). As generally known, a gas tankless water heater consumes less energy than a standard gas water heater. This is due to the reduction of wasted heat through the walls of the storage tank. From the simulation results given in Table 5, the reduction in source energy consumption was found to be $27.1 \%$ and $3.4 \%$ for the water heater itself and the total energy usage, respectively. As expected, changing from gas to electricity increases the source energy consumption. For the standard and tankless electric water heaters, the source energy usage increased $77.9 \%$ and $74.6 \%$ for the water heater itself, respectively. While the source energy usage increased 10\% and $9.7 \%$ with respect to the total energy usage. Results of the heat pump water heater show that this type of water heater reduces the energy consumption. The reduction in source energy consumption was found to be $3.6 \%$ and $0.4 \%$ for the water heater itself and the total energy usage, respectively. It can be noted that the energy consumption associated to cooling was reduced, while the energy consumption associated to heating was increased. This can be explained because the heat pump water heater will take heat from the house to heat the water. During the summer this is in favor of the HVAC system, but it is against it during the heating season.

\section{Variations in type of terrain}

In the B-10 benchmark settings, the default option corresponds to the suburban terrain, which match the terrain type the TxAIRE House \#1 is located. For the sensitive analysis, simulations were performed for each option available in BEopt: 
suburban, city, rural, plains, and oceans. Table 6 shows the results for the terrain options. The terrain option is used in simulations to modify the local free stream wind speed to account for ground roughness. This affects the wind speed at the building and the resulting air infiltration, as well as convection heat transfer coefficients. This effect is noticed in the HVAC performance on both cooling and heating and associated fan energy. For cooling energy, an increase in energy is found for the city option, but a reduction of energy is found for the rural, plains, and oceans options. For heating, the contrary effect appears, a reduction in energy is found for the city option, but an increase of energy is found for the rural, plains, and oceans options. Since the weather file used in the simulations is for the specific location of Tyler Pounds field, results should be used to infer upon the increase or decrease of energy usage but not on the magnitude. This is particularly true for the oceans option because the wind speed is higher on the coast compared to inland.

\begin{tabular}{|l|r|r|r|r|r|r|r|r|r|r|r|r|r|r|r|}
\hline Energy system & B10_N & \multicolumn{1}{|c|}{ S } & \% & \multicolumn{1}{|c|}{ E } & \% & \multicolumn{1}{|c|}{ W } & \% & \multicolumn{1}{|c|}{ SE } & \% & \multicolumn{1}{c|}{ SW } & \% & NW & \% & NE & \% \\
\hline Misc. (E) & 33.0 & 33.0 & 0.0 & 33.0 & 0.0 & 33.0 & 0.0 & 33.0 & 0.0 & 33.0 & 0.0 & 33.0 & 0.0 & 33.0 & 0.0 \\
\hline Vent Fan (E) & 1.5 & 1.5 & 0.0 & 1.5 & 0.0 & 1.5 & 0.0 & 1.5 & 0.0 & 1.5 & 0.0 & 1.5 & 0.0 & 1.5 & 0.0 \\
\hline Lg. Appl. (E) & 24.3 & 24.3 & 0.0 & 24.3 & 0.0 & 24.3 & 0.0 & 24.3 & 0.0 & 24.3 & 0.0 & 24.3 & 0.0 & 24.3 & 0.0 \\
\hline Lights (E) & 14.8 & 14.8 & 0.0 & 14.8 & 0.0 & 14.8 & 0.0 & 14.8 & 0.0 & 14.8 & 0.0 & 14.8 & 0.0 & 14.8 & 0.0 \\
\hline HVAC Fan/Pump (E) & 5.9 & 5.9 & 0.3 & 5.8 & 1.5 & 5.8 & 1.7 & 5.9 & 0.5 & 5.9 & 0.7 & 5.9 & 0.3 & 5.9 & 0.5 \\
\hline Cooling (E) & 15.2 & 15.3 & -0.3 & 14.9 & 2.1 & 15.0 & 1.2 & 15.2 & 0.4 & 15.2 & 0.0 & 15.2 & 0.0 & 15.0 & 1.2 \\
\hline Heating (G) & 21.8 & 21.4 & 2.1 & 21.8 & 0.0 & 21.2 & 3.0 & 21.7 & 0.7 & 21.2 & 2.8 & 21.5 & 1.4 & 22.1 & -1.2 \\
\hline Hot Water (G) & 17.3 & 17.2 & 0.9 & 17.2 & 0.5 & 17.3 & 0.3 & 17.2 & 0.8 & 17.2 & 0.6 & 17.3 & 0.1 & 17.3 & 0.1 \\
\hline Misc. (G) & 0.7 & 0.7 & 0.0 & 0.7 & 0.0 & 0.7 & 0.0 & 0.7 & 0.0 & 0.7 & 0.0 & 0.7 & 0.0 & 0.7 & 0.0 \\
\hline Total & 134.6 & 134.0 & 0.4 & 134.1 & 0.4 & 133.6 & 0.7 & 134.2 & 0.3 & 133.8 & 0.6 & 134.2 & 0.3 & 134.6 & 0.0 \\
\hline
\end{tabular}

Table 1. Source energy use (MMBtu/yr) and variation (\%) due to orientation settings.

\begin{tabular}{|c|c|c|c|c|c|c|c|c|c|c|c|c|c|}
\hline Energy system & B10_7 & ACH-6 & $\%$ & ACH-5 & $\%$ & ACH-4 & $\%$ & ACH-3 & $\%$ & ACH-2 & $\%$ & ACH-1 & $\%$ \\
\hline Misc. (E) & 33.0 & 33.0 & 0.0 & 33.0 & 0.0 & 33.0 & 0.0 & 33.0 & 0.0 & 33.0 & 0.0 & 33.0 & 0.0 \\
\hline Vent Fan (E) & 1.5 & 1.5 & 0.0 & 1.5 & 0.0 & 1.5 & 0.0 & 1.5 & 0.0 & 1.5 & 0.0 & 1.5 & 0.0 \\
\hline Lg. Appl. (E) & 24.3 & 24.3 & 0.0 & 24.3 & 0.0 & 24.3 & 0.0 & 24.3 & 0.0 & 24.3 & 0.0 & 24.3 & 0.0 \\
\hline Lights (E) & 14.8 & 14.8 & 0.0 & 14.8 & 0.0 & 14.8 & 0.0 & 14.8 & 0.0 & 14.8 & 0.0 & 14.8 & 0.0 \\
\hline HVAC Fan/Pump (E) & 5.9 & 5.9 & -0.7 & 5.9 & -0.2 & 5.9 & 0.3 & 5.8 & 0.8 & 5.8 & 1.0 & 5.8 & 1.2 \\
\hline Cooling (E) & 15.2 & 15.2 & -0.1 & 15.2 & 0.3 & 15.1 & 0.7 & 15.1 & 1.1 & 15.0 & 1.2 & 15.0 & 1.4 \\
\hline Heating $(\mathrm{G})$ & 21.8 & 22.1 & -1.5 & 21.7 & 0.6 & 21.3 & 2.5 & 20.9 & 4.0 & 20.7 & 5.2 & 20.5 & 6.0 \\
\hline Hot Water (G) & 17.3 & 17.3 & -0.1 & 17.3 & 0.0 & 17.3 & 0.1 & 17.3 & 0.2 & 17.3 & 0.2 & 17.2 & 0.3 \\
\hline Misc. (G) & 0.7 & 0.7 & 0.0 & 0.7 & 0.0 & 0.7 & 0.0 & 0.7 & 0.0 & 0.7 & 0.0 & 0.7 & 0.0 \\
\hline Total & 134.6 & 135.0 & -0.3 & 134.4 & 0.1 & 133.9 & 0.5 & 133.5 & 0.8 & 133.2 & 1.0 & 132.9 & 1.3 \\
\hline
\end{tabular}

Table 2. Source energy use (MMBtu/yr) and variation (\%) due to air leakage settings.

\begin{tabular}{|l|r|r|c|r|c|}
\hline Energy system & B10_13 & A/C-14 & \% & A/C-15 & \% \\
\hline Misc. (E) & 33.0 & 33.0 & 0.0 & 33.0 & 0.0 \\
\hline Vent Fan (E) & 1.5 & 1.5 & 0.0 & 1.5 & 0.0 \\
\hline Lg. Appl. (E) & 24.3 & 24.3 & 0.0 & 24.3 & 0.0 \\
\hline Lights (E) & 14.8 & 14.8 & 0.0 & 14.8 & 0.0 \\
\hline HVAC Fan/Pump (E) & 5.9 & 5.9 & 0.0 & 5.9 & 0.0 \\
\hline Cooling (E) & 15.2 & 13.9 & 8.7 & 12.6 & 17.0 \\
\hline Heating (G) & 21.8 & 21.8 & 0.0 & 21.8 & 0.0 \\
\hline Hot Water (G) & 17.3 & 17.3 & 0.0 & 17.3 & 0.0 \\
\hline Misc. (G) & 0.7 & 0.7 & 0.0 & 0.7 & 0.0 \\
\hline Total & 134.6 & 133.3 & 1.0 & 132.0 & 1.9 \\
\hline
\end{tabular}

Table 3a. Source energy use (MMBtu/yr) and variation (\%) due to air conditioning efficiency.

\begin{tabular}{|c|c|c|c|c|c|c|c|}
\hline Energy system & B10_None & HP-13 & $\%$ & HP-14 & $\%$ & HP-15 & $\%$ \\
\hline Misc. (E) & 33.0 & 33.0 & 0.0 & 33.0 & 0.0 & 33.0 & 0.0 \\
\hline Vent Fan (E) & 1.5 & 1.5 & 0.0 & 1.5 & 0.0 & 1.5 & 0.0 \\
\hline Lg. Appl. (E) & 24.3 & 24.3 & 0.0 & 24.3 & 0.0 & 24.3 & 0.0 \\
\hline Lights $(\mathrm{E})$ & 14.8 & 14.8 & 0.0 & 14.8 & 0.0 & 14.8 & 0.0 \\
\hline HVAC Fan/Pump (E) & 5.9 & 7.3 & -24.6 & 7.3 & -24.6 & 7.3 & -24.6 \\
\hline Cooling (E) & 15.2 & 15.4 & -1.1 & 14.2 & 6.5 & 13.6 & 10.7 \\
\hline Heating (E) & 0.0 & 16.9 & \multirow{2}{*}{22.7} & 15.2 & \multirow{2}{*}{30.4} & 14.5 & \multirow{2}{*}{33.7} \\
\hline Heating (G) & 21.8 & 0.0 & & 0.0 & & 0.0 & \\
\hline Hot Water (G) & 17.3 & 17.3 & 0.0 & 17.3 & 0.0 & 17.3 & 0.0 \\
\hline Misc. (G) & 0.7 & 0.7 & 0.0 & 0.7 & 0.0 & 0.7 & 0.0 \\
\hline Total & 134.6 & 131.2 & 2.5 & 128.4 & 4.6 & 127.0 & 5.6 \\
\hline
\end{tabular}

Table 3b. Source energy use (MMBtu/yr) and variation (\%) due to air source heat pump efficiency. 


\begin{tabular}{|l|r|r|r|r|r|r|r|r|r|}
\hline Energy system & B10_76/71 & $\mathbf{7 5 / 7 2}$ & \multicolumn{1}{|c}{$\boldsymbol{7}$} & $\mathbf{7 4 / 7 3}$ & $\mathbf{9}$ & $\mathbf{7 3 / 7 4}$ & \multicolumn{1}{c}{$\%$} & $\mathbf{7 2 / 7 5}$ & $\mathbf{\%}$ \\
\hline Misc. (E) & 33.0 & 33.0 & 0.0 & 33.0 & 0.0 & 33.0 & 0.0 & 33.0 & 0.0 \\
\hline Vent Fan (E) & 1.5 & 1.5 & 0.0 & 1.5 & 0.0 & 1.5 & 0.0 & 1.5 & 0.0 \\
\hline Lg. Appl. (E) & 24.3 & 24.3 & 0.0 & 24.3 & 0.0 & 24.3 & 0.0 & 24.3 & 0.0 \\
\hline Lights (E) & 14.8 & 14.8 & 0.0 & 14.8 & 0.0 & 14.8 & 0.0 & 14.8 & 0.0 \\
\hline HVAC Fan/Pump (E) & 5.9 & 6.7 & -13.6 & 7.6 & -29.0 & 8.5 & -44.7 & 9.3 & -58.2 \\
\hline Cooling (E) & 15.2 & 17.2 & -13.1 & 19.4 & -27.5 & 21.4 & -40.5 & 23.0 & -51.5 \\
\hline Heating (G) & 21.8 & 24.3 & -11.4 & 27.0 & -23.9 & 30.8 & -40.9 & 33.9 & -55.5 \\
\hline Hot Water (G) & 17.3 & 17.3 & 0.0 & 17.3 & 0.0 & 17.3 & 0.0 & 17.3 & 0.0 \\
\hline Misc. (G) & 0.7 & 0.7 & 0.0 & 0.7 & 0.0 & 0.7 & 0.0 & 0.7 & 0.0 \\
\hline Total & 134.6 & 139.9 & -3.9 & 145.7 & -8.2 & 152.3 & -13.2 & 158.0 & -17.4 \\
\hline
\end{tabular}

Table 4a. Source energy use (MMBtu/yr) and variation (\%) due to decrease in cooling and increase in heating setpoints.

\begin{tabular}{|l|r|r|r|r|r|r|r|}
\hline Energy system & B10_ 76/71 & $\mathbf{7 7 / 7 0}$ & \multicolumn{1}{|c}{$\mathbf{0}$} & $\mathbf{7 8 / 6 9}$ & \multicolumn{1}{c|}{$\mathbf{7}$} & $\mathbf{7 9 / 6 8}$ & \multicolumn{1}{c|}{} \\
\hline Misc. (E) & 33.0 & 33.0 & 0.0 & 33.0 & 0.0 & 33.0 & 0.0 \\
\hline Vent Fan (E) & 1.5 & 1.5 & 0.0 & 1.5 & 0.0 & 1.5 & 0.0 \\
\hline Lg. Appl. (E) & 24.3 & 24.3 & 0.0 & 24.3 & 0.0 & 24.3 & 0.0 \\
\hline Lights (E) & 14.8 & 14.8 & 0.0 & 14.8 & 0.0 & 14.8 & 0.0 \\
\hline HVAC Fan/Pump (E) & 5.9 & 5.2 & 12.6 & 4.5 & 23.8 & 3.9 & 34.0 \\
\hline Cooling (E) & 15.2 & 13.4 & 12.2 & 11.6 & 23.5 & 10.0 & 34.1 \\
\hline Heating (G) & 21.8 & 19.5 & 10.6 & 17.4 & 20.4 & 15.4 & 29.6 \\
\hline Hot Water (G) & 17.3 & 17.3 & 0.0 & 17.3 & 0.0 & 17.3 & 0.0 \\
\hline Misc. (G) & 0.7 & 0.7 & 0.0 & 0.7 & 0.0 & 0.7 & 0.0 \\
\hline Total & 134.6 & 129.7 & 3.6 & 125.1 & 7.1 & 120.9 & 10.2 \\
\hline
\end{tabular}

Table 4b. Source energy use (MMBtu/yr) and variation (\%) due to increase in cooling and decrease in heating setpoints.

\begin{tabular}{|c|c|c|c|c|c|c|c|c|c|}
\hline Energy System & B_10 Gas & GTWH & $\%$ & ESWH & $\%$ & ETWH & $\%$ & HPWH & $\%$ \\
\hline Misc. (E) & 33.0 & 33.0 & 0.0 & 33.0 & 0.0 & 33.0 & 0.0 & 33.0 & 0.0 \\
\hline Vent Fan (E) & 1.5 & 1.5 & 0.0 & 1.5 & 0.0 & 1.5 & 0.0 & 1.5 & 0.0 \\
\hline Lg. Appl. (E) & 24.3 & 24.3 & 0.0 & 24.3 & 0.0 & 24.3 & 0.0 & 24.3 & 0.0 \\
\hline Lights (E) & 14.8 & 14.8 & 0.0 & 14.8 & 0.0 & 14.8 & 0.0 & 14.8 & 0.0 \\
\hline HVAC Fan/Pump (E) & 5.9 & 5.9 & 0.2 & 5.9 & 0.2 & 5.9 & 0.2 & 5.9 & 0.5 \\
\hline Cooling (E) & 15.2 & 15.2 & 0.3 & 15.2 & 0.2 & 15.2 & 0.3 & 15.1 & 1.1 \\
\hline Heating (G) & 21.8 & 21.9 & -0.5 & 21.9 & -0.4 & 21.9 & -0.5 & 22.1 & -1.1 \\
\hline Hot Water (E) & 0.0 & 0.0 & \multirow{2}{*}{27.1} & 30.8 & \multirow{2}{*}{-77.9} & 30.2 & \multirow{2}{*}{-74.6} & 16.7 & \multirow{2}{*}{3.6} \\
\hline Hot Water (G) & 17.3 & 12.6 & & 0.0 & & 0.0 & & 0.0 & \\
\hline Misc. (G) & 0.7 & 0.7 & 0.0 & 0.7 & 0.0 & 0.7 & 0.0 & 0.7 & 0.0 \\
\hline Total & 134.6 & 130.0 & 3.4 & 148.1 & -10.0 & 147.6 & -9.7 & 134.0 & 0.4 \\
\hline
\end{tabular}

Table 5. Source energy use (MMBtu/yr) and variation (\%) due to water heating settings.

\begin{tabular}{|c|c|c|c|c|c|c|c|c|c|}
\hline Energy System & B_10 Suburban & City & $\%$ & Rural & $\%$ & Plains & $\%$ & Oceans & $\%$ \\
\hline Misc. (E) & 33.0 & 33.0 & 0.0 & 33.0 & 0.0 & 33.0 & 0.0 & 33.0 & 0.0 \\
\hline Vent Fan (E) & 1.5 & 1.5 & 0.0 & 1.5 & 0.0 & 1.5 & 0.0 & 1.5 & 0.0 \\
\hline Lg. Appl. (E) & 24.3 & 24.3 & 0.0 & 24.3 & 0.0 & 24.3 & 0.0 & 24.3 & 0.0 \\
\hline Lights (E) & 14.8 & 14.8 & 0.0 & 14.8 & 0.0 & 14.8 & 0.0 & 14.8 & 0.0 \\
\hline HVAC Fan/Pump (E) & 5.9 & 6.0 & -1.0 & 5.9 & 0.5 & 5.9 & 0.5 & 5.9 & -0.8 \\
\hline Cooling (E) & 15.2 & 15.6 & -2.6 & 15.0 & 1.7 & 14.8 & 2.7 & 14.7 & 3.4 \\
\hline Heating (G) & 21.8 & 21.2 & 3.1 & 22.5 & -2.9 & 23.1 & -6.0 & 24.6 & -12.6 \\
\hline Hot Water (G) & 17.3 & 17.2 & 0.5 & 17.4 & -0.3 & 17.4 & -0.6 & 17.5 & -1.1 \\
\hline Misc. (G) & 0.7 & 0.7 & 0.0 & 0.7 & 0.0 & 0.7 & 0.0 & 0.7 & 0.0 \\
\hline Total & 134.6 & 134.3 & 0.2 & 135.0 & -0.3 & 135.6 & -0.7 & 137.0 & -1.8 \\
\hline
\end{tabular}

With the idea of giving a visual representation of the results obtained from the sensitivity analysis, Figure 1 shows the total source energy use for each variation considered. For each series (labels B-10 and Table 1 through Table 6), the column bars have the same order from left to the right as the columns on the tables. 


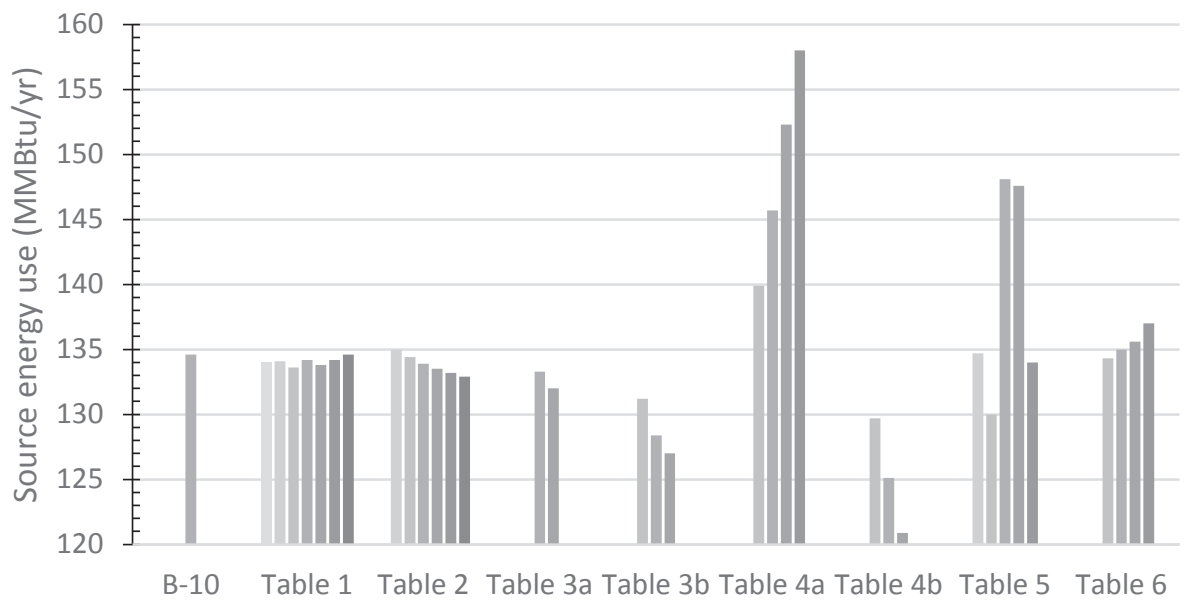

Figure 1. Total source energy use for each variation considered.

\section{CONCLUSION}

Building energy estimations for residential buildings are gaining a lot of importance due to the large energy consumption of the residential sector, which compares with the others sectors of the economy. This study provides the comparison of input parameters for the energy analysis of residential buildings. This study was intended to identify the most common and relevant input parameters for simulation of residential energy consumption. A model was developed in BEopt using information of the Building America B-10 benchmark and the TxAIRE House. The model was used to run simulations to perform sensitivity analysis of the most common input variables in selected software and webtools. The comparison of input parameters among the six tools investigated indicates that the common input parameters are building orientation, air leakage, space conditioning equipment, space conditioning schedule (thermostat set point), water heater, and terrain.

For the range of change in the input parameters considered in this study, it was found that the space conditioning schedule produced the highest variation in energy consumption. For a $4^{\circ} \mathrm{F}$ decrease in the cooling setpoint and $4^{\circ} \mathrm{F}$ increase in the heating setpoint, an increase of $17.4 \%$ was obtained for the annual energy source consumption. The second largest variation was found to be associated with the water heating equipment, and using the electric standard water heater produced an increase of $10 \%$ of the annual total energy use. Regarding water heaters, it is a good option to use gas tankless water heaters, as well, gas water heaters use less source energy than the electric water heaters. The third largest variation was found by the space conditioning equipment, which accounts for the efficiency of the equipment. Increasing the efficiency of the air conditioning from SEER 13 to SEER 15 a $1.9 \%$ reduction of source energy is obtained; while changing to a heat pump with SEER of 15 a $5.6 \%$ reduction is achieved. The other input parameters, orientation and air leakage, produced a maximum reduction of the annual source energy use of $0.3 \%$ and $1.3 \%$, respectively. The options for terrain indicates that the energy consumption due to HVAC systems will vary with the type of terrain. 


\section{REFERENCES}

1. Fumo, N. (2014) A review on the basics of building energy estimation, Renewable and Sustainable Energy Reviews 21, 53-60. doi:10.1016/j.rser.2013.11.040

2. National Resources Canada, http://oee.rncan.gc.ca/publications/statistics/trends11/chapter3.cfm (accessed May 2015)

3. National Renewable Energy Laboratory, U.S. Department of Energy, http:// wmw.nrel.gov/ (accessed May 2015)

4. National Resources Canada, Canada's CanmetENERGY, https://mww.nrcan.gc.ca/ energy/offices-labs/canmet/ 5715 (accessed May 2015)

5. M. Zhao, H. M. Künzel, and F. Antretter (2015) Parameters influencing the energy performance of residential buildings in different Chinese climate zones, Energy and Buildings 96, 64-75. doi:10.1016/j.enbuild.2015.03.007

6. R. Arababadi, H. Naganathan, K. Parrish, and W.K. Chong (2015) Determining the Feasibility of Statistical Techniques to Identify the Most Important Input Parameters of Building Energy Models, Procedia Engineering 118, $1258-1265$. doi:10.1016/j.proeng.2015.08.478

7. International Energy Conservation Code, International Code Council, http://publicecodes.cyberregs.com/icod/iecc/index.htm (accessed on November 2015)

8. ASHARE Standard 90.1-2010, Energy Standard for Buildings except Low-Rise Residential Buildings.

9. Bryan Urban and Leon Glicksman (2007) A Simplified Rapid Energy Model and Interface for Nontechnical Users, Buildings X Conference, ASHRAE, Clearwater FL. Available at bttp://designadvisor.mit.edu/design/papers/Urban_Glicksman_ORNL_2007.pdf

10. A. Ioannou and L.C.M. Itard (2015) Energy performance and comfort in residential buildings: Sensitivity for building parameters and occupancy, Energy and Buildings 92, 216-233. doi:10.1016/j.enbuild.2015.01.055

11. Building Energy Software Tools Directory, Energy Efficiency and Renewable Energy, U.S. Department of Energy, http:// apps1.eere.energy.gov/buildings/tools_directory/ (accessed on May 2015)

12. BEopt (Building Energy Optimization), National Renewable Energy Laboratory, U.S. Department of Energy, http:// beopt.nrel.gov/ (accessed on May 2015)

13. Building America Program, Energy Efficiency and Renewable Energy, U.S. Department of Energy, http:/ / energy.gov/ eere/buildings/building-america-bringing-building-innovations-market (accessed May 2015).

14. TxAIRE Research and Demonstration Houses, The University of Texas at Tyler, https:/ / wmw.uttyler.edu/txaire/ houses/ (accessed May 2015)

15. EnergyPlus, Energy Efficiency and Renewable Energy, U.S. Department of Energy, http:// apps1.eere.energy.gov/buildings/energyplus/ (accessed April 2015)

16. EnergyGauge, Florida Solar Energy Center, http:/ / www.energygauge.com/ (accessed May 2015)

17. Home Energy Saver, Lawrence Berkeley National Laboratory, http:// homeenergysaver.lbl.gov/consumer/ (accessed May 2015)

18. Home Energy Yard Stick, Energy Star program, the U.S. Environmental protection Agency, https:/ / wnw.energystar.gov/index.cfm?fuseaction=home_energy_yardstick.showgetstarted (accessed March 2015)

19. Home Energy Scoring Tool, Lawrence Berkeley National Laboratory, http:// homeenergyscore.lbl.gov/ (accessed February 2015)

20. HOT2XP, Energy, Energy Resources, National Resources Canada, http:// wmw.nrcan.gc.ca/energy/software-tools/ 7445 (accessed May 2015)

21. HOT2XP, Energy, Energy Resources, National Resources Canada, http://wmw.nrcan.gc.ca/energy/offices-labs/canmet/5715 (accessed May 2015)

\section{ABOUT THE STUDENT AUTHOR}

Sheikh Tijan Tabban is currently pursuing his B.S. in Mechanical Engineering and a minor in Mathematics. He has been in the University of Texas at Tyler for two years. He worked as an intern for Shell marketing Gambia Ltd as a quality control specialist at their fuel depot. He just finished his automated guided cart capstone project, and currently seeking employment in the mechanical engineering industry.

\section{PRESS SUMMARY}

Estimation of energy consumption of residential buildings using software tools depends on building characteristics and operation, which are defined through input parameters. This study provides the comparison of input parameters for the energy analysis of residential buildings, with the intention of identifying the most common and important input parameters. 


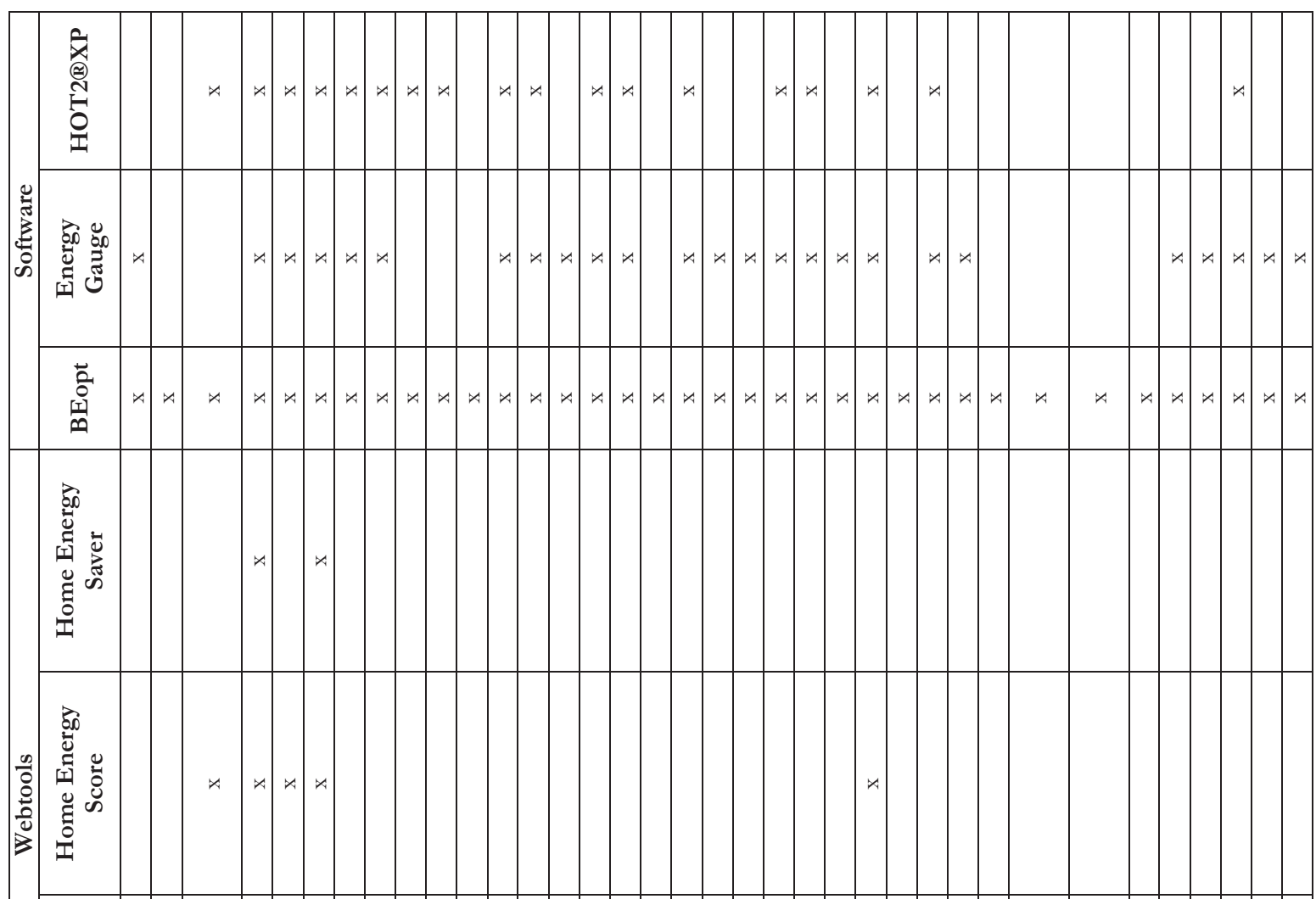

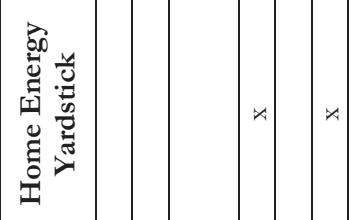

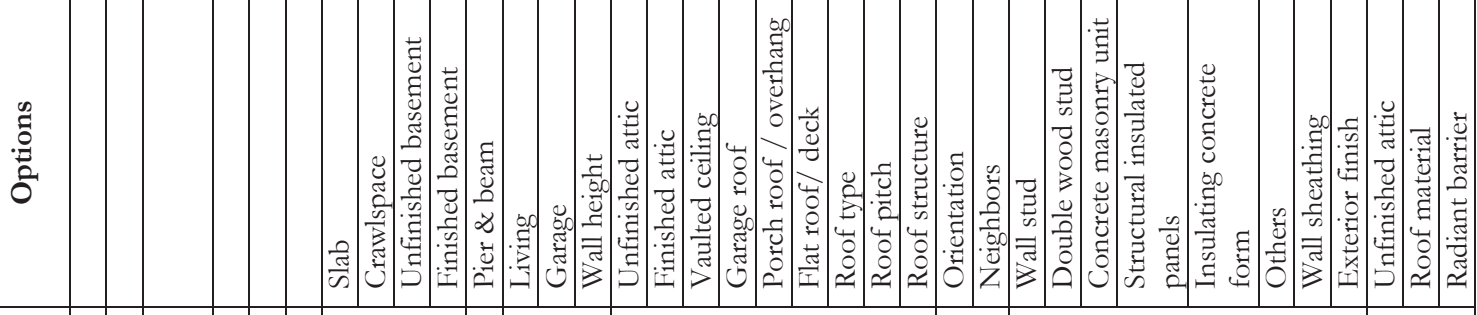

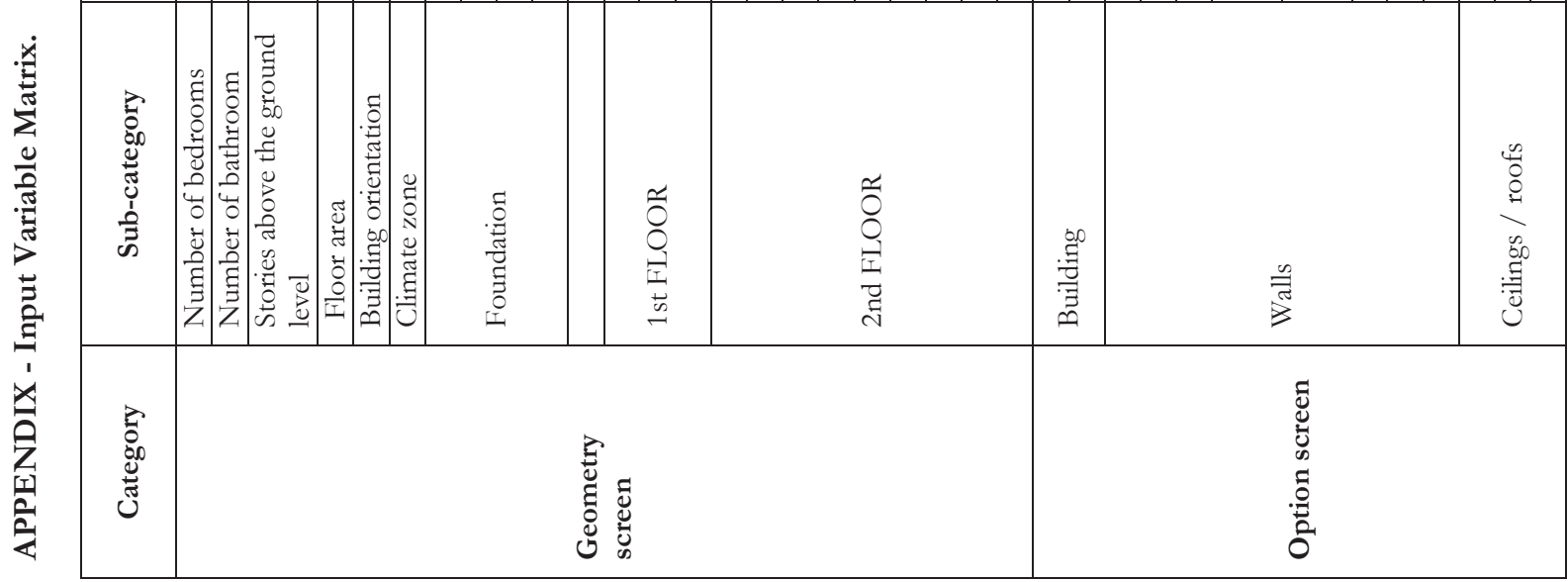




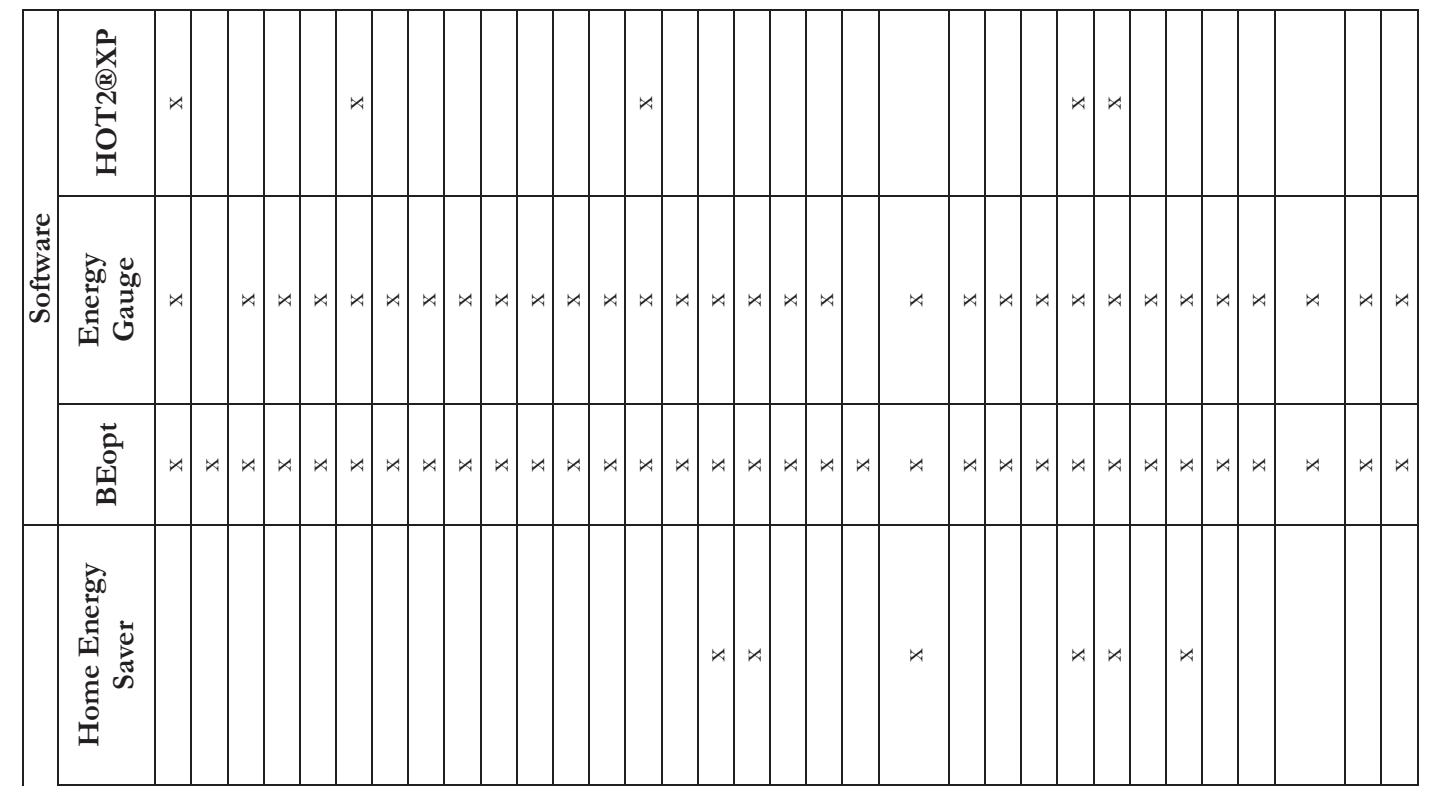

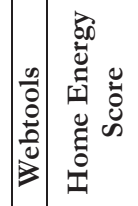

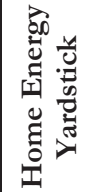

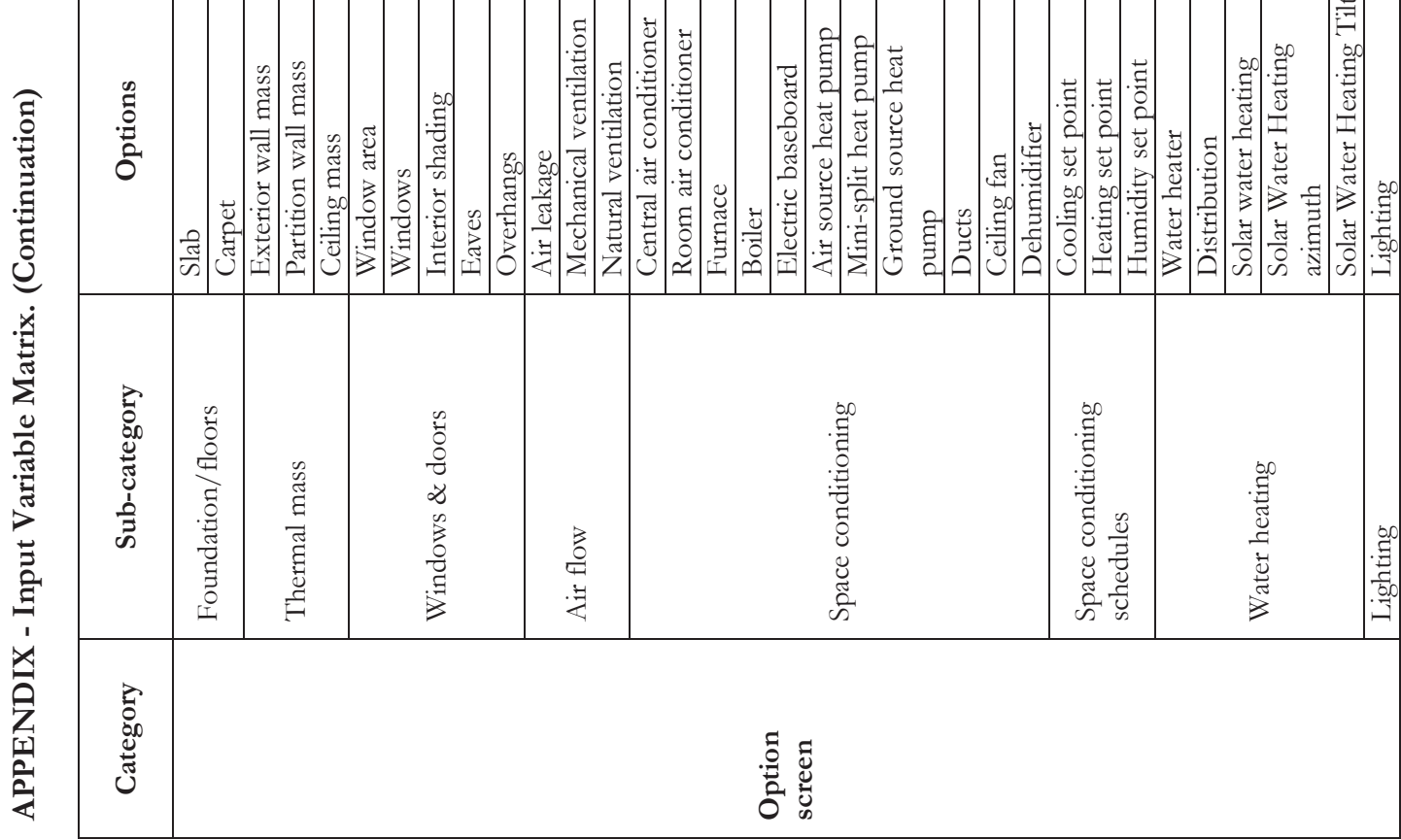




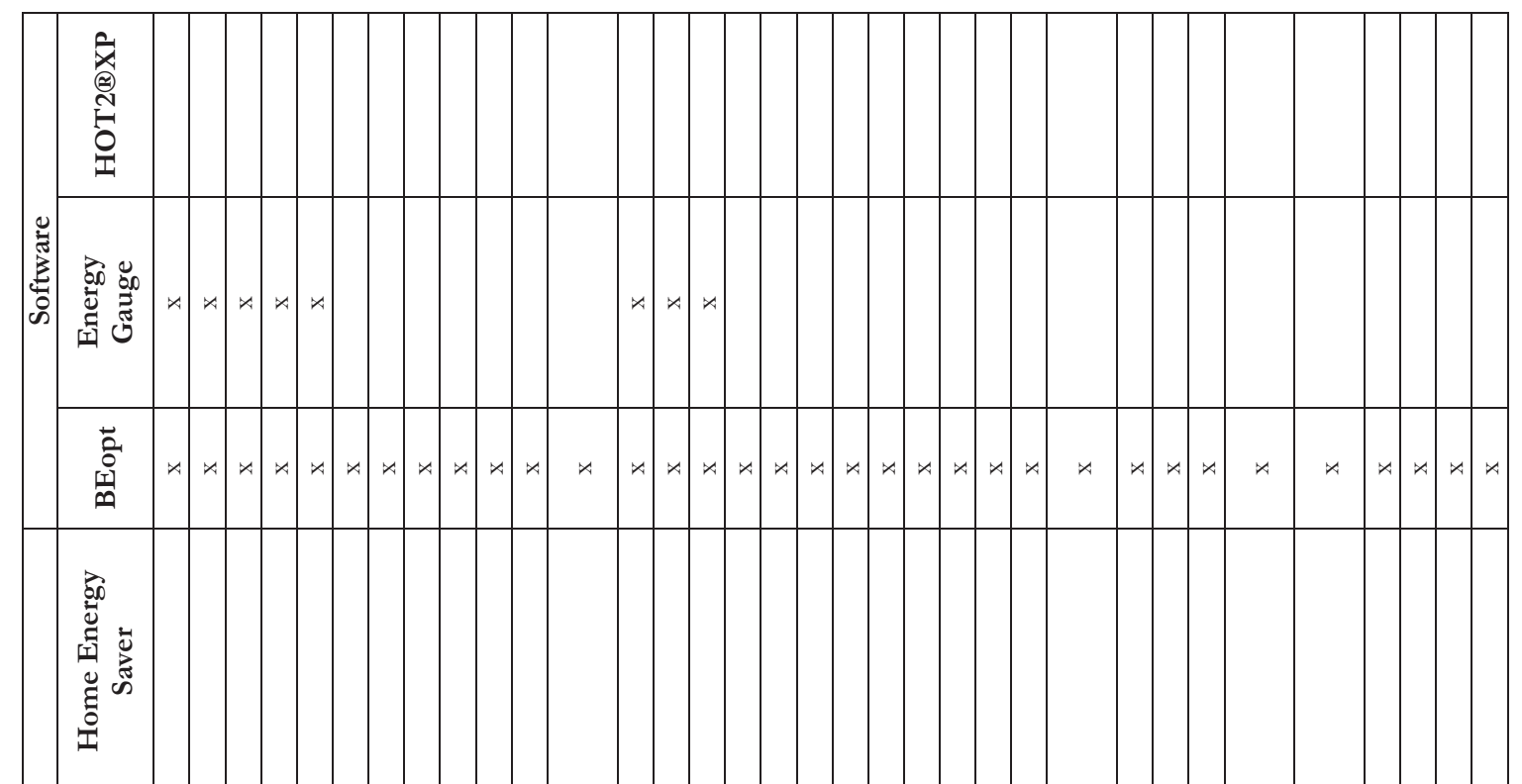

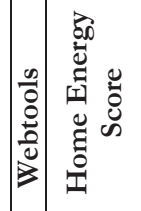

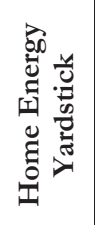

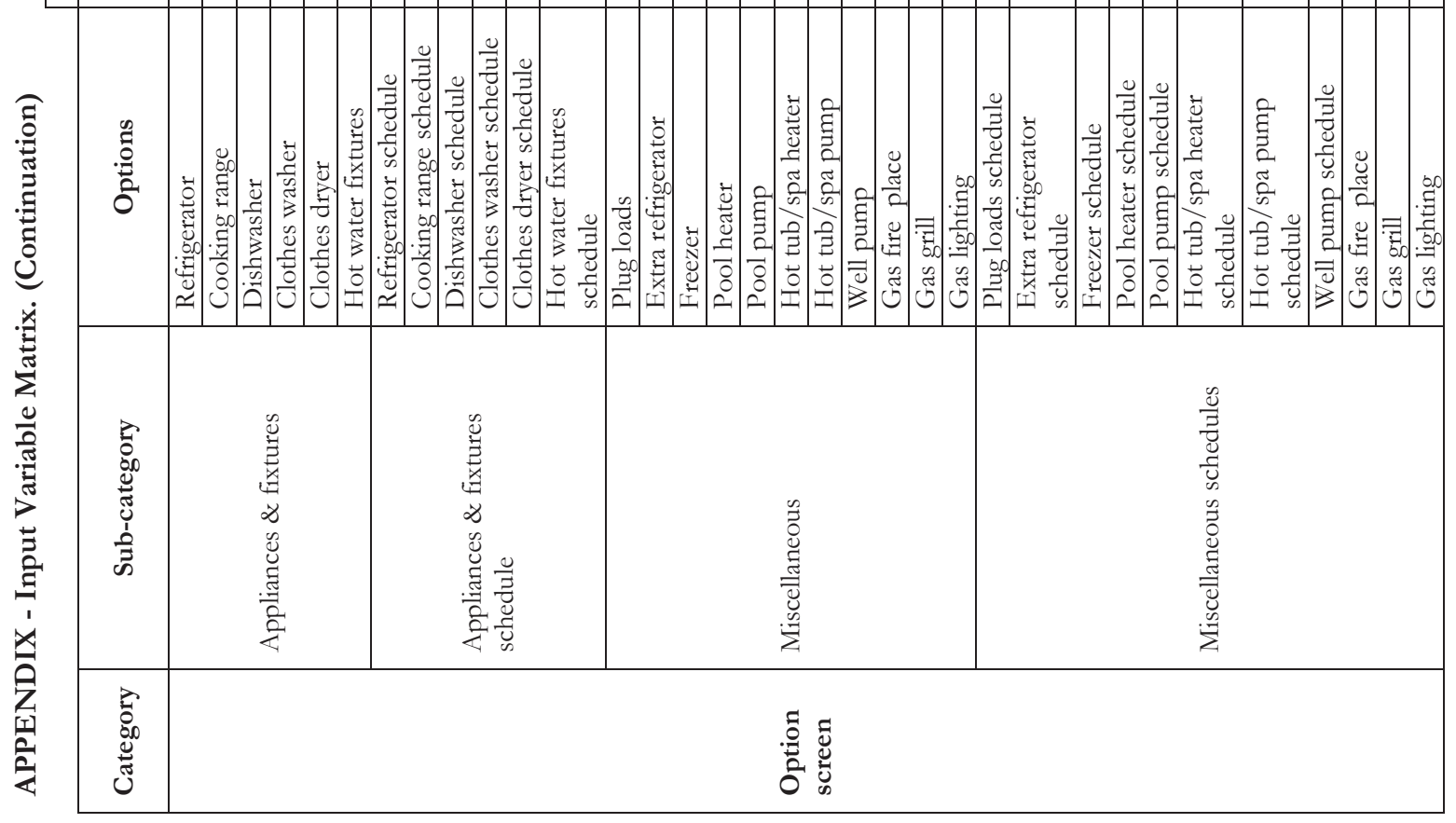




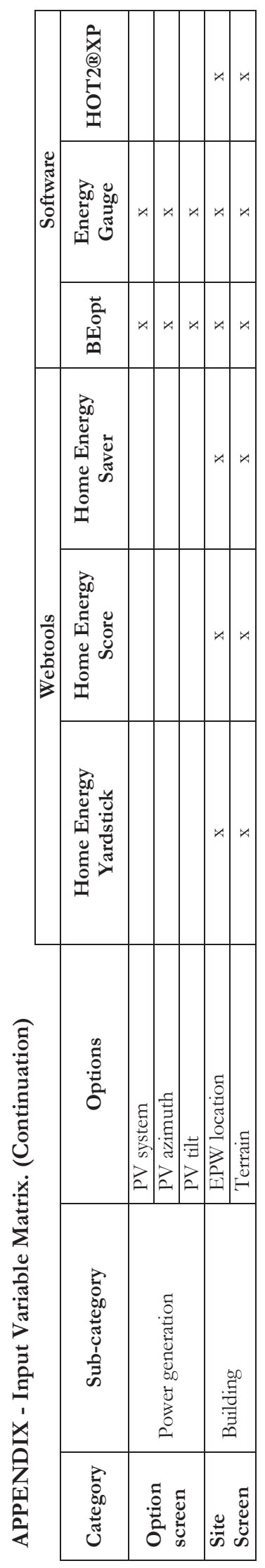




\title{
Feeding Anti-Semitism: Representations of Jewish Food Practices in Der ewige Jude
}

Forrest Picher*

Department of History, McGill University, Montreal, QC forrestpicher@gmail.com*

\begin{abstract}
The film Der ewige Jude has received a considerable amount of scholarship, but never solely in the context of its representations of Jewish food practices. This paper addresses this void arguing that the representations are used to de-civilize and dehumanize the Jewish people in the minds of the viewers. The representation of Jewish home life around the dinner table is done in such a way as to emphasize filth and bugs. Similarly the conditions of street food are naturalized and used as "evidence" that the Jewish people are a lower race. Later, as the film describes Jewish cultural practices it completely subverts the meaning of Purim in such a way as to access the longstanding prejudices of Jews as "bloodsuckers". Finally, kosher slaughter is used to separate Jewish people from both a sense of Germanness and a European identity altogether. In fact, I argue this representation served as an argument to deny European Jews their humanity altogether. In all of these ways the film creates a cinematic argument that attempts to justify what would become the mass-murder and genocide of the European Jews.
\end{abstract}

\section{KEYWORDS}

Food; Film; Representations; Ghetto; Purim; Kosher

\section{INTRODUCTION}

With the invasion of Poland in 1939, the National Socialist government increased the number of Jewish people under its control from 300,000 to two million. ${ }^{1}$ In response, the freshly appointed head of the Ministry of Propaganda's Film Department, Franz Hippler, was sent to the Jewish Ghettos in October of 1939 to create a "documentary" about the so-called "Jewish problem". The footage was compiled and spliced with fictional movies, newsreels and footage of an Adolph Hitler speech. On November 28th 1940, the film titled Der ewige Jude (The Eternal Jew) was premiered. After its release and throughout the war, the film served as a, "cinematic argument that legitimated the approaching Holocaust". The first transportations of German Jews to the East began immediately after the film's release. ${ }^{2}$

First, it will be important to explain why I have focused on this particular film. I chose to study Der ewige Jude for two reasons. The first reason is that the film tries hard to appear ethnographic. Indeed, the film frames itself as a "study," projecting a sense of scientific authority that would have given the film's representations more weight to the public than other, similar films.

Furthermore, because this was likely the first that everyday Germans would have witnessed of Jewish communities in Poland, the film's seemingly authoritative representations would have likely seemed "authentic" to the German public. The second reason for choosing this film is its time and location. Der ewige Jude, as I will argue later, provides footage of the immediate aftermath of the German Blitykrieg invasion of Poland. Because of this, the film offers a unique vantage point for studying the effects of Blitykrieg and the German occupation on Jewish practices. In addition, as I will argue later, the film offers a window into the way that the Nazi propaganda machine was able to create a positive feedback loop manipulating this Blitzkrieg destruction in order to create an argument for further destruction.

I argue that the film's representations of Jewish food and drink were mobilized to dehumanize the Jewish people, creating a culinary legitimation of the Holocaust. I will begin by analyzing the film's representation of food sale and consumption on the streets in the "ghettoes", deconstructing its argument of authenticity and addressing the ways the activity was used to dehumanize the Jews through direct comparisons to rats. I will then analyze the film's representations of Jewish Purim, particularly focusing on the representations of wine. I will argue that the film contextualizes the drinking of wine as "commemorat[ing] a slaughter" and was meant to refer directly to prejudiced conceptions of "the bloodthirsty Jew." In doing so, the representations of wine were meant to Other the Jewish and incite fear of them in ways that would legitimize their destruction. Finally, I will discuss the very graphic representations of kosher slaughter practices. I argue that these representations were a way to dehumanize the Jews to the German public, as well as to legitimize the Holocaust. By contrasting the "senseless brutality" of kosher slaughter with the humaneness of modern mechanized slaughter, aspects of which would later be used during the mass murder of European Jews, the film becomes both an argument for dehumanization as well as an argument for the mechanics of the Final Solution. 
While the film has not specifically been analyzed in terms of food representations, it has received significant scholarly attention. Rolf Giesen's seminal book Nazi Propaganda Films presents Der ewige Jude, and comparable films, as propaganda that sought to justify that Jews were "Untermenschen, undermen or subhuman specimens." Susan Tegel expands this idea in her book Nazis and the Cinema. She argues that this idea of inferiority was manifested in the film's representations of Jews' supposed inability to work the German way. Tegel argues that the film maintains Jews "rarely engage in useful work", showing footage of Polish Jews inefficiently clearing rubble from the streets. These images are later contrasted with the competency of the so-called German "Aryan" race. While in reality this particular representation is a testament to the forced labour of people who were not used to physical labour (middle class professionals according to Tegel), it is presented as an innate inability in the Jews themselves. According to the film, Jews are a lower, less-capable people. ${ }^{4}$ My analysis will build on these ideas. I argue that the film sought to dehumanize the Jews, using food practices to represent them as a race of Untermenschen in order to justify their removal from German society and legitimize the Holocaust.

In her chapter "A Cinematic Construction of Nazi Anti-Semitism", Joan Clinefelter argues that the film was both proof of the existence of the "Jewish problem" and an argument for its solution through the Holocaust. In making this argument, Clinefelter proposes that Der ewige Jude "constructs an illusory world" that sought to legitimate the Nazi party's perverse ideas in the minds of the German people. ${ }^{2}$ Hilmar Hoffman constructs a similar argument in his book, The Triumph of Propaganda. Hoffman argues that films such as Der ewige Jude sought "to justify in advance the mass murder of the European Jews." ${ }^{5}$ My argument in this paper will follow a similar interpretation, although taking it a step further. My analysis will anticipate the Final Solution in order to understand the true impact of the film and to contextualize the arguments made within it, while simultaneously understanding the Polish invasion and the film itself as part of the Holocaust.

In writing this article then, I am situating my argument within a recent trend of writing about the Holocaust that rejects the need to find the exact date at which the mass murder of Jewish people was decided by the Nazi leadership. Increasingly, many historians question whether there even was a single decision. Instead, recent scholarship has focused on a longer-term perspective that includes the initial invasion of Poland and Kristallnacht as part of the Holocaust. In his seminal book Histories of the Holocaust, Dan Stone writes that more and more, "historians' fixation on the timing of the Final Solution seems less important than explaining the steady and (with hindsight) seemingly unstoppable drift towards full-scale mass murder." The scholar continues, arguing "in terms of understanding how the Holocaust could happen, the paradigm turns to some extent away from a legalistic one of the search for incrimination documents and to a more anthropological one, which stresses the culture of racial fantasies that drove the Nazi regime." 6 This understanding will be fundamental to my approach. I am not seeking to pinpoint an exact moment when the Holocaust began. I am instead writing from this more anthropological perspective that sees Der ewige Jude as part of a development that led to mass murder. The implicit assumption within this argument is that the Holocaust began much earlier than the 1942 Wannsee Conference. To do otherwise would be to exclude the Jews murdered during the invasion and occupation of Poland, and those who starved in the Ghettoes, from the category of Holocaust victims. This would be untrue which to this author is unacceptable. Most of the people represented in a prejudiced manner in the film were later killed in the ghettoes, by starvation, or in death camps. Haunting the film is the fact that, for example, of the 230,000 Jew that lived in Łódź (one of the film's locations), only 877 remained alive when the Soviet army reached the city on January 19, 1945.7 In this way then, while my discussion anticipates what would become the mass murder of European Jews, it is also describing a part of the Holocaust that we as historians are increasingly coming to understand.

\section{FOOD AND THE “GHETTO”}

From the beginning of the film, the viewer is confronted with the frightful conditions of Jewish life in post-Blitzkrieg Poland. While largely a product of the German invasion and occupation, the film naturalizes these conditions as authentically Jewish, stating that these are "actual shots of the Polish ghettos" and that these Jews "have [not] suffered from the chaos of war as has the native Pole." " Hippler promoted the film as unbiased, as well. In an interview in the German magazine Judenfrage, he stated, "we let the filmed Jews be on their own and tried to shoot in moments when they were unaware of the camera's presence. Consequently we have rendered the ghetto Jews in an unprejudiced manner, real to life as they live and react in their own surroundings." Hippler's statements then corroborate the film in arguing that the conditions captured by the film were none other than the uninterrupted, natural conditions of the Polish Jews. Thus, from the very beginning, the viewer is expected to understand the footage as an unbiased documentary of a supposed race of Untermenschen. It is in this context that food is first mentioned.

The first representation of food in the film is footage of a family eating a meal in a run-down apartment. Nine people are shown cramped around a dinner table as a man approaches from off-scene carrying a bowl of bread. Immediately, all of the diners erupt into greedy fits, reaching for morsels of bread. The narrator simply notes, "Jewish home life reveals a remarkable lack of creative ability to civilize." 8 The viewer is therefore presented with the argument that this level of food-etiquette is demonstrative of the level of a people's civility. This emphasis is likely engaging with other German writing on civilization and food during this period, 
most notably with that of Norbert Elias. In 1939 Elias published his famous book The Civilizing Process in Basel, Germany. Andrew Linklater and Stephen Mennel write that this book was written "to explain how Europeans came to think of themselves as more 'civilized' than their forebears and neighboring societies."10 These "neighboring societies" could also include the Jews who had lived in communities alongside Christian communities in Europe for hundreds of years. This would help to explain this emphasis on a "lack of creative ability to civilize". By contrasting the Jewish experience to rising ideas of European civility, this (likely staged) meal is intended to begin a process of what I will call "de-civilization"11. The film then shows footage of what appears to be cockroaches collected on a wall (although it is unclear whether this is the wall of the original house or not), and then quickly cuts back to the dinner table. "In plain language," the narrator continues, "Jewish dwellings are filthy and neglected." 8 In this way, filth and bugs are presented as the types of things one would find surrounding the supposedly uncivilized eater, adding to the decivilization. In presenting this footage in this way the film is arguing that not only do the Jews lack food etiquette, they lack basic food hygiene. Because these conditions presented around food are repeatedly described as authentic, the viewer is led to believe that Jews are an uncivilized people. This is the first of a long series of efforts to dehumanize the Jewish people.

As the film moves out of the home and into the streets of the supposedly authentic ghetto, food is everywhere. People are selling and buying food, and young Jewish children, weaving through the crowd, find solace on a doorstep for a quick snack. The foods bought and sold range anywhere from live ducks to hanging meats to potatoes to prepared snacks on trays - all, of course, sold on the street. Every aspect of this is naturalized in the film's representation. Even the poor children selling food are deemed authentic: "One might want to regard these haggling children as a sign of great poverty" the narrator begins. "But watch them a while and it becomes clear that they are proud to act as their grownups do." 8 In this way, the film argues that the crowded streets are characteristic of the people, and any appearance of poverty among the sellers of food is not true poverty, but a realization of a supposedly Jewish nature.

This supposed authenticity of filthiness surrounding eating in the home, coupled with the naturalization of crowding activity surrounding the sale and consumption of food is essential for the film to make a direct comparison between Jews and the rat. The footage of Jews moving through the busy streets rife with food is juxtaposed with footage of rats running in packs through food stockpiles. Similarly, the footage of Jews selling and purchasing food and Jewish children eating on the steps of homes is juxtaposed with rats infiltrating grain stores. In these ways, the crowded conditions around Jewish food consumption of the early occupation period were used to make comparisons between the Jews and rats. In doing so, the film sought to further dehumanize the Jews.

These associations are not left solely to the interpretation of the viewer. Instead, the film attempts to make this comparison as explicit as possible. When discussing the Jewish "wanderings throughout the world" the narrator argues it is "parallel" to that of "a similarly restless animal: the rat." " Later, when discussing rats, the film states that, "They are cunning and cruel and usually appear in massive hoards... just as the Jews do among mankind." 8 Thus, the conditions in which a significant amount of food is exchanged and consumed are represented in a context of dehumanization. The heavily populated streets are used to represent the "massive hoards" of the Jews presented as a threat to Germany, much like rats were presented as a threat to her food. In doing this, the film is creating a cinematic argument for a "Jewish problem" - one that would require a solution.

The comparison between Jews and rats through the nexus of food was one aspect of the film that appears to have greatly impacted its audience. In an analysis of the film's reception, Terry Charman writes that a report from the Sichersheitsdienst noted that "the comparison with rats is mentioned as particularly impressive."12 The comparison to rats was also mentioned in the Nazi newspaper Deutsche Allgemeine Zeitung which commented favourably on the comparison between Jewish migrations and rat migrations. ${ }^{13}$ In a local German paper on the Dutch border, Moers, the comparison was lauded. The paper wrote that the representation would "clarify to the very last Germans that the Jews as a race is, and will forever remain, beneath human kind, as the rats are beneath the animals: parasites, poison carriers and subversive scroungers." 14 We can therefore see that not only did these food representations seek to dehumanize Jews through the comparisons to rats, but that these appear to have been at least somewhat successful.

Much as rats are a plague that needs to be eliminated for the health of a country's cities, the film argues that Jews, described as a plague at the beginning of the film, need to be eliminated. From the very beginning then, these representations of food corroborate Hoffman's interpretation of the film as "justify[ing] in advance the mass murder of the European Jews." In addressing the legacy of these representations as arguments for the legitimization of the Holocaust it becomes essential to show that these supposed "authentic" food practices are not actually authentic. Instead, they must be seen as the result of ghettoization policies and the destruction of Blitzkerieg warfare.

While all scholars agree that the film is not representing authentic conditions, there is substantial debate about what specifically created them. Particularly, the role of Nazi policies of ghettoization remains controversial. Some have argued that the film was 
shot after ghettoization had already been enforced. Susan Tegel, for example, wrote that Der ewrige Jude was filmed in "the newly created ghetto in Lódź."15 Tegel went on to argue that while the film represents the conditions as authentic, "at that point life was anything but ordinary for Polish Jews". The scholar concluded that we should interpret "[this] extraordinariness [as] a consequence of German policy." establishment of ghettos start[ed] in the same autumn of 1939."'17 This is an early theory of the emergence of the ghettos. Indeed, Tegel and Rozett's arguments rely on the assumption that ghettoization began immediately after the German occupation of Poland. The German invasion began on September $1^{\text {st }} 1939$, and one month later, filming had begun. ${ }^{18}$ According to Tegel and Rozett then, Jews were immediately ghettoized. Christopher R. Browning, however, argues for a later origin of ghettoization policies, beginning in Warthegau in the spring of $1940 .{ }^{19}$ According to Browning, these policies of ghettoization would have occurred after the filming of Der ewige Jude in Poland was finished.

The reality however was likely a mix of both of these interpretations. Ghettoes existed before the German invasion of Poland. ${ }^{19}$ Furthermore, it does not appear that the Germans had actually begun enforcing the sort of ghettoization necessary for Tegel and Rozett's argument immediately after the invasion. In a thorough analysis of communications between officers during the early German occupation of Poland, Dan Michman argues that the Jews were not being forced into ghettos. ${ }^{19}$ While it is true that Germans had demarcated the boundaries of these existing ghettos and "forced those Jews who had moved elsewhere in the city to return "home," 20 the full sealing of the ghettos that would come to characterize the experience of Jewish Poles did not begin in Łowicz until May 1940 and would not impact Warsaw until November of that year. ${ }^{21}$ While certain aspects of ghettoization must be included in the debate, the conditions were not entirely a result German policy.

Oddly, while much debate centres on ghettoization, there is little said about the bombing of Polish cities during the Blitzkrieg. After the Luftwaffe destroyed most of the Polish air force, it focused on bombing the cities. ${ }^{22}$ Warsaw, "the chief bastion of Polish defiance," was particularly hit hard. ${ }^{23}$ On September 20th 1939 , the Luftwaffe launched a colossal attack on the city, involving 620 aircrafts. The next day, these massive air attacks continued, with the Luftwaffe bringing in " 52 transport planes to drop incendiaries." 23 By the time Warsaw surrendered, it had incurred massive destruction. One study states that up to 40 per cent of buildings in Warsaw were severely damaged, and 10 per cent were destroyed entirely. ${ }^{24}$ This destruction would have put pressure on non-damaged buildings, leading in part to the crowded conditions of the ghetto. Indeed it is possible that the family of ten in the dinner scene could be a family hosting its relatives that had moved out of their damaged homes. In this way, the homes and street conditions surrounding eating in the beginning of the film are not representative of authentic conditions, but should be contextualized within intensively bombed cities. The degree to which this bombing was responsible for crowding is a topic that needs further research.

In addition, during the invasion of Poland the Nazi forces specifically targeted centres of Jewish community life. Jewish shops were attacked and destroyed and many synagogues that served as Jewish meeting places and community centres were razed. ${ }^{25}$ Thus, it is possible that the crowded streets full of salesmen and saleswomen selling food are a result of the destruction of Jewish shops by the German army and SS. Furthermore, the crowded nature surrounding this street food could be seen as representing a new centre of community life. It is possible that at the time of the film these crowded streets stood in for the Synagogues as centres of Jewish community after the latter's destruction by the German forces. The film therefore naturalizes conditions brought about by the German invasion and occupation of Poland as authentically Jewish in order to legitimize the further destruction of Jewish life. These two issues should be essential to historians in their interpretations of the film and deserve more attention in the future.

\section{PURIM AND BLOOD}

The film then discusses Jewish cultural practices with a particular focus on Purim. Purim is represented with the explicit intention of de-civilizing and dehumanizing the Jewish people in order to make a cinematographic argument for their mass murder. To make this argument, the film focuses on the imagery of wine drinking to access German folklore and stereotypes about the mythical Jew as a bloodsucker.

In framing this discussion it will be important to first establish what Purim is. Of course, Judaism is a very rich and diverse religion, and Purim is not celebrated the same way in every community. What I will describe then will not be true for all forms. Instead, I will focus in on the Eastern European Hasidic tradition, as that is most comparable to what is being represented in the film. According to Daniel Boyarin, there are two distinct forms of celebration: the high and the low. The high practice involves public readings of the Book of Esther, the story that Purim celebrates. ${ }^{26}$ The low practices, that will be the focus of this paper, are not as entrenched in the Tanakh as the high practice. Instead, these low practices are "explicitly prescribed in the balakic literature or by custom."26 According to Boyarin, these low practices include "public drunkenness, treated by the Talmud as an obligation." ${ }^{26}$ On many levels this drinking was an important engagement with the story of Esther. In her seminal article, "The 'Drinking 
Banquet' (Trink-Siyde)", Shifra Epstein writes, "drinking on Purim is necessary to fulfill the precept that one drink until one can no longer distinguish 'Blessed be Mordecai'... from 'Cursed be Haman." 27 In this way, the drinking on Purim is a direct engagement with the story. By engaging with this story, Jewish participants are celebrating a narrative of what Boyarin calls a "resistance through accommodation" in which Mordecai and Esther were able to overcome Haman's intended destruction of the Jewish population from a position of weakness. ${ }^{28}$

The film attempts to actively misrepresent this practice. As Purim is introduced, the narrator states that, "This harmless looking family celebration commemorates the slaughter of 75,000 anti-Semitic Persians by biblical ancestors of our Jews of today." 8 In this very swift distortion, the film decontextualizes the feasting and drinking, changing it from an engagement with a story of preservation to a celebration of murder. By centring the celebration on murder, the film lays the groundwork for the ways that the representations of food and drink, particularly wine, will reflect German folkloric conceptions of the Jew as a murderer and bloodsucker.

First, the Nazi's perverse interpretation of Purim as a celebration of murder is interpreted in the film as a product of Jewish character. "That's the race of Israel" the narrator starts, "still rubbing its hands over its feast of revenge." In this way, the film is making an argument to the viewer that this supposed celebration of murder is indicative of a perverse race, a murderous Untermenschen. In doing so, the film again seeks to de-civilize and dehumanize the Jew. The narrator continues stating that modern Jews "dressed in the Western European clothes" were trying to "hide their murderous nature." 8 Much like the comparison of the Jew to the rat, the film begins with allusions and then explicitly states its intent. Here, the Nazi interpretation of Purim is explicitly presented as indicative of a murderous nature within Jewish character itself.

This supposedly murderous character is then linked to the prejudiced conception of Jews as blood drinkers. Immediately after drawing attention to the so-called "murderous nature" of the Jews, the film shows a Jewish man pouring himself a glass of red wine and drinking it. This representation alludes not only to fears and prejudice of Jews as murderers but also to ideas about Jewish vampirism. Tegel argued that the term "bloodsucker" was a frequent slur used against Jews during this period in Germany. ${ }^{29}$ Jamil Khader would agree. In his article "Humanizing the Nazi?" Khader writes, "The trope of the Jew as a vampire, the blood-sucking Nosferatu, occupied a central position in the anti-Semitic Nazi racial ideology." 30 By bringing in a connection to Nosferatu, the 1922 German silent film adaptation of Bram Stoker's Dracula, Khader touches on an important point of analysis that needs to be developed further. There are, for example, many aspects of the Nosferatu narrative that are accessed in Der emige Jude to prime the audience to view the wine drinking as blood drinking.

First, the physical features of the Jews in caricatures promoting Der emige Jude (Figure 1) relied on stereotypical features such as large hooked noses, sunken black-ringed eyes and large pointed ears. These stereotyped caricatures are very similar to the representation of Nosferatu in the vampire film (Figures 2 and 3). By presenting a very similar image, the film intended to draw some of the expectations of the Nosferatu narrative in order to represent the Jews as vampires.

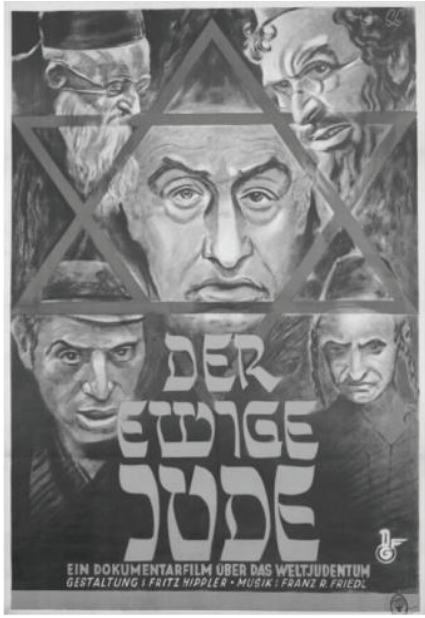

Figure 1: Der ewige Jude poster

"Der Ewige Jude [The Eternal Jew]", Collection of the Imperial War Museum PST 8237. Reprinted with permission of the Imperial War Museum. 


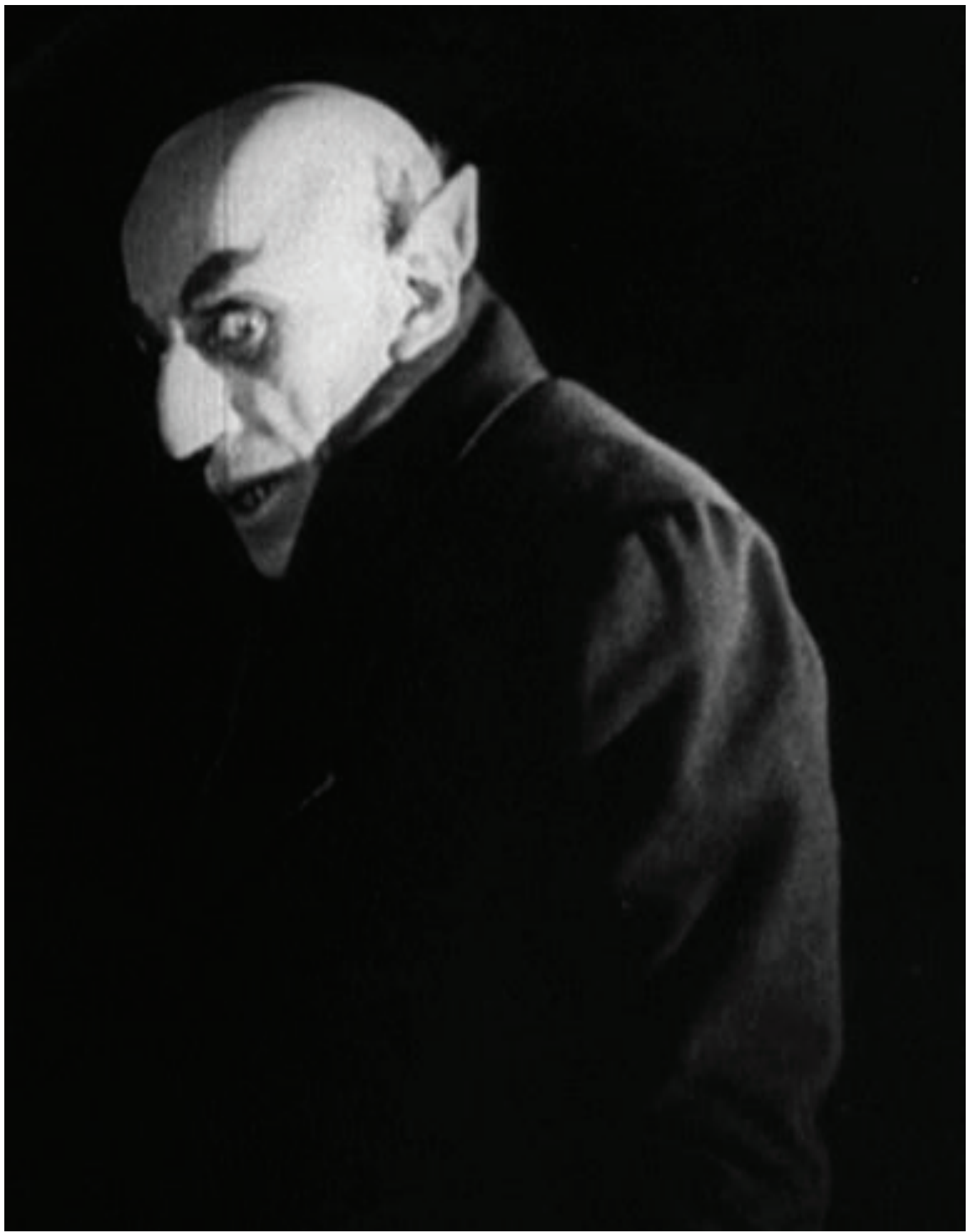

Figure 2: Nosferatu

Nosferatu: A Symphony of Horror, (1922) DVD, directed by F. W. Murnau, Image Entertainment, Chatsworth, CA. 


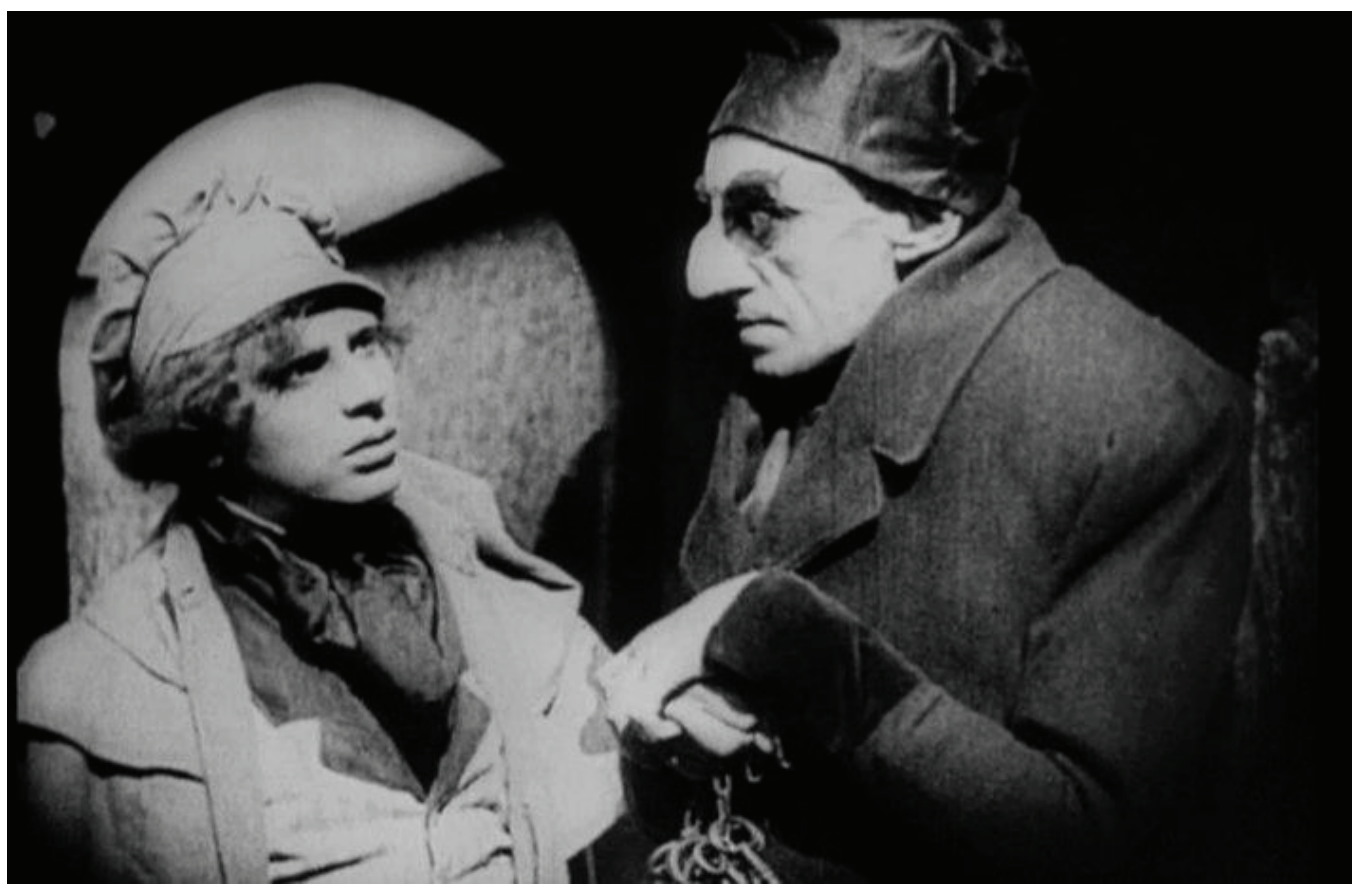

Figure 3: Nosferatu Nosferatu: A Symphony of Horror, (1922) DVD, directed by F. W. Murnau, Image Entertainment, Chatsworth, CA.

The second representation that anticipates the blood-drinking stereotype was the association of Jews with rats. Der ewige Jude makes direct comparisons between Jews and rats. This emphasis on the Jews as rats connects Jews to the vampire Nosferatu. In the film, Count Orlok (Nosferatu) is shipped from Transylvania to Wisborg, Germany. Alongside the coffin containing himself, Count Orlok ships coffins carrying hoards of rats. These rats, infested with the plague, cause disease in the town and leads to the death of many of Wisborg's residents. ${ }^{31}$ In addition, while rats bring the plague to Wisborg in Nosferatu, Der ewige Jude describes the Jews themselves as a "plague" drawing further associations.

By the time the film portrays the wine drinking, the viewer has already been primed with allusions to the Nosferatu vampire film and would be more likely to interpret the wine as blood, fuelling the already prominent prejudice promoted by the National Socialists of Jews as "bloodsuckers". By alluding to the Jews as bloodsuckers, the film tries to completely deny the humanity of Jewish people. Rather than being human beings, Jews become a monstrous race of inhuman evil vampires, leading to a justification for their mass murder. Again, the representation of food is used as a cinematographic argument for the Holocaust.

\section{KOSHER SLAUGHTER, BLOOD, AND THE JEWISH VAMPIRE}

The last section of the film is a representation of Jewish Kosher slaughter, a practice known as shehitah. According to Dayan L. Grunfeld's seminal work The Jewish Dietary Laws, the act of shebitah is a form of slaughter in which the shobet (a pious, learned person who has been trained according to Jewish law ${ }^{32}$ ) makes a "horizontal cut across the windpipe and gullet of the animal by means of a faultless and movable cutting instrument in a manner which is designed to secure a quick and painless death as well as the fullest draining of blood." 33 Indeed, this last point, the necessity of a full draining of blood, indicates an incredible irony in the film. While the Nazis represented the Jews as bloodsuckers comparable to Nosferatu, the consumption of blood in Judaism is Trefah (unfit for consumption according to Jewish dietary laws). ${ }^{34}$ This slaughter practice was therefore a way to drain the animal of blood for the very purpose of not consuming the blood.

However, as with the other food practices, Der ewige Jude represents the kosher slaughter in an incredibly distorted way. The film introduces the practice with a written warning:

One of the most illuminating customs of the Jews' so-called religion is the slaughter of animals. The following actual scenes are among the most horrifying ever captured. We show them despite objections about poor taste. It's more important that our people know the truth about Jewry. Sensitive citizens are advised not to watch.

The first thing that needs to be unpacked is the representation of this slaughter as an "illuminating custom." The viewer is being primed to interpret the slaughter in much the same way as the other food practices are intended to be interpreted: as evidence that the Jewish people are degenerate Untermenschen. Indeed, much like the crowded streets and the comparisons to rats, the slaughter is meant to de-civilize and dehumanize Jewish people in the eyes of the viewer. The narrator questions the humanity of the 
practice stating that "[the Jews] let the animals bleed to death while conscious." He continues saying, "The Jews deceptively describe this cruel method as the most humane way to slaughter." 8 Because this representation is supposedly illuminating about Jewish character, and is obviously being represented as inhumane, the film is arguing that the Jews themselves are inhumane. A similar dehumanization is reflected in the reactions to the scene. In a summary of the film, the Nazi newspaper Deutsche Allgemeine Zeitung wrote that "The most frightful chapter comes at the end: the cruel, inhuman, barbarous slaughter of animals." 35 Here we can see a similar emphasis: the practice is seen as a reflection of a barbarous nature inherent in the Jewish people and is seen as so cruel as to deny their very humanity. This is a very disingenuous representation of the practice however, which is actually intended as a fairly humane form of slaughter. Indeed, in the book Animals in the Third Reich, Boria Sax argues that while the animals don't lose consciousness instantaneously, this loss of consciousness "generally comes only after a lapse of a few seconds to a minute for most animals." 36

However, the representation of the very explicit and bloody nature of the deaths in the film is meant to obscure this quickness and humaneness. Sax argues this emphasis on the bloodiness of the practice was critical in kosher slaughter's interpretation by the Nazi regime. The author writes, "The enormous symbolic significance that the Nazis attached to blood made death by bleeding seem perverse." Sax continues, arguing that in the minds of Nazi ideologues this form of killing was worse than death because it first deprived the animal of "primeval vitality." 37 This sense of perversion was then packaged in the film as an inhumane and cruel practice, and presented to the viewer as such. In this way, bloodiness was used to silence and circumvent humaneness in order to present an image of the Jew as uncivilized and inhuman. ${ }^{38}$ In doing so, the film created an argument that such peoples had no place within supposedly civilized Europe and needed to be removed from it.

The film situates itself within a long and supposedly progressive history of opposition to this practice in order to further present the Jew as exogenous, both an outsider to European civilization, and more specifically an outsider to a general sense of Germanness. The narrator states, "European [my emphasis] science has long acknowledged the torturous character of this type of slaughter." The emphasis on what is projected as a unanimous opposition by European science presents an intentionally uneven representation of the actual debate. As Robin Judd argues in "The Politics of Beef", there were actually some animal protectionists that endorsed kosher butchering, "because they believed that it produced a healthier quality of meat or because they did not believe that religious particularities deserved punishment." 39 However, the emphasis on the so-called "science" is likely referring to the veterinary profession, which Boria Sax has argued was highly nationalistic and anti-Semitic much before the Nazis' rise to power. Indeed, Sax notes that in 1933 there were only two Jewish students of veterinary science in all of Germany. ${ }^{40}$ This highly anti-Semitic profession later became intimately tied to the National Socialist Party and was incorporated in many of the Nazi government's decisions concerning animals. The main advisor to Hitler on policy concerning animals was a veterinarian named Freidrich Weber who, Sax notes, "participated with Hitler in the aborted coup of 1923."41

The film goes on to state that "Jewish law has no love and respect for animals in the Germanic sense."8 In saying this, the film actively works to subvert the actual humane intentions of the slaughter in order to present the Jews as cruel and an outsider to ideas of Germanness. By not sharing a so-called "German" love for animals, the Jew becomes the Other. In this way, the representation of slaughter, much like the representations of the other food practices in the film, seeks to define the Jew as foreign and uses its representation of kosher slaughter in order to make this specific argument.

The representation of kosher slaughter was not only intended to represent the Jew as an outsider to the category of European, it was also intended to remove the Jew from the category of human being altogether. While the actual practice is intended to avoid the consumption of blood, it was imagined during this period as a way for Jews to have and to consume blood. Nowhere is this clearer than in a popular story by Hans-Peter Richter used as a piece of virulent Nazi propaganda:

[T] he Jewish priest approaches the cow and slowly lifts the knife of sacrifice. The animal feels threatened with death, it lows and seeks to break free, but the Jew knows no pity... The merciless Jew does nothing to shorten the suffering of the bloody animal; he wallows in it; he needs blood... ${ }^{37}$

In representing copious amounts of blood, the film was echoing this emphasis on a Jewish "need" for blood. In doing so, the representation of kosher butchering built on the idea of Jewish vampirism that occurs throughout the film. However, the association of kosher slaughter and blood drinking was not unique to Der ewige Jude but was occurring within a long history of debate within Germany. According to Robin Judd, many animal rights activists in the late $19^{\text {th }}$ and early $20^{\text {th }}$ centuries demanded that the newly established slaughterhouse commissions of the veterinarian profession create laws that forbid Jews from drinking the blood after kosher slaughter. ${ }^{34}$ There was therefore a long precedent associating this form of slaughter with blood drinking in the imaginations of the German people. By emphasizing this aspect, the film was accessing this widespread prejudice to further dehumanize the Jewish people. 
Furthermore, the film emphasizes the supposed torturous and cruel nature of the practice. The narrator states, "These [slaughters] ... also reveal the character of a race that hides its senseless brutality behind the façade of pious religious customs." 8 This idea of a "senseless brutality" as a Jewish characteristic was intended to speak to a long history of German prejudice that linked kosher slaughter to folklore of Jewish ritual murder. Judd explains that the late $19^{\text {th }}$ and early $20^{\text {th }}$ century debate on kosher butchering "consistently voiced concerns with the allegedly violent character of shehitah, thus implying that the Jews were themselves deviant and cruel." 42 By arguing that the supposedly cruel and torturous nature of the slaughter "reveal[s] the character of [the Jewish] race" the film is situating itself within an extensive literature on the subject of kosher slaughter that vilified Jewish people. In doing so, the film was also linking itself to some of the quite fanatical accusations within this literature, the most potent of which, Judd argues, was the link between kosher butchering and ritual murder. ${ }^{42}$ In the late $19^{\text {th }}$ century there were several cases in Germany in which the ability to perform kosher slaughter was actually used as evidence to prove the existence of ritual murder. For example, in 1892, there was a case in Rhineland in which a Jewish shohet was arrested for the murder of a child. According to Judd, the shohet had been suspected because "he was one of the few residents in Xanten [Rhineland] who would be capable of decapitating and bleeding a human, since he normally did so to cattle." 43 In the minds of many then these forms of slaughter would have alluded to ideas of the alleged Jewish practice in which Jews supposedly captured and killed Christian children in the Passover service. ${ }^{43}$ By portraying Jews as Christian murdering vampires, the film created an argument for the destruction of the European Jewry that would result in the mass-murder of Jewish people.

Similar allusions between kosher slaughter and ritual murder and blood drinking are seen in other propaganda sources of the time period. In May of 1934, for example, the German newspaper Der Stürmer released a special issue on "Ritualmord-Nummer", which translates to "Ritual Murder Issue." In this issue, the paper uses virulent hate speech intertwined with images that blatantly connect the practice of kosher slaughter with ritual murder myths. In Figure 4, for example, the newspaper shows a shochet with the traditional blade used in kosher slaughter standing under a group of children with cut throats. His Jewish helper is collecting the blood in a dish that features a subtle Star of David on the handle.

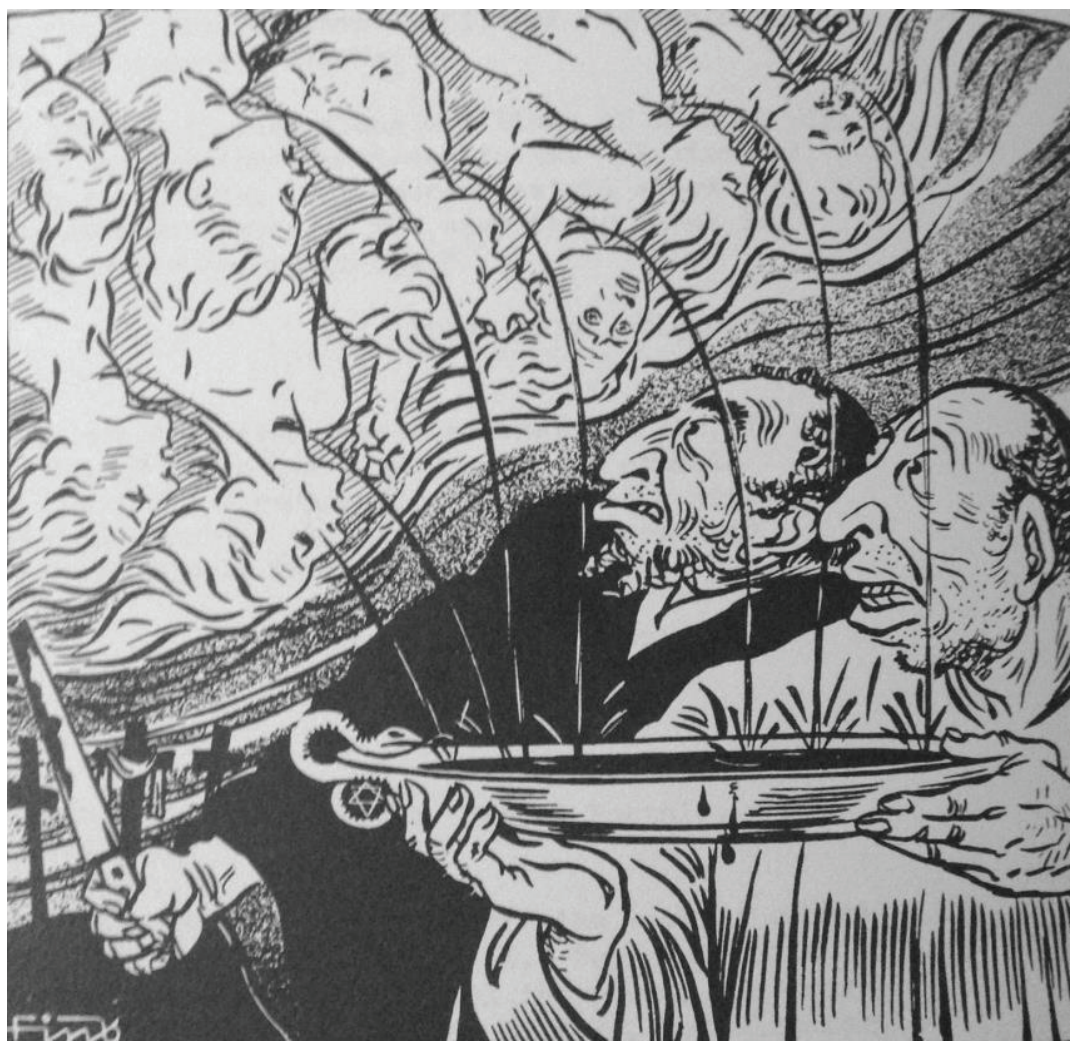

Figure 4: Caricature of Jews collecting the blood of ritually slaughtered children.

Source: "Ritualmord-Nummer" in Der Stürmer. May 1934.

In Figure 5, Jews in western dress are shown slitting someone's throat and holding him up, bleeding him into a bucket. The man cutting the throat is using a traditional blade for kosher slaughter. 


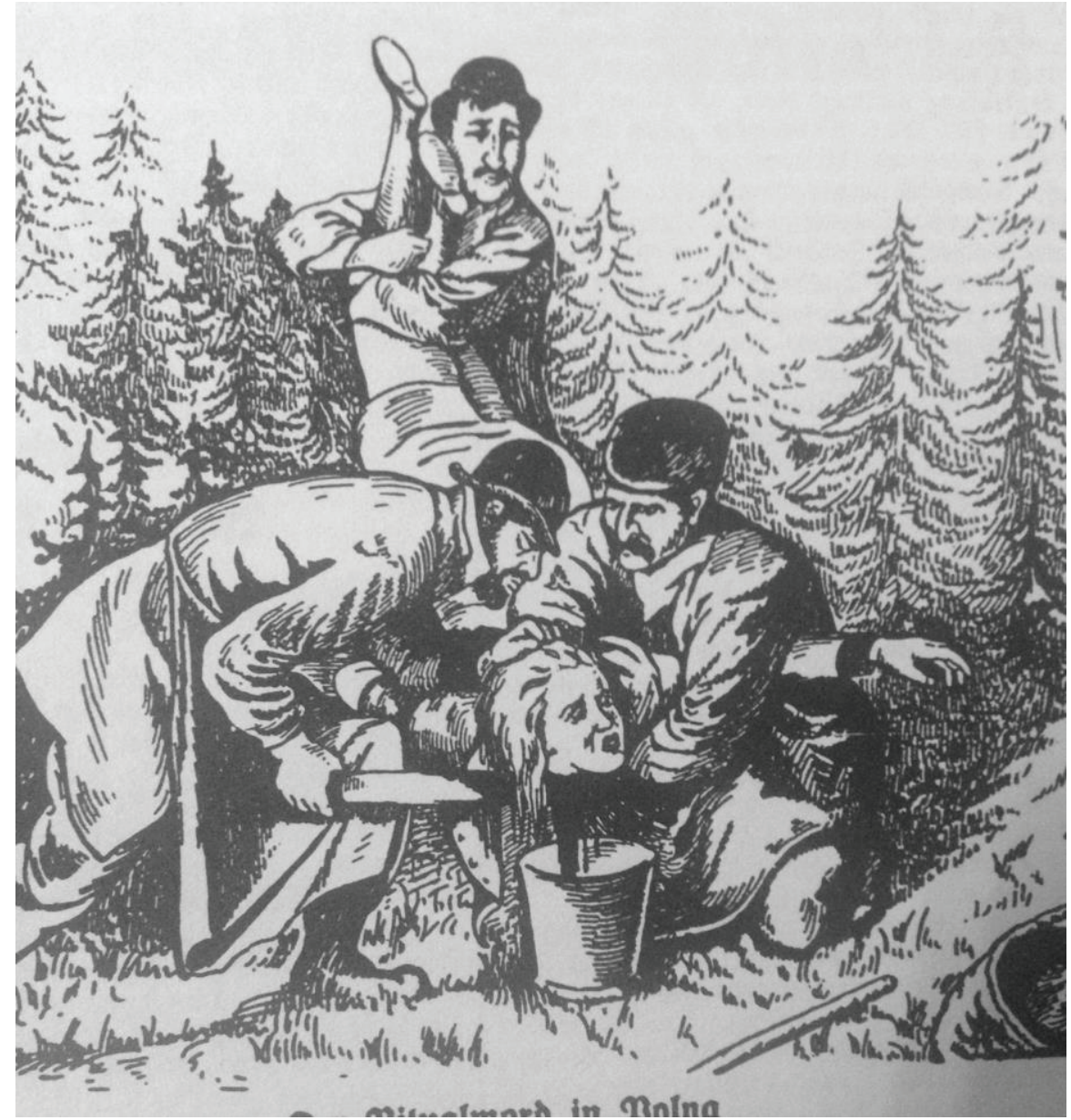

Figure 5: Caricature of Jews collecting the blood by ritually slaughtering a man.

Source: "Ritualmord-Nummer" in Der Stürmer. May 1934.

Finally, in Figure 6 we can see the most obvious allusion. A child is strewn naked across the table as four men wearing skullcaps drink the child's blood through straws. Thus, it becomes apparent that the connection between kosher slaughter and ritual murder and vampirism was established prior to the film's production. The film is therefore accessing a longstanding prejudice in order to further dehumanize the Jew in the mind of the viewer by calling to attention prejudices that the viewer was likely already aware of.

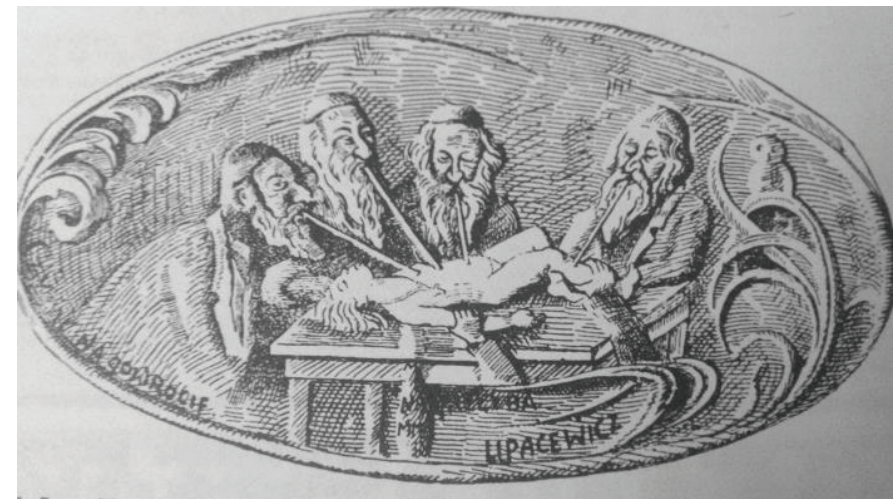

Figure 6: Caricature of Jews drinking the blood of a child. Source: "Ritualmord-Nummer" in Der Stürmer. May 1934. 


\section{KOSHER SLAUGHTER AND THE MECHANICS OF THE HOLOCAUST}

After this footage of the slaughter is shown the film presents the Nazi laws forbidding it in order to justify both the humanity of the Nazi party as well as their commitment to the welfare of animals. The narrator states, "Right after the Führer took power, a law enacted April 21, 1933 forbad the Jewish form of slaughter. It decreed that all warm-blooded animals be given anaesthetic before slaughter." "In this way, the film presents the Nazi party as eliminating the Jewish practices with the modern industrial form of slaughter involving stunning the animal first. However, this does not stop at the elimination of Jewish practices. Instead, this should also be seen as an argument for the elimination of Jews themselves by this modern industrial form of slaughter in what would later devolve into mass murder. Both the infrastructure and ideas of these modern industrial slaughter practices were used in the mass murder of European Jews. As the war extended in the Eastern front, the Wehrmacht began stealing animals from the occupied territories and shipping them West for slaughter. Simultaneously, these same train lines and cattle cars were used to transport Jews to death camps. ${ }^{44}$ Boria Sax argues that the very organization of industrial slaughterhouses and death camps were similar, writing that they "were [both] organized as factories that produced not conventional goods but death." 45

In addition, the ideas and practices of death camps were grounded in the ideas and practices of modern industrial slaughterhouses. Sax argues that Heinrich Himmler, notorious for both founding the SS and overseeing Auschwitz, had originally been a chicken farmer. Sax writes, "Many of his ideas for [the] systematic ... slaughter of human beings were simply the extension of mechanized farming to people." 46 Furthermore, Sax argues that practices such as forcing the Jews about to be murdered to strip naked and huddle together in crowds "suggests a herd of cattle or sheep." 46 This was furthered by other practices such as Heinrich Himmler's ordering for dogs to be trained to herd prisoners like livestock. ${ }^{47}$ By creating a performance of a slaughterhouse, the people running the death camps were able to mentally dehumanize the Jews as if they were animals in a slaughterhouse, thus making them easier to murder. ${ }^{46}$ In this way then, the representations of kosher slaughter in Der ewige Jude, and the drawing attention to the destruction of these Jewish practices by their replacement with modern industrial slaughtering, must also be seen as an argument that sought to legitimize not only the destruction of these practices by modern industrial slaughtering, but also the human beings to whom they belonged.

\section{CONCLUSIONS AND LEGACIES}

In her article "A Cinematic Construction of Nazi Anti-Semitism", Joan Clinefelter writes, "each cinematic ingredient [of Der ewige Jude] is transformed into visual proof of the 'Jewish problem' and the necessity of the Nazi's solution." 48 I have constructed my analysis to further this argument into the film's discussions of food. Food representations, as an essential and pervasive ingredient of the film, should be seen in this way. At every step, Jewish food is twisted and manipulated to create an argument for the destruction of Jewish people. In these ways, the film should be seen as presenting a justification and legitimation of the Holocaust. Moreover, these representations of food may have also contributed to a solidification of the Final Solution they sought to justify. Many of the architects of the Holocaust watched the film and had very strong reactions to it. Joseph Goebbels watched the kosher slaughter footage filmed in Poland and wrote: "This Jewry must be annihilated." ${ }^{49}$ Susan Tegel recounts that the footage was later shown to "the vegetarian Hitler and others who were 'deeply shocked'."49

\section{REFERENCES}

1. Tegel, S. (2007) Nazis and the Cinema, pp. 151, Hambledon Continuum, New York.

2. Clinefelter, J. (2000) A Cinematic Construction of Nazi Anti-Semitism: The Documentary Der ewige Jude, in Cultural History through a National Socialist Lens: Essays on the Cinema of the Third Reich, (Reimer, R., ed) pp.149, Camden House, Rochester.

3. Giesen, R. (2003) Nazi Propaganda Films: A History and Filmography, pp. 138, McFarland \& Co., Jefferson, N.C.

4. Tegel, S. (2007) Nazis and the Cinema, pp. 156, Hambledon Continuum, New York.

5. Hoffmann, The Triumph of Propaganda: Film and National Socialism, 1933-1945, 173.

6. Stone, D. (2010) Histories of the Holocaust, pp. 68, Oxford University Press, Oxford.

7. Charman, T. (2005) Fritz Hippler's The Eternal Jew, in Holocaust and the Moving Image: Representations in Film and Television Since 1933, pp.91, Wallflower Press, London.

8. Der Ewige Jude: ein dokümentarischer Film (1940), DVD, directed by Fritz Hippler, International Historic Films, Chicago.

9. Die Judenfrage, 28 November 1940.

10. Linklater, A. and Mennel, S. (2010) Norbert Elias, The Civilizing Process: Sociogenetic and Psychogenetic Investigations - An Overview and Assessment, History and Theory 49.3, 384.

11. "De-civilization," as I will be using it, refers to a process whereby one group attempts to deconstruct and deny the civilization of another group. This is done by Othering the latter group by presenting them as a negation to the understanding of what civilization is to the former group. It is therefore a virulent offshoot of ethnocentrism.

12. Charman, T. (2005) Fritz Hippler's The Eternal Jew, in Holocaust and the Moving Image: Representations in Film and Television Since 1933, pp.86, Wallflower Press, London.

13. Charman, T. (2005) Fritz Hippler's The Eternal Jew, in Holocaust and the Moving Image: Representations in Film and Television Since 1933, pp.85, Wallflower Press, London. 
14. Quoted in Johnson, E. A. (1999) Nazi Terror: The Gestapo, Jews and Ordinary Germans, pp. 385, John Murray, London.

15. Tegel, S. (2007) Naris and the Cinema, pp. 152, Hambledon Continuum, New York.

16. Tegel, S. (2007) Nazis and the Cinema, pp. 155, Hambledon Continuum, New York.

17. Rozett, R. (2005) Approaching the Holocaust: Texts and Context, pp. 4, Vallentine Mitchell \& CO. LTD, London.

18. Etlin, R. A. (2002) Art, culture, and media under the Third Reich, pp. 148, University of Chicago Press, Chicago.

19. Michman, D. (2011) The Emergence of Jewish Ghettos During the Holocaust, pp. 71, Cambridge University Press, Cambridge.

20. Michman, D. (2011) The Emergence of Jewish Ghettos During the Holocaust, pp. 74-75, Cambridge University Press, Cambridge.

21. Michman, D. (2011) The Emergence of Jewish Ghettos During the Holocaust, pp. 82, Cambridge University Press, Cambridge.; Bartoszewski, W. (1987) The Warsaw Ghetto: A Christian's Testimony, pp. 7, Beacon Press, Boston

22. Beevor, A. (2012) The Second World War, pp. 29, Little, Brown and Company, New York.

23. Beevor, A. (2012) The Second World War, pp. 34, Little, Brown and Company, New York.

24. facultystaff.richmond.edu, Bombing of Warsaw, https:// facultystaff.richmond.edu/ wgreen/ecdwarsaw.html (accessed Mar,2015)

25. Rossino, A. B. (2003) Hitler Strikes Poland: Blitzkrieg, Ideology, and Atrocity, pp. 90-91, The University Press of Kansas, Lawrence.

26. Boyarin, D. (1994) Introduction: Purim and the Cultural Poetics of Judaism - Theorizing Diaspora, Poetics Today, $15.1,3$.

27. Epstein, S. (1994) The 'Drinking Banquet; (Trink-Siyde): A Hasidic Event for Purim, Poetics Today, $15.1,142$.

28. Boyarin, D. (1994) Introduction: Purim and the Cultural Poetics of Judaism - Theorizing Diaspora, Poetics Today, $15.1,5$.

29. Tegel, S. (2007) Nazis and the Cinema, pp. 150, Hambledon Continuum, New York.

30. Khader, J. (2011) Humanizing the Nazi?: The Semiotics of Vampirism, Trauma, and Post-Holocaust Ethics in Louise Murphy's The True Story of Hansel and Gretel: A Novel of War and Survival, Children's Literature, 39.1, 136.

31. Nosferatu: A Symphony of Horror, (1922) DVD, directed by F. W. Murnau, Image Entertainment, Chatsworth, CA.

32. Grunfeld, D. I. (1972) The Jewish Dietary Laws, pp. 54, The Soncino Press, London.

33. Grunfeld, D. I. (1972) The Jewish Dietary Laws, pp. 57, The Soncino Press, London.

34. Judd, R. (2003) The Politics of Beef: Animal Advocacy and the Kosher Butchering Debates in Germany, Jewish Social Studies, 10.1, 126.

35. Quoted in Charman, T. (2005) Fritz Hippler's The Eternal Jew, in Holocaust and the Moving Image: Representations in Film and Television Since 1933, pp.85, Wallflower Press, London.

36. Sax, B. (2000) Animals in the Third Reich: Pets, Scapegoats, and the Holocaust, pp. 143, The Continuum International Publishing Group Inc, New York.

37. Sax, B. (2000) Animals in the Third Reich: Pets, Scapegoats, and the Holocaust, pp. 144, The Continuum International Publishing Group Inc, New York.

38. Trouillot, M. (1995) Silencing the Past: Power and the Production of History, pp. 26, Beacon Press, Boston.

39. Judd, R. (2003) The Politics of Beef: Animal Advocacy and the Kosher Butchering Debates in Germany, Jewish Social Studies, 10.1, 136.

40. Sax, B. (2000) Animals in the Third Reich: Pets, Scapegoats, and the Holocaust, pp. 145, The Continuum International Publishing Group Inc, New York.

41. Sax, B. (2000) Animals in the Third Reich: Pets, Scapegoats, and the Holocaust, pp. 146, The Continuum International Publishing Group Inc, New York.

42,42. Judd, R. (2003) The Politics of Beef: Animal Advocacy and the Kosher Butchering Debates in Germany, Jewish Social Studies, 10.1, 124.

43. Judd, R. (2003) The Politics of Beef: Animal Advocacy and the Kosher Butchering Debates in Germany, Jewish Social Studies, 10.1, 125.

44. Sax, B. (2000) Animals in the Third Reich: Pets, Scapegoats, and the Holocaust, pp. 147, The Continuum International Publishing Group Inc, New York.

45. Sax, B. (2000) Animals in the Third Reich: Pets, Scapegoats, and the Holocaust, pp. 148, The Continuum International Publishing Group Inc, New York.

46. Sax, B. (2000) Animals in the Third Reich: Pets, Scapegoats, and the Holocaust, pp. 150, The Continuum International Publishing Group Inc, New York.

47. Sax, B. (2000) Animals in the Third Reich: Pets, Scapegoats, and the Holocaust, pp. 86, The Continuum International Publishing Group Inc, New York.

48. Clinefelter, J. (2000) A Cinematic Construction of Nazi Anti-Semitism: The Documentary Der ewige Jude, in Cultural History through a National Socialist Lens: Essays on the Cinema of the Third Reich, (Reimer, R., ed) pp.134, Camden House, Rochester.

49. Tegel, S. (2007) Nazis and the Cinema, pp. 163, Hambledon Continuum, New York. 


\section{ABOUT THE STUDENT AUTHOR}

Forrest Picher is currently pursuing a Bachelor of Arts in honors history at McGill University in Montreal, Canada. His work on the history of sharks has emerged out of a research project in the history of science focusing on the interrelationship of nature and empire. His other work has also focused on environmental history including the relationship between flooding and structural violence in northern Indigenous communities in Canada and the historical interaction between snow and urban geography.

\section{PRESS SUMMARY}

Nazi representations of Jewish food played an integral role in the dehumanization of Jewish people during the Holocaust. This article analyzes one source of these representations: Der ewige Jude (The Eternal Jew). It finds that Jewish food practices are intentionally misrepresented to both naturalize the conditions of Eastern Jews in post-Blitzkrieg Poland as a matter of Jewish character and also to access existing prejudices about Jewish people such as the blood-libel myth. In doing so, representations of food in the film were a way to mobilize hatred and legitimize the Holocaust. 


\title{
hTERT Suppression via Small Interference RNA in Cervical Cancer Cells
}

\author{
Shawn Gray*, Douglas Christensen \\ Department of Life Sciences, Wayne State College, Wayne, NE \\ Student:shgray01@,outlook.com* \\ Mentor:dochris1@,wsc.edu
}

\begin{abstract}
Telomerase (TERT) functions to extend the telomeric repeat terminus of each chromosome allowing embryonic cells to proliferate into an adult organism. The TERT gene is subsequently inactivated following maturation, consequently conveying a finite lifespan to every adult cell line, as shortened chromosome arms trigger cell apoptosis. This process ensures that older cells lines, which are invariably accumulating mutations, are eliminated from the body and replaced by stem cells containing founding DNA. One of the defining attributes of a cancer cell is the ability to divide perpetually. This capability to divide continually is often due to the reactivation of TERT. Therefore, the abolishment of TERT activity presents a promising avenue for cancer treatment. Here, we demonstrate through qRT-PCR and ELISA techniques that although small interference RNA (siRNA) results in a transcription knockdown of ninety-seven percent the actual protein activity reduction is far less dramatic.
\end{abstract}

\section{KEYWORDS}

Telomerase; Small Interference RNA; Cancer; Tumor; hTERT; qRT-PCR; RNA Interference; ELISA

\section{INTRODUCTION}

Telomerase (TERT) is one of the many constituent proteins comprising an embryonic cells enzyme pool. TERTs function is to extend the simple telomeric repeat sequence fastened to the end of each chromosome. ${ }^{1}$ This sequence operates as a molecular timer, counting down to the exact time of apoptosis (typically forty to fifty divisions). TERT activity is of paramount importance to a developing embryo, by elongating the telomeric sequence, TERT obligates a cell to divide indefinitely. Thusly, TERT activity induces an embryo to proliferate into the trillions of cells that make up the adult organism. The TERT gene is subsequently inactivated following maturation, consequently conveying a finite lifespan to every adult cell line. ${ }^{1}$ By allowing each cell only a limited amount of environmental exposure, the body is able to impede the amplification of mutations that may engender a diseased state. One of the defining attributes of a cancer cell is immortality, or the ability to divide perpetually. This unique capability is due to the reactivation of TERT. Therefore, the abolishment of TERT activity presents a promising avenue for cancer treatment as TERT specific targeting may allow for a dramatic decrease in the side effects associated with many of the current cancer therapies.

Cancer, in the simplest description, is unregulated cell division. The sustained proliferation of a cancer cell will ultimately spawn a distended mass of daughter cells recognized as a tumor. The biochemical mechanisms that induce a cancerous state are invariably complex and can occur through many disparate routes. Nevertheless, there are six specific characteristics a cell must possess in order to be considered malignant. ${ }^{1}$ The six attributes include constant divisional signaling, unresponsiveness to growth suppressors, apoptotic resistance, the ability to induce angiogenesis, the ability to metastasize, and finally replicative immortality. Individually, these abnormal faculties would not breed a cancerous state, but when occurring concomitantly they confer an unrelenting proliferative capacity to whichever cell acquires them. Of the six requisite characteristics, replicative immortality is targeted in this research. This particular characteristic is greatly influenced by the Telomerase protein, the function of which is described below. The majority of normal somatic cells possess a finite replicative potential. This limited reproductive ability can be attributed to a eukaryotic cell's linear chromosomes and the "end replication problem" this linearity confers. ${ }^{2}$ In order for the DNA replicative machinery to form novel strands, short RNA primers are employed, these primers are eventually supplanted with DNA. However, due to the aforementioned chromosomal uniformity the RNA primer located at the 5' end of the novel strand cannot be replaced and disintegrates shortly following S phase. Consequently, a small segment of chromosomal DNA is forsaken during each mitotic event. The situation described hitherto is known as the "end replication problem" and (by limiting a cells lifespan) has been hypothesized to reduce the amount of mutational damage a cell will endure. ${ }^{3}$ This constraint will also act to curb the probability of a mutation based disease arising from the cell, which is advantageous to the organism as a whole.

The DNA squandered during each divisional sequence however, is not protein encoding, it is simply a component of a repetitive sequence known as the telomere. For eukaryotes, this sequence is most often 5'-TTAGGG-3'. The telomere acts as a molecular clock buffering the degenerative action of mitosis so as to confer to the cell a set number of potential divisions. ${ }^{2}$ All though apoptosis is a potential result of telomere shortening, Olovnikov demonstrates senescence as another possibility. ${ }^{3}$ Senescent cells do not undergo apoptosis, yet they do not continue to divide either. Senescence is rather a state of suspended animation in which 
the cell cycle perpetually rests in the G1 phase. Eventually, these languid cells initiate, and are subsequently cleared by an innate immune response. ${ }^{4}$ Nonetheless whether a cell undergoes apoptotic death or cell cycle arrest in the form of senescence, the end result with respect to cancer is the same; the cell is unable to contribute to tumor development. The actual mechanics by which shortened telomeres initiate senescence and apoptosis are complex and not fully understood. However, current literature from Blasco, Saretzki and colleagues as well as Janknecht has yielded some information about this process and it is almost certain more will be gathered. $5,6,7 \mathrm{As}$ is stands, however, both senescence and the potential of crisis leading to apoptosis is thought to only lessen the likelihood of cancer. In order for a cancer cell to have any prospect of reaching immortality, it must circumvent the crisis cascade.

Crisis evasion can only be attained by lengthening the telomere, which can only occur via the activity of telomerase. Consequently, the sole avenue by which a cancer cell can acquire immortality is through telomerase reactivation. ${ }^{2}$ Ninety percent of all characterized cancers achieve telomere elongation through the reactivation of human Telomerase (hTERT). Although some lowfrequency cancers do not appear to adhere to this mechanism. ${ }^{8}$ The specific mechanism by which these cells lengthen their telomeric repeat sequence has not been delineated and is hypothesized to occur through an ALT or alternative telomere lengthening mechanism. The ALT mechanism will conceivably employ a plethora of proteins that could probably be targeted by the same mechanism employed for hTERT degradation (described below). The use of organic inhibitors is one potential method by which protein activity, such as hTERT, can be inhibited. Organic inhibitor specifics and delivery methods can vary a great deal. The medical industry already employs a multitude of disparate materials to achieve protein degradation and/or inhibition. For example, many small organic molecules have proven useful in inactivating a given enzyme by either competitive or allosteric inhibition. An additional advantage of these organic materials is their ability to elicit enzymatic inactivation without the side effect of generating an immune response (due to their small size). ${ }^{9}$ Unfortunately, no matter how advantageous these minuscule particles are, accompanying them are at least a few undesirable side effects due to their low protein binding specificity. Many of the particles appropriated to treat enzyme disorders not only inhibit their target enzyme but a number of closely related protein catalysts. A much more specific degradation mechanism, microRNA, is already being utilized by many eukaryotic cells as a means of translational control.

MicroRNAs are $\sim 22$ nucleotides long, endogenously synthesized RNA particles encoded by specific regulatory genes. These microRNA fragments are never translated but instead act to inhibit mRNA translation by binding specific base pair sequences of protein producing mRNA strands and extorting their deterioration. ${ }^{10}$ Another more therapeutically useful form of RNA interference employs externally originating small interfering RNA (siRNA). Initially, an extended, double stranded segment of RNA is transformed into the target cell. Subsequently, the dsRNA is circumscribed by a cytoplasmic protein called Dicer. Dicer cleaves specific segments of dsRNA effectively releasing a 21-23 nucleotide fragment that possesses two nucleotide 3' overhangs at each terminus, these overhangs are important for downstream protein interactions. Traditionally, therapeutic RNA forgoes the Dicer modification by introducing an RNA fragment of 23 nucleotides with previously synthesized 3' overhangs. By directly inserting this preformed siRNA a researcher can ensure that the desired sequence is in fact incorporated into the interference machinery. The Dicer derived 21-23 nucleotide fragments are then incorporated into an immense protein complex known as RISC or RNA induced silencing complex. ${ }^{11}$ A constituent RISC protein called Argonaute-2 (Ago 2) binds the siRNA at its 3' overhang and removes one of the complementary strands. The resulting single stranded RNA segment (still within the RISC complex) can then bind a specific sequence in an mRNA (usually in the $3^{\prime}$ untranslated region). Upon binding, the RISC complex will cleave the mRNA in two, the resulting messenger RNA fragments are subsequently degraded by cytoplasmic nucleases. Either strand may be incorporated into the complex during RISC formation. The thermodynamic stability of the siRNA's 5' end dictates which strand will be assimilated. ${ }^{12}$ Consequently, a researcher is capable of definitively dictating which siRNA strand will be expressed on the RISC complex and in turn the specific mRNA that will be targeted for degradation (hTERT in this research). The fact that siRNA is of external origin and must, therefore, be incorporated into the cytoplasm of a cell from the surrounding environment introduces a formidable complication to the previously discussed approach. There are several mechanisms by which this transfection can be accomplished; the one employed in this research is a nanoparticle.

Many disparate nanoparticle classes exist; the one employed in this research is an MPG based peptide-RNA complex where the MPG proteins form stable, non-covalent bonds with the siRNA, typically in a 15:1 ratio. The resulting 15:1 amphipathic nanoparticle can subsequently interact with proteoglycans in a cell membrane. This collaboration induces actin rearrangements through a Rac-1 intermediate. The actin disruptions initiate the formation of ephemeral $\beta$-barrel like pores that allow the nanoparticle to diffuse through the plasmalemma and effectively enter the cells cytoplasm independent of phagocytosis. ${ }^{13}$ Consequently, the siRNA is also able to avoid lysosomal degradation. ${ }^{14}$ Once this particle enters the target cells cytoplasm it must discharge its nucleotide patron to the surrounding environment. This is accomplished by the overall negative charge within the cell. When the nanoparticle enters the negative cytoplasmic environment, the positive portion of the MPG protein begins to interact with many of the negatively charged compounds within the cell. As these interactions increase, the MPG peptide bonds with the nucleotide particle will begin to weaken until eventually the siRNA is released. 
The dominant inquiry of this research is whether or not siRNA can be effectively transfected into cancer cells and if that siRNA can subsequently elicit the degradation of hTERT mRNA. Furthermore, if hTERT mRNA degradation is achieved, what are the immediate consequences on hTERT protein accumulation? The relative quantification of hTERT mRNA from siRNA treated and untreated HeLa cell groups, via quantitative reverse transcriptase polymerase chain reaction (qRT-PCR), will yield a definitive answer to this first question while Enzyme Linked Immunosorbent Assays (ELISA) will shed light on the actual effect on hTERT proteins. The hypothesis of this procedure was as follows: siRNA can elicit the degradation of hTERT mRNA in cultured HeLa cells and this degradation will significantly reduce hTERT protein concentrations. Thus, this method could potentially be employed as an in vivo cancer treatment. Much research concerning siRNA and its knockdown effect on Htert mRNA has already been published, however research regarding how this treatment affects the protein itself is significantly scarcer. This research will not only demonstrate the effect siRNA has on hTERT mRNA but also how this knockdown correlates with protein degradation.

\section{METHODS AND PROCEDURES}

\section{Cell Culture}

HeLa (ATCC® CCL-2) cells $(1.5 \mathrm{~mL})$ were rapidly defrosted in a $37^{\circ} \mathrm{C}$ water bath and deposited into a $250 \mathrm{~mL}$ Fisher ${ }^{\mathrm{TM}}$ brand cell culture flask containing 10\% v/v Fetal Bovine Serum (ATCC), 1\% v/v Pen Strep and Delbecco's Modified Eagle Medium (DMEM) previously vacuum filtered for sterility prior to incubation at $37^{\circ} \mathrm{C}$ in $5 \% \mathrm{CO}_{2}$. Confluence level cells were displaced via Life Technologies TrypLE ${ }^{\mathrm{TM}}$ Express Enzyme, and once more grown to confluence. Additionally, confluence level HeLa cells were simultaneously developed in each well of two Fisher ${ }^{\mathrm{TM}}$ brand 6 well plates. Media containing Sigma-Aldrich N-TER Nanoparticle siRNA Transfection System ${ }^{\mathrm{TM}}$ was utilized in all six wells of one aforementioned plate per manufacturer's instruction (minus positive control). The same solution, minus the nanoparticle, was also instilled in the six remaining control wells. All cell inoculations were conducted in a UV sterilized laminar flow hood.

\section{$m \mathrm{RN} A$ and Protein Isolation}

The siRNA sequence exploited in this inquiry was designed by the researcher to complement two divergent regions of hTERT mRNA following the protocol developed by Reynolds and colleagues in 2004, these sequences are as follows: 5'-

GAAGCCGAAGGCCAGCACGUU-3', 5'-CAUCAGCCAGUGCAGGAACUU-3'. ${ }^{15}$ Successively ensuing a 24 hour incubation period with the experimental nanoparticle solution, each sample's mRNA and protein was isolated via the Trizol ${ }^{\mathrm{TM}}$ (Life Technologies ${ }^{\mathrm{TM}}$ ) method to include a DNAse I (New England Biolabs ${ }^{\mathrm{TM}}$ ) treatment to eliminate possible DNA feedback during qRT-PCR analysis. Subsequently, three specific samples from each group (control and experimental) were chosen at random for qRT-PCR and ELISA analysis.

\section{$m R N A$ Quantification}

Relative quantification of h'TERT mRNA was conducted via qRT-PCR utilizing an Illumina Eco ${ }^{\text {TM }}$ Real Time PCR System. A two-step procedure was conducted with a separate reverse transcription using New England Biolab's ${ }^{\text {TM }}$ AMV First Strand cDNA Synthesis Kit. Initially, $250 \mu \mathrm{L}$ of a PCR master mix (Bio-Rad Laboratories, Inc. ${ }^{\text {TM}}$ ), consisting of $2 \mathrm{X}$ qPCR reaction buffer, 4 mM $\mathrm{MgCl}_{2}, 0.4 \mathrm{mM}$ dNTP's, $0.0004 \mathrm{mM}$ forward primer and $0.0004 \mathrm{mM}$ reverse primer was generated for use in the final amplification. Beacon ${ }^{\mathrm{TM}}$ generated PCR primers (5'-TCCCTGCGT'TCT'TGGCTTTC -3' and 5'-CCTGCGCGTCATCTCTGA3') were designed to generate a $148 \mathrm{bp}$ long hTERT derived fragment. The primer sequence of the internal control gene, glyceraldehyde phosphate dehydrogenase (GAPDH), is: 5'-CCTGCACCACCAACTGCT'TAG-3', 5'-

TGAGTCCTTCCACGATACCAA-3'. qRT-PCR primer design was optimized through protocol published by Singh and Kumar (2001). ${ }^{16}$ qRT-PCR was conducted in an Illumina ${ }^{\text {TM }} 48$ well reaction plate. $14 \mu \mathrm{L}$ of the previously mentioned master mix was deposited into each designated well. Additionally, $6 \mu \mathrm{L}$ of cDNA sample (3 experimental and 3 control) was added to their proper

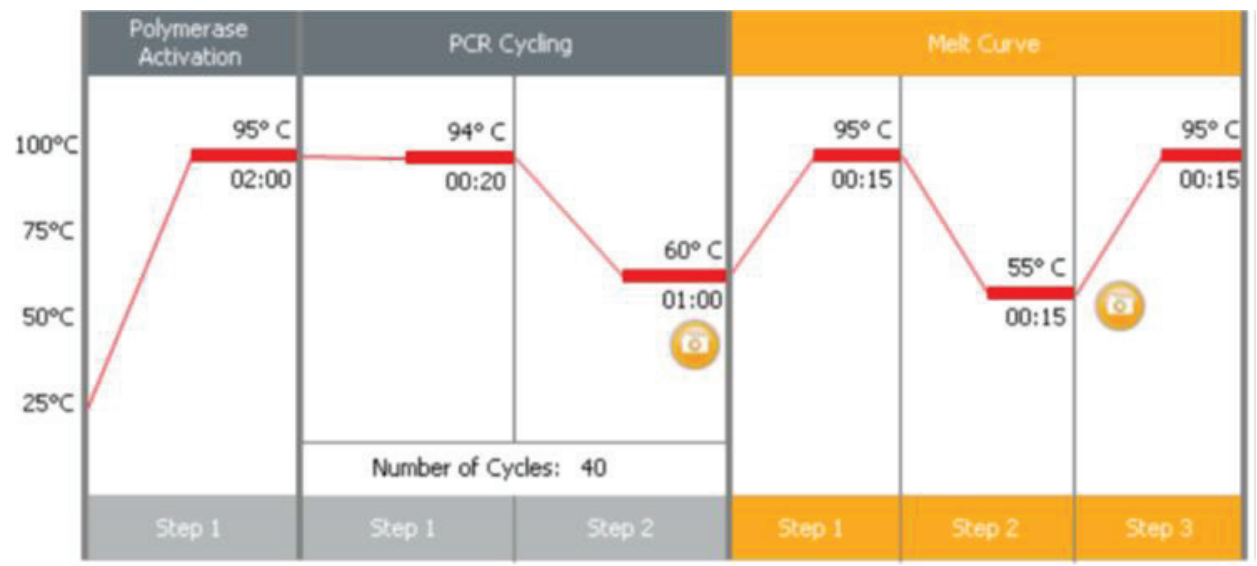

Figure 1. qRT-PCR thermal cycle diagram of format utilized for forty primer elongations. 
wells. One exception to this generalization can be found in the formation of the negative controls, each with either GAPDH or hTERT master mix and nuclease free water (no DNA sample). The overall mechanism underlying the PCR reaction itself is relatively simple. Initially, the PCR solution is warmed to $95^{\circ} \mathrm{C}$, at which point the cDNA fragments dissociate allowing primer binding. Next, the solution is cooled to $55^{\circ} \mathrm{C}$, allowing both primer binding and Taq $\mathrm{C}$ polymerase to catalyze primer elongation (Figure 1).

\section{qPCR Normalization}

In order to account for inevitable cell count differences between incubation wells, Glyceraldehyde phosphate dehydrogenase, was analyzed to normalize the data allowing a valid comparison between cell samples regardless of variation in cell count. Depicted in Figure 2 is the actual qRT-PCR plate layout (Illumina ${ }^{\text {TM }} 48$ well) employed in this research. Each six square grouping in the figure corresponds to analyzed mRNA that was initially isolated from cells grown in one well of the aforementioned 6 well plates. From each of these biological replicates, six technical replicates were produced. Three of these technical replicates were analyzed for hTERT mRNA, while the remaining three were evaluated for the internal control gene, GAPDH. Blue squares indicate exposure to siRNA whereas green highlights correspond to control samples. The possibility of primer-dimers and non-target amplifications exists in any PCR reaction. To determine whether or not such an aberration materialized during the reaction, a melt curve was generated (Figure 4). The overall question of this procedure is how effective was the siRNA treatment at reducing the cells hTERT mRNA content. In order to address this, Cq value analysis was performed. Cq is the number of cycles required to reach a previously specified fluorescence threshold. The fewer cycles required to reach the threshold, the more cDNA fragments there were in the original sample. The Cq value for each technical replicate in a given sample was averaged. Following this calculation, the average GAPDH Cq was subtracted from that of the average hTERT value to generate one $\Delta$ Cq value for each

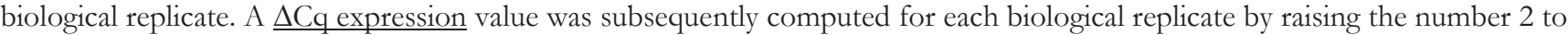
the negative $\Delta \mathrm{Cq}$ value. Next, the $\Delta \mathrm{Cq}$ expression level of each biological replicate, in a given treatment group, was averaged to beget 2 mean $\Delta \mathrm{Cq}$ expression levels for each analyzed group. The resulting mean $\Delta \mathrm{Cq}$ was divided by that of the control group. The resulting value is the $\Delta \Delta \mathrm{Cq}$ value for the experimental group while the control was given a reference number of 1 . The $\Delta \Delta \mathrm{Cq}$

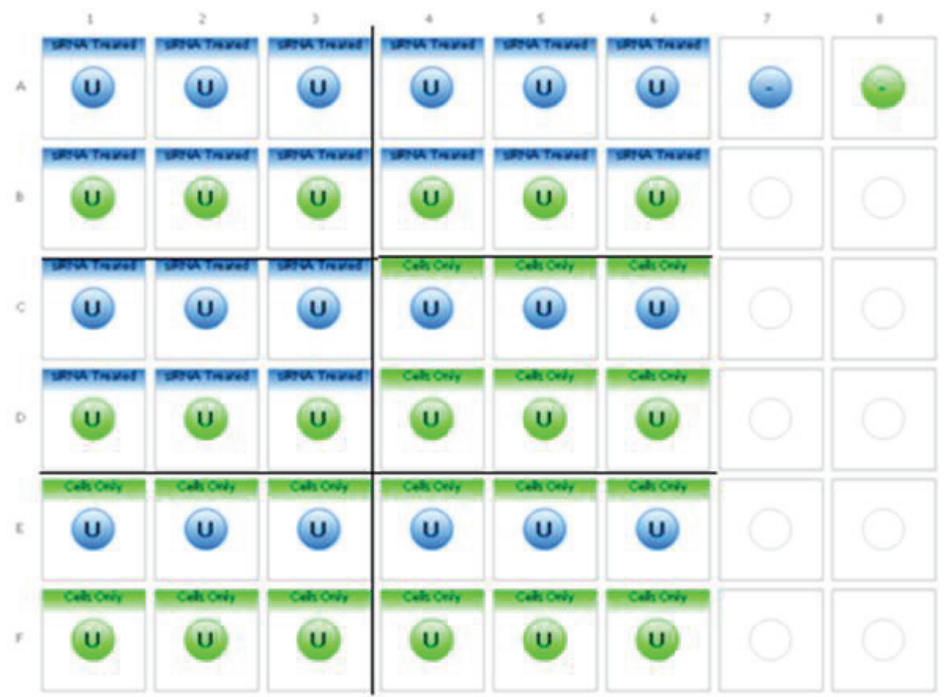

Figure 2. qRT-PCR plate layout, each six square grouping (separated by black lines) corresponds to analyzed mRNA initially isolated from cells grown in one well of a six well plate.

value of each group was subsequently used to generate a knockdown graph (Figure 5). All of the aforementioned mathematical analyses were conducted in an Excel spreadsheet following protocol published by Haimes and Kelley in $2013 .{ }^{17}$ 
ELIS A Analysis

Corresponding hTERT protein analysis was performed via an Enzyme Linked Immunosorbent Assay (ELISA) in a Fisher ${ }^{\mathrm{TM}}$ brand 96-well ELISA plate. A schematic representation of the ELISA plate layout is depicted in Figure 3. The three biological replicates from each experimental group (siRNA treated and control) were treated as described for the qRT-PCR samples above. TERT H-321 (cat \# 7212, Santa Cruz Biotech) and GAPDH FL-335 (Cat \# sc-25778, Santa Cruz Biotech) was utilized as primary antibody while the secondary antibody consisted of goat-anti rabbit IgG-HRP (cat \# sc-2004, Santa Cruz Biotech). Optimum protein concentrations were determined to be $10 \mu \mathrm{g} / \mathrm{mL}$ via criss-cross serial dilution assay. Each samples original protein concentration was ascertained through bicinchoninic acid assay (BCA) and subsequently diluted (in PBSN containing 137 $\mathrm{mM} \mathrm{NaCl}, 2.7 \mathrm{mM} \mathrm{KCl}, 4.3 \mathrm{mM} \mathrm{Na} \mathrm{HPO}_{4} \cdot 7 \mathrm{H}_{2} \mathrm{O}, 1.4 \mathrm{mM} \mathrm{KH} \mathrm{PO}_{4}$ and $0.05 \% \mathrm{w} / \mathrm{v} \mathrm{NaN}$ ) to this optimum ELISA concentration $(10 \mu \mathrm{g} / \mathrm{mL})$. Additionally, $50 \mu \mathrm{L}$ of protein sample was deposited into each respective well within the 96 -well ELISA plate and incubated overnight at room temperature. This plate was washed three separate times with deionized water, so as to remove any unbound proteins. A blocking buffer, consisting of $17 \mathrm{mM} \mathrm{Na} 2 \mathrm{~B}_{4} \mathrm{O}_{7} \cdot 10 \mathrm{H}_{2} \mathrm{O}, 120 \mathrm{mM} \mathrm{NaCl}, 0.05 \% \mathrm{v} / \mathrm{v}$ Tween 20, $1 \mathrm{mM}$ EDTA, $0.25 \% \mathrm{v} / \mathrm{v}$ Bovine Serum Albumin, and $0.05 \% \mathrm{w} / \mathrm{v}$ sodium azide, $\mathrm{pH}$ adjusted to $8.5 \mathrm{with} \mathrm{NaOH}$, was used to fill each well. This procedure was followed by an incubation period of 30 minutes at room temperature. Excess blocking buffer was removed by three DI water washes. $50 \mu \mathrm{L}$ of secondary antibody was then garnered into each well at a concentration of 50 $\mathrm{ng} / \mathrm{mL}$ in PBSN, as determined by criss-cross serial dilution. This solution was incubated for two hours at room temperature. The same DI water/ blocking buffer wash was performed as in the previous step at which point a final, secondary antibody solution of $50 \mu \mathrm{L}$ was employed. The concentration of this mixture was $250 \mathrm{ng} / \mathrm{mL}$. $100 \mu \mathrm{L}$ of TMB (tetramethylbenzidine) was added as the colorimetric substrate and analyzed at 450 nanometers on a microplate reader. This procedure was conducted following a

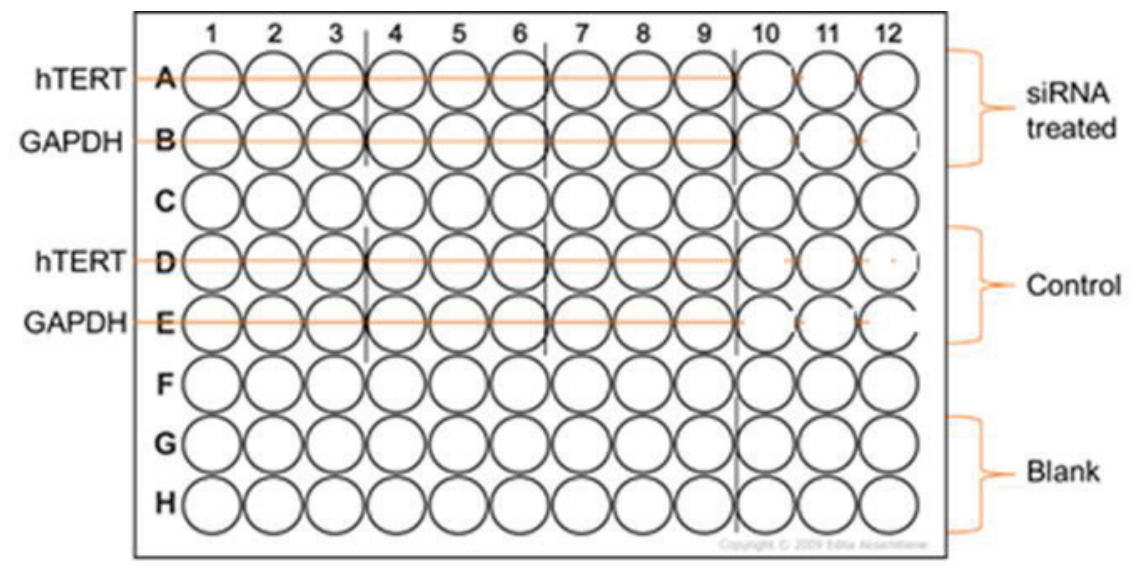

Figure 3. ELISA plate layout, each six square grouping (separated by vertical lines) corresponds to analyzed protein isolated from cells grown in one well of a six well plate.

protocol derived from Current Protocols in Molecular Biology by Ausubel and colleagues in 2003. ${ }^{18}$ Normalization of the ELISA absorbance values were performed as previously discussed with protocol published by Haimes and Kelley in $2013 .{ }^{17}$

\section{RESULTS}

The melt curve generated in this research (Figure 4) demonstrates that the PCR amplicons synthesized during the course of the reaction are from hTERT and GAPDH cDNA and that no detectable primer-dimers or non-specific amplifications occurred. The validity behind this conclusion can be found in the method by which this melting curve was generated. The final PCR solution is heated and each specific amplicon present within the solution will have a characteristic temperature at which it dissociates and therefore no longer fluoresces (due to the binding characteristics of SYBR ${ }^{\circledR}$ green). Due to this innate detachment temperature, each distinct amplicon will also produce a distinguishing peak on the melt curve. However, only two amplicons (one from hTERT and one from GAPDH) were synthesized during the course of the PCR reaction as validated by the two peaked melt curve. Without the melting curve data, it would be impossible to determine whether or not multiple, non-target amplicons were generated. Such an occurrence would engender false RNA quantification results. The data revealed that the siRNA treated cells possessed 97.8 percent less telomerase mRNA than the control group (Figure 5). Following ELISA absorbance normalization (as discussed above) a 53.1 percent protein knockdown was determined (Figure 6). Therefore, the siRNA treated cells possessed nearly fifty-three percent less telomerase protein than the untreated control cells. 


\section{DISCUSSION}

The 97.8 percent mRNA knockdown (p-value of 0.00768 , generated via t-test) attained in this investigation suggests that the transfection mechanism employed was relatively effective, supporting the original hypothesis. Which stated: siRNA can elicit the degradation of hTERT mRNA in cultured HeLa cells and this degradation will significantly reduce hTERT protein concentrations. Nonetheless, only a knockdown percentage of one hundred percent can effectively engender cancer cell crisis and in turn cell death. The efficacy of this PCR procedure is consistent with that determined by Deshayes and colleagues in $2008 .{ }^{13}$ Deshayes demonstrated that a specific domain in the MPG peptide, known as NLS, executes nucleotide binding. As the NLS domain was mutated, MPG's nucleotide binding ability was cooperatively modified. Thusly, the hTERT knockdown percentage may be fortified by manipulating the NLS domain structure. Additionally, their research discovered that the nucleotide delivery compartment (cytoplasm or nucleus) could be selectively chosen with certain NLS mutations. This occurrence advocates the fact that the NLS domain plays not only a role in nucleotide binding but a critical function in dictating the site at which the nanoparticles nucleotide passenger will depart. The MPG nanoparticle and its inclusive siRNA associate have been shown to participate in not only translational inhibition but transcriptional inhibition. The presence of a promoter binding sequence in a siRNA fragment may allow promoter synergy and consequently effective inhibition of gene transcription. A much more efficient, dual layered anti-cancer therapy could be introduced by utilizing such transcriptional and translational inhibition. This dual layered

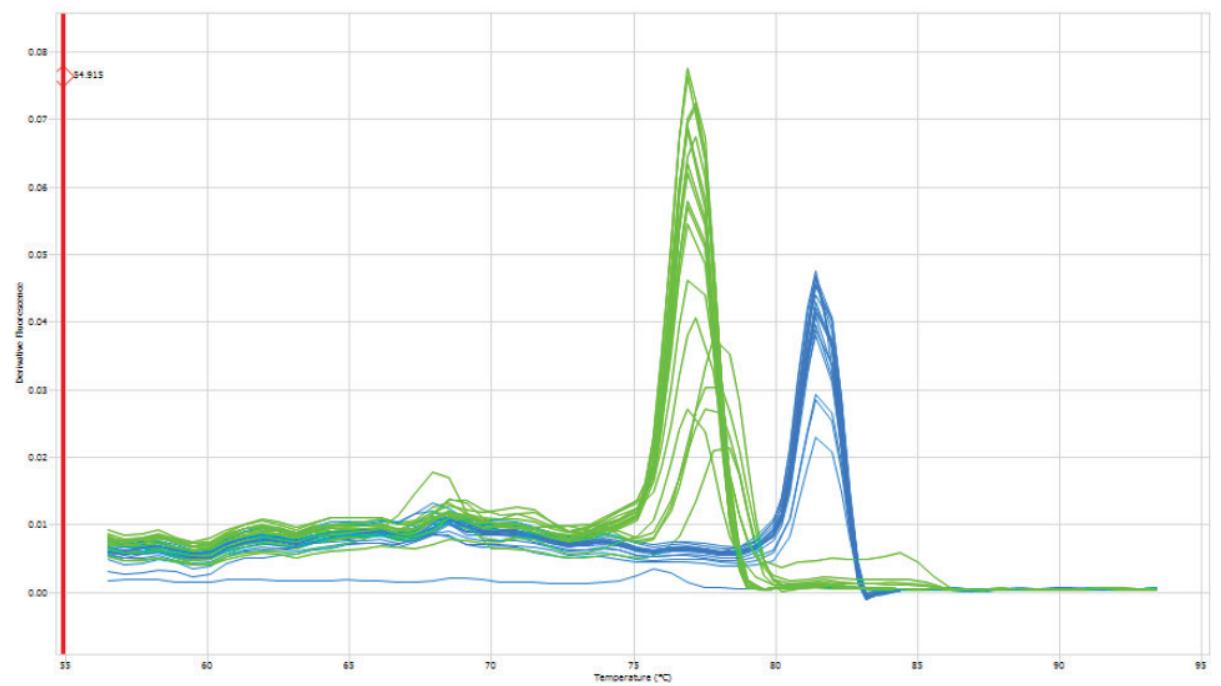

Figure 4. Melt Curve indicating PCR efficiency, twin peaks indicate that only two amplicons (GAPDH and hTERT) were generated in the reaction.

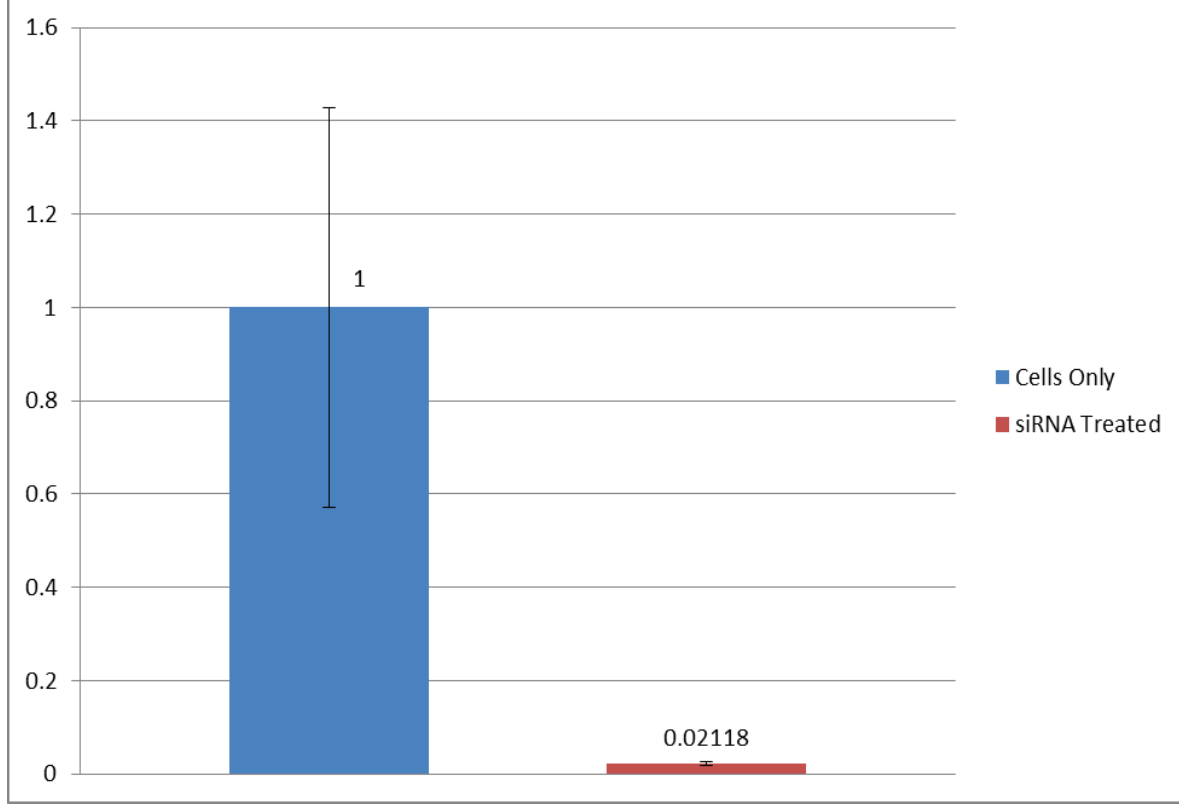

Figure 5. hTERT mRNA knockdown comparing control cells (set to $1 \mathrm{AU}$ ) to siRNA treated cells. 
anticancer therapy has the potential to augment the hTERT knockdown to one-hundred percent and thus be employed in anticancer clinical applications. The fifty-three percent protein knockdown, at first glance, may seem like an enormous aberration from the previously discussed PCR results. However, this knockdown value is consistent with previously published experimental data. Yi and colleagues in 2001 demonstrated that hTERT possesses a half-life value of around twenty-four hours; because the siRNA that was incorporated into the experimental cells does not directly induce telomerase protein degradation, those proteins present prior to siRNA exposure will still be functioning. ${ }^{19}$ However, throughout the course of the twenty-four hour incubation period with the small interference RNA, half or fifty percent of the hTERT protein will have degraded as exemplified by the 24hour half-life of the hTERT protein. Consequently, the 53.1 percent knockdown is consistent with the experimentally determined half-life value of the telomerase protein. The protein knockdown results presented herein is novel within the recently published research basin. The few published articles concerning hTERT protein knockdown via siRNA do correlate well with these results. For example, $\mathrm{Xu}$ and colleagues demonstrated that certain siRNA sequences can significantly reduce both the detectable hTERT mRNA and protein content of analyzed cells. ${ }^{20}$

\section{Conclusion}

A few conclusions can be gleaned from the results of the PCR analysis, the first of which is that siRNA can effectively trigger degradation of a particular mRNA and potentially destroy that proteins activity in the cell. This research also demonstrates that target proteins, not just the mRNA, are greatly reduced. In this case, any possible increase in translation of the TERT mRNA, if it occurred at all, did not offset the dramatic decrease in template available for translation. Consequently, if continual siRNA

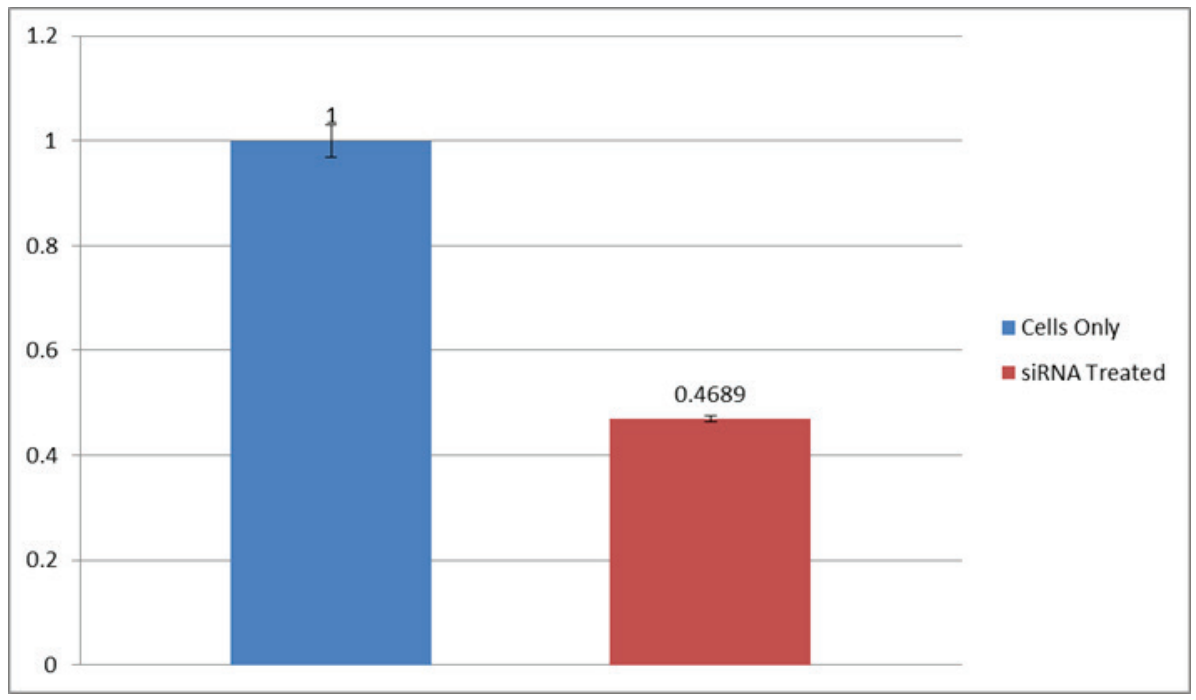

Figure 6. hTERT protein knockdown comparing control cells (set to 1 AU) vs. siRNA treated cells.

expression could be achieved, the telomerase content of a subjected cancer cell may eventually reach negligible levels at which point telomere elongation will no longer occur and crisis could soon follow. This research demonstrates that one potential mechanism by which perpetual siRNA expression and subsequent TERT protein knockdown may be achieved is with the use of h'TERT targeting, siRNA.

\section{Further Research}

The inclusion of an assay measuring cell proliferation, such as an MTT (3-(4,5-dimethylthiazol-2-yl)-2,5-diphenyltetrazolium bromide) between treated and untreated cells would substantiate the aforementioned claim of hTERT siRNA's ability to inhibit cancer cell proliferation. Such a project will be conducted in future research. Additionally, the author understands that a significant hurdle to effective treatment in a living system will likely be the continual delivery of siRNA to target cells (while avoiding non-targeted delivery). Continued research is warranted in both nanoparticle delivery as well as potential use of viral delivery systems tied to gene therapy.

\section{ACKNOWLEDGMENTS}

This research was supported in part by Dr. Douglas Christensen (Wayne State College), who advised the researcher and provided overall support for the project. A special thanks is also extended to Dr. Shawn Pearcy (Wayne State College) for his support with HeLa cell growth. Finally, I'd like to thank Dr. Gustavo Zardeneta for his assistance in Western Blot and ELISA protocol. 
Funding

This research was made possible by grants from the National Center for Research Resources (5P20RR016469) and the National Institute for General Medical Science (NIGMS) (8P20GM103427), a component of the National Institutes of Health (NIH) and its contents are the sole responsibility of the authors and do not necessarily represent the official views of NIGMS or NIH.

\section{REFERENCES}

1. Hanahan, D., Weinberg, R. (2011) Hallmarks of Cancer: The Next Generation, Cell 144, 646-674.

2. Hahn, W. (2003) Role of Telomeres and Telomerase in the Pathogenesis of Human Cancer, J Clin Oncol 21, $2034-2043$.

3. Olovnikov, A. (1996) Telomeres, telomerase, and aging: Origin of the theory, Exp Geront 31(4), 443-448.

4. Rodier, F., Campisi, J. (2011) Four faces of cellular senescence, J Cell Biol 192(4), 547-556.

5. Blasco, M. (2002) Telomerase beyond telomeres, Nat. Rev. Cancer 2, 627-633.

6. Saretzki, G., Sitte, N., Merkel, U., Wurm, R.E., von Zglinicki, T. (1999) Telomere shortening triggers a p53-dependent cell cycle arrest via accumulation of G-rich single stranded DNA fragments, Oncogene 18(37), 5148-5159.

7. Janknecht, R. (2004) On the road to immortality: hTERT upregulation in cancer cells, FEBS Lett 564(1-2), 9-13.

8. Bryan, T., Englezou, A., Dalla-Pozza, L., Dunham, M., Reddel, R. (1997) Evidence for an alternative mechanism for maintaining telomere length in human tumors and tumor-derived cell lines, Nat Med 3, $1271-1274$.

9. Sela, M. (1969) Antigenicity: Some Molecular Aspects, Science 166(3911), 1365-1374.

10. Bartel, D.P. (2004) MicroRNAs: genomics, biogenesis, mechanism, and function, Cell 116, 281-297.

11. Zeng, Y., Cullen, B.R. (2003) Sequence requirements for micro RNA processing and function in human cells, RNA9, 112123.

12. Carthew, R.W., Sontheimer, E.J. (2009) Origins and Mechanisms of miRNAs and siRNAs, Cell 136(4), $642-655$.

13. Deshayes, S., Morris, M., Heitz, F., Divita, G. (2008) Delivery of proteins and nucleic acids using a non-covalent peptidebased strategy, Adv Drug Deliv Rev 60, 537-547.

14. Whitehead, K., Langer, R., Anderson, D. (2009) Knocking down barriers: advances in siRNA delivery, Nat. Rev. Drug Discovery 8(2), 129-138.

15. Reynolds, A., Leake, D., Boese, Q., Scaringe, S., Marshall, W.S., Khvorova, A. (2004) Rational siRNA design for RNA interference, Nat Biotechnol 22(3), 326-330.

16. Singh, V., Kumar, A. (2001) PCR Primer Design, Mol Bio Today 2(2), 27-32.

17. Haimes, J., Kelley, M. (2013) Demonstration of a $\Delta \Delta$ Cq Calculation Method to Compute Thermo Scientific Relative Gene Expression from qPCR Data. Lafayette, CO: Thermo Scientific.

18. Ausubel, F.M., Brent, R., Kingston, R.E., Moore, D.D., Seidman, J.G., Smith, J.A., Struhl, K. (2003) Current Protocols in Molecular Biology, John Wiley \& Sons Inc. 4648.

19. Yi, X., Shay, J.W., Wrighta, W.E. (2001) Quantitation of telomerase components and hTERT mRNA splicing patterns in immortal human cells, Nucleic Acids Res 29(23), 4818-4825.

20. Xu, H., Gong, X., Zhang, H., Zhang, Q., Zhao, D., Peng, J.X. (2015) Targeting Human Telomerase Reverse Transcriptase by a Simple siRNA Expression Cassette in HepG2 Cells, Hepat Mon 15(3), 24343.

\section{ABOUT THE STUDENT AUTHOR}

Shawn is a 2015 graduate of Wayne State College where he earned a double major Bachelors of Science degree in Biology and Chemistry. Shawn graduated Summa Cum Laude from WSC and hopes to attend graduate school for biochemistry in the fall of 2016. While attending Wayne State College, Shawn conducted a two year research project that he presented at the annual 2014 Nebraska Academy of Science spring conference in Lincoln, Nebraska.

\section{PRESS SUMMARY}

Cancer is one of the most important human diseases today, much of this danger is directly related to a cancer cells capability of the unrelenting division. This characteristic is conferred to the cell via reactivation of the telomerase gene and in turn the corresponding protein. If the method described herein could be developed into an in-vivo treatment procedure, such a process could be employed to target cancer cells for destruction. 


\title{
Malate:Quinone Oxidoreductase and Malic Enzyme are required for the Plant Pathogen Pseudomonas syringae pv. tomato DC3000 to Utilize Malate
}

\author{
Zabrina Ebert*, Preston Jacob, Katrina Jose, Lina Fouad, Katherine Vercellino, Steven Van Dorn, Mahaa Sidiqqi, and Eve M. Mellgren \\ Department of Biology, Elmburst College, Elmburst, IL
}

Students:eberta@net.elmburst.edu*,preston.jacob@my.rfums.org,katrina.d.jose@net.elmburst.edu, lina.a.fouad@net.elmburst.edu, kcvercell@gmail.com,vandornsa@yahoo.com,mahaa.siddiqi@net.elmburst.edu

Mentor:mellgrene@elmburst.edu*

\begin{abstract}
Pseudomonas syringae pv. tomato strain DC3000 (DC3000) is a gram-negative bacterial plant pathogen that causes disease on tomato and the model plant Arabidopsis thaliana. Interestingly, previous studies showed that malate:quinone oxidoreductase (Mqo), an enzyme in the citric acid cycle, is required for DC3000 to cause disease on these plants. In addition, growth of DC3000 lacking the mqo gene in minimal medium with malate was significantly delayed, but eventually reached wild-type levels of growth, which is similar to growth in planta. This suggests that malate may be an important carbon source for DC3000. One reason the mqo::KO bacteria may be able to reach wild-type levels of growth in culture and plants is that the DC3000 malic ensyme may be used to complete the citric acid cycle. Our research shows that a mutant strain lacking a functional mqo gene and malic ensyme gene (mqo::KO;ME::pJP) fails to grow in minimal media cultures with malate and has reduced growth in media with citrate, indicating that both Mqo and ME are required for normal growth when utilizing these carbon sources. Future studies looking at growth of this double mutant in plants will identify how important the activities of both of these genes are for DC3000 to cause disease in plants.
\end{abstract}

\section{KEY WORDS}

Malate:quinone Oxidoreductase; Malic Enzyme; MQO; Psendomonas syringae; Arabidopsis thaliana; Malate; Citrate; DC3000

\section{INTRODUCTION}

With population growth and urbanization on the rise worldwide, there is less land left for farming and a growing demand for healthy crops. Because of this, it has become increasingly important to understand how plant pathogenic bacteria such as Pseudomonas syringae cause disease in crops. Not only does this pathogen have the potential to affect crop yields, it also has similar virulence mechanisms to many human pathogens, such as Pseudomonas aeruginosa, which is an opportunistic pathogen that can be life threatening. ${ }^{1}$ By studying virulence in this model bacterium, understanding of related bacterium can be gained.

Pseudomonas syringae pv. tomato DC3000 (DC3000) is a gram-negative bacteria that causes bacterial speck disease on plants such as Arabidopsis thaliana through colonization of the apoplast. ${ }^{2,3}$ DC3000 utilizes a Type III secretion system with a syringe-like apparatus that injects virulence factors into plant cells to manipulate cellular activities and benefit the pathogen.4, 5, 6 Disease symptoms induced by DC3000 include necrotic patches or lesions and chlorosis (yellowing), which are characteristics of speck disease..$^{3,7}$

Malate:quinone oxidoreductase (Mqo) is a flavin adenine dinucleotide (FAD)-dependent membrane associated protein. ${ }^{8}$ Mqo serves two functions within most organisms. First, Mqo catalyzes the oxidation of malate to oxaloacetate in the Tricarboxylic acid cycle (TCA) allowing for the regeneration of oxaloacetate. ${ }^{8,}{ }^{9}$ Secondly, Mqo is found within the electron transport chain. While other enzymes of the TCA cycle utilize NAD as an electron acceptor, the oxidation of malate to oxaloacetate by Mqo donates electrons to quinones of the electron transport chain. ${ }^{9}$ After donation the quinones are required to be oxidized to recycle the enzyme for further use. ${ }^{9}$

Surprisingly, previous studies showed that Mqo is required for DC3000 to cause disease on Arabidopsis thaliana. ${ }^{10}$ When the DC3000 mqo gene was replaced with an antibiotic resistance gene to create the mqo::KO strain, growth of the bacteria in plants was delayed. However, the bacteria would reach wild-type levels four days after inoculation. ${ }^{10}$ Even with the bacteria reaching wild-type levels of growth, disease symptoms in the mqo::KO infected plants never reached the severity of the plants infected with wild-type bacteria. This suggests that bacteria must reach a certain growth during infection for disease symptoms to develop to the severity of wild-type levels. ${ }^{10}$ Decreased growth and a slow recovery was also seen in culture when malate was the only carbon source, suggesting that Mqo may be needed to utilize malate during growth in the apoplast. ${ }^{10}$ The mutant grew similar to wild-type 
DC3000 in citrate and rich media. ${ }^{10}$ The ability of the mqo::KO mutant to eventually reach wild-type levels of growth in plants and in culture suggests an alternative pathway for which malate is processed in mqo::KO.

There are several possible alternative pathways for DC3000 utilization of malate without a functioning Mqo enzyme. In Corynebacterium glutamicum, mqo disruption reduces growth on various TCA cycle intermediates, but with the addition of nicotinamide, Malate dehydrogenase (Mdh) is able to maintain the conversion of malate to oxaloacetate. ${ }^{11}$ Finding both a mqo gene and $m d h$ gene in bacteria is quite common as it is not only seen in C. glutamicum but also E. coli and B. subtilis. ${ }^{12,13}$ B. subtilis is both different and unique because it lacks mqo, causing it to fully depend upon $m d h$ and the pyruvate shunt (formed by malic enzyme and pyruvate decarboxylase) to generate oxaloacetate. ${ }^{12}$ The shunt works by moving malate to pyruvate, which then cycles back through the TCA cycle with generation of oxaloacetate coming from pyruvate decarboxylase. ${ }^{12}$ However, unlike the previously mentioned bacteria, Pseudomonas aeruginosa utilizes two Malic enzymes (ME) in the absence of Mqo. The first one lacks specificity for NAD or NADP while the second one relies heavily upon NADP for the movement of electrons. This bacterium is also capable of growing aerobically with ethanol as the only carbon and energy source, utilizing a pathway not found within DC3000.8, 10

Searches of DC3000 genomic DNA indicated that the bacteria lacks an $m d h$ gene, suggesting a possible reliance on a different enzyme in mqo::KO strains. ${ }^{8,10}$ DC3000 is predicted to have a NAD-dependent malic ensyme (ME; PSPTO_3924), which has 64\% amino acid identity and 79\% similarity to the NAD-dependent malic enzyme from E. coli. Thus, we hypothesized that the DC3000 Malic enzyme was converting malate to pyruvate in the mqo::KO mutant, allowing slow growth to eventually wild-type levels. ${ }^{10}$

To test this hypothesis, a double mutant strain of DC3000 lacking both functional Mqo and ME was made and growth of this double mutant (as well as a single mutant lacking ME) was compared to wild-type DC3000 and the mqo::KO mutant in minimal media cultures. It was hypothesized disruption of just the $M E$ gene would not have a significant effect on growth of the bacteria, while the mqo::KO;ME::pJP double mutant will grow very minimally when malate is the only available carbon source. Similar to what was found with the mqo::KO mutant, it was predicted that growth on citrate would be unaffected or slightly reduced.

\section{METHODS AND PROCEDURES}

Bacterial strains, vectors, and cloning.

In order to disrupt the ME gene in wild-type DC3000 and the mqo::KO mutant strain, a suicide vector (pJP5603) was inserted into the ME gene in both strains (Figure 1). All strains and vectors used in this study are listed in Table 1. A 639 bp fragment of the ME gene was PCR amplified using Pfu Ultra II polymerase (Agilent Technologies, Santa Clara, CA) from DC3000 genomic DNA, isolated with a genomic DNA purification kit (Promega, Madison, WI). The primers used were: ME forward 5' CTATGGATCCTTGTTCAT'TTCTTACCCTGAG 3' and ME reverse 5' GCAATCTAGAACGATCCACCATGAAAATAC 3'. The PCR product was then ligated into a pCR Blunt vector (Invitrogen, Carlsbad, CA). Transformations were completed with the pME-Blunt plasmid into competent E. coli. The vector was purified with a Promega Wizard Miniprep Kit (Promega, Madison, WI). A digest of the $\mathrm{p} M E$-Blunt plasmid with EcoRI was performed. The $639 \mathrm{bp}$ fragment was separated from the vector via gel electrophoresis and then gel purified. Next, the ME insert was ligated into the $3.126 \mathrm{~kb}$ suicide vector pJP5603, ${ }^{14,15}$ which was also digested with EcoRI, and transformed into E. coli. The orientation of the ME gene fragment in the pJP5603 vector was tested via sequence analysis by ACGT, INC. (Wheeling, IL) to ensure that the LacZ promoter on the pJP5603 plasmid would not drive expression of the disrupted ME gene after insertion into the DC3000 genome.

A triparental mating was conducted to transfer the suicide vector with the ME insert (pME-pJP5603) into the DC3000 and mqo::KO strains using the helper strain MM294A(pRK600). ${ }^{16}$ To select for disruption of the ME gene, DC3000 with the pMEpJP5603 plasmid was grown on plates with kanamycin, and the mqo::KO mutant with the pME-pJP5603 plasmid was grown on plates with spectinomycin and kanamycin. The strains were single colony purified by streaking single colonies onto plates with the appropriate antibiotics, and repeating this process three times. Frozen stocks of each strain were created.

Wild-type DC3000, ME::pJP, mqo::KO, and mqo::KO;ME::pJP strains were routinely grown by incubation for two days at $28^{\circ} \mathrm{C}$ in King's Broth $(\mathrm{KB})$ medium ${ }^{17}$ unless otherwise described. Antibiotics were used the following concentrations (in $\left.\mu \mathrm{g} / \mathrm{ml}\right)$ for $P$. syringae strains: rifampin, 100; kanamycin, 25; and spectinomycin, 100. Antibiotics were used at the following concentrations for E. coli strains: kanamycin, $25 \mu \mathrm{g} / \mathrm{mL}$; spectinomycin, $80 \mu \mathrm{g} / \mathrm{mL}$; and chloramphenicol, $20 \mu \mathrm{g} / \mathrm{mL}$.

PCR to confirm disruption of the ME gene.

PCR was used to confirm the disruption of the $M E$ gene by first purifying genomic DNA from DC3000, ME::pJP, mqo::KO, and mqo::KO;ME::pJP using a Wizard genomic DNA purification kit (Promega, Madison, WI). The Taq Master Mix Kit (Qiagen, Hinden, Germany) was then used to PCR amplify a region of the genomic DNA and the pJP5603 vector inserted into the genome. Using the ME::pJP confirmation (5' CATGAGCCCACAT'TGATCG 3') and pJP5603 reverse primers (5' 
GGCGATTAAGTTGGGTAACG 3'; Figure 1), with the following parameters: $94^{\circ} \mathrm{C}$ for 3 minutes, then cycling from $94^{\circ} \mathrm{C}$ for 30 seconds, $55^{\circ} \mathrm{C}$ for 30 seconds, and two minutes at $72^{\circ} \mathrm{C}$ for 35 cycles. A second PCR was conducted to confirm the absence of the $m q o$ gene in the $m q 0:: \mathrm{KO}$ and $m q o:: \mathrm{KO} ; M E:: \mathrm{pJP}$ strains using mqo forward primer 5' GTGACAACATGGACCTGACC 3' and mqo reverse primer 5' CTCCAGCATGATCGACACC 3', with the same cycle parameters except an extension time of one minute. PCR products were then analyzed by gel electrophoresis using 1\% agarose gel at 100 Volts for approximately 30 minutes.

Growth of DC3000 strains in minimal media cultures.

To examine the ability of the bacterial strains to grow in single carbon sources, cultures of $5 \mathrm{~mL}$ of Hoitink Sinden media (HS) ${ }^{18}$ with either $10 \mathrm{mM}$ malate or $10 \mathrm{mM}$ citrate and $\mathrm{pH}$ adjusted to 6.5 were added into sterile culture tubes. DC3000 strains were grown in $5 \mathrm{~mL} \mathrm{~KB}$ media for two days, then $3 \mathrm{~mL}$ of cells from each $\mathrm{KB}$ culture were collected and re-suspended in $1 \mathrm{~mL} 10 \mathrm{mM}$ $\mathrm{MgSO}_{4}$. Bacterial cells were washed 2 times with $10 \mathrm{mM} \mathrm{MgSO}_{4}$ and all cultures were adjusted to the same concentration $\left(\mathrm{OD}_{600}\right.$ reading between $0.1-0.2$ or $4 * 10^{7}$ cells $/ \mathrm{mL}-8 * 10^{7}$ cells $/ \mathrm{mL}$ ). $500 \mu \mathrm{L}$ of each strain was added to sterile tubes containing the $5 \mathrm{~mL}$ of HS media supplemented with malate or citrate. Three replicates of each strain were grown in minimal media with each carbon source, and the levels of growth were monitored every four hours over a 40 hour time period by measuring OD 600 absorbance with GLOMAX Multi detection system microplate reader (Promega, Madison, WI). Three control tubes of HS and malate or citrate without bacteria were also included. When analyzing the data, each sample was first blanked by subtracting the average absorbance from its corresponding media-only controls. Growth curves with $95 \%$ confidence intervals were fit for the data using local polynomial regression fitting and plotted with the ggplot2 package in $\mathrm{R}$.

\section{RESULTS}

The DC3000 strains ME::pJP and mqo::KO;ME::pJP have disrupted ME genes.

Previously, a potential malic enzyme gene (ME; PSPTO_3924) was identified in the DC3000 genome that is 1722 bp in length and has $64 \%$ amino acid identity and $79 \%$ similarity to the malic enzyme from E. coli. ${ }^{10}$ It was suggested that this Malic enzyme could convert malate to pyruvate, possibly allowing for growth of the mqo::KO mutant in minimal media containing malate. To test this hypothesis, the $M E$ gene was disrupted by inserting a suicide plasmid, which lacks an origin of replication that functions in DC 3000, ${ }^{14}$ in the middle of the ME coding sequence. This was accomplished by cloning a 639 bp section (bases 394 to 1032 ) of the ME gene into the pJP5603 vector, and introducing this plasmid into DC3000, where the plasmid integrated through homologous recombination (Figure 1). DC3000 cells that integrated the plasmid were selected by growth on kanamycin plates. The resulting strains were named $M E:: \mathrm{pJP}$ and mqo::KO;ME::pJP (Table 1).

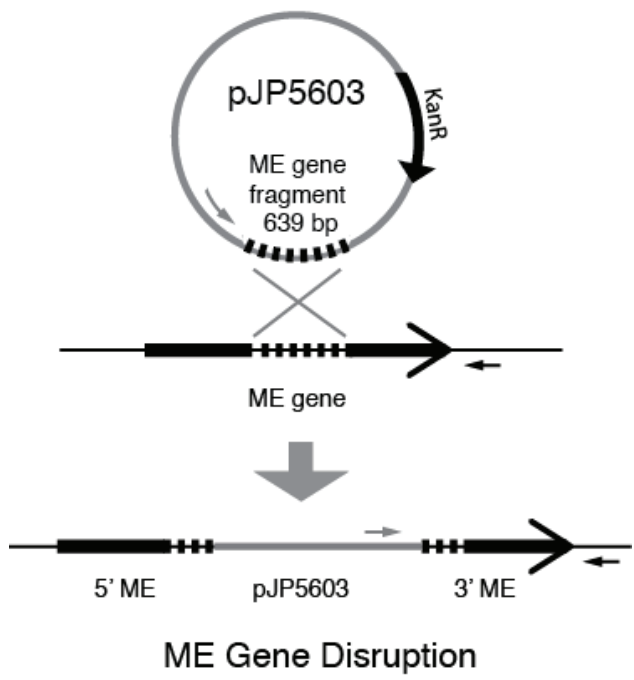

Figure 1: Distuption of the ME gene by plasmid integration into the DC3000 genome. An internal fragment of the ME gene was cloned into the pJP5603 plasmid. The new plasmid, pME-pJP5603, was introduced to DC3000 and allowed to integrate in the middle of the ME gene coding sequence. This strategy was used to create the single mutant $M E:: \mathrm{pJP}$ strain and the plasmid was introduced into the mqo::KO strain to create the double mutant mqo::KO;ME::pJP strain. Location of the primers used to confirm the disruption of the ME gene are shown by the small grey arrow (pJP5603 reverse) and small black arrow (ME::pJP confirmation). 


\begin{tabular}{|c|c|c|}
\hline Strain or Plasmid & Characteristics & Reference or Source \\
\hline \multicolumn{3}{|l|}{ Pseudomonas syringae strains } \\
\hline Pseudomonas syringae pv. tomato DC 3000 & Derivative of NCPPB1106; Rifr & 2 \\
\hline$m q o:: \mathrm{KO}$ & mqo gene replaced with $\mathrm{Sm} / \mathrm{Sp}^{\mathrm{r}}$ gene; $\mathrm{Rif}^{\mathrm{r}}, \mathrm{Sp}^{\mathrm{r}}$ & 10 \\
\hline$M E:: p J P$ & ME gene disrupted with pJP5603 vector & This study \\
\hline Mqo::KO;ME::pJP & mqo gene replaced and $M E$ gene disrupted & This study \\
\hline \multicolumn{3}{|l|}{ Escherichia coli strains } \\
\hline DH5-alpha Lambda-pir & recA, lacZ $\Delta M 15$, Lambda-pir & 19 \\
\hline MM294A (pRK600) & Triparental mating helper strain; $\mathrm{Cm}^{\mathrm{r}}$ & 16 \\
\hline \multicolumn{3}{|l|}{ Plasmids } \\
\hline pJP5603 & Suicide vector; $\mathrm{Km}^{\mathrm{r}}$ & 14 \\
\hline pCR Blunt & Cloning vector; $\mathrm{Km}^{\mathrm{r}}$ & Invitrogen \\
\hline $\mathrm{p} M E$-Blunt & pCR Blunt with ME gene fragment & This study \\
\hline $\mathrm{p} M E-\mathrm{pJP} 5603$ & pJP5603 with ME gene fragment & This study \\
\hline
\end{tabular}

Table 1: Bacterial strains and vectors used in this study.

To confirm that the $M E$ gene was disrupted in both of these strains, primers were designed that would amplify an approximately 900-1500 bp piece of DNA if the pJP5603 plasmid inserted into the ME gene, depending on exactly where the homologous recombination event occurred (see Figure 1). It was expected that the bacterial strains whose $M E$ gene was interrupted with a kanamycin resistance gene (ME:::pJP and mqo::KO;ME::pJP) would produce a PCR product, whereas DC3000 and mqo::KO would not. As seen in the Figure 2 Row 2, only ME::pJP (lane 1) and mqo::KO;ME::pJP (lane 4) show a PCR product just below $1.5 \mathrm{~kb}$, verifying malic ensyme gene disruption in these strains.

To confirm that the mqo gene was absent from the mqo::KO and mqo::KO;ME::pJP double mutant strains, PCR reactions with primers that amplify within the mqo coding sequence were used. The bacterial strains whose mqo gene was intact (DC3000 and ME:::pJP) produced a $275 \mathrm{bp}$ PCR product, whereas the mqo::KO and mqo::KO;ME::pJP strains did not have an amplified product (Figure 2, Row 1).

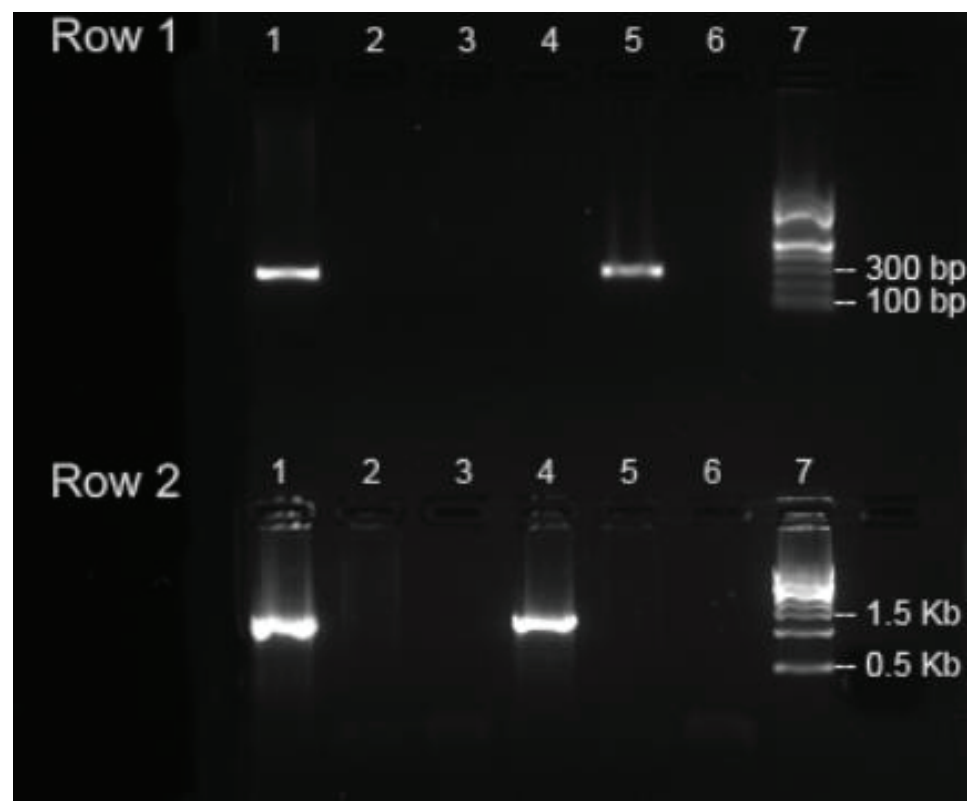

Figure 2: PCR confirmation of ME gene disruption. Row 1: Lane 7 contains the NEB 100 bp ladder. Band sizes for the 100 bp DNA ladder from top to bottom are: 1,517 bp, 1,200 bp, 1,000 bp, 900 bp, 800 bp, 700 bp, 600 bp, 500 bp, 400 bp, 300 bp, 200 bp and 100 bp. Lanes 1 through 6 contain PCR products from amplification with the mqo RT forward + mqo RT reverse primers for the following strains: lane 1 - ME::pJP, lane 2 - mqo::KO sample 1 , lane 3 - mqo::KO sample 2, lane 4 - mqo::KO;ME::pJP, lane 5 - DC3000, lane 6 - no DNA control reaction. Lanes 1 and 5 show amplification of a band of approximately 275 bp. Row 2: lane 7 contains the NEB $1 \mathrm{~Kb}$ ladder. Band sizes for the $1 \mathrm{~Kb}$ DNA ladder from top to bottom are: $10.0 \mathrm{~kb}, 8.0 \mathrm{~kb}, 6.0 \mathrm{~kb}, 5.0 \mathrm{~kb}, 4.0 \mathrm{~kb}, 3.0 \mathrm{~kb}, 2.0 \mathrm{~kb}$, $1.5 \mathrm{~kb}, 1.0 \mathrm{~kb}$ and $0.5 \mathrm{~kb}$. Lanes 1 through 6 contain PCR products from amplification with the ME::pJP confirmation + pJP5603 reverse primers for the following strains: lane 1 - ME::pJP, lane 2- mqo::KO sample 1, lane 3 - mqo::KO sample 2, lane 4 - mqo::KO;ME::pJP, lane 5 - DC3000, lane 6 - no DNA control reaction. Lanes 1 and 4 show amplification of a band just below the $1.5 \mathrm{~kb}$ band. 
ME allows growth of the mqo::KO mutant in media containing malate.

Previous studies indicated that the mqo gene is required for wild-type growth and disease in DC3000. A knockout of the mqo gene with a spectinomycin resistance gene $(m q o:: \mathrm{KO})$ resulted in delayed growth in minimal media with malate, however, eventually wild-type growth levels were reached. ${ }^{10}$ The ability for $m q 0:: \mathrm{KO}$ to reach wild-type levels could be due to the activity of $\mathrm{ME}$, which converts malate to pyruvate. Therefore, the $M E:: \mathrm{pJP}$ single mutant and mqo::KO;ME::pJP double mutant strain were created and grown in minimal media with malate to determine the significance of the $M E$ and mqo genes in DC3000. Growth of all four strains (DC3000, mqo::KO, ME::pJP, and mqo::KO;ME::pJP) in HS minimal media cultures with malate (Figure 3A) showed, as expected, delayed growth of mqo::KO, which reached wild-type levels by the end of 40 hours. The ME::pJP strain grew similar to DC3000 throughout the 40 hour period, but did show a slightly longer lag phase in some experiments (not shown). The $m q o:: \mathrm{KO} ; M E:: \mathrm{pJP}$ double mutant shows little to no growth throughout the curve (Figure 3A). Failure of mqo::KO;ME::pJP to grow in malate indicates the double mutant's inability to utilize malate as a carbon source.

A

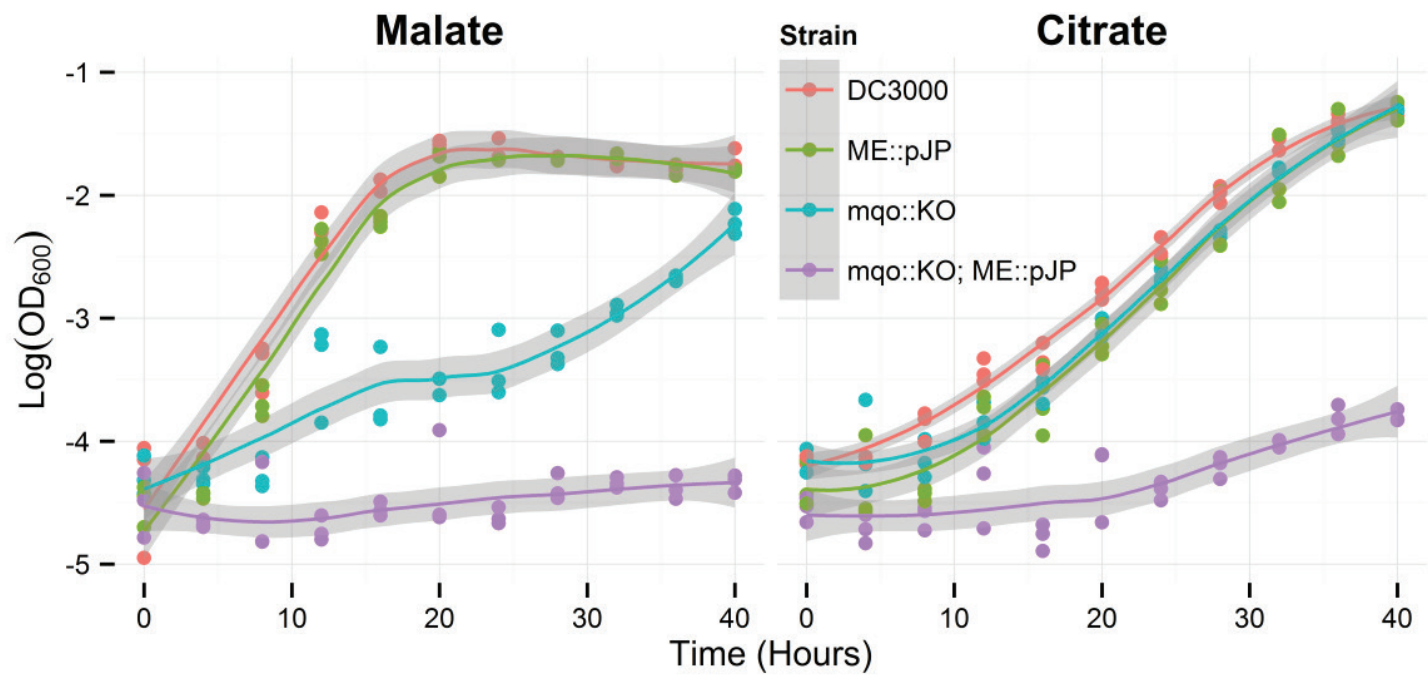

Figure 3: Growth of DC3000, ME::pJP, mqo::KO, and mqo::KO;ME::pJP in HS minimal media with 10mM malate (A) or citrate (B). Each point represents an individual culture absorbance reading and the shaded area around the curves represents the $95 \%$ confidence interval. Each growth curve was replicated at least three times with similar results.

$M q o$ and $M E$ are required for growth in minimal media with citrate.

In previous studies, ${ }^{10}$ the mqo::KO mutant did not show a growth defect when growing in HS minimal media cultures with citrate. Thus, it was hypothesized that growth of the double mutant in minimal media with citrate as its sole carbon source would generate a sufficient amount of ATP (which is generated by intermediates in the TCA cycle) to facilitate growth. When comparing growth in HS minimal media with citrate, (Figure 3B) both the mqo::KO and the ME::pJP had growth rates similar to wild-type bacteria for the entire 40 hour time period. In comparison, the mqo::KO;ME::pJP strain had a much reduced growth rate throughout the curve (Figure 3B). This indicates that in the absence of Mqo, ME is required for wild-type growth when citrate is the only available carbon source.

\section{DISCUSSION AND CONCLUSIONS}

Previous work showed that the mqo gene is required for virulence of the plant pathogen DC3000. However, a remaining question was why the mqo::KO mutant was able to grow in minimal media cultures with malate, despite lacking the enzyme for the last step in the TCA cycle where malate is converted to oxaloacetate. It was hypothesized that activity of the ME gene was allowing DC3000 to grow when Mqo is inactive. To answer this question, a mutant strain lacking mqo and with a disrupted $M E$ gene was created. Our current work supports the hypothesis, as we show that when the mqo gene is absent and the ME gene is disrupted, DC3000 can no longer grow in minimal media with malate.

The results obtained from this study show that the $M E$ gene is required for utilization of malate by DC3000 in the absence of $m q o$. The fact that the mqo::KO mutant has a more pronounced growth defect than the ME single mutant suggests that mqo is the primary enzyme responsible for malate utilization. Future studies could look at regulation of these genes to see if they are both used during normal growth, or if $M E$ expression is upregulated when mqo is missing. 
The mqo::KO mutant grew similarly to wild-type DC3000 in citrate, indicating that mqo was not required for normal growth when citrate is the provided carbon source. We found that the double mutant lacking mqo and a functional ME gene does not grow like wild-type DC3000. It was hypothesized that mqo::KO;ME::pJP would be able grow normally on citrate because growth in this source would allow for all of the steps of the TCA cycle before malate oxidation to be completed, reducing all electron carriers except for the final NADH in the last step of the cycle. However, the data collected (Figure 3B) shows that mqo::KO;ME::pJP has delayed growth when citrate is the available carbon source, unlike the wild-type bacteria.

One reason why the double mutant may not be able to grow like wild-type DC3000 in citrate is because of the lack of oxaloactetate. Oxaloacetate is an intermediate for synthesis of some amino acids; thus, the double mutant may be lacking a way to produce these amino acids, inhibiting growth. Alternatively, growth may be inhibited because of accumulation of an intermediate such as malate or one of the other dicarboxylates. Buildup of one of the TCA intermediates may be a signal to stop expressing some TCA cycle enzymes. Future experiments will try to distinguish between these two hypotheses by growing mqo::KO;ME::pJP in HS media with citrate and supplementing with oxaloacetate.

Future experiments will also include looking at if mqo and $M E$ are important for growth in planta. We predict that the double mutant will not grow as well as the mqo::KO bacteria and will not cause any disease symptoms on infected plants. These experiments looking at the growth of the mqo::KO;ME::pJP double mutant in plants will help to confirm that malate, which is present in the plant apoplast, ${ }^{20}$ is an important carbon source for DC3000 when it is growing in this environment.

\section{ACKNOWLEDGEMENTS}

The authors thank Dr. Keith Hultman for his help with generating figures for this manuscript. This work was supported by an Elmhurst College Faculty Research Grant to Eve Mellgren and an Elmhurst College Swords Scholar Grant to Zabrina Ebert.

\section{LITERATURE CITED}

1. Hauser, A.R. (2009) The type III secretion system of Pseudomonas aeruginosa: infection by injection, Nature Reviews Microbiology 7(9), 654-665.

2. Cuppels, D. A. (1986) Generation and characterization of Tn 5 insertion mutations in Pseudomonas syringae pv. tomato, Appl Environ Microbiol 51(2), 323-327.

3. Preston, G. M. (2000) Pseudomonas syringae pv. tomato: the right pathogen, of the right plant, at the right time, Mol Plant Pathol, 1(5), 263-275.

4. Galan, J. E., and Collmer, A. (1999) Type III secretion machines: bacterial devices for protein delivery into host cells, Science 284(5418), 1322-1328.

5. Grant, S. R., Fisher, E.H., Chang, J.H. Mole, B.M., and Dangl, J. L. (2006) Subterfuge and manipulation: type III effector proteins of phytopathogenic bacteria, Annu Rev Microbiol 60, 425-449.

6. Kunkel, B.N., and Chen, Z. (2006) Virulence strategies of plant pathogenic bacteria, in The prokaryotes (Dworkin et al., Ed.) vol. 2, 421-440, Springer, New York, NY.

7. Whalen, M. C., Innes, R.W., Bent, A.F., and Staskawicz, B. J. (1991) Identification of Pseudomonas syringae pathogens of Arabidopsis and a bacterial locus determining avirulence on both Arabidopsis and soybean, The Plant Cell 3(1), 49-59.

8. Kretzschmar U., Ruckert, A., Jeoung, J., and Görisch, H. (2002) Malate:quinone oxidoreductase is essential for growth on ethanol or acetate in Pseudomonas aeruginosa, Microbiology 148(12), 3839-3847.

9. Cohn, D. V. (1956) The oxidation of malic acid by Micrococcus lysodeikticus, J Biol Chem 221, 413-423.

10. Mellgren, E.M., Kloek, A. P., and Kunkel, B. N. (2009) Mqo, a tricarboxylic acid cycle enzyme, is required for virulence of Pseudomonas syringae pv. tomato strain DC3000 on Arabidopsis thaliana, J Bacteriol 191(9), 3132-3141.

11. Molenaar, D., Van Der Rest, M. E., Drysch, A., and Yucel, R. (2000) Functions of the membrane-associated and cytoplasmic malate dehydrogenases in the citric acid cycle of Corynebacterium glutamicum, J Bacteriol 182(24), 6884-6891.

12. Ohshima, T. and Tanaka, S. (1993) Dye-linked L-malate dehydrogenase from thermophilic Bacillus species DSM 465, EurJ Biochem 214(1), 37-42.

13. Van Der Rest, M. E., Frank, C., and Molenaar, D. (2000) Functions of the membrane-associated and cytoplasmic malate dehydrogenases in the citric acid cycle of Eschericia coli, J Bacteriol 182(24), 6892-6899.

14. Penfold, R.J., Pemberton, J.M. (1992) An improved suicide vector for construction of chromosomal insertion mutations in bacteria, Gene 118(1), 145-146.

15. Riedel, T., Rohlfs, M., Buchholz, I., Wagner-Döbler, I., Reck, M. (2013) Complete sequence of the suicide vector pJP5603, Plasmid 69(1), 104-107.

16. Finan, T. M.,Kunkel, B.N., De Vos, G.F., and Signer, E.R. (1986) Second symbiotic megaplasmid in Rhizobium meliloti carrying exopolysaccharide and thiamine synthesis genes, J Bacteriol 167(1), 66-72.

17. King, E. O., Ward, M.K., and Raney, D.E. (1954) Two simple media for the demonstration of pyocyanin and fluorescein, $J$ Lab Clin Med 44(2), 301-307. 
18. Sreedharan, A., Penaloza-Vazquez, A., Kunkel, B.N., and Bender, C.L. (2006) CorR regulates multiple components of virulence in Pseudomonas syringae pv. tomato DC3000, Mol Plant-Microbe Interact 19(7), 768-779.

19. Miller, V. L., and Mekalanos, J.J. (1988) A novel suicide vector and its use in construction of insertion mutations: osmoregulation of outer membrane proteins and virulence determinants in Vibrio cholerae requires toxR, $J$ Bacteriol 170(6), 2575-2583.

20. Lee, M., Choi, Y., Burla, B., Kim, Y.Y., Jeon, B., Maeshima, M., Yoo, J.Y., Martinoia, E., and Lee, Y. (2008) The ABC transporter AtABCB14 is a malate importer and modulates stomatal response to CO2, Nat Cell Biol 10(10), 1217-1223.

\section{ABOUT THE STUDENT AUTHORS}

Zabrina Ebert is a recent graduate of Elmhurst College with a Bachelor of Science in Biology. She has worked with Dr. Eve Mellgren on Psuedomonas syringae for two years and has presented research at NCUR and NCHC. She will be attending Midwestern University in the fall of 2015 to pursue a degree in Osteopathic Medicine.

Preston Jacob graduated from Elmhurst College in 2013 with a Bachelor of Science in Biology. Preston currently attends Chicago Medical School at Rosalind Franklin University of Medicine and Sciences in North Chicago, IL where he is pursuing a degree in Allopathic Medicine.

Katrina Jose worked on this project her senior year at Elmhurst College. She is a recent graduate of Elmhurst College with a Bachelor of Arts in Biology with a minor in Psychology. She is a member of the Beta Beta Beta National Biological Honor Society, Pi Gamma Mu International Honor Society in Social Science and the American Society for Clinical Pathology. She is currently pursuing a career in Medical Laboratory Science.

Lina Fouad is a senior at Elmhurst College pursuing a Bachelor of Science in biology and psychology. She has been working on this project since spring semester of her junior year.

Katherine Vercellino graduated from Elmhurst College in May 2014 with a Bachelor of Science in Biology. She is currently working as a research scientist for Archer Daniels Midland Company.

Steven Van Dorn graduated from Elmhurst College in May 2014. He has acquired licensing as an EMT in the state of Illinois, and is considering pursuing a Master's degree in genetics or attending medical school.

Mahaa Siddiqi is a senior at Elmhurst College and is working towards her Bachelor's degree in Biology with minors in Chemistry and Medical Humanities. She is the Vice President of the pre-health national honor society Alpha Epsilon Delta as well as a national member of Beta Beta Beta. Her future plans include medical school with a specialty in infectious disease.

\section{PRESS SUMMARY}

Pseudomonas syringae pv. tomato strain DC3000 (DC3000) is a bacterial plant pathogen known to cause disease in Arabidopsis thaliana and tomato plants. Interestingly, previous studies have shown that malate:quinone oxidoreductase (Mqo), an enzyme in the tricarboxylic acid cycle, is required for DC3000 to cause disease. A mutant strain lacking the mqo gene had significantly delayed growth when malate was the only carbon and energy source, but eventually reached wild-type levels of growth. This may be due to the activation of a secondary pathway mediated by Malic Enzyme (ME). Our research shows that a mutant strain lacking both the mqo gene and the malic enzyme gene fails to grow in minimal media cultures with malate. The roles of both genes on DC3000 energy and amino acid production, as well as virulence, are the topics of future research. 


\title{
Engaging Students in Science through a Nature Hike: A Case of Two Students with ADHD
}

\author{
Ashleigh Moore ${ }^{a}$, Kristy Lynn Daniel* ${ }^{*}$, and Aimée K. Thomas \\ ${ }^{a}$ Department of Psychology, University of Southern Mississippi, Hattiesburg, MS \\ ${ }^{b}$ Department of Biological Sciences, Texas State University, San Marcos, TX \\ 'Department of Biological Sciences, Loyola University New Orleans, New Orleans, LA \\ Student:ashleigh.dais@eagles.usm.edu \\ Mentor:kristydaniel@txstate.edu*
}

\begin{abstract}
Attention-Deficit/Hyperactivity Disorder (ADHD) is becoming prevalent amongst elementary school aged students and can lead to learning disorders. Additionally, informal science education is a field of study that is becoming increasingly popular and important in the world of science, especially with elementary students. Thus, it is important to understand how students with ADHD react to informal learning experiences. We measured learning gains and changes in environmental awareness among 84 fifth grade students that participated in an informal nature hike associated with the Over, Under, and Through: Students' Informal Discover the Environment program. We also used a case study approach to reveal the hike experiences of two students with ADHD. Both students demonstrated increased attention and interest in science during and after their participation in the nature hike. While this is a small scale, case study, findings from this work and related literature suggest that more informal experiential learning opportunities should be integrated into science classes as they help improve student attention, content recall, and attitude toward science.
\end{abstract}

\section{KEYWORDS}

ADHD; Engagement; Environmental Science Education; Informal Science Education; Mobile Technology; Nature Hike

\section{INTRODUCTION}

Attention Deficit Hyperactivity Disorder (ADHD) is of growing concern within elementary schools, with a worldwide prevalence of 5.29\%-7.1\% among children and adolescents. ${ }^{1,2}$ The high numbers of ADHD among students in public schools can interfere with learning and limit interest in science. ${ }^{3,4}$ It is common that students diagnosed with ADHD have difficulties with reading comprehension, ${ }^{5}$ achieving high academic performance, ${ }^{6}$ and developing interpersonal relationships. ${ }^{7}$ Much is known about how students with ADHD interact with peers and learn while in formal traditional classroom settings. ${ }^{7}, 8$ Students with ADHD have a need for special accommodations in learning environments. ${ }^{9}$ For example, accommodations for young students with ADHD include seating students in areas where their behavior can be easily monitored, seating students near positive model students, limiting environmental distractions, creating routine daily schedules, allowing students to be active in a productive manner, assisting with organization through scaffolds, limiting blocks of instructional time, limiting written assignments, and encouraging students to go outside. ${ }^{10}$ Likewise, hands-on, realistic example and the use of physical materials have increased performance and learning. ${ }^{11}$ However, only seven studies have been conducted that explores how elementary school students with ADHD perform (e.g., learning gains, engagement, and content recall) in informal environmental education settings. ${ }^{12-18}$

Informal learning environments typically use experiential learning, ${ }^{19}$ discovery learning, ${ }^{20}$ self-directed learning, ${ }^{21}$ and play-based inquiry ${ }^{22}$ to direct learning experiences. Learning about environmental science naturally lends itself to learning in outdoor environments (e.g., nature preserves, zoos, environmental centers). However, most students do not spend enough time studying, exploring and engaging in the natural history of an environment. ${ }^{23}$ In our current climate, children would prefer to sit inside playing video games or watching TV rather than venture outside and explore nature. ${ }^{24,25}$ Lawrence ${ }^{26}$ looked at behavioral inhibition and executive functioning in boys (ages 6-12) with ADHD in real life settings (playing video games and going to the zoo) and found that they all had poor results for behavioral inhibition and motor control. Educators know that by the time students reach middle school years, their time spent outdoors experiencing nature has diminished and they experience "nature deficit disorder," which may lead to a wide range of behavioral problems. ${ }^{12,23,27}$

Museums, learning centers, and other informal activities (e.g., nature hikes) help build student interest in science. ${ }^{28,}{ }^{29}$ Students that have participated in such informal programs have been found to have high science content learning gains ${ }^{30}$ and positive attitudes with regard to learning science. ${ }^{31}$ Additionally, one month after participation, students still held positive attitudes and were able to easily recall the hands-on interactions. ${ }^{29}$ 
Technology is becoming a standard in educational settings, particularly hand-held devices such as the popular Apple iPads ${ }^{\circledR} .{ }^{32}$ The use of iPads to promote engagement and interactivity during learning has become a popular focus in educational settings. ${ }^{33}$ However, very few studies have looked specifically at the impacts of iPad apps on managing ADHD, ${ }^{34}$ and most have taken place with students at the collegiate level. ${ }^{32,35}$ One investigation ${ }^{35}$ captured evidence that iPad games can be used to improve comprehension and hold user attention among young students with ADHD.

We have situated our study within the informal environmental program-Over, Under, and Through: Students' Informally Discover the Environment (OUTSIDE) — a program that encourages underrepresented 5th grade students to interact with nature and develop observational skills while using a project iPad app. ${ }^{36} \mathrm{~A}$ major goal of this program was to promote equity of access and create opportunities for underrepresented children, including those with ADHD, to access environmental science. In traditional classrooms, it can be problematic for students with ADHD to develop observational skills ${ }^{2}$ and find opportunities to participate in environmental education.

The purpose of our study is to understand how students with ADHD react to science learning in nature through the OUTSIDE program. Our specific research questions include: 1 . What learning gains do students demonstrate after participating in OUTSIDE? 2. How do students with ADHD interact with nature, naturalists, and other students during OUTSIDE?

\section{METHODS AND PROCEDURES}

\section{Participants}

We used a mixed methods approach to complete our study. For our first research question, we gathered data from 84 students to measure learning gains and changes in environmental awareness after participating in the OUTSIDE program. OUTSIDE consists of a series of three hikes that take place once per semester over three semesters (5th through 6th grade). We used all of the student participants in order to obtain large enough numbers to capture potentially significant changes in student learning. This analysis also provides us with data necessary to compare our cases to the general population of students included in the OUTSIDE hikes. For our second research question, we identified two male, fifth-grade students with a documented ADHD diagnosis from our sample population, Taylor (Case Study Participant 1) and Allen (Case Study Participant 2), who participated in the first semester hike. Each of these students used for our case study were males from low-income families, Taylor was black and Allen was Hispanic. To maintain the confidentiality of our participants, we have used pseudonyms for all participants and conducted all research in accordance with the University of Southern Mississippi's Institutional Review Board guidelines (Approval \#CH12072603). All participants were enrolled in one of two southern elementary schools that are part of a high needs district with $84 \%$ poverty and 95\% underrepresented in STEM. When the students arrived at the environmental center for the hike, we placed them into groups of six and assigned a naturalist leader. Taylor and Allen were placed in the same group with Anne serving as their group naturalist. Each boy partnered with a different student within the group and was provided with an iPad with the program app. ${ }^{37}$ During this hike, students participated in activities that focused on practicing skills necessary for becoming a naturalist: making observations, following directions, careful listening, proper nature handling, etc. and learning about human impacts on nature and the nature of science in accordance with the Next Generation Science Standards ${ }^{38}$ (i.e., Disciplinary Core Idea, ESS3.C: Human Impacts on Earth Systems and Cross Cutting Concept: Science Addresses Questions About the Natural and Material World).

\section{Data Collection}

We collected data from a pre/post multiple choice content exam, Likert-style environmental awareness questionnaire, field notes of observations from student actions and communications during the hike, video recordings of student activities from two stations, and student responses during individual, semi-structured follow-up interviews. ${ }^{39}$

Pre/Post/Delayed-Post Content Exam. Students completed a nine-question, multiple-choice content exam before the hike (pre), and immediately following the first hike (post). These questions covered content such as: Which venomous snakes have been identified in Mississippi? Should people touch a snake's head? What is the best way to find the bird in the wild? How do you identify poison ivy? and What should you do is you accidentally touch poison ivy? During the following semesters, students completed a 12-item and another 9-item exam, covering fauna and flora content respectively, before and immediately after each hike. The students were exposed to related content during the OUTSIDE Program through information available on the iPad app and interactions with naturalists. Each assessment was developed and validated by the OUTSIDE research team to measure targeted content learning gains that were expected after participating in each of the OUTSIDE nature hikes: Walk the Train, Meet the Wildlife, and Explore the Plants. 
Pre/Post Environmental Awareness Questionnaire. Students responded to 28 Likert-style questions regarding five facets of awareness (learning about environmental science, interest in nature, technology use, communication skills, and learning science). ${ }^{37}$ Students completed this reliable questionnaire $(\alpha=0.793)$ before the hike (pre), immediately following the hike (post).

Field Notes and Video Recordings. During the entirety of the 10-station nature hike, we gathered data about Taylor's and Allen's actions and remarks. We gathered detailed field notes describing Taylor's and Allen's experiences during the nature hike, including documentation of what each student saw, the students' actions, and students' communications for the entirety of the hike. Each of the targeted students wore a lapel microphone attached to an audio recorder during the hike to allow us to double check the field notes for accuracy. Additionally, we video recorded the entire group interactions at two of the ten stations during the nature hike. The first recording was at a station at the beginning of the hike and the second recording was at a station near the end of the hike. These stations were chosen due to similarities in content related to dams. The naturalist was trained to draw parallels between the two stations and also emphasize differences between the dams. These video recordings allowed us to check for consistency among field notes and compare reliability between observers.

Follow-up Interviews. Upon completion of the hike, we transcribed the field notes and conducted a follow-up interview with each student to better understand their experiences. We asked students to describe their experience, willingness to return to the environmental center or participate in a similar nature hike experience, and any previous experiences or encounters with nature. Some questions included: 1) Tell me about your experiences when you went on the nature hike at Lake Thoreau Environmental Center. 2) What did you learn while you were on this hike? and 3) What did you like best/worst about this trip? We were particularly interested in using these interviews to gather data regarding three types of interactions: 1) Interactions with nature, 2) Interactions with each other and with the naturalist, and 3) Interactions with technology.

\section{Analysis}

To address the first research question, we scored student responses on the content exam and environmental awareness questionnaire. We used a paired dependent t-test to compare averages in content learning gains among all students who participated in the hike to identify if there were significant differences in student learning gains and/or awareness scores pre/post participation. Next, we use a Non-parametric Wilcoxon Signed Rank Test to compare Pre/Post EAQ scores across semesters. To address the second research question, we used data from field notes and student interviews to create individual profiles of each 'Taylor's and Allen's experiences during the hike. We used an inductive approach to code student's actions and communications in search of emergent themes. We used the video recordings of the two stations along the hike to triangulate the findings and ensure the credibility of the created profiles. We report findings from the perspective of a non-participant observer describing student experiences through rich description.

\section{RESULTS}

Learning Gains

We found that while there was an increasing pattern of content learning gains among all student participants during the first and third semester (first semester-Pre: $M=5.26, S D=1.67$; Post: $M=5.68, S D=1.36$; third semester-Pre: $M=3.1, S D=1.67$; Post: $\mathrm{M}=4.63, \mathrm{SD}=1.97$ ), and zero net difference during the second semester (second semester- Pre: $\mathrm{M}=4.92, \mathrm{SD}=1.86$; Post: $\mathrm{M}=4.92$, $\mathrm{SD}=1.81$ ) (See Figure 1). However, the gains identified were only significant during the third semester of the program $(t(30)=$ $-3.72, \mathrm{p}=0.001)$. We also found that environmental awareness scores of all our participants steadily increased after participation in OUTSIDE, but there was no statistical difference among these scores $(z(69)=-0.325, p>0.745)$. Of our two case study participants, both students answered one additional question correctly after participating in the OUTSIDE program after the first semester, this was consistent with scores from the other participants. We could not compare later learning gains across semesters as the two case study participants changed schools and dropped out of the OUTSIDE program after the first semester. 


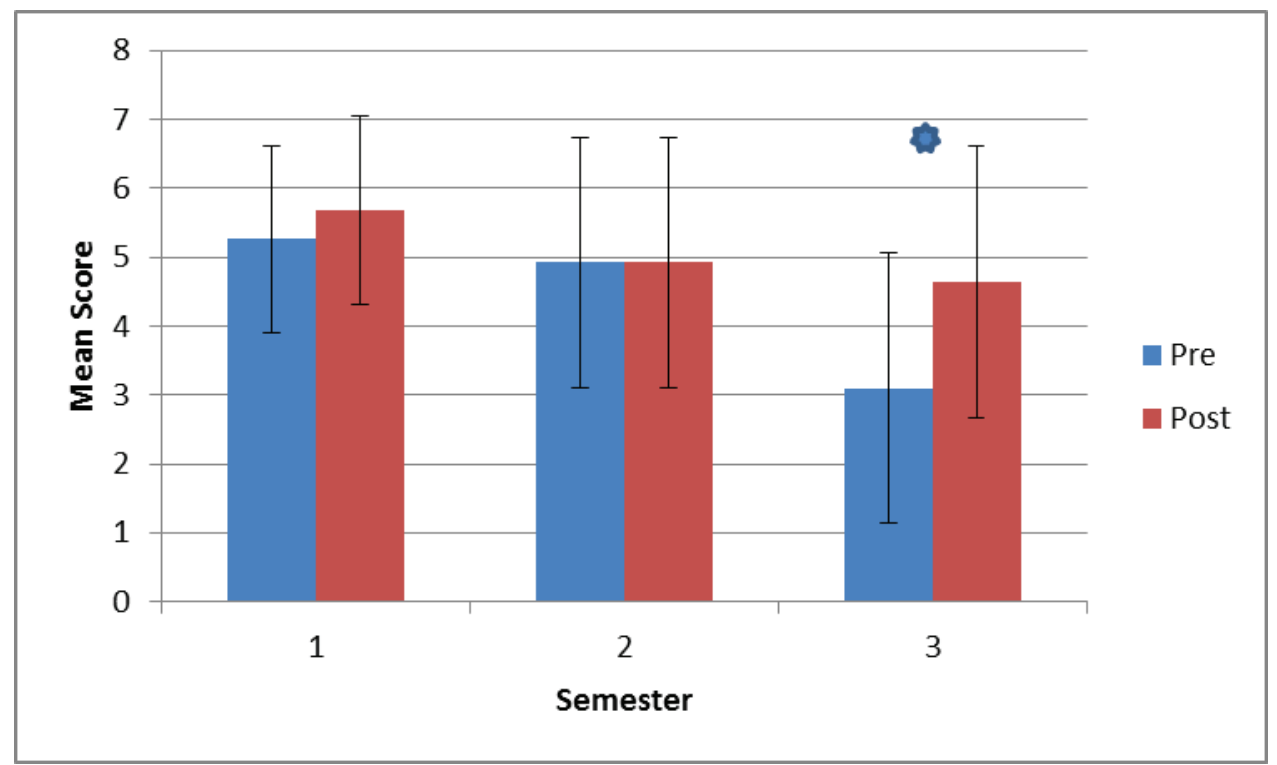

Figure 1. Changes in all participants' pre/post mean scores of content knowledge by semester. There was a significant increase in content knowledge $(t(30)=-3.72, \mathrm{p}=0.001)$ during semester three.

\section{Case Study Findings}

On their first hike, students were eager to participate because of the chance to play with iPads, but initially hesitant to touch things in the natural environment (e.g., plants, insects) for fear of getting dirty. Some initially argued with each other over who got to carry the iPad, but eventually, all became more comfortable interacting with their natural surroundings and less focused on the iPads.

The following are two case study snapshots of Taylor's and Allen's student experience on the first hike. Each of these two students was previously diagnosed with ADHD. These profiles document the experiences of each student while participating in a nature hike and their reflections a month after the experience. The findings are reported from the perspective of a non-participant observer and interviewer, and seek to describe the experience that each student had during each nature hike through rich description.

Taylor. Taylor stated that he enjoyed going outside but, “It's just that I have to go to the park or somewhere because it's crowded over where I live." Thus, Taylor's prior experiences revolved around playing in the city park with cousins where playground equipment was available.

When Taylor first began the OUTSIDE hike, he was observed to be reserved and had little communication with other students. However, once the hike began and the naturalist, Anne, began encouraging the students to interact with nature, Taylor was observed showing interest in the activities at each station and paid attention to questions that were asked. He was polite about answering questions and raised his hand before providing a response and was careful not to interrupt other students when they were speaking. When asked questions, he would nod or shake his head in reply. Taylor stayed at the front of the group and observed organisms highlighted by the naturalist, but he was still hesitant to fully interact with nature. For example, at the first station, Taylor observed the water closely and asked questions about bladderworts when Anne held the plant up. He took photos and recorded notes on the iPad about bladderworts. He withdrew and asked not to have to touch the bladderwort when Anne offered. Instead, Taylor preferred to participate by reading the station introductions and browse the photo gallery in the program app. When his partner had the iPad, he would help spell words and encourage them to take notes about each station.

As the hike proceeded, Taylor became more verbal and offered comments about beavers. They make sounds with their tails as, "a predator alert," build dams, "to stop the water," and use lodges as, "a place where [beavers] hide." Taylor also observed pine trees that had been burned in efforts to reestablish the natural Longleaf Pine Savannah habitat and stated, "They burned the bark on that pine tree. Why would they do that?" Such comments were made without prompting and he verbally responded to questions directed at him by this time. Although Taylor preferred not to touch anything, he engaged with nature through other activities. For example, he cupped his hands around his ears to listen for birds and imitated a tree swaying back and forth when discussing how trees use buttressing to stand in aquatic environments. 
After the hike, Taylor recalled his experiences easily and with excitement. He stated that his favorite part of the hike was, "getting outdoors and seeing all the stuff you can't ordinarily see," recalling the photos he took of the bladderwort and taking notes on the iPad. Taylor stated he could, "still enjoy nature without technology;" however, he was thankful for the iPad because he was able to take notes about the experience to help him remember later.

Allen. While there was a park area within his apartment complex, Allen stated, 'I get bullied by big kids, that's why I don't like to go outside that much." His outdoor experiences were limited to playing kickball, soccer, football, going to the park, and jumping ditches.

Allen was observed to be energetic and consistently active in his participation throughout the hike and responsive to questions. He was very eager to touch plants and quick to pick up leaves, pine cones, and other organisms that he found along the trail, even when asked not to. When Anne pointed out bladderworts, Allen was fascinated by the organism and immediately picked some up from the water, asking, "Is it prey, or like a predator?" He proceeded to take notes on the iPad notepad about how the "bladder" of the plant is used to feed while also assisting classmates in spelling and taking notes. Allen also tried to listen for sounds such as wind blowing, fish bubbling, or frogs and birds calling. Allen was frequently observed volunteering to read the station content aloud and would follow along attentively when other students read.

During a moment of downtime, Allen became visibly distracted and was playing in a moist patch of ground with his foot rather than participating with the group. During this time, he gave no verbal or physical responses to questions. Once Anne began a new activity, showing a dragonfly that she caught, Allen refocused his attention. His attention remained focused as long as he was a part of whatever activity was taking place. For example, at a bird watching station, Allen was alert and involved with searching for nests and listening for the sounds of birds calling. As a classmate began to raise his voice, Allen quickly turned and asked him not to yell because it will scare away the birds. When Anne asked students to stop and cup their hands around their ears to try and hear the sounds happening in nature, Allen would stop and listen for animals, running water, or wind blowing the leaves. He practiced doing such observations even when not prompted, to the point that Allen's interest in nature at times appeared to distract him from the conversation happening amongst the group. For example, Allen would walk around and observe trees, leaves, moss, pine cones, tadpoles in the water, etc. However, as soon as Anne or a student in the group asked him a question, he responded with an appropriate answer, reflecting his attentiveness despite his seemingly distracted actions.

After the hike, Allen was visibly distracted due to not having taken his ADHD medication, although he had taken it on the day of the hike. Still, Allen was able to recall what he saw during the hike, "I heard a goose calling, cricket frogs calling for mating, and we used iPads. That was cool. We got to take pictures, I took pictures like paparazzi, work it." He was interested going on another hike because he liked participating in activities while immersed in nature.

Both Allen and Taylor used the mobile technology provided throughout the hike to facilitate participation and to document experiences. Students used the iPads as a way to access and learn information about nature. Each student also interacted with the naturalists, responding to and asking questions.

\section{DISCUSSION AND CONCLUSIONS}

The purpose of our study was to understand how elementary students with ADHD react to science learning in nature through the OUTSIDE program. We wanted to understand what learning gains students demonstrated and how these students with ADHD interacted on the hike. We know that the elementary-age group has a passion for learning that can diminish in older students. ${ }^{40,41}$ Thus, it is imperative that these students are given an opportunity to maintain their enthusiasm for science. One way students have engaged in learning science through the years is through nature education. However, recent studies suggest that children do not spend enough time studying, exploring and engaging in nature although essential to their overall development. ${ }^{e . g}$, 23 Thus, we hoped that through the opportunities proved with the OUTSIDE programming, our students would demonstrate content gains and constant engagement in hike activities.

Informal experiences afford better opportunities for learning environmental science than traditional classrooms due to the firsthand interactions with nature $22,42,43$ particularly for students with ADHD. ${ }^{44}$ For example, one of the accommodations suggested for students with ADHD is to encourage them to go outside. In our study, learning takes place in an outdoor setting that should be more suited for students with ADHD. Even when a teacher incorporates active learning in the classroom, immersion within the content is not always possible, particularly with nature. Through OUTSIDE, students who tended to struggle with focusing in a traditional classroom demonstrated constant engagement while on a nature hike. Both students we observed actively participated, were able to recall organisms they had seen, and offered positive feedback about the experience over a month after the hike. This response was consistent with engagement by students that did not have an ADHD diagnosis. ${ }^{37}$ Have found such a response is promising for the field given that our case study participants were able to take part in a learning 
environment in a similar manner as other students. Furthermore, we found that our ADHD students learning gains were consistent with those found in other students. We would have liked to have been able to continuously measure learning gains over multiple semesters, but retention issues made this problematic. As such, we would encourage further studies to explore this facet of research. The evidence from our study still supports the notion that educators should include more hands-on, out-of-class, experiential learning opportunities for students.

When compared to conventional settings, an informal learning environment creates greater interest and helps students build a positive attitude towards science. ${ }^{45}$ One way to promote and continue engagement is through the use of technology. When informal learning environments incorporate technological aspects, there is increased engagement and retention of learning. ${ }^{46,47,48}$ The use of tablet technology in OUTSIDE provided ADHD students with a means of capturing ideas about their experiences in real time: photo evidence, written descriptions, and video/audio recordings of their experiences. This finding is pertinent to the field as past work has only looked at the role of iPads apps in managing ADHD ${ }^{34}$ and improving reading comprehension through games. ${ }^{35}$ In traditional classroom settings, students with ADHD tend to fall behind and recall less information when prompted later.e.g., 6 Through our experiential, multimodal approach, we found that students' long-term recall ability was consistent across all 84 student participants.

While we are making progress on understanding how students, particularly those with ADHD, learn about the environment in informal settings, there is still much to be understood. We need to further examine learning gains at a larger scale. Additionally, it would be useful to explore if we can leverage the use of mobile technology within conventional settings to mimic the impacts of outdoor environmental experiences. It is also essential to explore how teachers may be able to apply the techniques of informal experiences in traditional outdoor classrooms.

\section{ACKNOWLEDGEMENTS}

We thank Marks McWhorter, Carrie Jo Boyce, Dr. Mike Davis, David Reider, Dr. Julie Cwikla, Dr. Brian Gearity, our advisory board, other OUTSIDE volunteers and the Daniel Research Lab for all of their support. This material is based upon work supported by the National Science Foundation under Grant No. (\#1224051).

\section{REFERENCES}

1. Wrońska, N., Garcia-Zapirain, B., and Mendez-Zorrilla, A. (2015). An iPad-Based Tool for Improving the Skills of Children with Attention Deficit Disorder, I J Env Rch and Public Health, 12, 6261-6280.

2. American Psychiatric Association (2013) Diagnostic and Statistical Manual of Mental Disorders, 5th ed.: DSM-5. American Psychiatric Association, Washington.

3. Goepel, J. (2009) Constructing the individual education plan: Confusion or collaboration? Brit J Special Educ 24, 126-132. doi: 10.1111/j.1467-9604.2009.01412.x

4. Grumbine, R., and Alden, P. B. (2006) Teaching science to students with learning disabilities, Sci Teach 73, 26-31.

5. Brock, S. E., and Knapp, P. K. (1996) Reading comprehension abilities of children with attention-deficit/hyperactivity disorder, J Attention Disord 1, 173-185. doi: 10.1177/108705479600100305

6. Biederman, J., Monuteaux, M. C., Doyle, A. E., Seidman, L. J., Wilens, T. E., Ferrero, F., Morgan, C. L., and Faraone, S. V. (2004) Impact of executive function deficits and attention-deficit/hyperactivity disorder (ADHD) on academic outcomes in children, J Consult Clin Psych 71, 757-766. doi: 10.1037/0022-006X.72.5.757

7. Mrug, S., Hoza, B., and Gerdes, A.C. (2001) Children with attention-deficit/hyperactivity disorder: Peer relationships and peeroriented interventions, New Dir Child \& Adol Dev 91, 51-78. doi: 10.1002/cd.5

8. Minskoff, E., and Allsopp., D. (2003) Academic Success Strategies for Adolescents with Learning Disabilities and ADHD. Brookes Publishing, Baltimore, MD.

9. Lam, P., Doverspike, D., Zhao, J., Zhe, J., and Menzemer, C. (2008) An evaluation of a STEM program for middle school students on learning disability related IEPs, J STEM Educ 9, 21-29.

10. Reid, R. (1999) Attention deficit hyperactivity disorder: Effective methods for the classroom, Focus on exceptional children 32, 1.

11. Wolery, M. (1997) Instructional methods with students who have significant disabilities, J Spec Educ 31, 61-79. doi: $10.1177 / 002246699703100106$

12. Allen, K., Varner, K., and Sallee, J. (2011) Addressing nature deficit disorder through primitive camping experiences, J Extension 49, n3.

13. Beyer, K. M., Heller, E. F., Bizub, J. M., Kistner, A. J., Szabo, A., Shawgo, E. E., and Zetts, C. J. (2015) More than a pretty place: Assessing the impact of environmental education on children's knowledge and attitudes about outdoor play in nature, $I J$ Env Rch and Public Health 12, 2054-2070.

14. Kuo, F., and Taylor, A. F. (2004) A potential natural treatment for Attention-Deficit/Hyperactivity Disorder: Evidence from a national study, Am J Public Health 94, 1580-1586. 
15. Taylor, A. F., and Kuo, F. E. (2009) Children with attention deficits concentration better after walk in the park, $J$ Attention Disorders 12, 402-409. doi: 10.1177/1087054708323000

16. Taylor, A. F., and Kuo, F. E. M. (2011) Could exposure to everyday green spaces help treat ADHD? Evidence from children's play settings, Applied Psy: Health and Well-Being 3, 281-303.

17. Van den Berg, A. E., and Van den Berg, C. G. (2011) A comparison of children with ADHD in a natural and built setting, Child: Care, Health, and Development 37, 430-439.

18. Wells, N. M. (2014) The role of nature in children's resilience: Cognitive and social processes, in Greening in the Red Zone (95109). Springer, Dordrecht, Netherlands.

19. Kolb, D. A. (1984) Experiential Learning: Experience as the Source of Learning and Development. Prentice Hall, Englewood Cliffs, NJ.

20. Bruner, J. (1960) The Process of Education. Harvard University Press, Cambridge, MA.

21. Deci, E. L., and Ryan, R. M. (1982) Intrinsic motivation to teach: Possibilities and obstacles in our colleges and universities, New Dir Teach Learn 10, 27-35. doi: 10.1002/tl.37219821005

22. Henderson, T., and Atencio, D. (2007) Integration of play, learning, and experience: what museums afford young visitors, Ear Child Educ J 35, 245-251. doi: 10.1007/s10643-007-0208-1

23. Louv, R. (2005) Last Child in the Woods: Saving our Children from the Nature-Deficit Disorder. Algonquin Books, Chapel Hill, NC.

24. Roberts, D., and Foehr, U. (2004) Kids and Media in America. University Press, Cambridge.

25. Weiss, M. D., Baer, S., Allan, B. A., Saran, K., and Schibuk, H. (2011) The screens culture: Impact on ADHD. ADHD Attention Deficit and Hyperactivity Disorders 3, 327-334.

26. Lawrence, V., Houghton, S., Tannock, R., Douglas, G., Durkin, K., and Whiting, K. (2002). ADHD outside the laboratory: Boys' executive function performance on tasks in videogame play and on a visit to the zoo, J Abnormal Child Psy 30, 447-462. doi: 10.1023/A:1019812829706

27. Driessnack, M. (2009) Children and nature-deficit disorder. J Specialists in Pediatric Nursing 14, 73-75.

28. Mayhew, L. M., and Finkelstein, N. D. (2009) Learning to communicate about science in everyday language through informal science education, AIP Conf Proc 1179, 205-208. doi:10.1063/1.3266716

29. Nadelson, L., and Jordan, J. (2012) Student attitudes toward and recall of outside day: An environmental science field trip, J Educ Res 105, 220-231. doi: 10.1080/00220671.2011.576715

30. Bartley, J. E., Mayhew, L. M., and Finkelstein, N. D. (2009) Promoting children's understanding and interest in science through informal education, Phys Educ Res Conf 1179, 93-96.

31. Wulf, R., Mayhew, L. M., and Finkelstein, N. D. (2009) Impact of informal science education on children's attitudes about science, AIP Conf Proc 1179, 93-96. doi: 10.1063/1.3515238

32. Drake, N., Fletcher, L., Tabb, W., Smith, W., Forsythe, C., Sutton, S., and Bryant, K. (2014, January). The iPad as instructional tool: An examination of Jackson State University faculty implementation experience, in $N A A A S$ Conference Proceedings (p. 289). National Association of African American Studies.

33. Omiteru, E. (2012, June) Using iPad apps to enhance teaching and learning, in World Conference on Educational Multimedia, Hypermedia and Telecommunications (Vol. 2012, No. 1, 736-740).

34. Kumaragama, K., and Dasanayake, P. (2015) iOS Applications (apps) for Attention Deficit Hyperactivity Disorder (ADHD/ADD): A preliminary investigation from Australia, J Mobile Tech in Med, 4(2), 33-39.

35. Wasniewski, E. (2013, March) One-on-one with an iPad: A faculty perspective on iPad supports for students with disabilities, in Society for Information Technology \& Teacher Education International Conference (Vol. 2013, No. 1, pp. 4346-4351).

36. Over, Under, and Through: Students' Informally Discover the Environment, http:// www.usm.edu/get-outside (accessed Aug 2014)

37. Boyce, C. J., Mishra, C., Halverson, K. L., and Thomas, A. K. (2014) Getting students outside: Using technology as a way to stimulate engagement, J Sci Educ Technol 23, 815-826. doi: 10.1007/s10956-014-9514-8

38. Next Generation Science Standards: 5-ESS3 Earth and Human Activity, http://www.nextgenscience.org/5ess3-earth-buman-activity (accessed Nov 2014)

39. Patton, M.Q. (2002) Qualitative Research \& Evaluation Methods. Sage, Thousand Oaks, CA.

40. McPhail, J.C., Pierson, J.M., Freeman, J.G., Goodman, J., and Ayappa, A. (2000) The role of interest in fostering sixth grade students' identities as competent learners, Curriculum Inq 30, 43-70.

41. Harvard Family Research Project: Findings from HFRP's study of predictors of participation in out-of-school time activities Fact sheet, http:/ / wmw. hfrp.org/publications-resources/browse-our-publications/findings-from-hfrp-s-study-or-predictors-of-participation-in-out-ofschool-time-activities-fact-sheet (accessed Oct 2014)

42. Speaker, K. M. (2001) Interactive exhibits theory: Hints for implementing learner-centered activities in elementary classrooms, Educ 121, 610-614.

43. Falk, J. H., and Diekring, L. D. (2010) The 95 percent solution: School is not where most Americans learn most of their science, Am Sci 98, 386-493.

44. Ames, C. (2013) My learning curve on learning disabilities, Liberal Educ 99, 56-60. 
45. National Research Council (2009) Learning Science in Informal Environments: People, Places, and Pursuits. The National Academics Press, Washington, D.C.

46. Clough, G., Jones, A.C., McAndrew, P., and Scanlon, E. (2008) Informal learning with PDAs and smartphones, J Comput Assist Lear 24, 359-371. doi: 10.1111/j.1365-2729.2007.00268.x

47. Sung, Y.-T., Chang, K.-E., Lee, Y.-H., and Yu, W.-C. (2008) Effects of a mobile electronic guidebook on visitors' attention and visiting behaviors, Educ Technol Soc 11, 67-80.

48. Woodruff, A., Aoki, P.M., Hurst, A., and Szymanski, M.H. (2001) Electronic guidebooks and visitor attention, Proc Int Conf Cult Heritage Technol.

\section{ABOUT THE STUDENT AUTHOR}

Ashleigh Davis Moore received her B.S. in Psychology, minor in Biological Sciences at the University of Southern Mississippi in 2014 where she completed this research as part of her honors thesis under the direction of Kristy L. Daniel, Ph.D. Through working with programs such as OUTSIDE, her desire to discover how students learn science was strengthened, and she has plans to further her education and implement new strategies and programs for science education in school systems.

\section{PRESS SUMMARY}

Attention disorders can make learning difficult for students and cause frustration. We brought students out of the classroom to learn science on a nature hike. We found evidence that using tablet technology in this outdoor setting increased students' attention and improved interest in learning science. 


\title{
Evaluation of Antiulcer Activity of Laghusoothshekhar (an Ayurvedic Formula) in Pyloric Ligature Induced Gastric Ulcers in Albino Rats
}

\author{
Nilofer Sayed*, Vandana Barve \\ Department of Pharmaceutical Sciences, P.R.E.S College of Pharmacy, Nashik, Maharashtra, India \\ Student:syeda_g@rediffmail.com* \\ Mentor:vandanabarve26@gmail.com
}

\begin{abstract}
Laghusoothshekhar is an ayurvedic formula widely used for gastritis and peptic ulcers that has been described in various ayurvedic texts such as Bharat Bhaishajya Ratnakar, Ayurved saar sangraha and Nav sambita with slight variations in their ingredients. Marketed formulas from the first two references are available but the study of this formula from nav sambita is not yet carried out nor is it available commercially. It is a simple formula of few ingredients and is widely prepared and used by ayurvedic practitioners for treating gastritis (both acute and chronic) and peptic ulcers. Hence, efforts were taken to evaluate its antiulcer activity. Four groups comprising of six animals each were studied. Control Group: vehicle ( $2 \% \mathrm{w} / \mathrm{v}$ gum acacia), Group A: $(50 \mathrm{mg} / \mathrm{kg})$, Group B: (100 mg/kg), Group C: ranitidine (25 mg/kg). One hour after the last dose, pyloric ligation was done and animals were deprived of food and water for 4 hours, thereafter sacrificed and the number of ulcers and their severity was calculated. Both the doses of Laghusoothshekhar showed significant anti-ulcer activity and the histopathological findings of the gastric tissues confirmed the same. The results proved that the drug is as efficient as the standard drug ranitidine used in the treatment of gastritis and peptic ulcers. Ranitidine inhibits acid production by reversibly blocking $\mathrm{H}_{2}$ receptors on the basolateral membrane of parietal cells in the stomach.
\end{abstract}

\section{KEYWORDS}

Laghusoothshekhar; Pyloric Ligation; Ranitidine; Nav Sambita; Ayurveda; Amlapitta; Peptic Ulcers; Gastritis; Naagvel Patra; Ginger; Suvarna Gairik

\section{INTRODUCTION}

Gastritis is simply defined as inflammation of the stomach lining; it may be acute or chronic in nature leading to formation of peptic ulcers. With the present lifestyle changes, improper working conditions, improper eating habits, smoking, alcohol, emotional stress, over consumption of caffeine, over consumption and long term use of aspirin and other non-steroidal antiinflammatory drugs (NSAIDs), Helicobacter pylori infection; all these reasons have made gastritis as common as cold or flu. The current medicinal treatment of gastritis and gastritis induced peptic ulcer is generally based on triple therapy regimen inhibition of gastric acid secretion by histamine $\mathrm{H}_{2}$ antagonists, Proton pump inhibitors as well as mucosal protective therapy provided by sucralfate and bismuth along with use of antibiotics for $H$. pylori. These therapies are costly along with its numerous side effects such as a headache, bowel upset, dry mouth, rashes, elevation of liver enzymes seen in $\mathrm{H}_{2}$ antagonists and achlorhydria and hypergastrinemia seen due to prolonged use of proton pump inhibitors. ${ }^{1}$ The problem of antibiotic resistance in the treatment of $H$. pylori infection is also a major concern these days. Hence need arises for safer and efficient drugs which are easy to manufacture and cost effective. Hence, herbal and herbo-mineral formulas stand a good alternative in the present scenario.

Laghusoothshekhar a well-known formula for pitta dosh and amlapitta, ${ }^{2}$ which can be correlated with gastritis has been described in many ayurvedic texts such as Bharat Bhaishajya Ratnakar, Ayurved Saar Sangraha and Nav Sambita with slight variations in their ingredients of these the former two are manufactured and marketed by pharmaceutical companies but no marketed samples are available from the reference mentioned in Nav Sambita even though it is simple to prepare and widely used by Ayurvedic practitioners. Hence, the present study is undertaken to evaluate the efficacy of this formula with regards to its anti-ulcer activity.

This formula consists of three major ingredients, dry ginger powder; fresh juice of betel leaves (Piper betle) called Naagvel patra in Sanskrit and purified yellow ochre called suvarna gairik in Sanskrit. It has been reported that ginger has shown its efficacy in gastritis and peptic ulcer in many ways. It has found to have in vitro activity against H. Pylori, ${ }^{3}$ a potent inhibitor of protonpotassium ATPase activity, ${ }^{4}$ thus proves to have a multi-step approach in treating gastritis and peptic ulcers. It also enhances gastric emptying. ${ }^{5}$ 
It also has anti 5-HT inhibitor activity, ${ }^{6,7}$ thus proving to have a good antiemetic activity which helps in alleviating one of the major symptoms of gastritis. ${ }^{8}$ In a recent study done on betel leaves, it was seen that its hot water extract increased the mucus content adhering to the wall of gastric mucosa thereby having a gastro protective action over the gastric mucosal layer. It also possesses anti-ulcer activity by inhibiting free radical induced chain reaction in the process of ulcer formation. ${ }^{9}$ Yellow ochre, an oxide of iron, is known to be effective against various bleeding disorders, vomiting, disorders due to poison ingestion, antiemetic activity, burning sensation and diseases of the abdomen. ${ }^{10}$ Hence, the anti-ulcer activity of Laghusoothshekhar which is a combination of the above mentioned ingredients was studied in pyloric ligature induced gastric ulcers in albino rats.

\section{MATERIALS AND METHODS}

\section{Procurement of test drugs}

Laghusoothshekhar as per Nav Sambita indicates the presence of three components, dried ginger powder, purified yellow ochre and fresh betel leaves. Dried ginger powder and yellow ochre was provided by the in-house dispensing stores of Ayurved Mahavidyalaya and Fresh betel leaves were taken from the botanical garden of Ayurved Mahavidyalaya, Sion which was authenticated by Dr. Sudha Asthana, MSc, Ph.D. (Botany), Department of Botany at S.I.E.S College of Arts, Science and Commerce, Sion.

\section{Formulation of the drug}

The drug was formulated at Sion Ayurved Mahavidyalaya as per the procedure mentioned in the ayurvedic text Nav Sambita with certain modifications done as per the present requirements. Yellow ochre and ginger powder was sterilized in hot air over at $160^{\circ} \mathrm{C}$ for two hours. Yellow ochre was purified by mixing and grinding it in cow's milk using the mortar and pestle till it acquired a paste like consistency, then the mixture was placed in the refrigerator at $4^{\circ} \mathrm{C}$ for drying. Cow's milk was again added to the dried mixture and ground, this cycle was repeated thrice. Next day equal quantities of this dried purified yellow ochre and ginger powder was taken and soaked in fresh juice of betel leaves. This mixture was mixed and ground till it acquired a pasty consistency. The mixture was then placed in a refrigerator and kept overnight, next day the dried mixture was again submerged in the juice of fresh betel leaves and ground, this procedure was repeated five times. The process of mixing and grinding solid particles with a liquid component is called Bhavana in Ayurveda. The amount of liquid component should be sufficient enough to submerge all the powder ingredients. ${ }^{11}$ The dried powder was then suspended in purified water using $2 \%$ gum acacia as suspending agent thus making it convenient to administer the formula to the experimental rodents.

\section{Experimental site}

The antiulcer study carried out at Pharmacology laboratory of P.R.E.S College of Pharmacy, Chincholi, Nashik. The experiments were performed after approval from institutional animal ethics committee CPCSEA Registration No: 1345/a/10/CPCSEA.

\section{Experimental Animals}

Sprague Dawley rats (200-250 g) were used for the present study. Each rat was placed in a separate cage with wide mesh wire bottoms to prevent coprophagia during the experiment. They were maintained under standard environmental conditions (temperature $23 \pm 2^{\circ} \mathrm{C}$, relative humidity $55 \pm 10 \%$ and 12 hours light dark cycle) and were fed with standard pellet diet and water ad libitum. ${ }^{12,13}$

\section{Dose Fixation}

The human dose of Laghusoothshekhar is $500 \mathrm{mg}-1000 \mathrm{mg} /$ day. The dose for the experimental study was calculated by converting the human dose to animal dose based on the body surface area ratio using the table of Paget and Barnes. ${ }^{14}$ i.e. [Adult dose $\times 0.018] \times 5$.

Animal grouping

Thus, 24 rats were kept in four groups comprising of six animals each.

Control: Received vehicle i.e. $2 \% \mathrm{w} / \mathrm{v}$ gum acacia for a period of 5 days twice a day

Group A: Received the drug in dose $50 \mathrm{mg} / \mathrm{kg}$ twice a day for a period of 5 days

Group B: Received the drug in dose $100 \mathrm{mg} / \mathrm{kg}$ twice a day for a period of 5 days

Group C: Received Ranitidine (standard drug) $25 \mathrm{mg} / \mathrm{kg}$ twice a day for period of 5 days

Gastric ulcer induction in the rats

Shay's pyloric technique was used to induce gastric ulcers in rats. The drug (Laghusoothshekhar) and ranitidine were suspended in the vehicle and after 24 hours of fasting the drug was administered via the oral route twice a day for five days. One hour after the last dose, pyloric ligation was done in all the rats under general anesthesia (ether) and the animals were deprived of food and water for four hours. ${ }^{15}$

After four hours all rats were sacrificed using cervical dislocation technique. Stomach was removed after tying the lower oesophageal end and the pyloric end of the stomach. Then the stomach was incised along the greater curvature and rinsed 
with $2 \mathrm{~mL}$ distilled water. After rinsing, the entire stomach was stretched on a frog board and with the help of magnifying glass the number and degree of ulceration were noted and the ulcer index, $\%$ protection was calculated. Ulcers were mostly seen near the pyloric end and the lower part of gastric fundus. The entire stomach was then placed in bottles containing $10 \%$ formalin and sent to the histopathology department, where the sections were taken mainly from the lower portion of the gastric fundus and the pyloric end of the stomach, slides were prepared and the reporting was done at the pathology department of Holy Family Hospital, Bandra.

Assessment of stomach ulcer

The severity of ulcer and the total number of ulcer in each rat was recorded for calculating ulcer index. Ulcer index was calculated as follows: ${ }^{16}$

0-No visible ulcer

0.5-Red colouration

1-Superficial ulcers

1.5-Haemorrhagic streak

2-Deep ulcers

3-Perforation of gastric wall

Calculation of ulcer index:

$$
\mathbf{U I}=\mathbf{U N}+\mathrm{US}+\mathrm{UP} \times 10^{-1}
$$

where $\quad$ UI $=$ Ulcer index

$$
\begin{aligned}
& \mathrm{UN}=\text { Average of number of ulcer per animal } \\
& \mathrm{US}=\text { Average of severity score } \\
& \mathrm{UP}=\text { Percentage of animal with ulcer }
\end{aligned}
$$

and percentage protection was calculated by using the formula:

\section{$\%$ Protection $=\underline{\text { Ulcer Index }(\text { control })-\text { Ulcer Index (test) }}$ Ulcer Index (control)}

Histopathological Studies

For the histopathological study, the incised stomach was washed with distilled water and placed in 10\% formalin solution prior to dehydrating, wax embedding, sections were taken mainly from the lower portion of gastric fundus and the pyloric end of the stomach, staining was done with haematoxylin and eosin. Histological evaluation of the gastric damage was done using light microscopy under 10x and 50x magnifications.

\section{RESULTS AND DISCUSSIONS}

Gastritis is inflammation of the stomach lining which at a chronic stage leads to the formation of peptic ulcers. Laghusoothshekhar, the formula taken from nav samhita is widely used by many Ayurveda practitioners but no documented evidence is available, hence, this study was carried out. Pyloric ligature method was used to induce ulcers in the rats. Pyloric ligation causes accumulation of gastric juice and hindrance of gastric blood circulation which leads to damage of gastric tissue lining and ulcer formation. It was found that pyloric ligation produced expected lesions in the control group and in animals of pre-treated groups ulcer score was significantly reduced. The percentage protection and ulcer index of animals in group B which received $100 \mathrm{mg} / \mathrm{kg} /$ day of the drug Laghusoothshekhar showed effects similar to ranitidine which is a standard drug used in the treatment of gastritis. The histopathology studies also supported the results. It has been reported that each of the ingredients used in this formula individually helps in the treatment of gastritis. ${ }^{3-10}$ Hence it can be concluded that the antiulcer activity of Laghusoothshekhar is a synergistic action of all the ingredients; moreover, the unique method of its preparation plays an important role in enhancing its activity. Yellow ochre is chemically $\mathrm{Fe}_{2} \mathrm{O}_{3}$. Iron is a transition element; these elements are known for its good adsorption properties and tendency to form interstitial compounds. Small atoms of non-metallic elements such as carbon, hydrogen, nitrogen get trapped in the vacant spaces of lattices of the transition metal atoms. ${ }^{18}$ Thus, during the process of mixing and grinding yellow ochre with the juice of betel leaves, there is every possibility that the active components of the juice interacts with iron leading to a more stable and effective combination of these ingredients. Although 
more research needs to be done to ascertain the interactions between various ingredients that take place during the preparation of an Ayurveda formula. During the entire period that the drug was administered animals did not show any toxic signs such as weight loss or loss of hair. Detailed study can be conducted related to its toxicity. Other parameters, such as the mucus content and $\mathrm{pH}$, can be evaluated which will provide more complete information of Laghusoothshekhar.

\section{Control: Vebicle $(2 \% \mathrm{w} / \mathrm{v}$ gum acacia)}
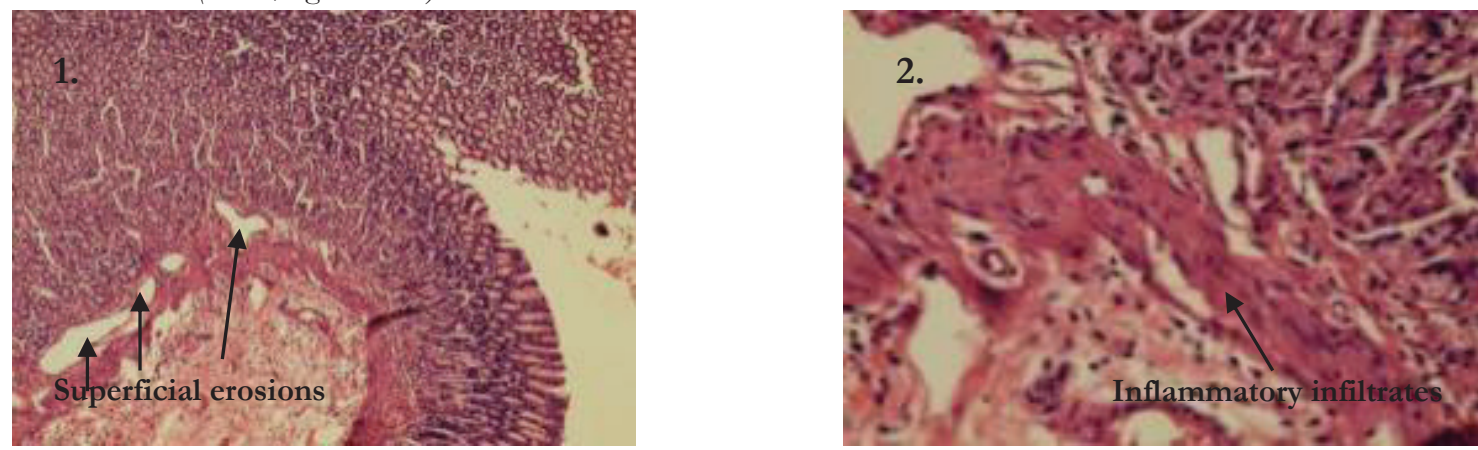

Figure $1 \& 2$. Photomicrograph showing surface erosions in gastric tissue with moderate inflammatory infiltrates in mucosal epithelium and very mild infiltrate in deeper coats
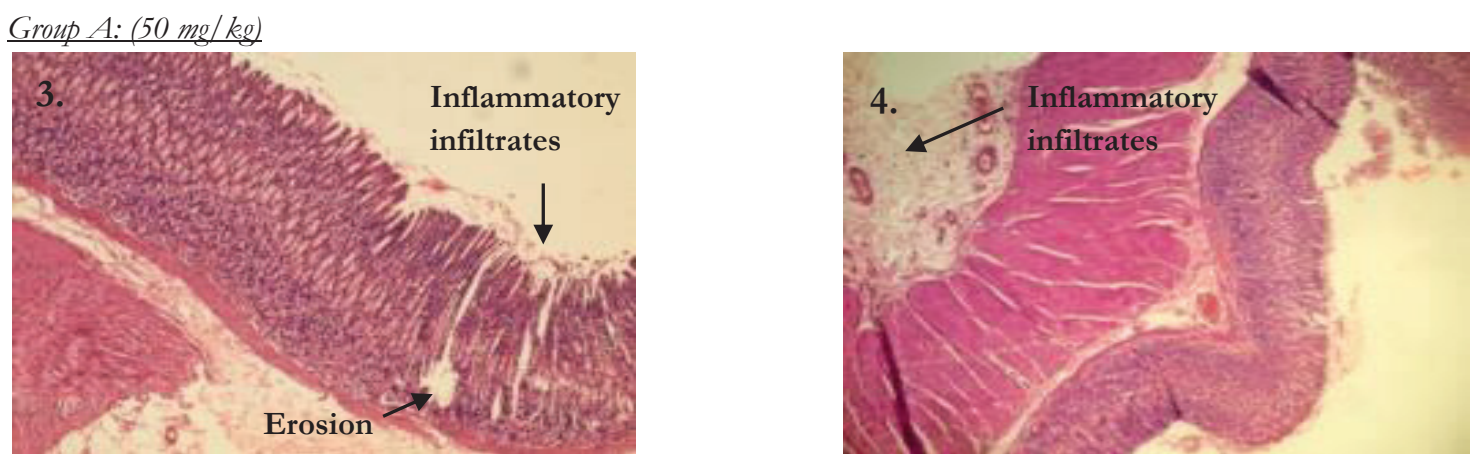

Figure $3 \& 4$. Photomicrograph of gastric tissue showing mild surface erosions
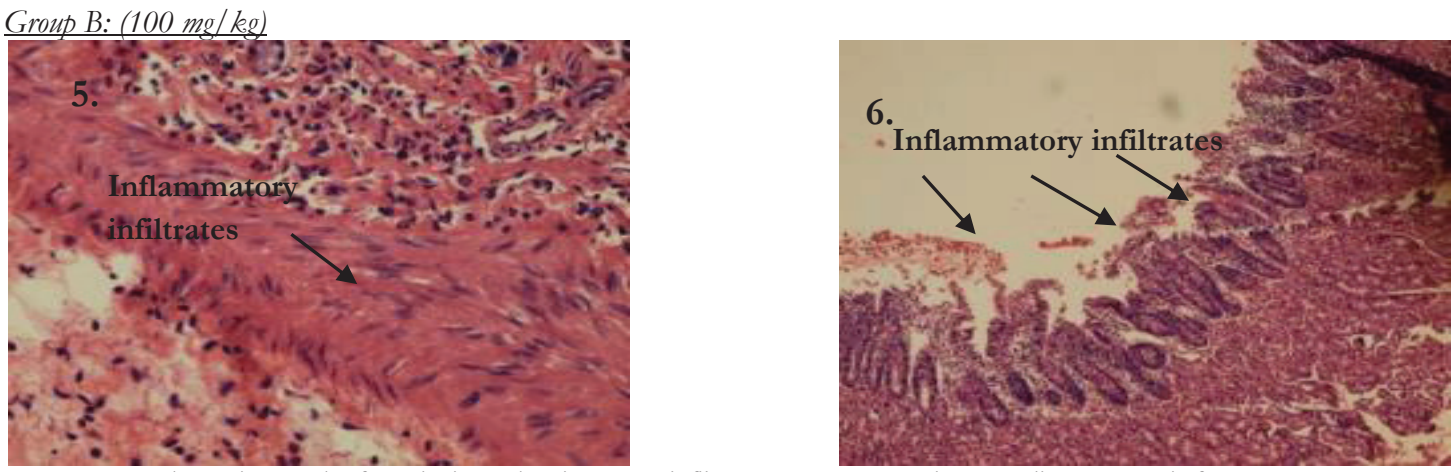

Figure $5 \&$ 6. Photomicrograph of gastric tissue showing sparse infiltrates up to serosa and surrounding mesenteric fat

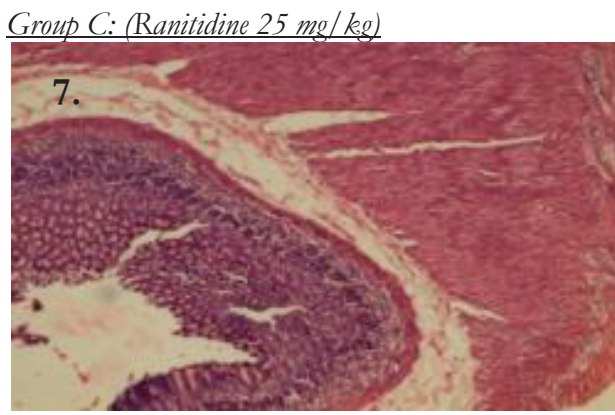

Figure 7. Photomicrograph of gastric tissue showing no ulcer, sparse infiltration 
STATISTICAL ANALYSIS

All values were reported as Mean \pm SD. The statistical significance of differences between groups was assessed by ANOVA, followed by student t-test. A probability value of ${ }^{*} \mathrm{p}<0.001$ was considered to be statistically significant.

\begin{tabular}{|c|c|c|c|c|c|}
\hline GROUPS & DOSE & $\begin{array}{c}\text { AVERAGE } \\
\text { NUMBER OF } \\
\text { ULCERS }\end{array}$ & $\begin{array}{c}\text { AVERAGE OF } \\
\text { SEVERITY SCORE }\end{array}$ & $\begin{array}{c}\text { ULCER INDEX } \\
\text { Mean } \pm \text { SD }\end{array}$ & PROTECTION \\
\hline $\begin{array}{c}\text { Control } \\
\text { (Vehicle } \% \text { gum acacia) }\end{array}$ & 7.5 & 18.33 & $* 18.33 \pm 1.67$ & 31.79 \\
\hline Group A & $50 \mathrm{mg} / \mathrm{kg} / \mathrm{day}$ & 1.16 & 1.33 & ${ }^{*} 1.33 \pm 0.33$ & 72.73 \\
\hline Group B & $100 \mathrm{mg} / \mathrm{kg} / \mathrm{day}$ & 0.5 & 0.5 & ${ }^{*} 0.50 \pm 0.34$ & 73.05 \\
\hline $\begin{array}{c}\text { Group C } \\
\text { (Ranitidine) }\end{array}$ & $25 \mathrm{mg} / \mathrm{kg} / \mathrm{day}$ & 0.33 & 0.33 & $* .33 \pm 0.21$ & \\
\hline
\end{tabular}

Table 1. Effect of Laghusoothshekhar on pyloric ligature induced gastric ulcers in albino rats

\section{CONCLUSION}

Laghusoothshekhar an ayurvedic formula for gastritis is a cost effective and holistic solution in the treatment of gastritis and peptic ulcers. The findings obtained proved the conventional indications of the drug and contributed to their antiulcer pharmacological validation leading to more credibility of its clinical applications.

\section{ACKNOWLEDGEMENT}

The authors thank the principal of Sion Ayurved Mahavidyalaya, Sion, Mumbai for providing fresh betel leaves and facility to prepare the formulation, also thank the Botany Department of SIES College of Arts, Science and Commerce, Sion, Mumbai for authenticating the betel leaves and ginger. We thank Dr. Jude Vaz HOD Pathology department of Holy Family Hospital, Bandra, Mumbai and Dr. Ketki Shah, Nanavati Hospital, Vile Parle, Mumbai for the reporting and photography of the histopathological slides of the gastric tissues provided.

\section{REFERENCES}

1. Tripathi, K.D. (1999) Essentials of Medical Pharmacology, drugs on peptic ulcers, $6^{\text {th }}$ ed., 628-642, Jaypee brothers, Medical publishers Pvt. Ltd., New Delhi.

2. N.L. Dashputre, Naikwade, N.S. (2011) Evaluation of antiulcer activity of methanolic extract of Abutilon indicum Linn leaves in experimental rats, Int. J. Pharma. Sci. Drug Res. 3(2), 97-100.

3. Mahady, G., Pendland, S., Yun, G., Lu, Z. and Stoia, A. (2003) Ginger (Zingiber officinale Roscoe) and the gingerols inhibit the growth of Cag A+ strains of Helicobacter pylori. Anticancer Res. 23, 3699-3702.

4. Siddaraju, M. N. and Dharmesh, S. M. (2007) Inhibition of gastric $\mathrm{H}^{+}, \mathrm{K}^{+}$-ATPase and Helicobacter pylori growth by phenolic antioxidants of Zingiber officinale. Mol. Nutr. Food Res. 51, 324-332.

5. Yamahara, J., Huang, Q., Li, Y., Xu, L. and Fujimura, H. (1990) Gastrointestinal motility enhancing effect of ginger and its active constituents. Chem Pharm Bull (Tokyo). 38(2), 430-431.

6. Yamahara, J., Rong, H., Iwamoto, M., Kobayashi, G., Matsuda, H. and Fujimura, H. (1989) Active components of ginger exhibiting antiserotinergic action. Phytotherapy. Res. 3, 70-71.

7. Huang, Q., Iwamoto, M., Aoki, S., Tanaka, N., Tajima, K., Yamahara, J., Takaishi, Y., Yoshida, M., Tomimatsu, T. and Tamai, Y. (1991) Anti-5-hydroxytryptamine 3 effect of galanolactone, diterpenoid isolated from ginger. Chem. Pharm. Bull. (Tokyo). 39, 397-399.

8. Ali, B., Blunden, G., Nemmar, A. (2008) Some phytochemical, pharmacological \& toxicological properties of ginger (Zingiber officinale Roscoe) a review of recent research, Food \& chemical toxicology, 46(2), 409-420.

9. Periyanayagam, K., Jagadeesan, M., Kavimani, S., Vetriselvan, T. (2012) Pharmacognostical \& phytophysiochemical profile of leaves of piper betel L.var Pachaikodi (piperaceae) - valuable assessment of its quality, Asian Pac J Trop Biomed. 2(2), 5065510 .

10. Jha, C. (2007) Ayurvediya ras shastra (A textbook of Rasashastra), Maharasa uprasa sadharan rasa-gairik, $2^{\text {nd }}$ edition, 249-250, Chaukmbha Surbharti Prakashan, Varanasi.

11. Gune, V.G.G. (2008) Ayurvediya Aushadhigundharmashastra, Vaidyagranth Bhandar Press, Pune, 447.

12. Bongo, S., Vijayakumar, S. (2012) Animal models in experimental gastric ulcer screening: a review, International journal of pharmacological screening, 2(2), 82-87.

13. Kulkarni, S.K., (1999) To study the antisecretory \& ulcer protective effect of cimetidine in pylorus ligated rats, Handbook of experimental pharmacology, $3^{\text {rd }}$ edition, Vallabh prakashan, Delhi, 148-150.

14. Paget, G.E., Berns, J.M., Lawranle, D.R., Bacharch, A.L. (1969) Evaluation of Drug Activities: Pharmacometrics, Vol. 1. New York: Academic Press. 
15. Shay, H., Komarov, S.A., Fels, S.E., Meraze, D., Gruenstein, M., Siplet, H.A. (1945) Simple method for the uniform production of gastric ulceration in rat, Gastroenterology, 5, 43-61.

16. Tammu, J., Venkataraman, K., Thallu, S. (2013), Antiulcer activity of methanolic extract of Physalis minima leaves, Int. J. PharmaTech Res. 337-340.

17. Nair, V., Arjuman, A., Gopalakrishna, H.N., Dorababu, P., Mirshad, P.V., Bhargavan, D., Chatterji, D. (2010) Evaluation of the antiulcer activity of NR-ANX-C (polyherbal formulation) in aspirin \& pyloric ligature induced gastric ulcers in albino rats, India J Med Res.132, 218-223

18. Jauhar, S.P. (2005) Modern's ABC of Chemistry, $d$ and f block elements, $9^{\text {th }}$ edition, 528-586, Modern publishers Pvt. Ltd, New Delhi.

\section{ABOUT THE STUDENT AUTHOR}

Nilofer Sayed is a final year undergraduate student in Pharmaceutical sciences (B. Pharm) and has done her Bachelors in Ayurved medicine \& surgery. Her interest lies in the discovery of new lead molecules and targets in the field of drug discovery and development.

\section{PRESS SUMMARY}

Laghusoothshekhar, an ayurvedic formulation comprising of dried ginger powder, purified yellow ochre and juice of betel leaves used by practitioners for gastritis and peptic ulcers but no documented evidence available. Hence, the study was carried out by administering the drug to albino rats and inducing ulcers by pyloric ligation. Animals were deprived of food and water for four hours thereafter sacrificed and the number of ulcers and their nature noted. The histological examinations of the gastric tissues were also performed. The effects of the formulation were as effective as ranitidine and the histological examinations supported the results. 


\title{
Using Statistical Approaches to Model Natural Disasters
}

\author{
Audrene S. Edwards, Kumer Pial Das, Ph.D. \\ Department of Mathematics, Lamar University, Beaumont, TX \\ Students: *audreneedwards@yaboo.com \\ Mentor: kumer.das@lamar.edu
}

\begin{abstract}
The study of extremes has attracted the attention of scientists, engineers, actuaries, policy makers, and statisticians for many years. Extreme value theory (EVT) deals with the extreme deviations from the median of probability distributions and is used to study rare but extreme events. EVT's main results characterize the distribution of the sample maximum or the distribution of values above a given threshold. In this study, EVT has been used to construct a model on the extreme and rare earthquakes that have happened in the United States from 1700 to 2011.The primary goal of fitting such a model is to estimate the amount of losses due to those extreme events and the probabilities of such events. Several diagnostic methods (for example, QQ plot and Mean Excess Plot) have been used to justify that the data set follows generalized Pareto distribution (GPD). Three estimation techniques have been employed to estimate parameters. The consistency and reliability of estimated parameters have been observed for different threshold values. The purpose of this study is manifold: first, we investigate whether the data set follows GPD, by using graphical interpretation and hypothesis testing. Second, we estimate GPD parameters using three different estimation techniques.Third, we compare consistency and reliability of estimated parameters for different threshold values.Last, we investigate the bias of estimated parameters using a simulation study. The result is particularly useful because it can be used in many applications (for example, disaster management, engineering design, insurance industry, hydrology, ocean engineering, and traffic management) with a minimal set of assumptions about the true underlying distribution of a data set.
\end{abstract}

\section{KEYWORDS}

Extreme Value Theory; QQ Plot; Mean Excess Plot; Mean Residual Plot; Peak Over Threshold; Generalized Pareto Distribution; Maximum Likelihood Method; Method of Moments; Probability-Weighted Moments; Shapiro-Wilk test; AndersonDarling Test

\section{INTRODUCTION}

Extreme Value Theory (EVT) can be used to analyze data that deviates from the median of probability distributions, and can be used as a tool for analyzing the risk for events that happen seldom, for example events such as the California earthquake of 1906, and Hurricane Katrina from 2005. Usually the earthquakes that occur in America are non catastrophic, resulting in minor damages, and even minor expenditures when it comes to restoring the city, or town that the earthquake happened in. But then there are earthquakes with higher than normal magnitudes that are catastrophic, resulting in major damage of the infrastructure within a city or town, as well as high expenditures to reconstruct its infrastructure. Catastrophic earthquakes rarely happen in comparison to non catastrophic earthquakes. Since earthquakes with high magnitudes happen seldom, analyzing or modeling these rare events presents a unique and important challenge. These events can be analyzed and modeled by EVT which provides tools to focus on extreme and rare events that occur. For this study, EVT will be used to focus on the extreme and rare earthquakes that have happened in the United States from 1700 to 2011.

In this paper, starting in Section 2, we will discuss two methods, namely, block maxima and peak over threshold (POT), which can be used to analyze a data set containing extreme values. Proceeding to Section 3, we will discuss definition, 
formulation and properties of three estimation techniques namely, maximum likelihood estimation (MLE) method, method of moments (MOM), and method of probability weighted moments (PWM). In Section 4, we describe the data set and use graphical procedure in modeling the right-hand tail. In Section 5, we compare GPD estimators obtained by three estimation techniques: MLE, MOM and PWM, as the threshold increases. In Section 6, we see if GPD fits into the data by performing the Anderson-Darling test. In Section 7, a simulation study has been conducted to examine bias and root mean square error (RMSE) for each estimator produced by the three techniques. Mis-specification bias has also been investigated in this section. And finally, conclusions appear in Section 8.

\section{EXTREME VALUE THEORY}

Extreme value analysis is a branch of statistics focusing attention on issues for modeling extreme values. ${ }^{1}$ It deals with the extreme deviations from the median of probability distributions and seeks to assess, from a given ordered sample, the probability of events that are more extreme than a certain large value. EVT states that the shape of the distribution below this certain large value is not important. From an actuarial point of view, the distributions of large losses are very important since the insurer (or re-insurer) makes a payment only when the loss exceeds a certain large value. There are two common approaches to analyze an extreme data set: the block maxima modeling technique, and the peak over threshold (POT) technique. While both are used for modeling extreme events, each has more specific uses, especially when deciding which model would be preferable to work with the data set.

\subsection{Block Maxima Method}

In block maxima modeling, the data is grouped into blocks of equal length and fit the data to the maximums of each block, for example, annual maximum of daily rainfall amounts. The block maxima approach is closely associated with the use of the generalized extreme value distribution. The choice of block size can be critical to the entire study as blocks that are too small can lead to bias and blocks that are too large generate too few block maxima. Moreover, it is very often more useful to analyze the values of random variables that exceed or fall below a given threshold value. For example, in this study, it would be better to have earthquake data that exceed a certain magnitude than to have data that consist of only yearly maximum over a period of $n$ years. Maxima in some years can be much below than several high-order statistics in other years. Thus, POT approach has been applied in this study.

\subsection{Peaks Over Threshold(POT) Method}

Let $Y_{1}, Y_{2}, \cdots, Y_{n}$ be a sequence of independent and identically distributed (iid) random variables with common distribution function $F(y)$.

To model the upper tail of $F(y)$, consider $k$ exceedances of $Y$ over a threshold $u$ and let $X_{1}, X_{2}, \cdots, X_{k}$ denote the excesses (or peaks). POT is used when taking these peak values that occurred during any period of time, from a continuous record. POT depends on the threshold $u$, and is defined by $X_{i}$, where

$$
X_{i}:=Y_{i}-u \mid Y_{i}>0
$$

Equation 1.

are the exceedances over $u$ for $i=1,2, \cdots, k$, which are asymptotically distributed and follow a GPD. ${ }^{2}$

\subsection{Generalized Pareto Distribution}

The cumulative distribution function (cdf) of GPD is defined as:

$$
F(x)= \begin{cases}1-\left(1-\frac{k x}{\alpha}\right)^{\frac{1}{k}} & \text { if } k \neq 0 \\ 1-\exp \left(\frac{-x}{\alpha}\right) & \text { if } k=0\end{cases}
$$

Equation 2.

where, the scale parameter, $\alpha>0$ and for the shape parameter $k \geq 0$ the support is $0 \leq x<\infty$ while for $k<0$ the support 
is $0 \leq x \leq-\alpha / k .^{3}$

The probability density function (pdf) of GPD is defined as:

$$
f(x)= \begin{cases}\frac{1}{\alpha}\left(1-\frac{k x}{\alpha}\right)^{\frac{1}{k}-1} & \text { if } k \neq 0, \alpha>0,\left(1-\frac{k x}{\alpha}\right) \geq 0 \\ \frac{1}{\alpha} \exp \left(\frac{-x}{\alpha}\right) & \text { if } k=0, \alpha>0, x \geq 0 .\end{cases}
$$

Equation 3.

There are three related distributions in the family of GPD. The distributions are: exponential, Pareto, and beta. GPD has popularly been used in analyzing extreme natural and man made events. ${ }^{4-6}$

\section{ESTIMATION TECHNIQUES TO FIND PARAMETERS}

\subsection{The Maximum Likelihood Method}

Let $X_{1}, X_{2}, \ldots, X_{n}$, be a random sample, that depends on one or more unknown parameters say, $\left(\theta_{1}, \theta_{2}, \ldots \theta_{m}\right)$. Assume that those unknown parameters $\left(\theta_{1}, \theta_{2}, \ldots \theta_{m}\right)$, are restricted to a given parameter space, $\Omega$. Then the joint probability mass function (p.m.f) of the random sample size $X_{1}, X_{2}, \ldots, X_{n}$, is called the likelihood function, such that

$$
L\left(\theta_{1}, \theta_{2}, \ldots \theta_{m}\right)=f\left(x_{1} ; \theta_{1}, \theta_{2}, \ldots \theta_{m}\right) f\left(x_{2} ; \theta_{1}, \theta_{2}, \ldots \theta_{m}\right) \ldots \ldots f\left(x_{n} ; \theta_{1}, \theta_{2}, \ldots \theta_{m}\right),
$$

Equation 4.

where $\theta_{1}, \theta_{2}, \ldots, \theta_{m} \in \Omega$, and is represented as

$$
L(\theta)=\prod_{i=1}^{n} f\left(x_{i} ; \theta_{n}\right)
$$

Equation 5.

when regarded as a function of $\theta_{1}, \theta_{2}, \ldots, \theta_{m}$.

Consider

$$
\left[u_{1}\left(X_{1}, X_{2}, \ldots X_{N}\right), u_{2}\left(X_{1}, X_{2}, \ldots X_{N}\right), \ldots, u_{m}\left(X_{1}, X_{2}, \ldots X_{N}\right)\right] .
$$

Equation 6.

We refer to $\left[u_{1}\left(X_{1}, X_{2}, \ldots X_{N}\right), u_{2}\left(X_{1}, X_{2}, \ldots X_{N}\right), \ldots, u_{m}\left(X_{1}, X_{2}, \ldots X_{N}\right)\right]$, as the $m$-tuple in $\Omega$ that maximizes $L\left(\theta_{1}, \theta_{2}, \ldots \theta_{m}\right)$. Then, $\hat{\theta_{1}}=u_{1}\left(X_{1}, X_{2}, \ldots X_{N}\right), \hat{\theta_{2}}=u_{2}\left(X_{1}, X_{2}, \ldots X_{N}\right), \ldots, \hat{\theta_{m}}=u_{m}\left(X_{1}, X_{2}, \ldots X_{N}\right)$, are the unique maximum likelihood estimators of

$$
\left[u_{1}\left(X_{1}, X_{2}, \ldots X_{N}\right), u_{2}\left(X_{1}, X_{2}, \ldots X_{N}\right), \ldots, u_{m}\left(X_{1}, X_{2}, \ldots X_{N}\right)\right]
$$

Equation 7.

Let $x=\left\{x_{1}, x_{2}, \ldots, x_{n}\right\}$ be a sample from the GPD with pdf in Equation 3:

$$
\begin{aligned}
L\left(x_{i} ; k, \alpha\right) & =-n \ln \alpha+\left(\frac{1-k}{k}\right) \sum_{i=1}^{n} \ln \left(1-\frac{k}{\alpha} x_{i}\right), \text { for } k \neq 0 \\
& =-n \ln \alpha-\frac{1}{\alpha} \sum_{i=1}^{n} x_{i}, \text { for } k=0 .
\end{aligned}
$$

Equation 8.

The $\log$-likelihood function for $k \neq 0$ states that the function can be made arbitrarily large by taking $k>1$ and $\alpha / k$ close to the maximum order statistic $x_{n: n} \cdot{ }^{7}$ Maximum likelihood estimates of $\alpha$ and $k$ can be obtained by minimizing the likelihood function above. However, in order for the MLE to perform its best for the GPD, there are certain criterion that must be present. One, the sample size $n$, must be large (preferably, greater than 500). Two, the values of $k$, the shape parameter must stay within the bounds of $\frac{-1}{2}$ and $\frac{1}{2}$. When these criterion are met, MLE would be preferred due to its effective efficiency with large samples. ${ }^{4}$ 


\subsection{The Method of Moments}

Let $X_{1}, X_{2}, \ldots X_{n}$, be a random sample size from a distribution with the following p.d.f:

$$
f\left(x_{i} ; \theta_{1}, \theta_{2}, \ldots \theta_{r}\right),
$$

Equation 9.

where the sample space, $\theta_{1}, \theta_{2}, \ldots, \theta_{r} \in \Omega$. Then $E\left(x^{k}\right)$, where $k=1,2, \ldots$ is the $k^{\text {th }}$ moment of the population, and $M_{k}=\sum_{i=1}^{n} \frac{x_{i}^{k}}{n}$, where $k=1,2, \ldots$ is the $k^{\text {th }}$ moment of the sample. We take $E\left(x^{k}\right)$, set it equal to $M_{k}$, starting with $k=1$, and keep equating $E\left(x^{k}\right)$ to $M_{k}$ until enough equations are provided to find the unique solutions for the parameters, $\theta_{1}, \theta_{2}, \ldots, \theta_{r} .^{7}$

In this study, for GPD, MOM can be used to find the unique solutions for the parameters, $k$ and $\alpha$, by finding the first and second population moment, and equating them with the corresponding sample moments.

We will first start with finding the first and second population moments of GPD. In order to achieve the task at hand, we will use the expected value approach, instead of the moment generating function (mgf) approach, since the mgf of the GPD does not exist for all values of $k$. Consider $E\left(1-\frac{k x}{\alpha}\right)^{r}$, where the $r^{\text {th }}$ moment exist when $k>\frac{-1}{r}$. Assume $r=1$ and $k<0$, where $0<x<\infty$. By the definition of expected value and Equation 3, we now have:

$$
\begin{aligned}
E\left(1-\frac{k x}{\alpha}\right)^{1} & =\int_{0}^{\infty}\left(1-\frac{k x}{\alpha}\right)^{1} \times\left[\frac{1}{\alpha}\left(1-\frac{k x}{\alpha}\right)^{\frac{1}{k}-1}\right] d x \\
& =\frac{1}{\alpha} \int_{0}^{\infty}\left(1-\frac{k x}{\alpha}\right)^{\frac{1}{k}} d x .
\end{aligned}
$$

Equation 10.

using the method of substitution, we have:

$$
E\left(1-\frac{k x}{\alpha}\right)=\frac{1}{1+k}
$$

Equation 11.

Therefore, for $r=1, k<0$, and $0<x<\infty$, we have

$$
E\left(1-\frac{k x}{\alpha}\right)^{r}=\frac{1}{1+r k}, \text { where } 1+r k>0
$$

Equation 12.

For $r=1$, the properties of expectation have been used to obtain $E(x)$ as follows:

$$
\begin{aligned}
E(x) & =\frac{\alpha}{1+k} \\
& =\mu .
\end{aligned}
$$

Equation 13.

Similarly, letting $r=2$ in Equation 12, $E\left(x^{2}\right)$ can be found as:

$$
E\left(x^{2}\right)=\frac{2 \alpha^{2}}{(1+k)(1+2 k)}
$$

Equation 14.

By using $E\left(x^{2}\right)$ and $E(x)$,

$$
\sigma^{2}=\frac{\alpha^{2}}{(1+k)^{2}(1+2 k)} .
$$

Equation 15.

Now that we have $\mu$ and $\sigma^{2}$, we can now equate the first sample moment with the first population moment, using Equation 12:

$$
\bar{x}=\frac{\alpha}{1+k}
$$

Equation 16. 
where $\bar{x}$ is the first sample moment, and $\mu$ is the first population moment.

We can also equate our second sample moment with the second population moment as such:

$$
S^{2}=\frac{\alpha^{2}}{(1+k)^{2}(1+2 k)} \text {. }
$$

Equation 17.

where $S^{2}$ is the second sample moment, and $\sigma^{2}$ is the second population moment. These two equations (Equation 16 and Equation 17) will provide the unique solutions for $k$ and $\alpha$, in which we will be able to find out the MOM estimators for $k$ and $\alpha$ denoted by $\hat{k}$ and $\hat{\alpha}$ respectively as follows:

$$
\hat{k}=\frac{1}{2}\left(\frac{\bar{x}^{2}}{S^{2}}-1\right) \text { and } \hat{\alpha}=\frac{1}{2} \bar{x}\left(\frac{\bar{x}^{2}}{S^{2}}+1\right) .
$$

Equation 18.

\subsection{The Probability-Weighted Moments}

Let $x_{1: n} \leq x_{2: n} \leq \ldots \ldots . \leq x_{i: n}$ be a random sample from GPD $(k, \sigma)$, where $x_{i: n}$ is the $i t h$ order statistics of sample size $n$. Consider

$$
\alpha_{v}=\frac{1}{n} \sum_{i=1}^{n}\left(1-P_{i: n}\right)^{v} x_{i: n} .
$$

Equation 19.

where $P_{i: n}=\frac{i-.35}{n}$. Then,

$$
\hat{k}_{P W M}=\frac{\alpha_{o}}{\alpha_{o}-2 \alpha_{1}}-2 \text { and } \hat{\sigma}_{P W M}=\frac{2 \alpha_{o} \alpha_{1}}{\alpha_{o}-2 \alpha_{1}} .
$$

Equation 20.

The following is an illustration of how the parameters $\hat{k}$ and $\hat{\sigma}$ were calculated in terms of $\bar{x}$ and $t$, from $\alpha_{v}$. Note that,

$$
\hat{k}_{P W M}=\frac{\bar{x}}{\alpha_{o}-2 \alpha_{1}}-2
$$

where $\alpha_{v}=\frac{1}{n} \sum_{i=1}^{n}\left(1-P_{i: n}\right)^{v} x_{i: n}$.

Let $v=0$, then

$$
\begin{aligned}
\alpha_{0} & =\frac{1}{n} \sum_{i=1}^{n}\left(1-P_{i: n}\right)^{0} x_{i: n} \\
& =\frac{1}{n} \sum_{i=1}^{n} 1 \times x_{i: n} \\
& =\bar{x} .
\end{aligned}
$$

Equation 22.

and let $v=1$,

$$
\alpha_{1}=\frac{1}{n} \sum_{i=1}^{n}\left(1-P_{i: n}\right) x_{i: n}
$$

Equation 23.

where $\frac{1}{n} \sum_{i=1}^{n}\left(1-P_{i: n}\right) x_{i: n}$, will be represented by $t$, so $\alpha_{1}=t$. From Equation 21 we have:

$$
\hat{k}_{P W M}=\frac{\bar{x}}{\bar{x}-2 t}-2 \text {. }
$$

Equation 24.

The same follows for $\hat{\sigma}_{P W M}$ :

$$
\hat{\sigma}_{P W M}=\frac{2 \alpha_{o} \alpha_{1}}{\alpha_{o}-2 \alpha_{1}}
$$

Equation 25. 
where as previously calculated $\alpha_{0}=\frac{1}{n} \sum_{i=1}^{n} 1 \times x_{i: n}=\bar{x}$ and $\alpha_{1}=\frac{1}{n} \sum_{i=1}^{n}\left(1-P_{i: n}\right) x_{i: n}=t$. Then,

$$
\begin{aligned}
\hat{\sigma}_{P W M} & =\frac{2\left(\frac{1}{n} \sum_{i=1}^{n} x_{i: n}\right)\left(\frac{1}{n} \sum_{i=1}^{n}\left(1-P_{i: n}\right) x_{i: n}\right)}{\left(\frac{1}{n} \sum_{i=1}^{n} x_{i: n}\right)-2\left(\frac{1}{n} \sum_{i=1}^{n}\left(1-P_{i: n}\right) x_{i: n}\right)} \\
& =\frac{2 \bar{x} t}{\bar{x}-2 t} .
\end{aligned}
$$

Equation 26.

So,

$$
\hat{k}_{P W M}=\frac{\alpha_{o}}{\alpha_{o}-2 \alpha_{1}}-2=\frac{\bar{x}}{\bar{x}-2 t} \text { and } \hat{\sigma}_{P W M}=\frac{2 \alpha_{o} \alpha_{1}}{\alpha_{o}-2 \alpha_{1}}=\frac{2 \bar{x} t}{\bar{x}-2 t}
$$

Equation 27.

\section{ANALYZING THE EARTHQUAKE DATA}

To fulfill a complete understanding of EVT, this study uses a data set of earthquakes. ${ }^{8}$ Forecasting earthquake is always a challenging problem and it has been studied by many authors. ${ }^{9-14}$ Turning to the United States Geological Survey, the data of historic earthquakes in the U.S. and its territories were retrieved. Magnitudes of earthquake, measured in Richter scale, from 1700 to 2011 have been used in this study. Using the statistical package R the data was processed so that the following information could be found: 5 number summary, a histogram, box plot, Q-Q plot, mean residual plot and mean excess plot.

\subsection{Descriptive Statistics}

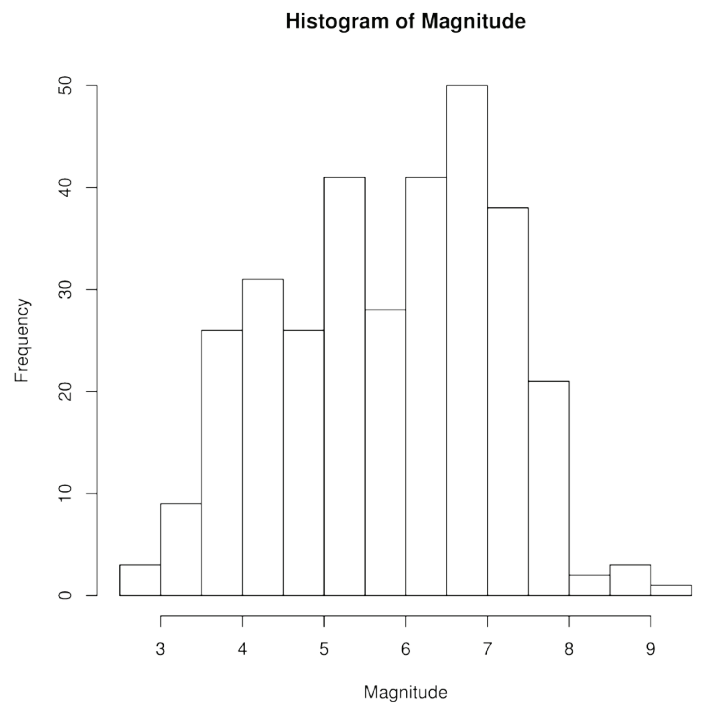

Figure 1. Histogram of Magnitude

We construct a histogram to understand the overall nature of the data. Even though the histogram does not show a very skewed pattern, it can be seen that there are some extreme values in the right tail. The box plot provides a visual for the 5 number summary plot, which includes the median of the data, the $1^{\text {st }}$ and $3^{\text {rd }}$ quartile, and the maximum and minimum values of the data. The 5 number summary and a box plot can be obtained by using R:

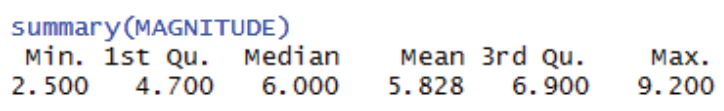

Figure 2. Five Number Summary 
Boxplot for the 5 Number Summary of Earthquake Magnitudes

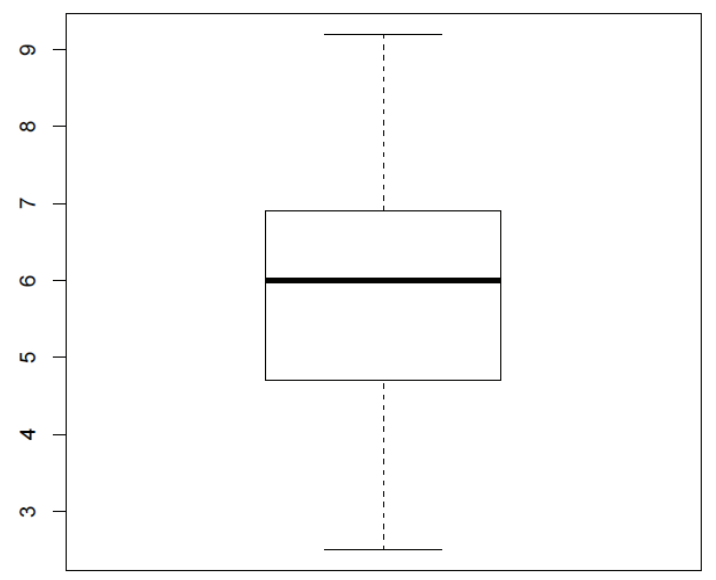

Figure 3. Box Plot for Earthquake Magnitude Data

The 5 number summary in Figure 2 and the box plot in Figure 3 reveals the identical information. We see that our maximum value and minimum value of the data is 9.2, and 2.5 respectively which the box plot portrays with the highest bar that is at 9.2, and the lowest bar that is at 2.5. Notice that there is a thick black line within the box. This line is the median of the data. The median of the data is 6.0, and that is where the line is placed. The space below the black line is the $1^{\text {st }}$ quartile and the space above the black line is the $3^{\text {rd }}$ quartile (which seems to be where most of our data lies).

\subsection{The Q-Q Plot}

The Q-Q plot is a graphical analysis of the distribution of the processed data compared to the normal distribution. When the model fits the data well, the pattern of points in Q-Q plots would exhibit a linear trend.

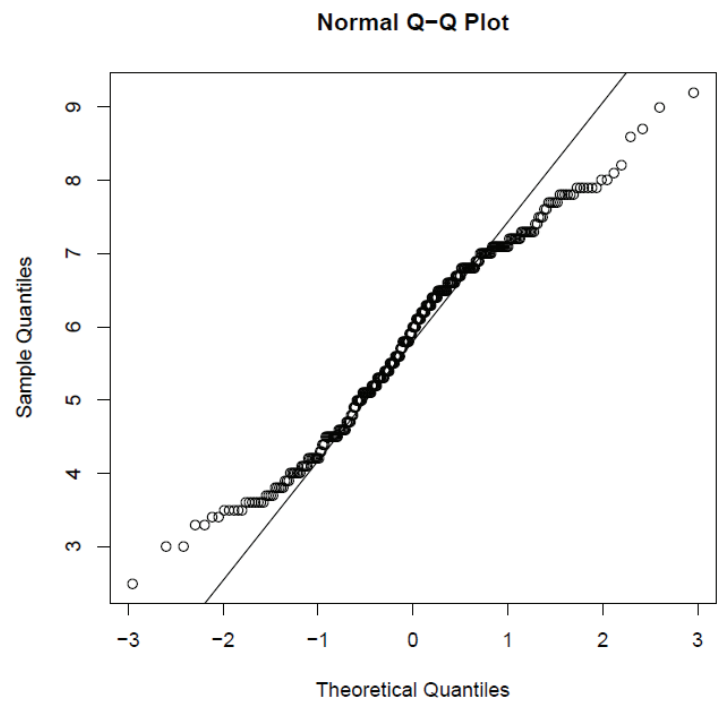

Figure 4. Normal Q-Q Plot

In Figure 4, the line in the plot is drawn through the first and third quartiles of the data. The circles that start to deviate from the line, are the data that do not follow a normal distribution, the data that we will need for the POT method. 


\subsection{Normality Test}

The Q-Q Plot in Figure 4 graphically shows whether the processed data, are from a normal distribution. To see if the data follows a normal distribution or does not follow a normal distribution, the Shapiro-Wilk test will be used. The Shapiro-Wilk test will be used to test the following hypotheses:

$H_{o}$ : The data are normally distributed.

$H_{a}$ : The data are not normally distributed.

The Shapiro-Wilk test has a test statistic $W$ that is mathematically defined as:

$$
W=\frac{\left(\sum_{i=1}^{n} a_{i} x_{(i)}\right)^{2}}{\sum_{i=1}^{n}\left(x_{(i)}-\bar{x}\right)^{2}} .
$$

where the $x_{(i)}$ represent the the order sample values, and $a_{i}$ represent the constants that are generated from the mean, variance and covariance of the order statistics of a sample $n$, from a normal distribution.

When performing the Shapiro-Wilk test for normality in R, we get the following:

\begin{tabular}{|c|c|c|}
\hline Test & Test Statistic & p-value \\
\hline Shapiro-Wilk & 0.97637 & 0.00004058 \\
\hline
\end{tabular}

Table 1. Results of the Shapiro-Wilk Test

We use the $p$-value approach to draw the final conclusion of the hypothesis test. Since the $p$-value is less than $\alpha=0.05$, where $\alpha$ is our confidence level of significance, we reject $H_{o}$ in favor of $H_{a}$. The meaning of this conclusion is that there is evidence showing that the data does not follow a normal distribution.

\subsection{The Mean Excess and Mean Residual Plots}

The mean excess and mean residual plots, are ways to graphically analyze extreme values to validate a GPD model for the excess distribution, a foundation for POT modeling. Used for estimating and choosing a threshold to work with, we look for a threshold such that the plot is roughly linear. Choosing a threshold can be challenging but depending on how the threshold is chosen, the parameter estimates become sensitive to this particular threshold of choice. ${ }^{15}$ 


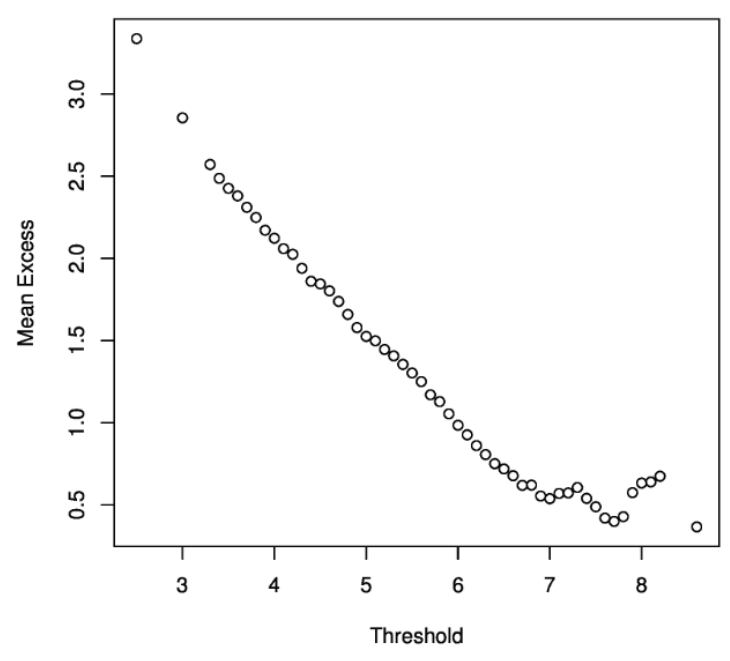

Figure 5. Mean Excess Plot

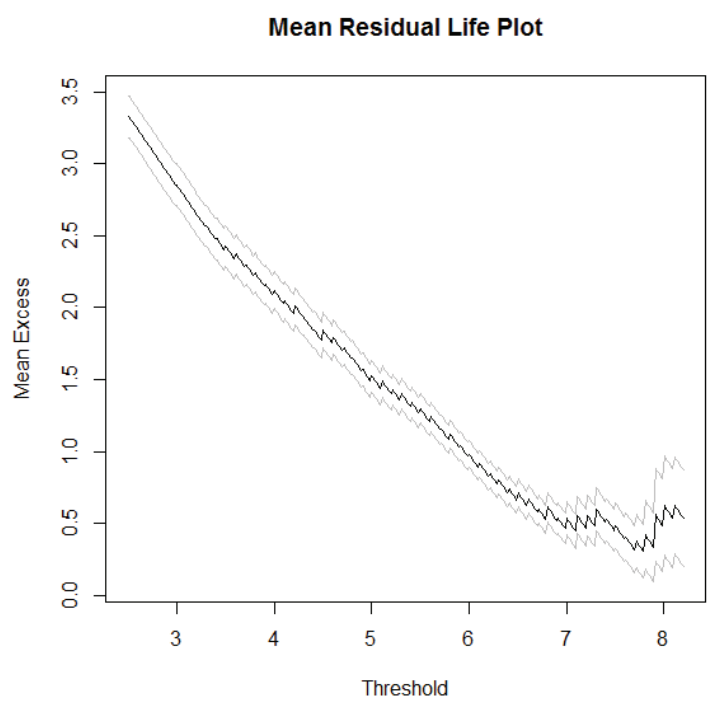

Figure 6. Mean Residual Plot

In Figures 5 and 6, we notice that the data for the threshold values 1-6 the data follows closely to a linear line (normal distribution) until about threshold 7 where the data starts to follow a nonlinear pattern. This is how the threshold of the data, represented by $u$, was chosen.

\section{ESTIMATING GPD PARAMETERS}

The MLE, MOM, and PWM estimation techniques can be used, now that a value for the threshold has been chosen. In $\mathrm{R}$, with the data and threshold, the shape and scale parameters can be calculated, in order to determine which distribution within GPD would be a good fit, for the data. We need the parameters to be as unbiased as possible, so we need to see which estimation technique will be most effective when determining the scale and shape parameters. Once the parameters have been found, we will compare each technique to see which one provides the most accurate estimation for the parameters 
needed.

\subsection{Calculating $\hat{k}$ and $\hat{\alpha}$ from Actual Data}

The calculations needed in R, for the peak over threshold (POT) method was enabled by the POT package downloaded in $\mathrm{R}$. The POT package, is a package in which tools are developed to perform most functions related to EVT, that can be used to statistically analyze POT. ${ }^{16}$ Using the statistical package R, refer to Figure 7, to see the values calculated for $\bar{x}$ and $S^{2}$, where $\bar{x}$ is the mean and $S^{2}$ is the variance, were calculated:

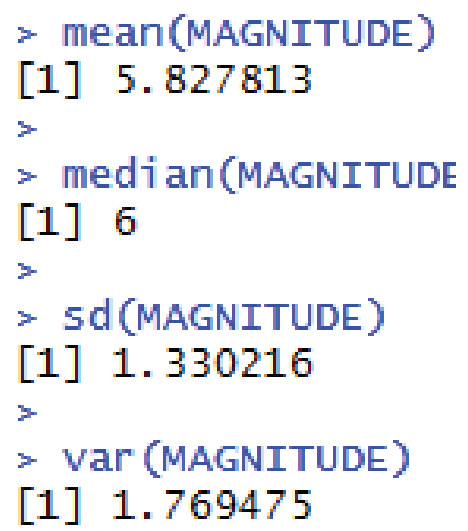

Figure 7. Calculations of the Mean, Median, Standard Deviation, and Variance by R.

Using the equations for $\hat{k}$ and $\hat{\alpha}$, along with the following values for $\bar{x}$ and $S^{2}$ calculated in $\mathrm{R}$, we find that:

$$
\hat{k}=4.924 \text { and } \hat{\alpha}=17.261
$$

Equation 29.

For this study, three estimation techniques, namely, the maximum likelihood, method of moments, and probabilityweighted moments, will be used to find the estimation of the shape and scale parameters of the processed data. After comparing techniques, we will be able to see which technique provides a more accurate, unbiased estimator for the shape and scale parameters needed for the GPD. 


\subsection{Comparing Estimation Techniques}

Now that the threshold has been analyzed and chosen for the data set, using the package POT in R, we are able to find our shape and scale parameters for the MLE, MOM and PWM estimation techniques. We are also able to compare how accurate MLE, MOM and PWM are as the threshold increases, in Table 2:

\begin{tabular}{llllllll}
\hline & & \multicolumn{3}{c}{ Shape $(k)$} & \multicolumn{3}{c}{ Scale $(\alpha)$} \\
\cline { 3 - 8 } $\mathbf{u}$ & $\mathbf{m}$ & MLE & MOM & PWM & MLE & MOM & PWM \\
\hline \multirow{2}{*}{5.5} & \multirow{2}{*}{184} & -0.48 & -1.23 & -1.32 & 1.82 & 2.91 & 3.0 \\
& & $(0.04)$ & $(0.20)$ & $(0.20)$ & $(0.14)$ & $(0.35)$ & $(0.36)$ \\
\multirow{4}{*}{6.0} & \multirow{2}{*}{156} & -0.39 & -0.86 & -0.10 & 1.32 & 1.83 & 2.0 \\
& & $(0.05)$ & $(0.15)$ & $(0.18)$ & $(0.12)$ & $(0.23)$ & $(0.25)$ \\
\multirow{4}{*}{6.5} & \multirow{2}{*}{115} & -0.28 & -0.46 & -0.61 & 0.91 & 1.05 & 1.16 \\
& & $(0.06)$ & $(0.12)$ & $(0.15)$ & $(0.10)$ & $(0.14)$ & $(0.17)$ \\
7.0 & \multirow{2}{*}{65} & -0.15 & -0.15 & -0.18 & 0.62 & 0.62 & 0.64 \\
& & $(0.11)$ & $(0.12)$ & $(0.15)$ & $(0.10)$ & $(0.11)$ & $(0.12)$ \\
7.5 & \multirow{2}{*}{27} & -0.19 & -0.21 & -0.45 & 0.58 & 0.59 & 0.71 \\
& & $(0.18)$ & $(0.19)$ & $(0.28)$ & $(0.15)$ & $(0.16)$ & $(0.21)$ \\
\hline
\end{tabular}

Table 2. Estimated Parameters

Now that $m$ is the number of exceedances over the threshold value $u$; the standard errors are in parentheses. While analyzing Table2, we are able to recognize two findings. One, that our $k$ stays within its restricted bounds $-\frac{1}{2}<k<\frac{1}{2}$, and two, as the value of $u$ increases, the estimators for the scale and shape parameter, for MLE and MOM begin to take on similar values; while the values for the shape and scale parameter for PWM are sporadic when the threshold value is more than seven.

\section{FITTING GPD TO THE DATA}

Now that we have analyzed our data, used estimation techniques such as MLE, MOM, and PWM to estimate the scale and shape parameters, $k$ and $\alpha$, we are now able to take the data, and model it to see how accurately it follows the generalized Pareto distribution under the Peak Over Threshold (POT) method.
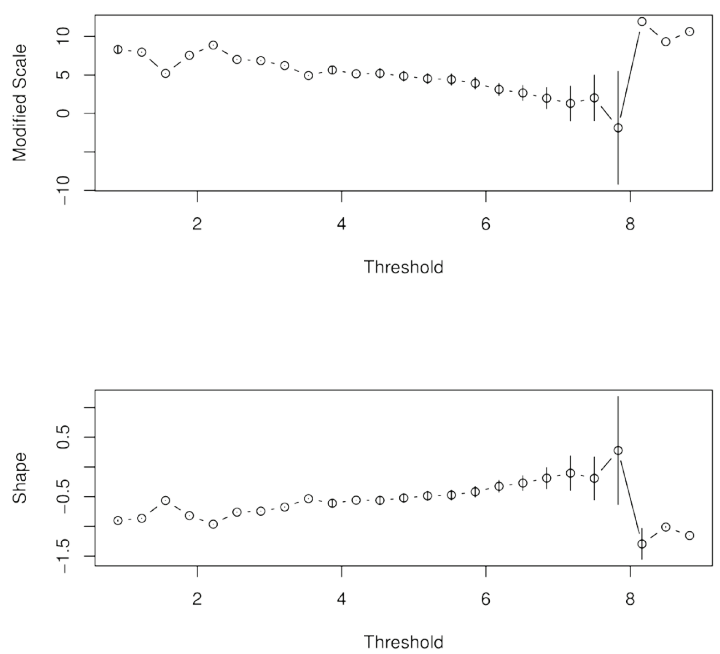

Figure 8. $E[x-u \mid x \geq u]$ Plot 


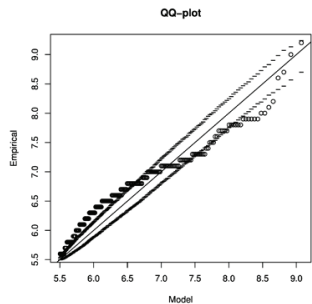

(a) $\mathrm{u}=5.5$

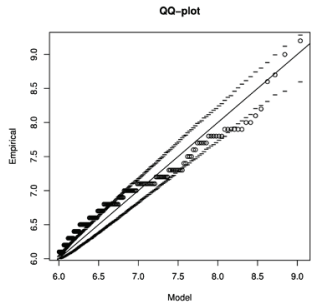

(b) $\mathrm{u}=6.0$

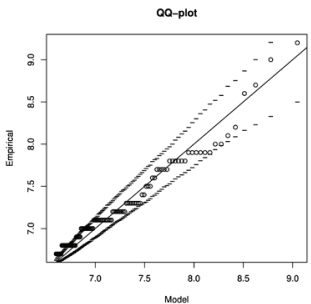

(c) $\mathrm{u}=6.5$

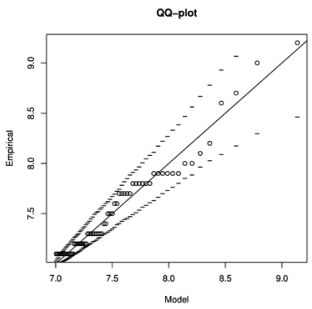

(d) $\mathrm{u}=7.0$

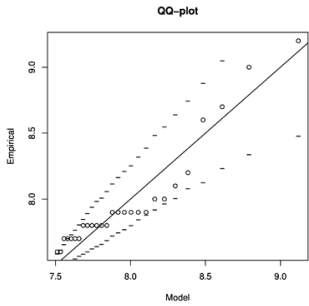

(e) $u=7.5$

Figure 9. GPD qq Plots for Threshold Values 5.5-7.5

Figure 8, depicts the stability of the respective parameters, scale and shape, as the threshold value increases. Notice after the threshold value of $u=7$, the parameter is not as stable which can be concluded by the behavior seen after the threshold value compared to the behavior before and up onto the chosen threshold value. Figure 9, using MLE for the shape and scale parameters, we graph the GPD qq plots for the threshold values of $u$ from 5.5 to 7.5. Notice that as the threshold value approaches the chosen threshold value of $u=7$ the model shows a better fit for the generalized Pareto distribution, for the POT method.

\subsection{Goodness of Fit Test}

As mentioned in the previous section, from the GPD qq plots, as the threshold value approaches the chosen threshold value of $u=7.0$, the model shows a better fit for the data. To ensure that the data indeed follows the GPD, a goodness of fit test will be used. More specifically, the Anderson-Darling (A-D) test will be performed to test the following hypothesis:

$H_{o}$ : The data follow the generalized Pareto Distribution $H_{a}$ : The data does not follow the generalized Pareto Distribution

The Anderson-Darling test also has a test statistic mathematically defined as:

$$
A^{2}=-N-S
$$

Equation 30.

where $S=\sum_{i=1}^{N} \frac{(2 i-1)}{N}\left[\ln F\left(X_{i}\right)+\ln \left(1-F\left(X_{N+1-i}\right)\right)\right]$ where $F$, is the cumulative distribution function, and $X_{i}$ represents the ordered data. When performing the Anderson-Darling test for the data that exceeds the threshold, $u=7.0$, using MLE as the chosen estimation technique in $\mathrm{R}$, we get the following:

\begin{tabular}{|l|l|l|}
\hline Test & Test Statistic (A) & $p$-value \\
\hline Anderson-Darling & 3.3729 & 0.09091 \\
\hline
\end{tabular}

Table 3. Results of the Anderson-Darling Test

Again, we use the $p$-value approach to draw the final conclusion of the hypothesis test. Since the $p$-value is greater than $\alpha=0.05$, where $\alpha$ is our confidence level of significance, we fail to reject $H_{o}$ in favor of $H_{a}$. In other words, there is evidence showing that the data values exceeding the threshold $u=7$ indeed follows the generalized Pareto distribution.

\section{SIMULATION ANALYSIS}

To assess the performance of the three estimation techniques a simulation study has been conducted. We have generated 10,000 GPD data points using $\mathrm{R}$ and we calculated estimates using all three techniques in each trial. We have performed 30 trials in this analysis. 


\subsection{Bias and RMSE in Parameter Estimation}

Bias is defined as the following: a point estimator $\hat{\theta}$ is said to be an unbiased estimator if for every possible value of $\theta$, $E(\hat{\theta})=\theta$. If $E(\hat{\theta}) \neq \theta$, then $\theta$ is biased, and the difference $E(\hat{\theta})-\theta$ is called the bias of $\hat{\theta}$, and is denoted as $B(\hat{\theta})$. In practice relative bias is used to measure the efficiency of any estimation methods. Mathematically, the relative bias is defined as:

$$
B(\hat{\theta})=\frac{E[(\hat{\theta}-\theta)]}{\theta}
$$

Equation 31.

where $\hat{\theta}$ is an estimate of $\theta$ (parameter) and $E(\hat{\theta})=\frac{1}{N} \sum_{i=1}^{N} \hat{\theta}_{i}$

The Root Mean Square Error (RMSE) is one of the most important performance indices used in literature and is defined as:

$$
\operatorname{RMSE}(\theta)=\sqrt{E\left[(\hat{\theta}-\theta)^{2}\right]}
$$

Equation 32.

The bias of each parameters estimated by the three methods is summarized in Table 4. Each threshold value is represented by $u$. In absolute terms the MOM produced the least bias of the three methods for the following threshold values: 5.5, 7.0 and 7.5. MLE provides the least bias when the threshold value is 6.0 and PWM performs the best for a threshold value of 6.5 .

The RMSE of each estimation technique for each of the threshold values specified in Table 5. As before, each threshold value is represented by $u$. With an exception of the RMSE for shape parameter for threshold value 5.5, MLE performs the best among all methods for both shape and scale parameters and for all threshold values. The least RMSE values for almost all MLE estimates guarantee that MLE is the best of estimation.

\begin{tabular}{|c|c|c|c|c|}
\hline $\mathbf{u}$ & Sample Size & Method & Shape & Scale \\
\hline \multirow{3}{*}{5.5} & \multirow{3}{*}{30} & MLE & 0.0069 & 0.0086 \\
& & MOM & -0.0003 & -0.0002 \\
& & PWM & 0.0003 & 0.0003 \\
\hline \multirow{3}{*}{6.0} & \multirow{3}{*}{30} & MLE & -0.0001 & -0.0003 \\
& & MOM & 0.0010 & 0.0010 \\
& & PWM & 0.0005 & 0.0005 \\
\hline \multirow{3}{*}{6.5} & \multirow{3}{*}{30} & MLE & 0.0007 & 0.0043 \\
& & MOM & -0.0021 & -0.0049 \\
& & PWM & -0.0004 & -0.0004 \\
\hline \multirow{3}{*}{7.0} & \multirow{3}{*}{30} & MLE & -0.0004 & 0.0032 \\
& & MOM & -0.00004 & 0.0018 \\
& & PWM & 0.0013 & 0.0056 \\
\hline \multirow{3}{*}{7.5} & \multirow{3}{*}{30} & MLE & 0.0010 & 0.0036 \\
& & MOM & -0.0004 & -0.0006 \\
& & PWM & 0.0008 & 0.0015 \\
\hline
\end{tabular}

Table 4. Bias of Parameter Estimates 


\begin{tabular}{|c|c|c|c|c|}
\hline $\mathbf{u}$ & Sample Size & Method & Shape & Scale \\
\hline \multirow{3}{*}{5.5} & \multirow{3}{*}{30} & MLE & 0.0185 & 0.0058 \\
& & MOM & 0.0153 & 0.0085 \\
& & PWM & 0.0144 & 0.0080 \\
\hline \multirow{3}{*}{6.0} & \multirow{2}{*}{30} & MLE & 0.0041 & 0.0016 \\
& & MOM & 0.0082 & 0.0059 \\
& & PWM & 0.0071 & 0.0048 \\
\hline \multirow{3}{*}{6.5} & \multirow{2}{*}{30} & MLE & 0.0037 & 0.0038 \\
& & MOM & 0.0059 & 0.0056 \\
\hline \multirow{3}{*}{7.0} & \multirow{2}{*}{30} & PWM & 0.0048 & 0.0046 \\
& & MLE & 0.0022 & 0.0025 \\
& & PWM & 0.0026 & 0.0030 \\
\hline \multirow{3}{*}{7.5} & \multirow{3}{*}{30} & MLE & 0.0031 & 0.0041 \\
& & MOM & 0.0024 & 0.0029 \\
& & PWM & 0.0029 \\
\hline
\end{tabular}

Table 5. RMSE of Parameters Estimates

\subsection{Mis-specification Bias}

A simulation analysis has also been performed to investigate the miss-specification bias. We have miss-specified the threshold parameter to see the miss-specification bias, if any, of the scale and shape estimates. We have used estimates obtained in Table 2 for this miss-specification. For example, we choose MLE shape parameter (-0.48) and scale parameter (1.82) when the actual threshold is 5.5 in Table 4. Using these two estimated values we simulated 10,000 GPD values; however, we have chosen a different threshold value for this simulation. We continue in this process for all other threshold values. In short, we simulated value for threshold values 6, 6.5, 7 and 7.5 with estimated values obtained from threshold value 5.5. Figures 10 to 20 display all possible mis-specification bias in this study. It is very obvious from these graphs that MLE performs the best in all threshold values. MOM performs better than PWM in all cases. 


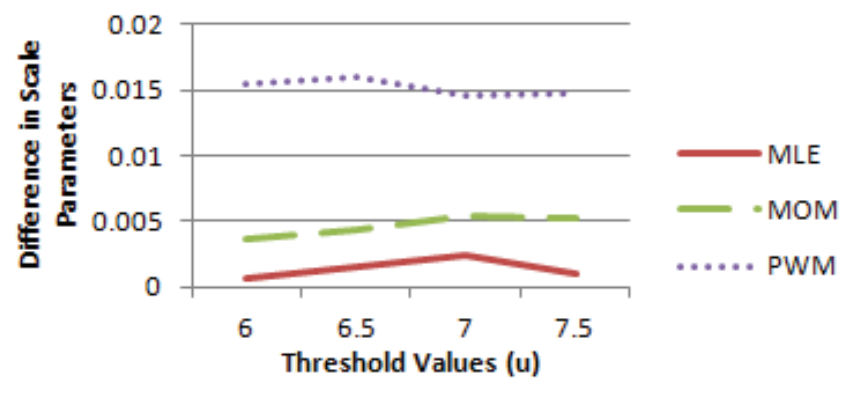

Figure 10. Actual Threshold 5.5

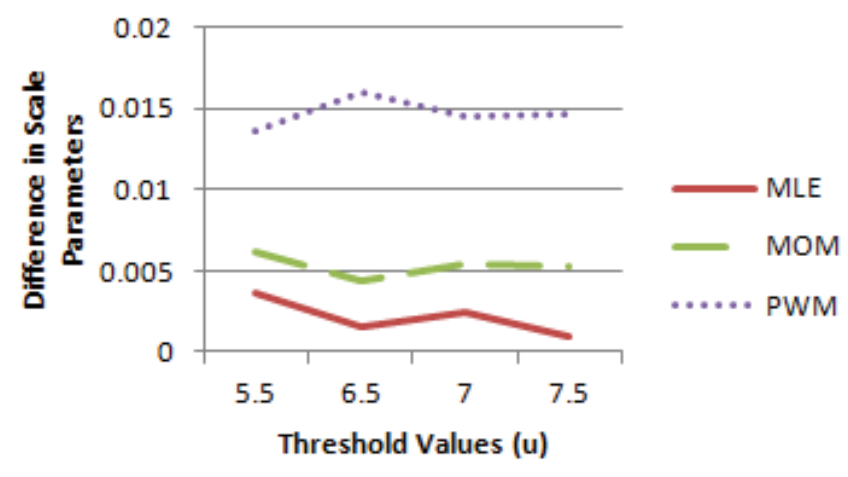

Figure 11. Actual Threshold 6.0

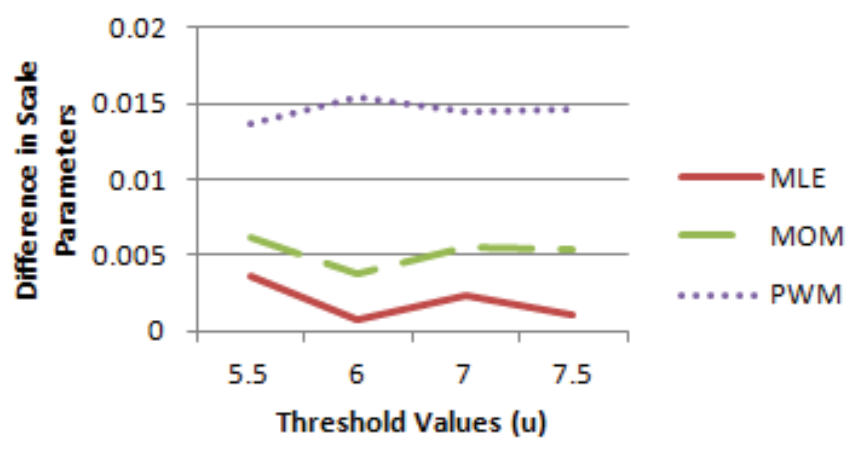

Figure 12. Actual Threshold 6.5 


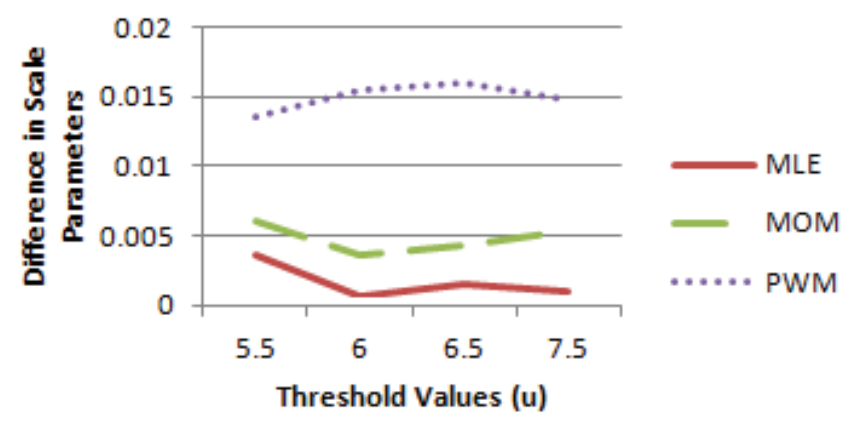

Figure 13. Actual Threshold 7.0

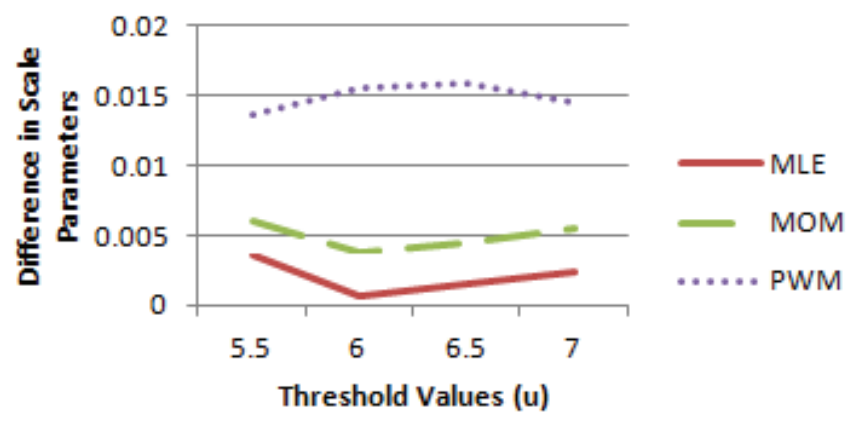

Figure 14. Actual Threshold 7.5

Figure 15. Mis-specification Bias of Scale Parameter

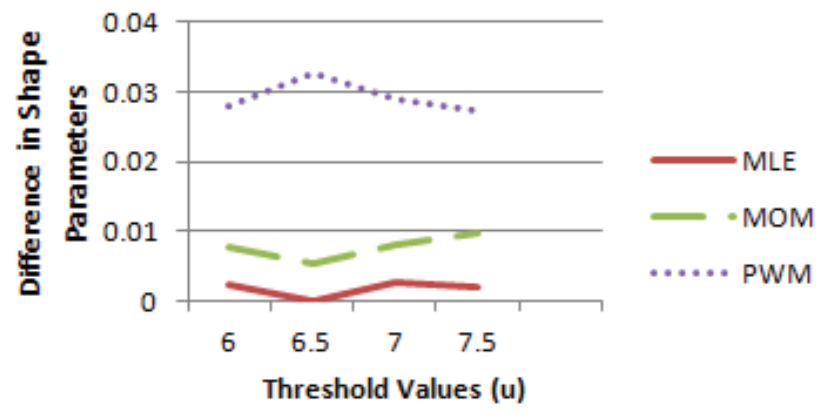

Figure 16. Actual Threshold 5.5 


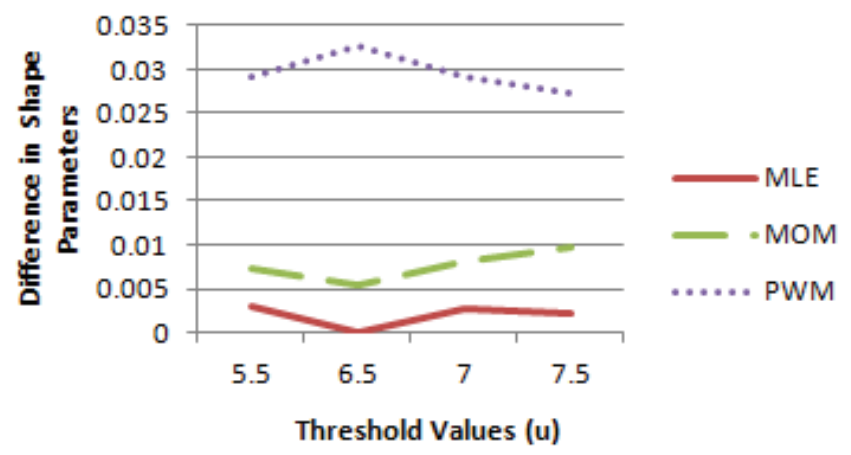

Figure 17. Actual Threshold 6.0

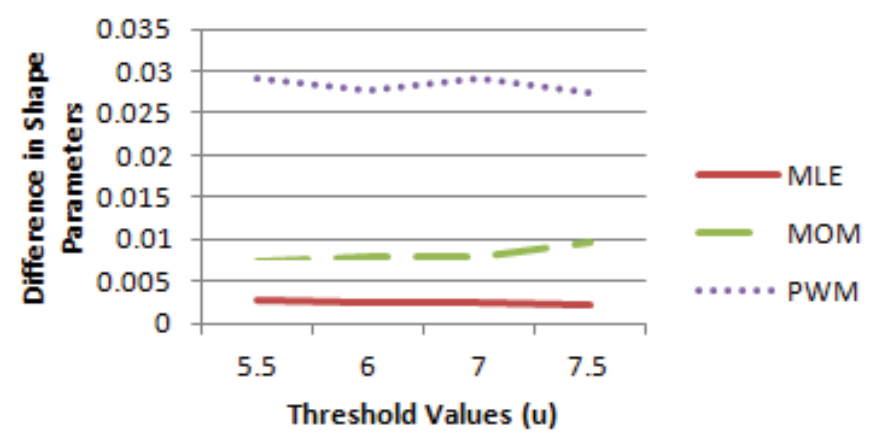

Figure 18. Actual Threshold 6.5

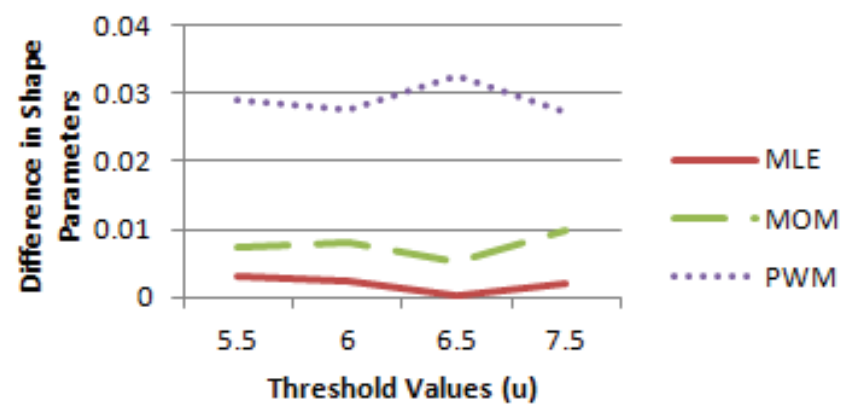

Figure 19. Actual Threshold 7.0

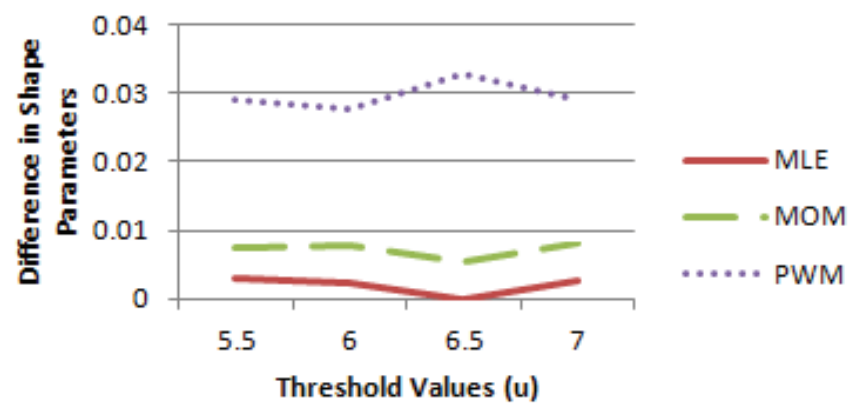

Figure 20. Actual Threshold 7.5 


\section{CONCLUSIONS}

The following conclusions can be drawn from this study: (1) it is reasonable to fit GPD to earthquake data; (2) MLE, MOM and PWM offer methods for estimating the parameters of GPD; and (3) the simulation study and the mis-specification analysis show that MLE performs the best among all methods.

\section{REFERENCES}

1. Klugman, S.A., Panjer, H. H., Willmot. G.E.(2008). Loss Models: From Data to Decisions, Wiley.

2. Pickands, J. (1975). Statistical inference using order statistics. Ananls of Statistics, 3, 119-31.

3. Hosking, J.R.M, and Wallis, J. (1987). Parameter and Quantile Estimation for the Generalized Pareto Distribution. Technometrics, 29(3), 339-349.

4. Castillo, Enrique, and Hadi, Ali,S.(1997). Fitting the Generalized Pareto Distribution to Data. Journal of the American Statistical Association, 92(440), 1609-1620.

5. Dey, A and Das, K., (2014), Quantifying extreme Hurricane risk in the US Gulf Coast, In JSM Proceedings, Statistical Computing Section. Alexandria, VA: American Statistical Association.

6. Dey, A, and Das, K., (2016), Modeling Extreme Hurricane Damage using the Generalized Pareto Distribution, American Journal of Mathematical and Management Sciences, 35(1), 55-66.

7. Hogg, R.V., Tanis, E.(2009). Probability and Statistical Inference (8th ed., pp.273-281). Upper Saddle River, NJ: Pearson.

8. Historic Earthquakes in the United States and Its Territories. http://earthquake.usgs.gov/earthquakes/states/historical.php/(accessed March 2014)

9. Castanos, H., and Lomnitz C.(2002). PSHA: is it science? Engineering Geology, 66, 315-317.

10. Cornell, C.A.(1968). Engineering seismic risk analysis. Bulletin of the Seismological Society of America, 58, 1583-1606.

11. Field, E. H.(2007). Overview of the working group for the development of regional earthquake likelihood models (RELM). Seismological Research Letters, 78(1), 7-16.

12. Jordan, T.(2006). Earthquake predictability, brick by brick. Seismological Research Letters, 77(1), 3-6.

13. Krintzsky, E. L.(2002). Epistemic and aleatory uncertainty: a new shtick for probabilistic seismic hazard analysis. Engineering Geology, 66, 157-159.

14. Pisarenko, V.F., Lyubushin, A. A., Lysenko, N.B., and Golubieva, T.V.(1996). Statistical estimation of seismic hazard parameters: maximum possible magnitude and related parameters. Bulletin of the Seismological Society of America, 86, 691-700.

15. Ghosh, S. and Resnick, S.(2010) A discussion on mean excess plots. Stochastic Processes and their Applications, 120: 1492-1517.

16. R Core Team (2006). A User's Guide to the POT Package. URL http://cran.r-project.org/.

\section{ABOUT THE STUDENT AUTHOR}

Audrene S. Edwards is from Groves, Texas. She graduated from Lamar University in 2014 with a B.S. in Mathematics. Audrene is presently a graduate student of Lamar University. She is currently working on receiving her Masters in Mathematics. She aspires to pursue her $\mathrm{PhD}$ in statistics to become a professor.

\section{PRESS SUMMARY}

The extreme value theory (EVT) is a well known discipline in statistics and in many other physical sciences and engineering disciplines. It has been developed in order to model and analyze rare but extreme events. Using data from selected earthquakes of general historic interest, EVT has been used to construct a model on the extreme and rare earthquakes that have happened in the United States from 1700 to 2011. The primary goal of fitting such a model is to estimate the amount of losses due to those extreme events and the probabilities of such events. By estimating the amount of losses and the probabilities of such events, this information can be useful in precautionary measures created for natural disasters and catastrophe bonds. 


\title{
Explicit Solution for Cylindrical Heat Conduction
}

\author{
Kaitlyn Parsons ${ }^{* a}$, Tyler Reichanadter ${ }^{a}$, Andi Vicksman $^{a}$, Harvey Segur $^{a}$ \\ ${ }^{a}$ Department of Applied Mathematics, University of Colorado, Boulder, CO \\ Students: *kaitlyn.parsons@colorado.edu,jonathan.reichanadter@colorado.edu,andi.vicksman@colorado.edu \\ Mentor: harvey.segur@colorado.edu
}

\begin{abstract}
The heat equation is a partial differential equation that elegantly describes heat conduction or other diffusive processes. Primary methods for solving this equation require time-independent boundary conditions. In reality this assumption rarely has any validity. Therefore it is necessary to construct an analytical method by which to handle the heat equation with time-variant boundary conditions. This paper analyzes a physical system in which a solid brass cylinder experiences heat flow from the central axis to a heat sink along its outer rim. In particular, the partial differential equation is transformed such that its boundary conditions are zero which creates a forcing function in the transform PDE. This transformation constructs a Green's function, which admits the use of variation of parameters to find the explicit solution. Experimental results verify the success of this analytical method.
\end{abstract}

\section{KEYWORDS}

Heat Equation; Bessel-Fourier Decomposition; Cylindrical; Time-dependent Boundary Conditions; Orthogonality; Partial Differential Equation; Separation of Variables; Green's Functions

\section{INTRODUCTION}

Separation of variables is a versatile method for solving linear, homogenous partial differential equations (PDEs). In elementary applications, the heat equation satisfies the requirements for separation of variables. More robust physical phenomena regarding heat, however, are not always ideally isolated. In this paper we derive an explicit solution of the heat equation in a cylindrical system with non-trivial time-dependent boundary conditions in order to demonstrate an approach in which separation of variables is still applicable to an inhomogeneous form of the heat equation given an appropriate change of variables.

The heat equation is solved for a brass cylinder $(70 \% \mathrm{Cu}: 30 \% \mathrm{Zn})$ with an electrical heating unit in the center and with a chilled water bath running along the outer rim. The brass medium experiences two time-dependent boundary conditions, rendering traditional analytic PDE solving techniques inapplicable. ${ }^{1}$ A transformation is applied to the cylindrical heat equation such that the transformed boundary conditions are zero. Additionally, a forcing function is now added to the transformed heat equation as a result of the transformation. This inhomogeneous PDE can then be split into a particular and homogenous solution. The latter is solved by the method of separation of variables. The inhomogeneous is solved by variation of parameters and construction of Green's functions. ${ }^{2}$ The establishment of Fourier-Bessel decomposition via orthogonality conditions enable calculation of the coefficients in the homogeneous and particular solutions.

The brass cylinder was heated until each thermistor reached its steady-state temperature. Next the water chiller was turned on and data were collected at each thermistor as the temperature changed with respect to time. Data from the outer and inner thermistors were input as the boundary conditions in the theoretical model. Similarly, the steady-state temperatures measured on all six thermistors were input as the initial condition in the theoretical model. The remaining set of data for the four inner thermistors served as a comparison for the explicit solution derived in our paper. 


\section{Experimental Apparatus}

The experimental setup consisted of a brass cylinder of radius $150 \mathrm{~mm}$ and height $35 \mathrm{~mm}$ manufactured by Armfield Ltd. (Ringwood Hampshire, U.K.). An electric heating unit located in the center of the cylinder transferred heat into the apparatus while cool water from the chilling bath flowed simultaneously around the outer edge. Seven temperature probes spaced evenly apart in a radial path collected data deep within the brass cylinder over time. The probes were located at $10 \mathrm{~mm}$ increments starting with temperature-thermistor 1 at $10 \mathrm{~mm}$ and ending with the last temperature-thermistor at $70 \mathrm{~mm}$. The thermistor located at $30 \mathrm{~mm}$ failed to collect data so it was not used in the experiment or data analysis. For clarity, the thermistors were renumbered 1 through 6, skipping the failed thermistor. Thus, thermistor 6 refers to the thermistor located at $70 \mathrm{~mm}$. The innermost probe, labeled temperature-thermistor 1 , recorded the boundary condition at $R_{i}$, corresponding to the inner boundary condition $v\left(R_{i}, t\right)=g(t)$. The outermost probe, labeled temperature-thermistor 6, recorded the boundary condition at $R_{o}$, corresponding respectively to the outer boundary condition $v\left(R_{o}, t\right)=h(t)$.

Figure 1 portrays the apparatus with the skipped thermistor crossed out:

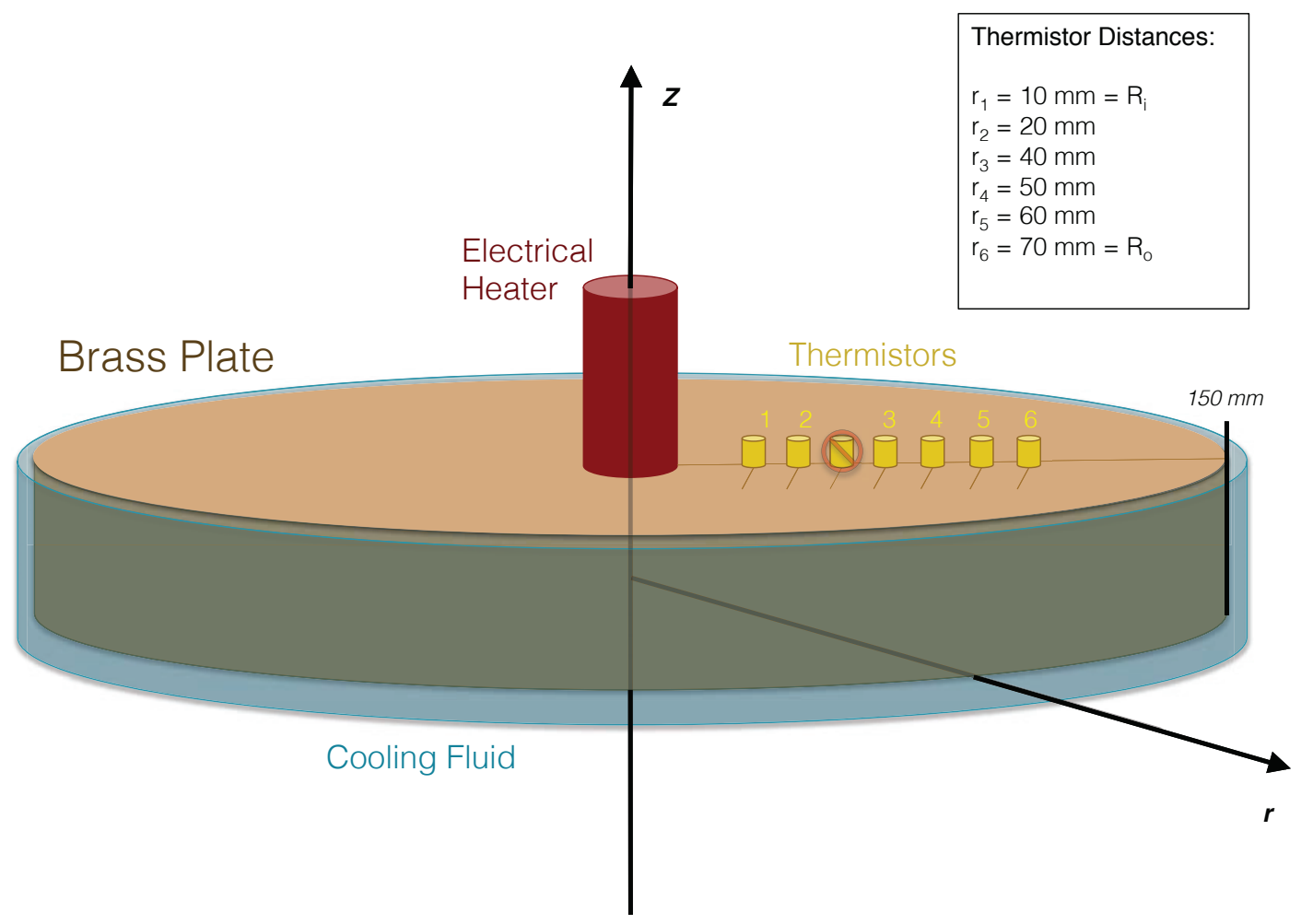

Figure 1. Physical setup for thermal experiment and data collection.

Before collecting data, the water was chilled to $10^{\circ} \mathrm{C}$. In addition, the power regulator was set to approximately 15 Watts and was allowed to reach a steady state. Once this occurred the pump connected from the water chiller to the apparatus was turned on allowing water to flow around the outside of the cylinder. After turning this on, thermistor data were collected every six seconds. About four minutes later, the experiment reached steady state and the data collection was stopped. Two trials were conducted with consistent results. 


\section{Mathematical Model}

The standard heat equation is

$$
\frac{\partial v}{\partial t}-\kappa \nabla^{2} v=0
$$

Equation 1.

where $v(\mathbf{r}, t)$ is the temperature at point $\mathbf{r}$ and time $t, \kappa$ is the thermal diffusivity, and $\nabla^{2} v(\mathbf{r}, t)$ is the Laplacian of the function $v$ or the divergence of the gradient of $v$.

The temperature varies with radial distance from the boundaries while remaining uniform in the $z$ direction so the most appropriate coordinate system for this analysis is polar coordinates. Additionally, the apparatus is radially symmetric, thus the temperature is only a function of radius $r$. This results in the following equation

$$
\begin{gathered}
\frac{\partial v}{\partial t}=\kappa\left[\frac{1}{r} \frac{\partial}{\partial r}\left(r \frac{\partial v}{\partial r}\right)\right]+F(r, t), \quad R_{i}<r<R_{o}, \quad t>0 \\
v\left(R_{i}, t\right)=g(t) \\
v\left(R_{o}, t\right)=h(t) \\
v(r, 0)=V(r) \quad R_{i}<r<R_{o},
\end{gathered}
$$

Equation 2.

where $R_{i}$ is the radius of the inner probe, $R_{o}$ is the radius of the outer probe, and $F(r, t)$ is the forcing function induced by the central heater and the outer rim heat sink. For brass the thermal diffusivity is $\kappa=37.52 \times 10^{-6} \frac{m^{2}}{s} .^{3}$ The functions $g(t)$ and $h(t)$ represent the boundary conditions at the inner probe and outer probe respectively and $V(r)$ is the initial condition.

\section{ANALYTICAL SOLUTION}

Currently the non-zero, time-dependent boundary conditions prevent the use of Fourier's decomposition method. ${ }^{4}$ The solutions to (Equation 2) do not form a closed function space; a linear combination of eigenfunctions satisfying the differential equation in (Equation 2) will not necessarily satisfy the conditions associated with (Equation 2).

Thus the first step is to change variables so that the boundary conditions are identically zero. The characteristic properties of Green's function are then utilized to find the explicit solution. Green's function enables linear boundary-value problems to be solved by transforming the original problem so that the solution depends exclusively on the boundary conditions and the differential equation. ${ }^{2}$ There are five characteristic properties of Green's function. ${ }^{2}$ In order to use Green's function we must transform our problem so that the boundary conditions are identically zero. This is accomplished by defining $z(r, t)$ as $z(r, t)=v(r, t)-\tau_{1}(r) g(t)-\tau_{2}(r) h(t)$.

In order for $z(r, t)$ to exist in a closed function space it is required that $z\left(R_{i}, t\right)=z\left(R_{o}, t\right)=0$ so the following must be true: $\tau_{1}\left(R_{i}\right)=1, \tau_{1}\left(R_{o}\right)=0, \tau_{2}\left(R_{i}\right)=0, \tau_{2}\left(R_{o}\right)=1$. These functions are defined as:

$$
\begin{aligned}
\tau_{1}(r) & =\frac{\ln (r)-\ln \left(R_{o}\right)}{\ln \left(R_{i}\right)-\ln \left(R_{o}\right)} \\
\tau_{2}(r) & =\frac{\ln \left(R_{i}\right)-\ln (r)}{\ln \left(R_{i}\right)-\ln \left(R_{o} 1\right)}
\end{aligned}
$$

Substituting this back into (Equation 2) results in a new differential equation that can be solved using separation of variables, since the modified boundary conditions of (Equation 2) form a closed function space.

These particular choices for $\tau_{1}$ and $\tau_{2}$ are convenient since their derivatives with respect to $r$ become $\pm \frac{1}{r}$. This is useful because on the right hand side of the PDE the solution $z(r, t)$ is differentiated, multiplied by $r$, and then differentiated 
again with respect to $r$. So the derivative of $\tau_{1}$ and $\tau_{2}$ of $\pm \frac{1}{r}$ gets multiplied by $r$, making the derivatives constant which results with the second derivatives equal to zero. Therefore, the forcing term only contains time-derivative information. The problem now becomes:

$$
\begin{gathered}
\frac{\partial z}{\partial t}=\kappa\left[\frac{1}{r} \frac{\partial}{\partial r}\left(r \frac{\partial z}{\partial r}\right)\right]+\hat{F}(r, t), \quad R_{i}<r<R_{o}, \quad t>0 \\
z\left(R_{i}, t\right)=0 \\
z\left(R_{o}, t\right)=0 \\
z(r, 0)=\hat{V}(r) \quad R_{i}<r<R_{o},
\end{gathered}
$$

where

$$
\begin{aligned}
& \hat{F}(r, t)=F(r, t)-\left[\frac{\ln (r)-\ln \left(R_{o}\right)}{\ln \left(R_{i}\right)-\ln \left(R_{o}\right)}\right] \frac{d g}{d t}-\left[\frac{\ln \left(R_{i}\right)-\ln (r)}{\ln \left(R_{i}\right)-\ln \left(R_{o}\right)}\right] \frac{d h}{d t} \\
& \hat{V}(r)=V(r)-\left[\frac{\ln (r)-\ln \left(R_{o}\right)}{\ln \left(R_{i}\right)-\ln \left(R_{o}\right)}\right] g(0)-\left[\frac{\ln \left(R_{i}\right)-\ln (r)}{\ln \left(R_{i}\right)-\ln \left(R_{o}\right)}\right] h(0)
\end{aligned}
$$

The next logical step is to solve for $z(r, t)$ of the form $z(r, t)=z_{h}(r, t)+z_{p}(r, t)$ where $z_{h}(r, t)$ is the homogenous solution and $z_{p}(r, t)$ is the particular solution. ${ }^{5}$ By applying the method of variation of parameters, the resulting form of the particular solution will be similar to the homogenous solution. In order to find the particular solution, the homogenous solution must therefore be solved for first.

\section{Homogenous Solution}

The PDE corresponding to the homogenous solution is by construction:

$$
\frac{\partial z_{h}}{\partial t}=\kappa\left[\frac{1}{r} \frac{\partial z_{h}}{\partial r}+\frac{\partial^{2} z_{h}}{\partial r^{2}}\right]
$$

Equation 4.

With a homogenous PDE and $z_{h}\left(R_{i}, t\right)=z_{h}\left(R_{o}, t\right)=0$ boundary conditions, $z_{h}(r, t)$ is solved by separations of variables. The solution is redefined by $z_{h}(r, t)=U(r) S(t)$. Following the process of separation of variables leads to:

$$
\frac{1}{\kappa} \frac{S^{\prime}(t)}{S(t)}=\frac{1}{r} \frac{U^{\prime}(r)}{U(r)}+\frac{U^{\prime \prime}(r)}{U(r)}=-\lambda
$$

in which $\lambda$ is an eigenvalue of the equation. ${ }^{6}$

\section{Case 1: $\lambda<0$}

For the case in which the eigenvalue is negative $\lambda \equiv-q^{2}$ the differential equation becomes

$$
U^{\prime \prime}(r)+\frac{1}{r} U^{\prime}(r)-q^{2} U(r)=0
$$

Equation 5.

This second-order differential equation is a specific form of Bessel's Equation which is shown below: ${ }^{7}$

$$
y^{\prime \prime}(x)+(d-1) \frac{1}{x} y^{\prime}(x)-\left(\nu-\frac{\mu}{x^{2}}\right) y(x)=0
$$


Notice the choice of $d=2, \mu=0$, and $\nu=q^{2}$ recovers the radial equation. With these constraints the solution to the radial equation is of the form $F(x)=C_{1} K_{\mu}(x \sqrt{\nu})+C_{2} I_{\mu}(x \sqrt{\nu})$ where $K_{\mu}$ and $I_{\mu}$ are the modified Bessel functions of the first and second kind which simplify in this application to: ${ }^{8}$

$$
U(r)=C_{1} K_{0}(r q)+C_{2} I_{0}(r q)
$$

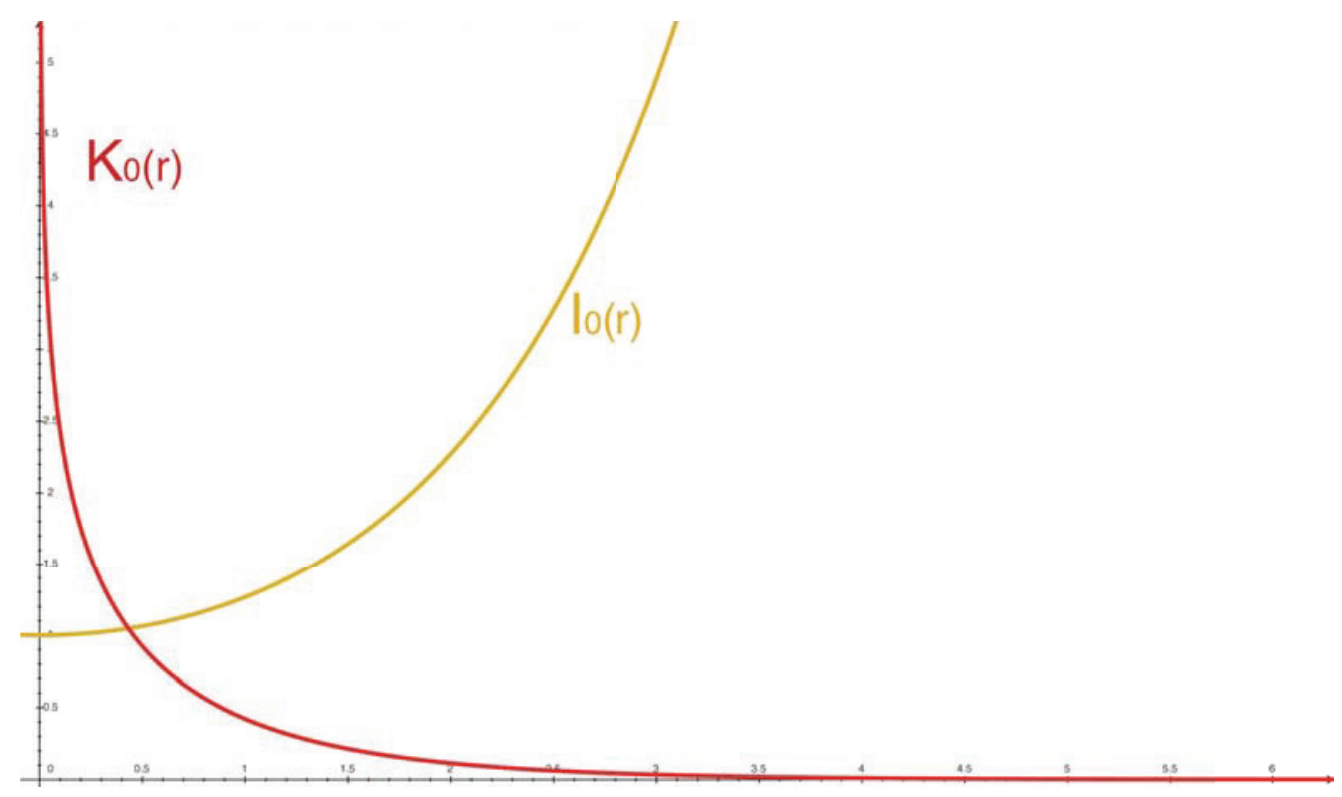

Figure 2. Modified Bessel functions of the first and second kind $I_{0}, K_{0}\left(d=2, \mu=0\right.$, and $\left.\nu=q^{2}\right)$.

Substituting in boundary conditions results in

$$
\begin{gathered}
U\left(R_{i}\right)=C_{1} K_{0}\left(R_{i} q\right)+C_{2} I_{0}\left(R_{i} q\right)=0 \\
U\left(R_{o}\right)=C_{1} K_{0}\left(R_{o} q\right)+C_{2} I_{0}\left(R_{o} q\right)=0
\end{gathered}
$$

The two equations above form a matrix with a solution of the zero vector. Since $K_{0}$ and $I_{0}$ are linearly independent functions it follows that the null space is empty and $C_{1}=C_{2}=0$, rendering the trivial solution.

Case 2: $\lambda=0$

For this case $\lambda \equiv 0$. Substituting this into the differential equation and simplifying results in:

$$
\frac{U^{\prime \prime}(r)}{U^{\prime}(r)}=-\frac{1}{r}
$$

Equation 6.

The first step in solving (Equation 6) is to integrate both sides, producing the expression $\ln \left(U^{\prime}(r)\right)=-\ln (r)+C$. From here $U^{\prime}(r)=e^{\ln (1 / r)+C}=C_{1} \frac{1}{r}$. After integrating once more the solution is found to be

$$
U(r)=C_{1} \ln r+C_{2} .
$$

Substituting in boundary conditions results in

$$
\begin{aligned}
& U\left(R_{i}\right)=C_{1} \ln R_{i}+C_{2}=0 \\
& U\left(R_{o}\right)=C_{1} \ln R_{o}+C_{2}=0
\end{aligned}
$$

From this, $C_{2}=-C_{1} \ln R_{i}$ and $C_{2}=-C_{1} \ln R_{o}$. Combined these become $0=C_{1}\left(\ln R_{o}-\ln R_{i}\right)$ which implies $C_{1}=$ $C_{2}=0$ resulting in the trivial solution. 


\section{Case 3: $\lambda>0$}

Finally for $\lambda \equiv m^{2}$ the resulting differential equation is

$$
U^{\prime \prime}(r)+\frac{1}{r} U^{\prime}(r)+m^{2} U(r)=0
$$

Equation 7.

This third case produces a radial ODE almost identical to the equation for the negative eigenvalue. The key difference between the two is that $q^{2}=-m^{2}$ so the linearly independent solutions to this equation are the Bessel functions of the first and second kind: ${ }^{9}$

$$
U(r)=C_{1} J_{0}(r m)+C_{2} Y_{0}(r m)
$$

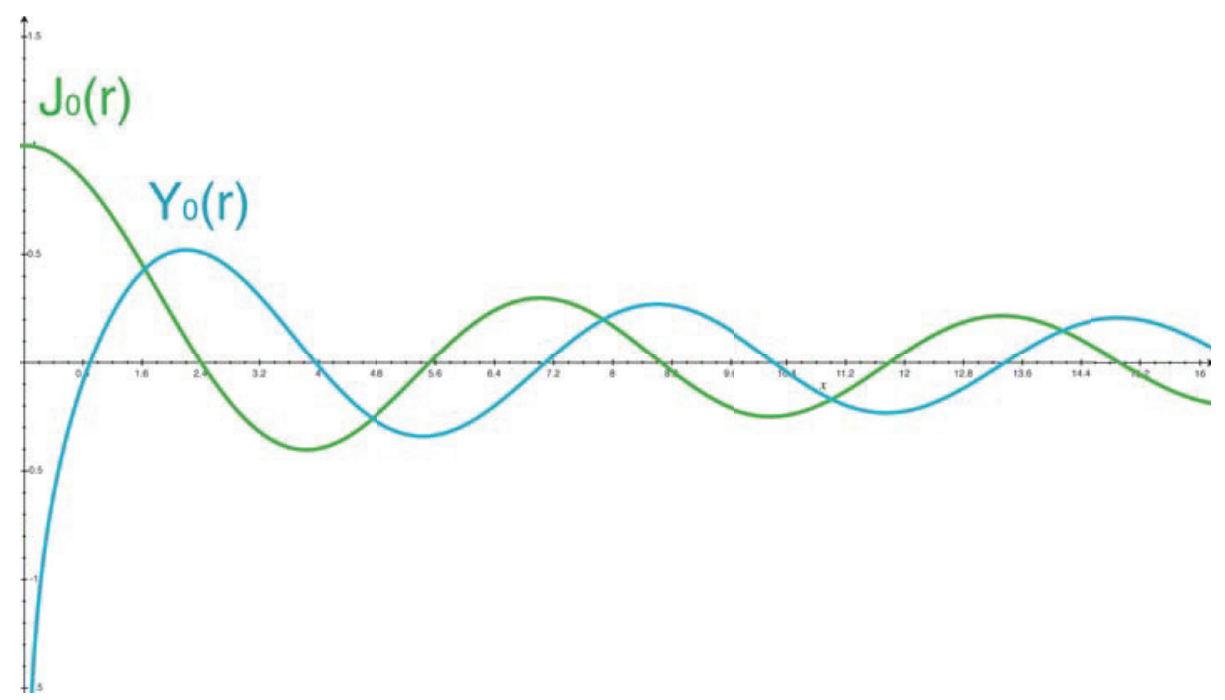

Figure 3. Modified Bessel functions of the first and second kind $J_{0}, Y_{0}\left(d=2, \mu=0\right.$, and $\left.\nu=-m^{2}\right)$.

Substituting in boundary conditions results in

$$
\begin{gathered}
U\left(R_{i}\right)=C_{1} J_{0}\left(R_{i} m\right)+C_{2} Y_{0}\left(R_{i} m\right)=0 \\
U\left(R_{o}\right)=C_{1} J_{0}\left(R_{o} m\right)+C_{2} Y_{0}\left(R_{o} m\right)=0
\end{gathered}
$$

Equation 8.

Equation 9.

The boundary condition equations (Equation 8) and (Equation 9) establish that $\frac{C_{2}}{C_{1}}=-\frac{J_{0}\left(R_{i} m\right)}{Y_{0}\left(R_{i} m\right)}=-\frac{J_{0}\left(R_{o} m\right)}{Y_{0}\left(R_{o} m\right)}$. Given the oscillatory behavior of the Bessel equations of the first and second kind, there exists an infinite set of nontrivial coefficients. We will denote this set by $\left\{m_{n}\right\}_{n=1}^{\infty}$ and solve for terms in this set using the equality of $\frac{C_{2}}{C_{1}}$. Similar to the equations in case two, equations (Equation 8) and (Equation 9) form a matrix. The correct eigenvalues can be determined as they make the matrix singular and its determinant zero. Given the experimental values of $R_{i}$ and $R_{o}$, the first five terms are provided in table Table 1:

The $m_{n}$ values are the square roots of the eigenvalues satisfying the boundary conditions.

\section{Solution}

As a result from solving the radial equation, the set of eigenvalues is strictly positive and defined by $\lambda_{n}=m_{n}^{2}$ where $n=1,2,3 \ldots$ as portrayed in table Table 1 . Now the temporal equation $S^{\prime}(t)=\kappa m_{n}^{2} S(t)$ is easily derived resulting in 


\begin{tabular}{|c|c|}
\hline $\mathbf{n}$ & $\mathbf{m}_{\mathbf{n}}$ \\
\hline 1 & 50.3 \\
\hline 2 & 103.4 \\
\hline 3 & 156.1 \\
\hline 4 & 208.7 \\
\hline 5 & 261.2 \\
\hline
\end{tabular}

Table 1. Table of first five eigenvalues.

$S_{n}(t)=C_{n} e^{-m^{2} \kappa t}$. Putting this together with $U(r)$ produces the homogeneous solution:

$$
z_{h}(r, t)=\sum_{n=1}^{\infty} A_{n}\left[J_{0}\left(m_{n} r\right)+B_{n} Y_{0}\left(m_{n} r\right)\right] e^{-m_{n}^{2} \kappa t}
$$

Equation 10.

where the new coefficient $B_{n} \equiv \frac{C_{2}}{C_{1}}$ is calculated from $-\frac{C_{2}}{C_{1}}=\frac{J_{0}\left(R_{i} m_{n}\right)}{Y_{0}\left(R_{i} m_{n}\right)}=\frac{J_{0}\left(R_{o} m_{n}\right)}{Y_{0}\left(R_{o} m_{n}\right)}$ and $A_{n}$ is a free constant.

\section{Particular Solution of the PDE}

In order to solve for the particular solution $z_{p}(r, t)$ of the transformed PDE, we use the technique of variation of parameters. ${ }^{10}$ The free constants $A_{n}$ in the homogeneous solution (Equation 10) are extended to have time-dependency $A_{n}(t)$ :

$$
z_{p}(r, t)=\sum_{n=1}^{\infty} U_{n}(r) S_{n}(t)=\sum_{n=1}^{\infty} A_{n}(t)\left[J_{0}\left(m_{n} r\right)+B_{n} Y_{0}\left(m_{n} r\right)\right] e^{-m_{n}^{2} \kappa t}
$$

Equation 11.

Observe that equation (Equation 11)is a generalization of equation (Equation 10). The transformed forcing function is re-introduced into the differential equation shown below:

$$
\frac{\partial z_{p}}{\partial t}-\kappa\left[\frac{1}{r} \frac{\partial z_{p}}{\partial r}+\frac{\partial^{2} z_{p}}{\partial r^{2}}\right]=\hat{F}(r, t)
$$

Equation 12.

When $z_{p}(r, t)$ of the form given by (Equation 11) is substituted into the differential equation (Equation 12), the product rule of derivatives applies and results in two terms from the partial derivative with respect to $t$. The time-derivative term in (Equation 12) is similar to the homogenous solution, only varying by the time-dependent coefficients $A_{n}(t)$. Since this term mimics the form of the homogeneous solution it therefore similarly satisfies the homogeneous PDE and cancels to zero as given by: $\frac{\partial z_{h}}{\partial t}-\kappa\left[\frac{1}{r} \frac{\partial z_{h}}{\partial r}+\frac{\partial^{2} z_{h}}{\partial r^{2}}\right]=0$. The radial derivative terms of (Equation 12) are a consequence of the product rule applied to $\frac{\partial}{\partial t}\left[z_{p}(r, t)\right]=U(r) \frac{d}{d t}\left[A_{n}(t) e^{-m_{n}^{2} \kappa t}\right]$, so the reduced form of (Equation 12) is given by:

$$
\hat{F}(r, t)=\sum_{n=1}^{\infty} A_{n}^{\prime}(t)\left[J_{0}\left(m_{n} r\right)+B_{n} Y_{0}\left(m_{n} r\right)\right] e^{-m_{n}^{2} \kappa t}
$$

Equation 13.

(Equation 13) for the transformed forcing function provides an avenue by which to calculate the particular solution coefficients $A_{n}(t) . \hat{F}(r, t)$ is calculated from the experimental boundary conditions, so we may determine each $A_{n}^{\prime}(t)$ by expressing it in the basis of adjusted Bessel functions $\left[J_{0}\left(m_{n} r\right)+B_{n} Y_{0}\left(m_{n} r\right)\right]$. This decomposition into the basis functions requires identifying the orthogonality conditions of these functions which will be developed in the next section. After finding $A_{n}^{\prime}(t)$, the $A_{n}(t)$ terms are determined by integrating with respect to time from 0 to $t: A_{n}(t)=\int_{0}^{t} A_{n}^{\prime}(\tau) d \tau$. 
The full transformed solution then becomes:

$$
z(r, t)=\sum_{n=1}^{\infty}\left[A_{n}(t)+A_{n}\right]\left[J_{0}\left(m_{n} r\right)+B_{n} Y_{0}\left(m_{n} r\right)\right] e^{-m_{n}^{2} \kappa t}
$$

Equation 14.

First we solve for the homogeneous constants. If $z(r, t)$ is evaluated at $t=0$ the solution becomes:

$$
z(r, 0)=\sum_{n=1}^{\infty}\left[A_{n}(0)+A_{n}\right]\left[J_{0}\left(m_{n} r\right)+B_{n} Y_{0}\left(m_{n} r\right)\right] e^{-m_{n}^{2} \kappa(0)} \equiv \hat{V}(r)
$$

This expression quickly simplifies, starting with the fact that $e^{-m_{n}^{2} \kappa(0)}=1$. Additionally, as a result of the particular solution's construction, $A_{n}(0)=0$ for $n=1,2,3 \ldots$ since the bounds of integration are $(0,0)$. The remaining expression elicits a technique for retrieving the $A_{n}$ terms

$$
\hat{V}(r)=\sum_{n=1}^{\infty} A_{n}\left[J_{0}\left(m_{n} r\right)+B_{n} Y_{0}\left(m_{n} r\right)\right]
$$

Equation 15.

using a similar basis decomposition method that is discussed in the following section, in which we will show how to explicitly calculate $A_{n}^{\prime}(t)$ and $A_{n}$ from (Equation 13) and (Equation 15) respectively.

\section{Bessel-Fourier Decomposition}

To find the $A_{n}^{\prime}(t)$ and $A_{n}$ terms it is essential to establish the conditions of orthogonality for the basis functions $Q_{n}(r)=$ $J_{0}\left(m_{n} r\right)+B_{n} Y_{0}\left(m_{n} r\right) .{ }^{10}$ The derivation requires analysis based on the general Sturm-Liouville equation. Such conditions emerge from the substitution of the basis functions into the radial ODE (Equation 7):

$$
\frac{d}{d r}\left[r \frac{d Q_{n}}{d r}\right]+r m^{2} Q_{n}=0 .
$$

Equation 16.

Note that the $r$ dependence in $Q_{n}$ still exists, yet $Q_{n}(r)$ is notationally simplified to $Q_{n}$ in this derivation for convenience. Two equations $Q_{p}$ and $Q_{s}$ are established with eigenvalues $\lambda_{p}=m_{p}^{2}$ and $\lambda_{s}=m_{s}^{2}$. This generates the two following ODEs:

$$
\begin{aligned}
& \frac{d}{d r}\left[r \frac{d Q_{s}}{d r}\right]+r m_{s}^{2} Q_{s}=0 \\
& \frac{d}{d r}\left[r \frac{d Q_{p}}{d r}\right]+r m_{p}^{2} Q_{p}=0
\end{aligned}
$$

Multiplying the top equation by $Q_{p}$ and the second by $Q_{s}$ results in:

$$
\begin{aligned}
& Q_{p} \frac{d}{d r}\left[r \frac{d Q_{s}}{d r}\right]+r m_{s}^{2} Q_{s} Q_{p}=0 \\
& Q_{s} \frac{d}{d r}\left[r \frac{d Q_{p}}{d r}\right]+r m_{p}^{2} Q_{p} Q_{s}=0
\end{aligned}
$$

Equation 17.

Equation 18.

Then subtracting (Equation 18) from (Equation 17) and expanding results in

$$
r Q_{p} Q_{s}^{\prime \prime}-r Q_{s} Q_{p}^{\prime \prime}+Q_{p} Q_{s}^{\prime}-Q_{s} Q_{p}^{\prime}+r m_{s} Q_{s} Q_{p}-r m_{p} Q_{p} Q_{s}=0
$$

The next step is to integrate this equation.

$$
\int_{R_{i}}^{R_{o}} r Q_{p} Q_{s}^{\prime \prime} d r-\int_{R_{i}}^{R_{o}} r Q_{s} Q_{p}^{\prime \prime} d r+\int_{R_{i}}^{R_{o}}\left(Q_{p} Q_{s}^{\prime}-Q_{s} Q_{p}^{\prime}\right) d r+\left(m_{s}-m_{p}\right) \int_{R_{i}}^{R_{o}} r Q_{p} Q_{s} d r=0
$$


With the application of the integration by parts theorem on the first two integrals and the boundary conditions $z\left(R_{i}, t\right)=0$ and $z\left(R_{o}, t\right)=0$, the entire expression collapses to:

$$
\left(m_{s}-m_{p}\right) \int_{R_{i}}^{R_{o}} r Q_{p} Q_{s} d r=0 .
$$

Equation 19.

Only when $m_{s}-m_{p}=0$ is the integral not necessarily zero. Therefore it is concluded that

$$
\int_{R_{i}}^{R_{o}} r Q_{p} Q_{s} d r=\left\{\begin{array}{rll}
0 & \text { if } & p \neq s \\
L_{p} & \text { if } & p=s
\end{array}\right.
$$

Equation 20.

where $L_{p}$ is a numerically calculated constant. (Equation 20) defines the orthogonality condition required for calculating the terms in the Fourier-Bessel decomposition of a function.

Both the transformed forcing function $\hat{F}(r, t)$ and the transformed initial condition $\hat{V}(r)$ are expressible as a linear combination of the basis functions:

$$
\begin{gathered}
\hat{V}(r)=\sum_{k=1}^{\infty} A_{n} Q_{n}\left(m_{n} r\right) \\
\hat{F}(r, t)=\sum_{k=1}^{\infty} A_{n}^{\prime}(t) Q_{n}\left(m_{n} r\right) e^{m_{n}^{2} \kappa t}
\end{gathered}
$$

The orthogonality condition identified in (Equation 20) provides a method of solving for the coefficients. The transformed initial condition and forcing function are linear combinations of the basis functions, so it follows that

$$
\begin{gathered}
A_{n}=\frac{1}{L_{n}} \int_{R_{i}}^{R_{o}} r Q_{n}\left(m_{n} r\right) \hat{V}(r) d r \\
A_{n}^{\prime}(t)=\frac{1}{L_{n}} e^{m_{n}^{2} \kappa t} \int_{R_{i}}^{R_{o}} r Q_{n}\left(m_{n} r\right) \hat{F}(r, t) d r
\end{gathered}
$$

Equation 21.

Equation 22.

From (Equation 22), we find $A_{n}(t)=\int_{0}^{t} A_{n}^{\prime}(\tau) d \tau$.

Solution Summary

Putting all of the above sections together leads to the general solution of the transformed PDE (Equation 3),

$$
z(r, t)=\sum_{n=1}^{\infty}\left[A_{n}(t)+A_{n}\right]\left[J_{0}\left(m_{n} r\right)+B_{n} Y_{0}\left(m_{n} r\right)\right] e^{-m_{n}^{2} \kappa t}
$$

with the following definitions: 


$$
\begin{aligned}
& A_{n}=\frac{1}{L_{n}} \int_{R_{i}}^{R_{o}} r Q_{n}\left(m_{n} r\right) \hat{V}(r) d r \\
& A_{n}(t)=\frac{1}{L_{n}} \int_{0}^{t} e^{m_{n}^{2} \kappa t} \int_{R_{i}}^{R_{o}} r Q_{n}\left(m_{n} r\right) \hat{F}(r, \tau) d r d \tau \\
& L_{n}=\int_{R_{i}}^{R_{o}} r Q_{n}\left(m_{n} r\right)^{2} d r \\
& Q_{n}\left(m_{n} r\right)=J_{0}\left(m_{n} r\right)+B_{n} Y_{0}\left(m_{n} r\right) \\
& B_{n}=-\frac{J_{0}\left(m_{n} R_{i}\right)}{Y_{0}\left(m_{n} R_{i}\right)} \\
& m_{n}:=\text { solutions to } \frac{J_{0}\left(m_{n} R_{o}\right)}{J_{0}\left(m_{n} R_{i}\right)}-\frac{Y_{0}\left(m_{n} R_{o}\right)}{Y_{0}\left(m_{n} R_{i}\right)}=0 \text { from the BCs of (Equation 7) ODE }
\end{aligned}
$$

The known parameters for this problem are the inner and outer radii $R_{i} \& R_{o}$, the Bessel functions $J_{0}(x) \& Y_{0}(x)$, the time-varying boundary equations $g(t) \& h(t)$, and the initial condition $V(r)$. With this collective information regarding the experiment, the temperature of the cylinder is numerically calculated by the elegant formula below, which is a consequence of the transformation $z(r, t)=v(r, t)-\tau_{1}(r) g(t)-\tau_{2}(r) h(t)$ originally stated:

$$
v(r, t)=\sum_{n=1}^{\infty}\left[\left[A_{n}(t)+A_{n}\right] Q_{n}\left(m_{n} r\right) e^{-m_{n}^{2} \kappa t}\right]+\frac{\ln (r)-\ln \left(R_{o}\right)}{\ln \left(R_{i}\right)-\ln \left(R_{o}\right)} g(t)+\frac{\ln \left(R_{i}\right)-\ln (r)}{\ln \left(R_{i}\right)-\ln \left(R_{o}\right)} h(t)
$$




\section{COMPARISON OF EXPERIMENTAL AND THEORETICAL RESULTS}

So far this report has developed the tools necessary to construct an explicit solution to the cylindrical heat equation with time-variant boundary conditions. In order to use these tools, the derived formulas require information of the physical experiment. This information includes the diffusivity constant of the brass cylinder $\left(\kappa=37.52 \times 10^{-6} \frac{\mathrm{m}^{2}}{\mathrm{~s}}\right)$, the initial condition function $V(r)$ between $R_{i}$ and $R_{o}$, the inner boundary condition function $g(t)$, and the outer boundary condition function $h(t)$. To acquire the functions $V(r), g(t)$, and $h(t)$, we collected two trials of temperature readings at each thermistor after the coolant was introduced. From these data we could determine $V(r)$ by fitting a polynomial to the initial temperature readings at each thermistor, $g(t)$ by fitting a polynomial to the innermost thermistor readings during the duration of the experiment, and $h(t)$ by fitting a polynomial to the outermost thermistor readings. The remaining temperature data are not necessary for the construction of the theoretical model, but may still serve as a means to compare the developed mathematical model with experiment. Since two trials were conducted we will build two mathematical models and compare each model with their respective data sets.

The experimental data collection began once the heater was turned on. Once the brass cylinder reached a steady temperature state the coolant was introduced to the system. Our model is developed based on the the cooling process and therefore the initial and boundary conditions are fit to the data corresponding to when the coolant was engaged. For trial one this occurred at $t=0.3$ minutes and for trial two this occurred at $t=1.0$ minutes.

\section{Solving for Initial and Boundary Conditions}

Two of the necessary inputs for the theoretical model are the two time-varying boundary conditions. The inner-radius boundary condition $g(t)$ was recorded by thermistor 1 located at the innermost radius $R_{i}=10 \mathrm{~mm}$ while the coolant was engaged. Similarly $h(t)$ is recorded by the outer thermistor-temperature probe 6 located at $R_{o}=70 \mathrm{~mm}$ from the axis center. We obtained the boundary condition functions $g(t)$ and $h(t)$ by fitting a sixth-order polynomial expression to the data (Figure 4 and 5). A sixth order fit was chosen as it was the lowest order polynomial to accurately fit the initial boundary behavior.

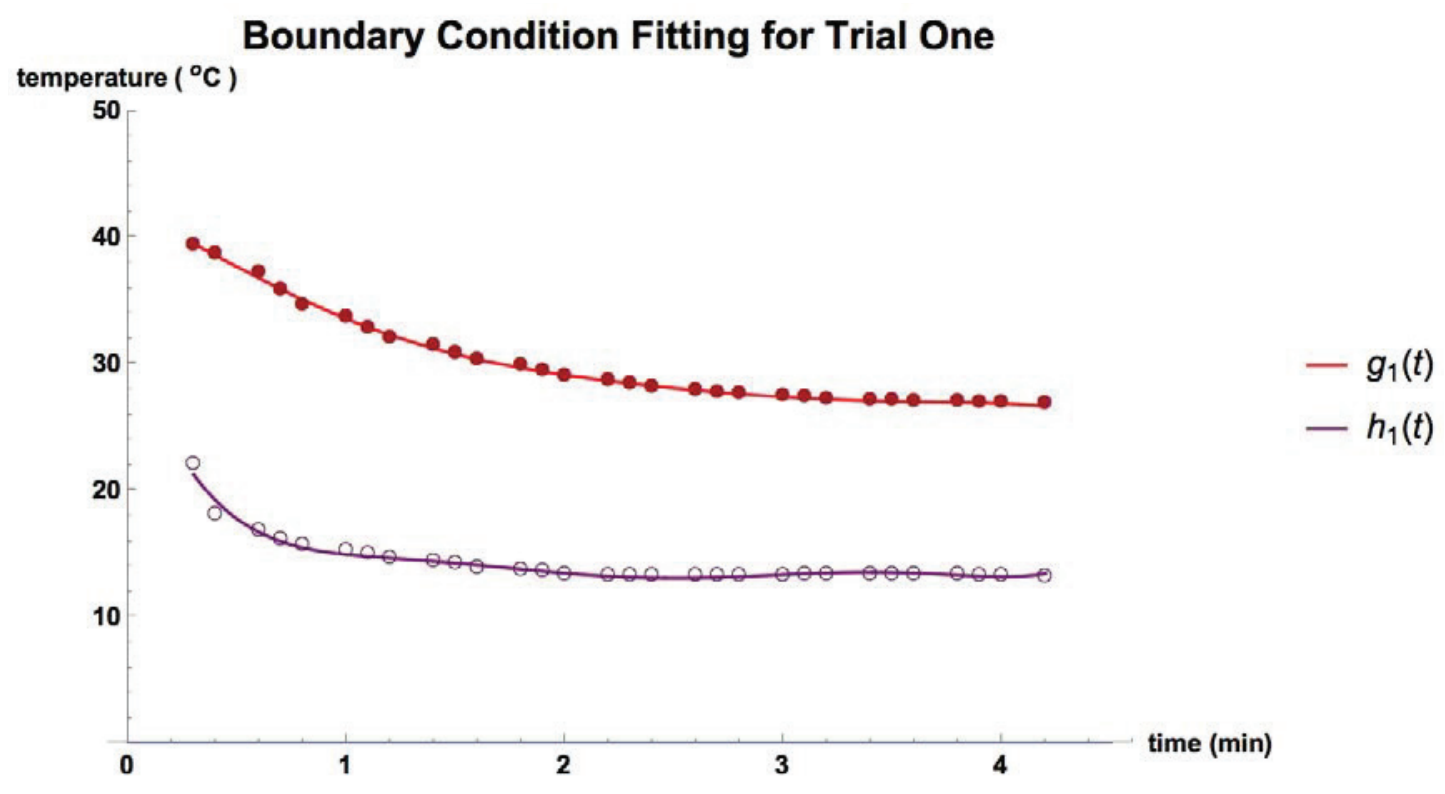

Figure 4. Trial 1 boundary condition fitting. The inner-radius boundary condition $g(t)$ was recorded by thermistor 1 located at the innermost radius $R_{i}=10 \mathrm{~mm}$. The outer-most boundary condition $h(t)$ was recorded by thermistor 6 located at $R_{o}=70 \mathrm{~mm}$ from the axis center. 


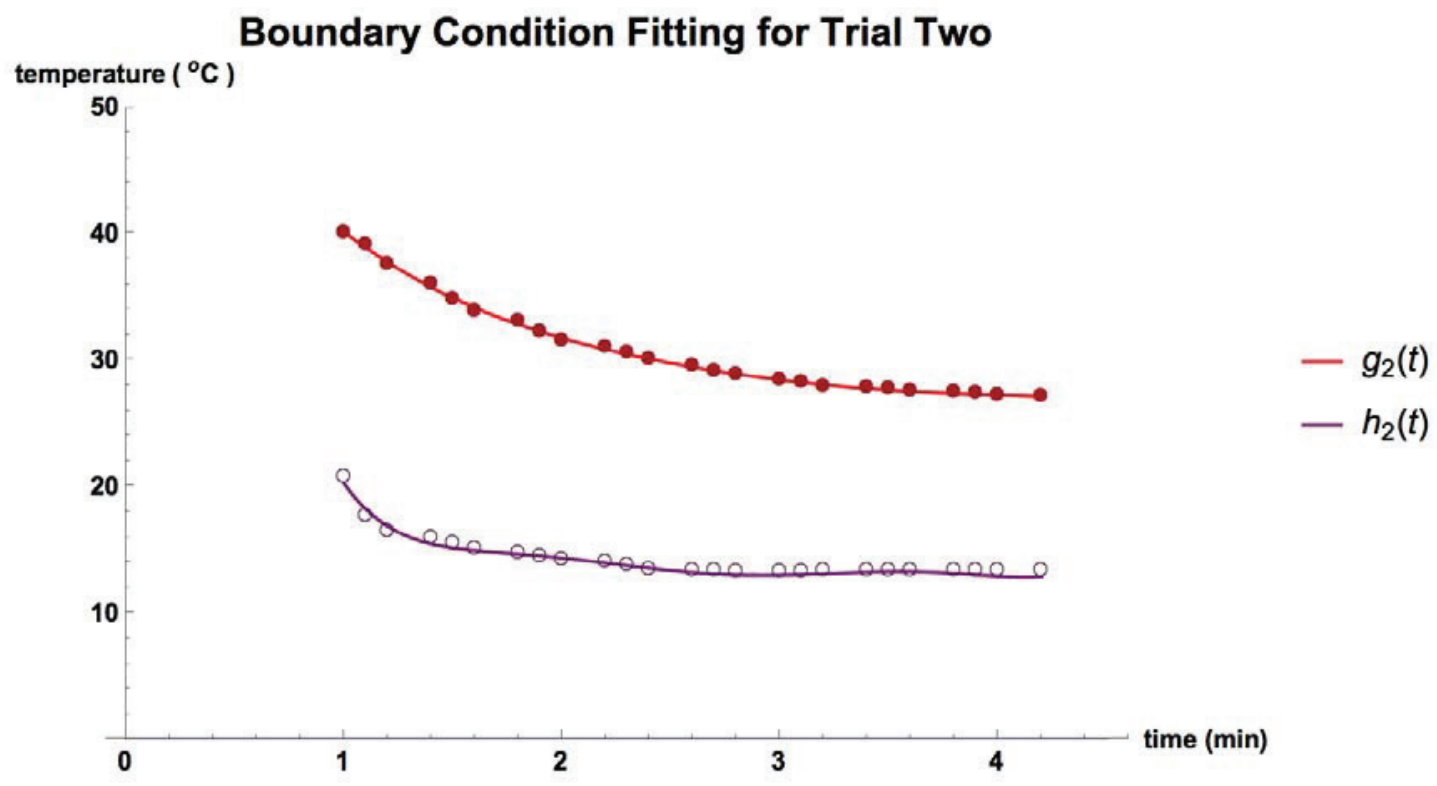

Figure 5. Trial 2 boundary condition fitting. The inner-radius boundary condition $g(t)$ was recorded by thermistor 1 located at the innermost radius $R_{i}=10 \mathrm{~mm}$. The outer-most boundary condition $h(t)$ was recorded by thermistor 6 located at $R_{o}=70 \mathrm{~mm}$ from the axis center.

Attaining the initial condition requires a similar approach as used for the boundary conditions. The initial condition function $V(r)$ for both trials was obtained by fitting a quadratic polynomial to the data, which was the lowest order polynomial to accurately represent the initial behavior. As opposed to fitting a function to the data from one thermistor, the initial condition $V(r)$ is attained by fitting the quadratic to the initial probe measurements across all thermistors as a function of radial distance from the center (Figure 6 and 7). These initial condition functions are fit to the data at $t=0.3$ minutes and $t=1.0$ minutes for trials one and two respectively when the coolant was added.

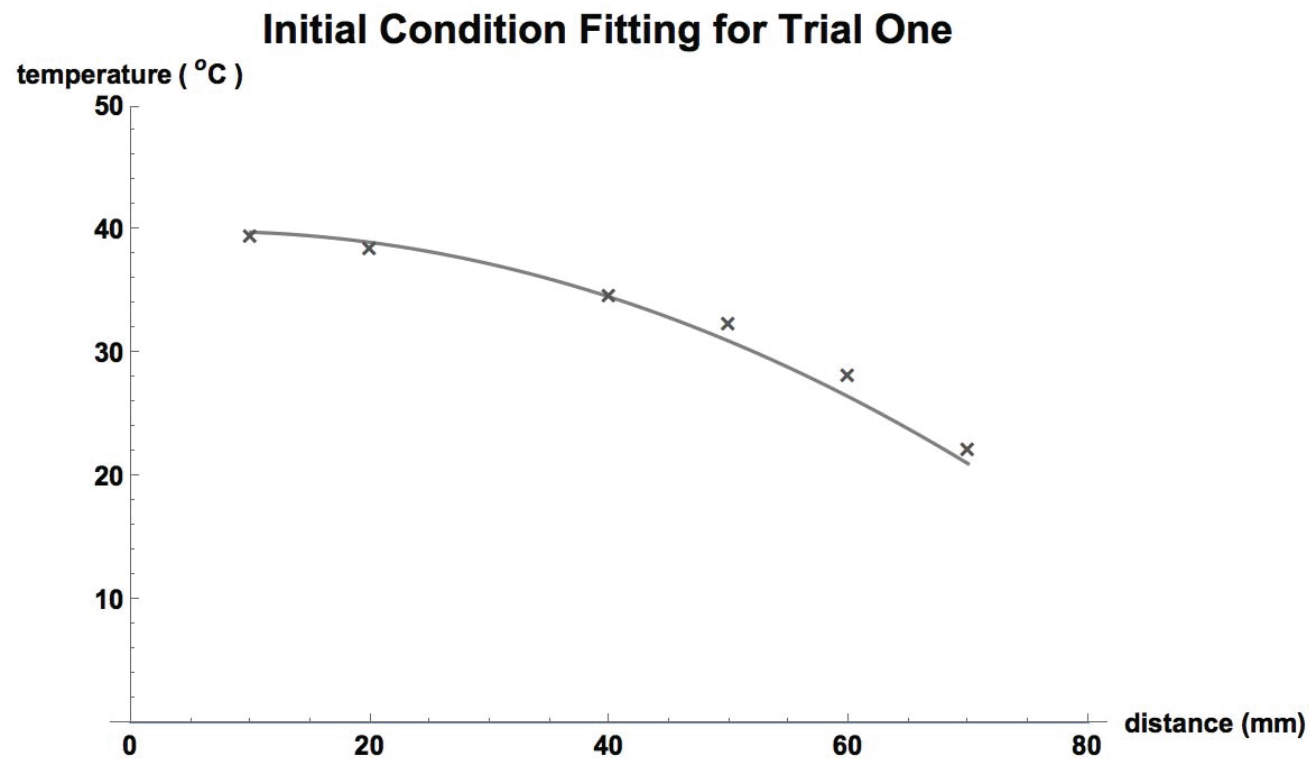

Figure 6. Trial 1 initial condition fitting from initial probe measurements across all thermistors as a function of radial distance from the center. 


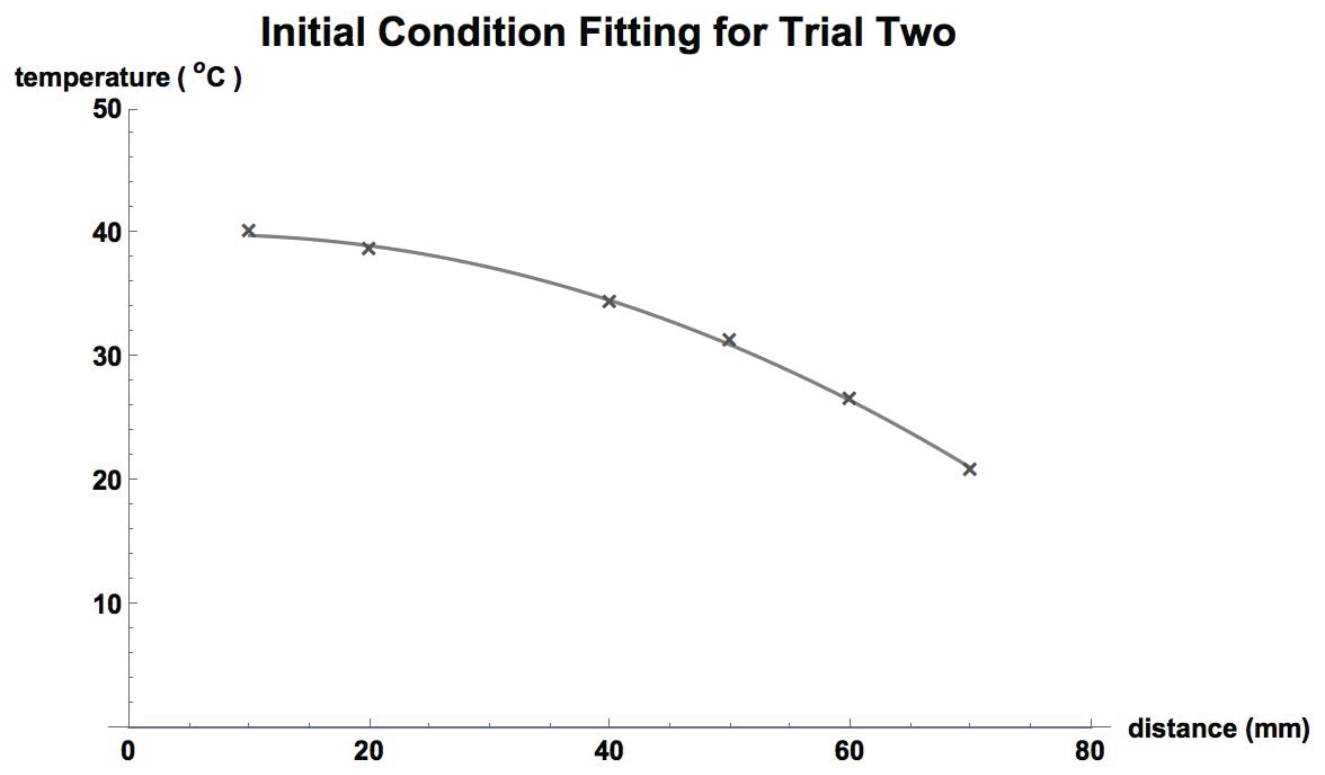

Figure 7. Trial 2 initial condition fitting from initial probe measurements across all thermistors as a function of radial distance from the center.

After finding fitting functions for the boundary and initial conditions, we have assembled all of the necessary information to construct our model:

$$
\begin{aligned}
& R_{i}=10 \mathrm{~mm} \\
& R_{o}=70 \mathrm{~mm} \\
& \kappa=37.52 \times 10^{-6} \frac{\mathrm{m}^{2}}{\mathrm{~s}} \\
& g_{1}(t)=-0.0461 t^{6}+0.6391 t^{5}-3.4099 t^{4}+8.4423 t^{3}-7.6973 t^{2}-6.1995 t+41.889 \\
& g_{2}(t)=-0.0314 t^{6}+0.4346 t^{5}-2.1891 t^{4}+4.1342 t^{3}+2.8109 t^{2}-24.435 t+59.484 \\
& h_{1}(t)=0.1897 t^{6}-2.7714 t^{5}+15.945 t^{4}-45.935 t^{3}+69.986 t^{2}-55.093 t+32.671 \\
& h_{2}(t)=0.5125 t^{6}-8.5651 t^{5}+57.822 t^{4}-201.41 t^{3}+381.78 t^{2}-375.47 t+165.64 \\
& v_{1}(r)=-0.0046(1000 r)^{2}+0.0551(1000 r)+39.776 \\
& v_{2}(r)=-0.0045(1000 r)^{2}+0.0541(1000 r)+39.698
\end{aligned}
$$

Before making use of the calculated condition functions, we must first form the basis functions that satisfy the heat equation in the cylindrical system. Since there is not an explicit formula for the eigenvalues of the equation, a finite list of basis functions must be created numerically. This is accomplished by calculating a set $\left\{m_{n}\right\}$ which are the square roots of the eigenvalues, a set of basis weights $\left\{B_{n}\right\}$, and a set of constants from the orthogonality principle $\left\{L_{n}\right\}$. Calculating the first thirty terms in these sets will lead us to generate the first thirty basis functions for the model. (Table 2) shows the calculations of these terms for $n=1,2,3,4,5$. 


\begin{tabular}{|c|c|c|c|}
\hline $\mathbf{n}$ & $\mathbf{m}_{\mathbf{n}}$ & $\mathbf{B}_{\mathbf{n}}$ & $\mathbf{L}_{\mathbf{n}} \times \mathbf{1 0}^{\mathbf{4}}$ \\
\hline 1 & 50.3 & 2.13 & 20.64 \\
\hline 2 & 103.4 & -6.57 & 80.85 \\
\hline 3 & 156.1 & -1.18 & 2.90 \\
\hline 4 & 208.7 & -0.34 & 1.02 \\
\hline 5 & 261.2 & 0.21 & 0.76 \\
\hline
\end{tabular}

Table 2. Table of square-root eigenvalues and weighting coefficients.

The values from (Table 2) allow the basis functions $Q(r)$ to be explicitly calculated. (Figure 8 ) verifies that these basis functions do indeed meet the necessary boundary conditions:

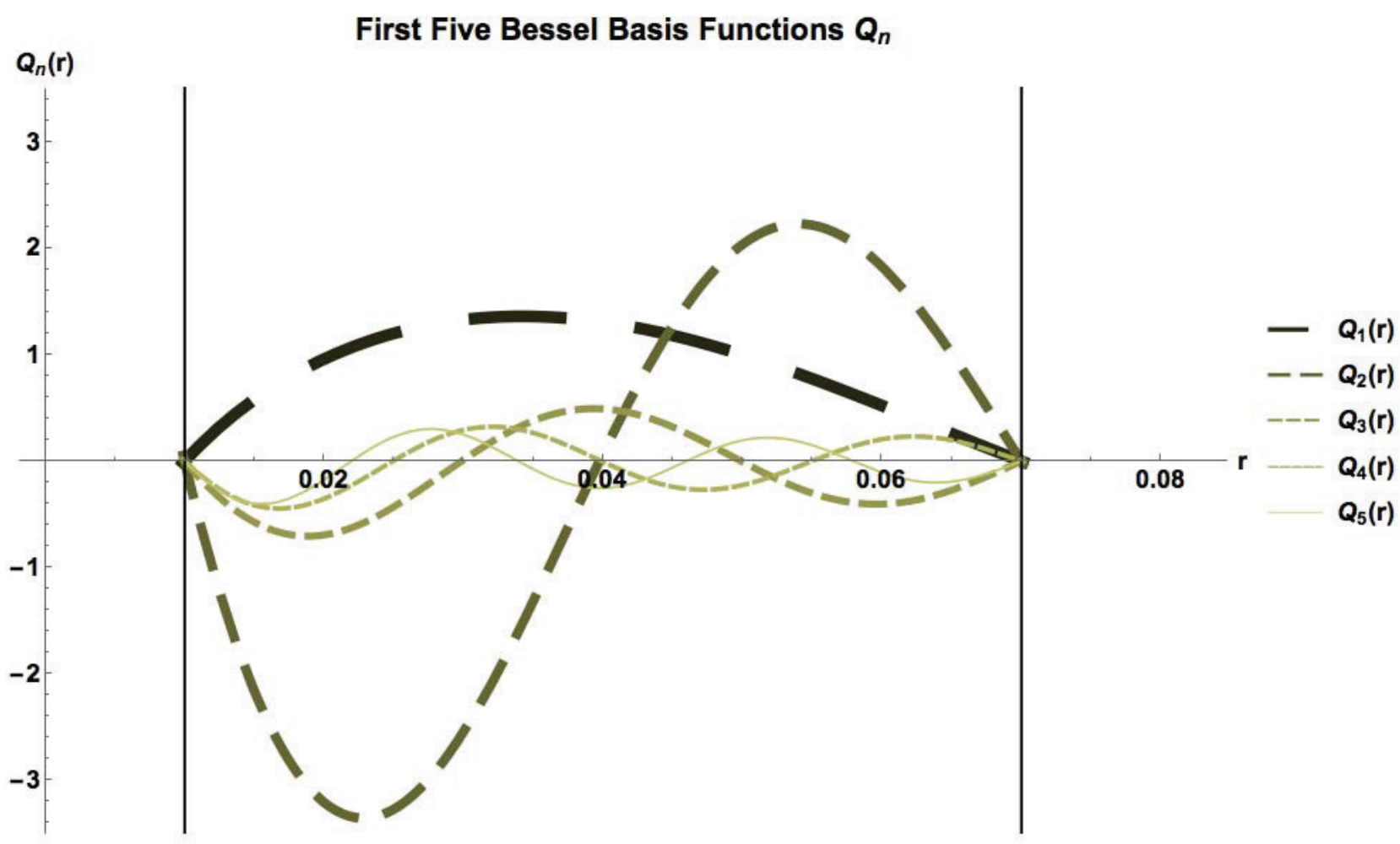

Figure 8. The first five $Q_{n}$ terms using the $m_{n}$ and $B_{n}$ values.

Vertical lines in the plot identify the inner and outer radii $R_{i}=10 \mathrm{~mm}$ and $R_{o}=70 \mathrm{~mm}$ respectively, and the colored curves represent the first five radial basis functions $Q_{n}$ based on the $m_{n}$ and $B_{n}$ values. Evidently the $m_{n}$ and $B_{n}$ values successfully produce a family of solutions satisfying both the radial ODE and the boundary conditions. This family of basis functions is then used to decompose $\hat{V}(r)$ and $\hat{F}(r, t)$.

All of the necessary information is present to successfully calculate the sets of coefficients in the solution $v(r, t)$ :

$$
\begin{gathered}
A_{n}=\int_{R_{i}}^{R_{o}} r \hat{V}(r) Q_{n}(r) d r \\
A_{n}(t)=\int_{0}^{t} \int_{R_{i}}^{R_{o}} r \hat{F}(r, \tau) Q_{n}(r) d r e^{m_{n}^{2} \kappa \tau} d \tau
\end{gathered}
$$


both of which substitute directly into the final form:

$$
v(r, t)=\sum_{n=1}^{30}\left[\left[A_{n}(t)+A_{n}\right]\left[J_{0}\left(m_{n} r\right)+B_{n} Y_{0}\left(m_{n} r\right)\right] e^{-m_{n}^{2} \kappa t}\right]+\frac{\ln (r)-\ln \left(R_{o}\right)}{\ln \left(R_{i}\right)-\ln \left(R_{o}\right)} g(t)+\frac{\ln \left(R_{i}\right)-\ln (r)}{\ln \left(R_{i}\right)-\ln \left(R_{o}\right)} h(t)
$$

The following figures verify the success of the Fourier-Bessel decomposition method for determining coefficients. (Figure 9) and (Figure 10) compare the initial condition functions for each trial with their respective thirty-term Fourier-Bessel expansions.

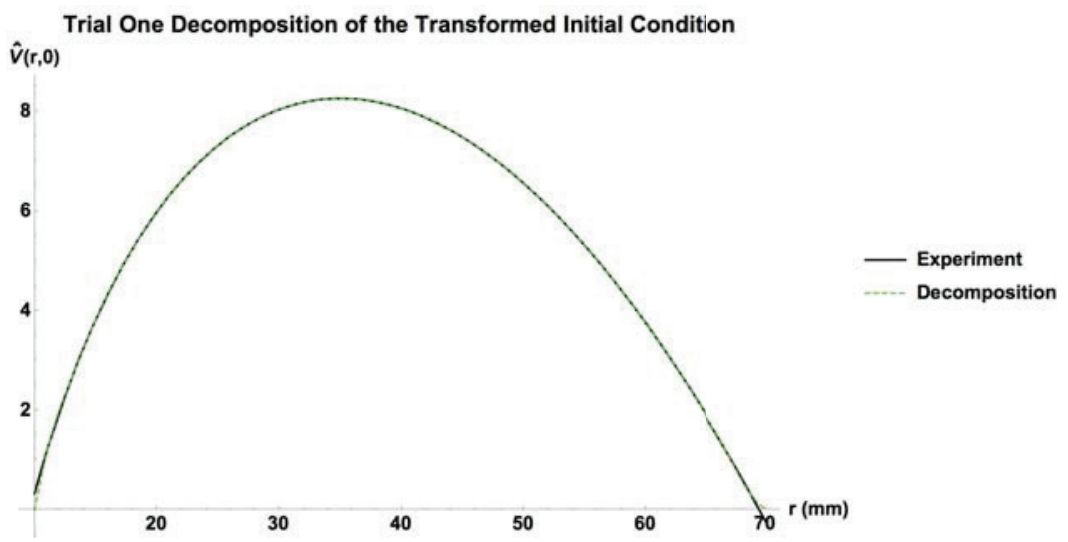

Figure 9. The 30 term decomposition of the transformed initial condition $\hat{V}(r)$ for trial 1.

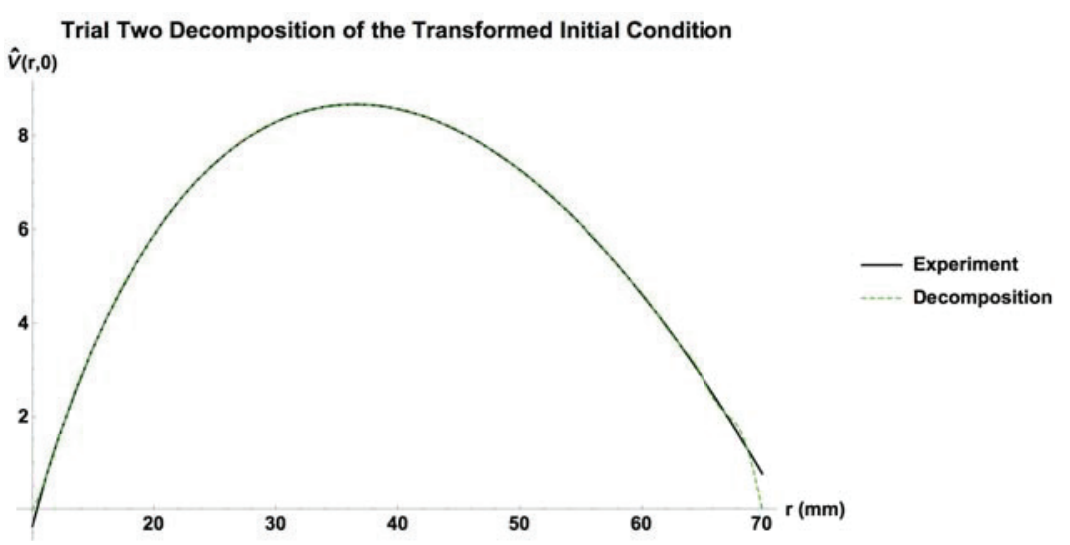

Figure 10. The 30 term decomposition of the transformed initial condition $\hat{V}(r)$ for trial 2.

This high degree of correlation between the initial conditions and their expansions inspires confidence in the decomposition method utilized in developing this model. The success of this explicit solution is shown graphically in (Figure 11) . Evidently, the $A_{n}$ coefficients determined from the Bessel-Fourier decomposition were accurate as the modeled heat solution matches closely with the intermediate thermistor measurements. With fewer than 30 terms of the sequence, we found that the model deviated further from the experimental data. As more terms are added to the model, the better the explicit solution agrees with the data.

Finally, the resulting analytical solution evaluated at the thermistor positions correlates to the measured data as shown in (Figure 11) and (Figure 12). Note that $T_{1}(r, t)$ and $T_{2}(r, t)$ replace $v(r, t)$ in the plots below to avoid ambiguity with the initial condition function $v(r)$ in (Figure 11), (Figure 12), (Figure 13), and (Figure 14). 


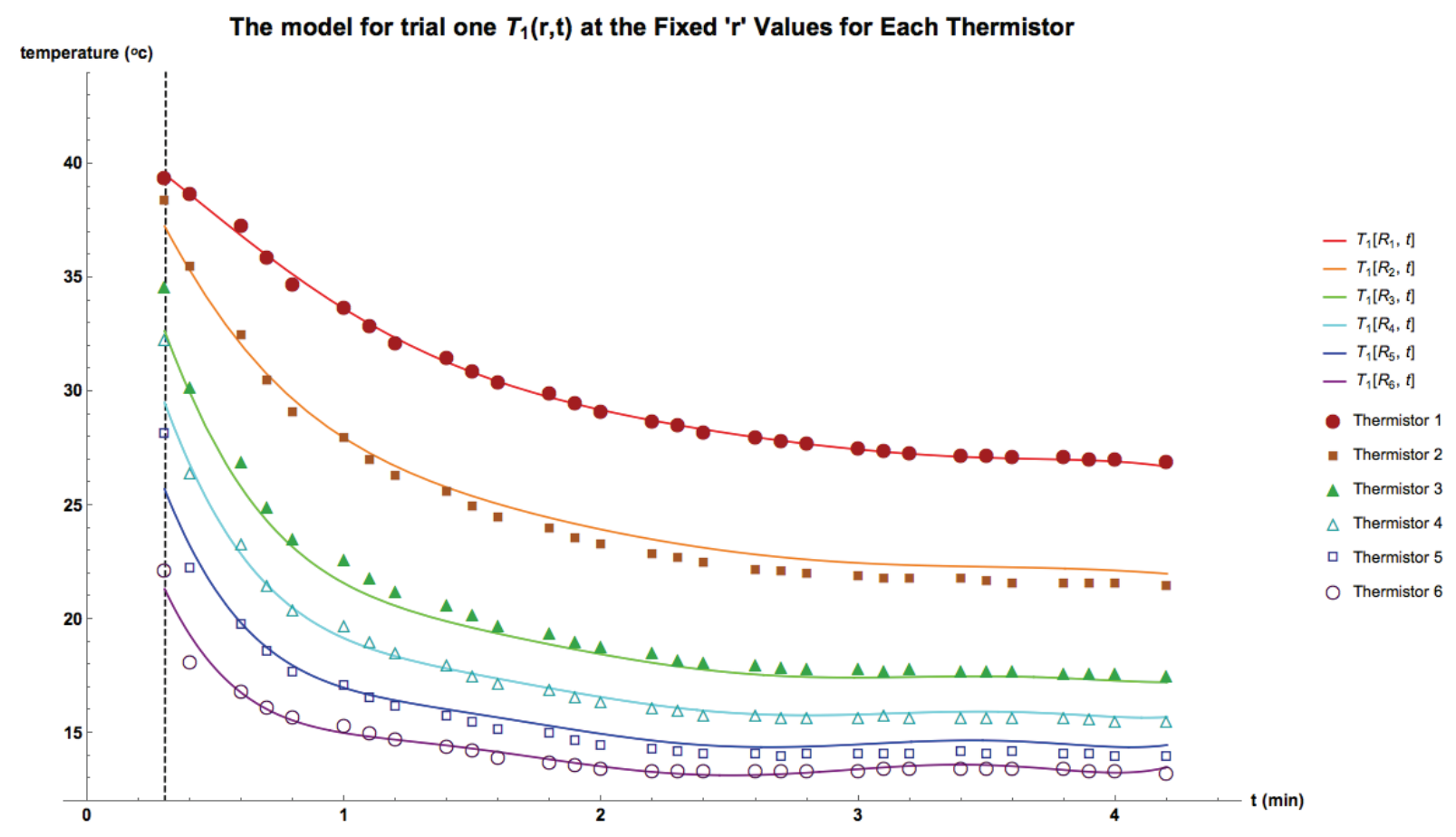

Figure 11. Trial 1 temperature data with analytic solution.

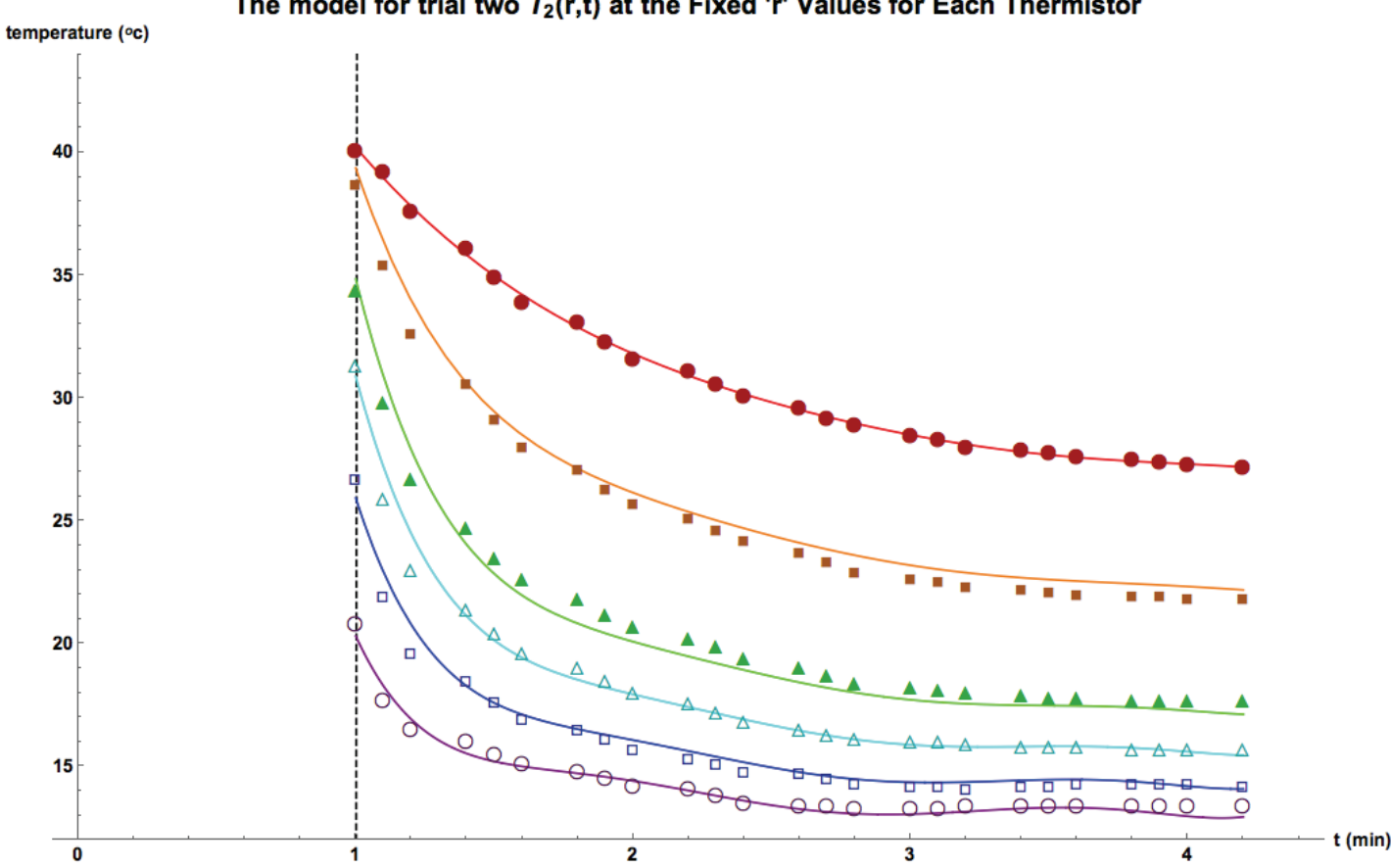

Figure 12. Trial 2 temperature data with analytic solution. 
Clearly, the mathematical models accurately describe the heat diffusion in the brass cylinder. For both trials, each color plot shows the time evolution of the temperature at the specific thermistors located a given distance from the center. As expected from the transform identity, the inner and outer radii solutions match up perfectly with the data. This can be seen by evaluating the solution at the boundary points $R_{i}, R_{o}$ :

$$
\begin{aligned}
& v\left(R_{i}, t\right)=\sum_{n=1}^{30}\left[\left[A_{n}(t)+A_{n}\right] Q_{n}\left(R_{i}\right) e^{-m_{n}^{2} \kappa t}\right]+\frac{\ln \left(R_{i}\right)-\ln \left(R_{o}\right)}{\ln \left(R_{i}\right)-\ln \left(R_{o}\right)} g(t)+\frac{\ln \left(R_{i}\right)-\ln \left(R_{i}\right)}{\ln \left(R_{i}\right)-\ln \left(R_{o}\right)} h(t)=g(t) \\
& v\left(R_{o}, t\right)=\sum_{n=1}^{30}\left[\left[A_{n}(t)+A_{n}\right] Q_{n}\left(R_{o}\right) e^{-m_{n}^{2} \kappa t}\right]+\frac{\ln \left(R_{i}\right)-\ln \left(R_{o}\right)}{\ln \left(R_{o}\right)-\ln \left(R_{o}\right)} g(t)+\frac{\ln \left(R_{i}\right)-\ln \left(R_{o}\right)}{\ln \left(R_{i}\right)-\ln \left(R_{o}\right)} h(t)=h(t)
\end{aligned}
$$

in which the strike-throughs indicate elements equal to zero. The remaining data set supports the success of our model.

\section{ANALYSIS}

To test the developed model, we tried varying the thermal diffusivity constant $\kappa$. This test was conducted by altering the thermal diffusivity constant from $\kappa=37.52 \times 10^{-6} \frac{\mathrm{m}}{\mathrm{s}^{2}}$ to $\kappa=57.52 \times 10^{-6} \frac{\mathrm{m}}{\mathrm{s}^{2}}$. The most illuminating method for viewing the alteration this causes is by comparing the initial condition quadratic fits from the experiment with the model's reconstruction of the initial condition. (Figure 11) and (Figure 12) clearly indicate that the models' initial conditions fit the data well as can be seen on the dashed lines. By switching the thermal diffusivity constant, the models' initial conditions fail to align as well with the initial quadratic fit function.

In (Figure 13) the left plots shows the alignment of the initial condition generated from the mathematical model to the experimental initial condition function using the proper thermal diffusivity for brass $\kappa=37.52 \times 10^{-6} \frac{\mathrm{m}}{\mathrm{s}^{2}}$. The right plot shows the alignment of the two functions for the modified thermal diffusivity of $\kappa=57.52 \times 10^{-6} \frac{\mathrm{m}}{\mathrm{s}^{2}}$.

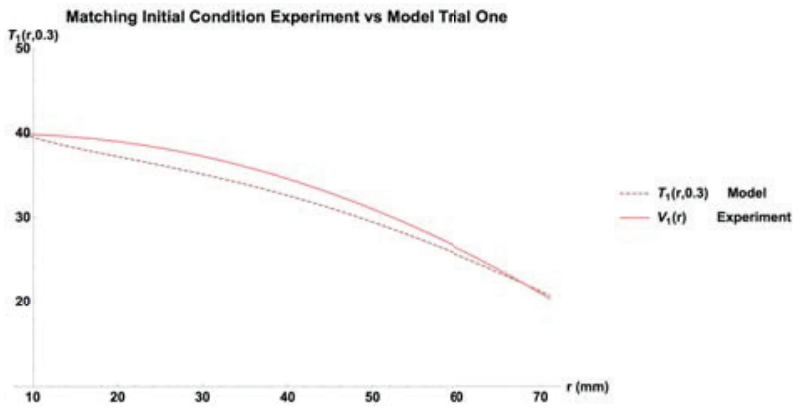

(a) $\kappa=37.52 \times 10^{-6} \frac{m}{s^{2}}$

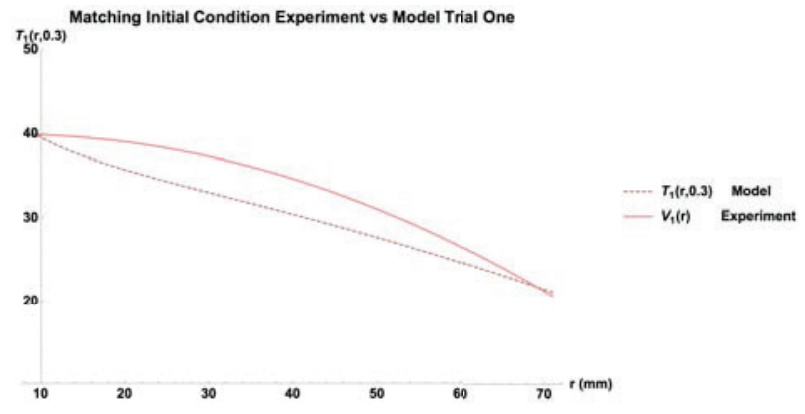

(b) $\kappa=57.52 \times 10^{-6} \frac{\mathrm{m}}{\mathrm{s}^{2}}$

Figure 13. Trial One Initial Condition Comparison with Varying Thermal Diffusivity $\kappa$

Similarly, (Figure 14) compares the alignment of initial conditions for the two different thermal diffusivity constants. 


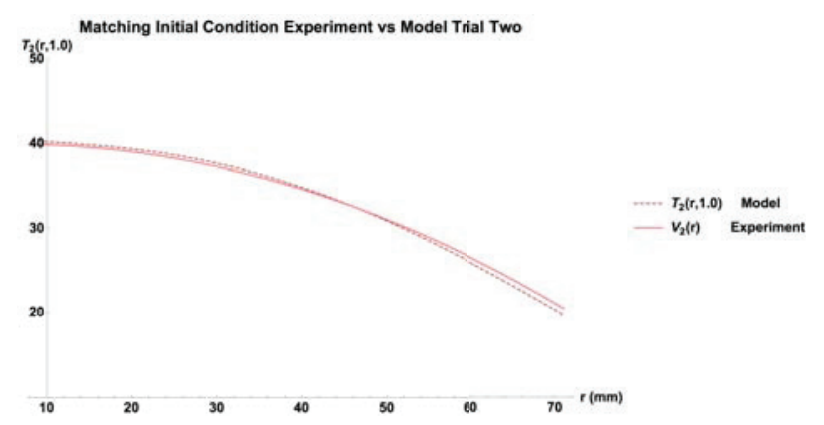

(a) $\kappa=37.52 \times 10^{-6} \frac{\mathrm{m}}{\mathrm{s}^{2}}$

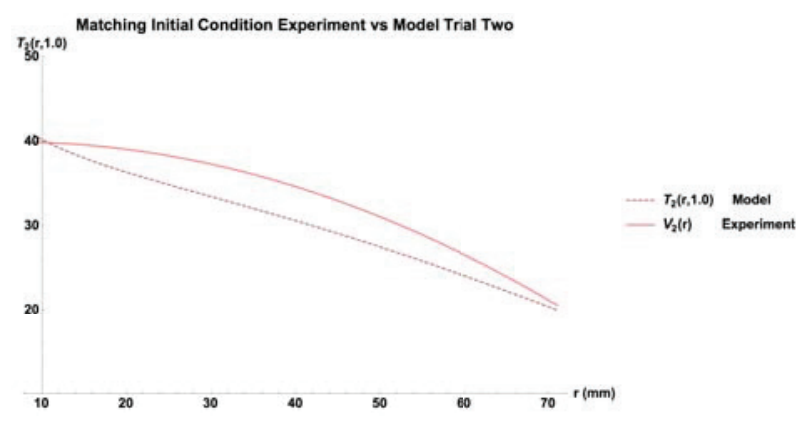

(b) $\kappa=57.52 \times 10^{-6} \frac{\mathrm{m}}{\mathrm{s}^{2}}$

Figure 14. Trial Two Initial Condition Comparison with Varying Thermal Diffusivity $\kappa$

Notice both (Figure 13) and (Figure 14) illustrate that altering the thermal diffusivity constant significantly reduces the success of the model to match the initial condition data. The altered diffusivity constant was increased by approximately $53 \%$ and this change substantially increased the discrepancy between the model and the experiment. Not only does our developed model accurately simulate the experiment, it also confirms the thermal diffusivity constant chosen for brass.

\section{CONCLUSION}

The results in (Figure 11) and (Figure 12) deeply support the agreement of the explicit method for solving the heat equation in cylindrical coordinates with time-varying boundary conditions with empirical data.

To construct the explicit solution it was necessary to approximate the boundary conditions of the cylinder using polynomial fits on the inner and outer thermistor data sets, which intrinsically each have their own error with respect to the data. The error metric we use to evaluate the success of our model is the relative error based on the square difference error at each point. Explicitly we use the formula

$$
E\left(r_{n}\right)=\frac{\sqrt{\sum_{t=0}^{t_{\text {final }}}\left(p\left(r_{n}, t\right)-v\left(r_{n}, t\right)\right)^{2}}}{\sqrt{\sum_{t=0}^{t_{\text {final }}} p\left(r_{n}, t\right)^{2}}}
$$

in which $r_{n}$ is the chosen thermistor ( $r_{1}$ is the innermost thermistor and thus indicative of the inner boundary condition) for the error metric, $t$ is an index of the times data were collected, $p\left(r_{n}, t\right)$ is the collected thermistor data, and $v\left(r_{n}, t\right)$ is the explicit solution. For trial one the errors were found for the inner and outer boundary conditions: $1.9 \%$ error on the inner boundary condition (red curve) and $8.8 \%$ error on the outer boundary condition (purple curve). So the errors on the explicit solution were $4.7 \%$ for $r_{2}, 6.3 \%$ for $r_{3}, 6.3 \%$ for $r_{4}$, and $7.9 \%$ for $r_{5}$. All of these errors were between the two errors accounted with the boundary condition fits, which suggests our explicit solution accurately fits with the thermistor data. The involved process of solving the heat diffusion problem by building a Green's function and then utilizing variation of parameters proves to be rigorous and accurate. This accuracy is further verified by the observed convergence to the measured data after only 30 terms in the Fourier-Bessel decomposition. In the future, other physical partial differential equations with time variant boundaries may be solved by applying this method of PDE transformation and solving the inhomogeneous equation by constructing a Green's function and then applying variation of parameters.

\section{ACKNOWLEDGEMENTS}

We thank Professor Harvey Segur for his devoted effort and insightful advice throughout the development of our project. We also thank the Department of Applied Mathematics at the University of Colorado, Boulder for generously providing the experimental resources to make this project possible. 


\section{REFERENCES}

1. Pinsky, M. (1991) Partial differential equations and boundary-value problems with applications 2nd ed., pp 171-235, McGraw-Hill, New York.

2. Pinsky, M. (1991) Partial differential equations and boundary-value problems with applications 2nd ed., pp 427- 465, McGraw-Hill, New York.

3. Laskar, J.M., Bagavathiappan, S., Sardar, M., Jayakumar, T., Philip, J., and Raj, B. (2008) Measurement of thermal diffusivity of solids using infrared thermography, Mater. Lett. 62, 2740-2742.

4. Pinsky, M. (1991) Fourier Series, in Partial Differential Equations and Boundary-Value Problems with Applications, (Sally, P., Su, F., Silverman, J., \& Tolman, S. Eds.) 2nd ed., 35-45, American Mathematical Society, Rhode Island.

5. Pinsky, M. (1991) Appendixes, in Partial Differential Equations and Boundary-Value Problems with Applications, (Sally, P., Su, F., Silverman, J., \& Tolman, S. Eds.) 2nd ed., 465-476, American Mathematical Society, Rhode Island.

6. Pinsky, M. (1991) Preliminaries, in Partial Differential Equations and Boundary-Value Problems with Applications, (Sally, P., Su, F., Silverman, J., \& Tolman, S. Eds.) 2nd ed., 10-20, American Mathematical Society, Rhode Island.

7. Pinsky, M. (1991) Boundary-Value Problems in Cylindrical Coordinates, in Partial Differential Equations and BoundaryValue Problems with Applications, (Sally, P., Su, F., Silverman, J., \& Tolman, S. Eds.) 2nd ed., pp 183, American Mathematical Society, Rhode Island.

8. Abramowitz, M., \& Stegun, I. A. (1964). Handbook of mathematical functions with formulas, graphs, and mathematical tables, pp 374 - 376 , U.S. Govt. Print. Off., Washington, DC.

9. Abramowitz, M., \& Stegun, I. A. (1964). Handbook of mathematical functions with formulas, graphs, and mathematical tables, pp 358 - 363, U.S. Govt. Print. Off., Washington, DC.

10. Pinsky, M. (1991) Appendixes, in Partial Differential Equations and Boundary-Value Problems with Applications, (Sally, P., Su, F., Silverman, J., \& Tolman, S. Eds.) 2nd ed., pp 465-468, American Mathematical Society, Rhode Island.

\section{ABOUT THE STUDENT AUTHORS}

Kaitlyn Parsons graduated from the University of Colorado, Boulder with two Bachelor of Science degrees in Engineering Physics and Applied Mathematics in May 2016. Kaitlyn will obtain her PhD in materials science and engineering.

Tyler Reichanadter is at the University of Colorado, Boulder working towards a double major in Applied Mathematics and Engineering Physics. After finishing both of his BS degrees, Tyler intends to obtain his Masters in Applied Mathematics at CU Boulder.

Andi Vicksman is starting her senior year as a General Engineering and Applied Mathematics double major at University of Colorado Boulder. In General Engineering coursework her emphasis is on Civil Engineering, while also getting a Secondary Math Teaching License. She has a passion for education and hopes to teach engineering in K-12 after graduation.

\section{PRESS SUMMARY}

The heat equation is a partial differential equation that elegantly describes heat conduction or other diffusive processes. Primary methods for solving the heat equation are only applicable when the boundary conditions do not change with time. In this paper, we analyzed a physical system in which a solid, brass cylinder experiences heat flow from the central axis to a heat sink along its outer rim. We constructed an explicit mathematical framework by which to handle the heat equation with these time-variant boundary conditions. Experimental results verify the success of this analytical method. 
Print Edition ISSN 1536-4585

Online Edition ISSN 2375-8732 